Jorge Luis Moltó Doncel

\title{
La enseñanza de piano en España
}

Etapas, hitos y modelos

Cuadernos de Bellas Artes / 44

Colección Música

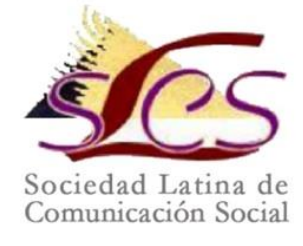


Cuadernos de Bellas Artes - Comité Científico

Presidencia

Dolores Schoch, artista visual

Secretaría

José Luis Crespo Fajardo, Universidad de Sevilla (España)

María Arjonilla Álvarez

Universidad de Sevilla (España)

Antonio Bautista Durán

Universidad de Sevilla (España)

\section{Atilio Doreste}

Universidad de La Laguna

(España)

Sebastián García Garrido

Universidad de Málaga (España)

Carmen González Román

Universidad de Málaga (España)

Ricard Huerta

Universidad de Valencia

(España)
Natalia Juan García

Universidad de Zaragoza

(España)

David Martín López

Universidad de Granada, UGR -

Universidade Nova de Lisboa,

UNL (Portugal)

\section{Maria Portmann}

Universidad de Friburgo (Suiza)

Aida María de Vicente

Domínguez

Universidad de Málaga

(España) 


$$
\text { Jorge Luis Moltó Doncel }
$$

\author{
Prólogo de Francisco Carlos Bueno Camejo
}

\title{
La enseñanza de piano en España
}

Etapas, hitos y modelos

Cuadernos de Bellas Artes / 44

Colección Música

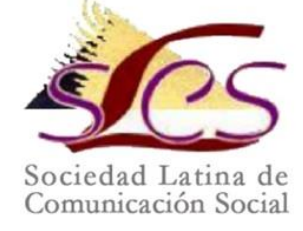


44- La enseñanza de piano en España. Etapas, hitos y modelos

Jorge Luis Moltó Doncel | trinyjorge@hotmail.com

Precio social: 13,55€| Precio en librería: 17,60€

Editores de la colección: José Luis Crespo Fajardo, Francisco

Carlos Bueno Camejo y Samuel Toledano

Director de la colección: José Salvador Blasco Magraner

Diseño: Samuel Toledano

Ilustración de portada: sin nombre, por José María Moltó Doncel (2015)

Imprime y distribuye: F. Drago. Andocopias S. L.

c/ La Hornera, 41. 38296 La Laguna. Tenerife.

Teléfono: 922250554 | fotocopiasdrago@telefonica.net

Edita: Sociedad Latina de Comunicación Social - edición no venal

- La Laguna (Tenerife), 2015 - Creative Commons

www.revistalatinacs.org/09/Sociedad/sede.html

www.cuadernosartesanos.org/CBA.html

Protocolo de envío de manuscritos con destino a CBA:

www.cuadernosartesanos.org/protocolo_CBA.html

* Queda expresamente autorizada la reproducción total o parcial de los textos publicados en este libro, en cualquier formato o soporte imaginables, salvo por explícita voluntad en contra del autor o en caso de ediciones con ánimo de lucro. Las publicaciones donde se incluyan textos de esta publicación serán ediciones no comerciales y han de estar igualmente acogidas a Creative Commons. Harán constar esta licencia y el carácter no venal de la publicación.

* La responsabilidad de cada texto e imagen es de su autor o autora.

ISBN-13: 978-84-16458-10-3

D. L.: TF-768-2015

DOI.: $10.4185 / \mathrm{CBA} 44$

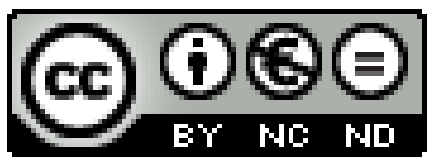


Para Trini 


\section{Resumen}

Intentar descifrar las transformaciones acaecidas en materia educativa y más concretamente en la educación musical impartida a través de los conservatorios durante los últimos dos siglos, presenta un interesante escenario con la suficiente entidad como para ser examinado con mayor detenimiento. Estas instituciones especializadas en el desarrollo práctico y creativo de la música se hallan, como cualquier otro establecimiento educativo en la actualidad, sumergidas en un contexto sociocultural de imparable fluidez en el que parecen diluirse los tradicionales puntos de referencia.

Por esta razón, se inicia en el presente volumen un repaso a la ordenación de las enseñanzas de música en los conservatorios a través de los Sistemas Educativos, un modelo que arranca en España en 1812, coincidiendo con el inicio de su historia constitucional en las Cortes de Cádiz, y que se convierte en el punto de partida de un trayecto que conducirá al lector hasta la reciente oleada de prescripciones legislativas que han empujado en las últimas décadas a las enseñanzas artísticas superiores, hacia un nuevo horizonte determinado por el Espacio Europeo de Educación Superior.

Este marco es el que propicia en la recta final del estudio, una reflexión positiva sobre la enseñanza de la especialidad de Interpretación de Piano, área instrumental que compone la materia prima de la labor pedagógica del autor, y que se enfrenta actualmente a los desafíos de la actividad investigadora y su implementación en los centros artísticos superiores de música.

\section{Palabras clave}

Enseñanzas Superiores de Música; Conservatorios; Investigación Artística; Piano. 


\begin{abstract}
Attempting to decipher the transformations which have transpired in Education and, more specifically, Musical Education, as taught at conservatories over the last two centuries yields an interesting scenario, one of sufficient consequence to merit examination greater detail. These institutions specialized in the practical and creative development of Music are, like any other educational establishment today, immersed in a sociocultural context of relentless flux in which traditional reference points seem to be fading.

Therefore, this volume features a review of the music conservatories' regulations under the different Educational Systems, a model that can be traced back to 1812 in Spain, coinciding with the beginning of its constitutional history at the Cortes de Cádiz, taken as the point of departure for a journey that will take the reader all the way up to the recent tidal wave of legislative directives that in recent decades have pushed higher artistic education towards a new horizon, determined by the European Higher Education Area.

This framework is that which yields, in the final section of the study, a positive reflection on education in the specialized area of Piano Performance, an instrumental area that represents the focus of the author's pedagogical work, and which currently faces the challenges of research activity and its implementation at advanced Music Education institutions.
\end{abstract}

\title{
Keywords
}

Higher Music Education; Conservatories; Artistic Research; Piano.

\section{FORMA DE CITAR ESTE ARTÍCULO}

Moltó Doncel, Jorge Luis (2015): La enseñanza de piano en España. Etapas, hitos y modelos. Cuadernos de Bellas Artes 44. La Laguna (Tenerife): Latina. 



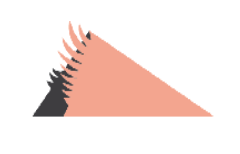

\section{Relación de siglas}

ACESEA Asociación Española de Centros Superiores de Enseñanzas Artísticas

AEC Association Européenne des Conservatoires, Académies de Musique et Musikhochschulen

ANECA Agencia Nacional de Evaluación de la Calidad y Acreditación

CSEA Consejo Superior de Enseñanzas Artísticas

ECTS European Credits Transfer System

EEAASS Enseñanzas Artísticas Superiores

EEES Espacio Europeo de Educación Superior

ELIA European League of Institutes of the Arts

ENQA European Network for Quality Assurance in Higher Education 
EQF European Qualifications Framework

ISEACV Instituto Superior de Enseñanzas Artísticas de la Comunidad Valenciana

JQI Joint Quality Initiative

LOCE Ley Orgánica de Calidad de la Educación

LOCFP Ley Orgánica de las Cualificaciones y de la Formación Profesional

LODE Ley Orgánica reguladora del Derecho a la Educación

LOE Ley Orgánica de Educación

LOECE Ley Orgánica que regula el Estatuto de Centros Escolares

LOGSE Ley Orgánica de Ordenación General del Sistema Educativo

LOMCE Ley Orgánica para la Mejora de la Calidad Educativa

LOPEG Ley Orgánica de la Participación, la Evaluación y el Gobierno de los Centros Docentes

LOU Ley Orgánica de Universidades

LRU Ley Orgánica de Reforma Universitaria

MC-EEES Marco de Cualificaciones del Espacio Europeo de Educación Superior

MECES Marco Español de Cualificaciones para la Educación Superior

MECD Ministerio de Educación, Cultura y Deporte

MECU Marco Español de Cualificaciones para el aprendizaje a lo largo de la vida

PAP Programa de Aprendizaje Permanente (LLP- Lifelong Learning Program) 


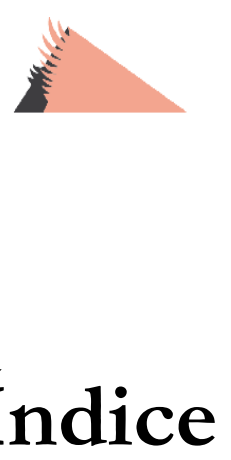

Prólogo, por Francisco Carlos Bueno Camejo [ 17 ]

\section{Introducción [ 19]}

1. Seguir a hombros de gigantes frente a una modernidad líquida [19]

2. Algunos aspectos metodológicos sobre esta obra [23 ]

\section{Los orígenes [ 31 ]}

1.1. Génesis de los sistemas educativos [31]

1.2. La música en los sistemas de enseñanza de 1812 a 1836 [39]

1.3. Fundación del primer establecimiento de Música en España [47] 
1.4. Las bases de 1830 y la revisión de 1838. Los reglamentos de Francisco Piermarini y Cándido Nocedal [ 54 ]

1.5. Los Métodos Oficiales de Piano como herramienta programadora [65]

\section{De la Ley Moyano a la revolución de 1868 [ 75 ]}

2.1. Marco Legislativo: el Plan Duque de Rivas, el Plan Pidal y la Ley de Instrucción pública de 1857 [ 75 ]

2.2. El Reglamento de Salaverría. Las Instrucciones de 1863 [82]

2.3. La crisis sociopolítica de 1865 y las reformas educativas de Manuel de Orovio. Un Reglamento inédito [ 95 ]

\section{El sexenio democrático y los inicios del siglo XX [ 109]}

3.1. Reglamentación de las enseñanzas de Música durante el Sexenio democrático. Un hito en la historia de la Programación de Piano [109]

3.2. Comienzos del siglo XX: los reglamentos de 1901, 1911 y 1917 [120]

3.3. Restauración y Segunda República, dos programaciones análogas en mundos opuestos [137]

\section{La ordenación académica de los conservatorios de música durante el régimen franquista [ 141 ]}

4.1. La nueva ordenación académica de los conservatorios de Música: la organización de 1942 y la reglamentación de 1966 [ 141$]$ 
4.2. Un nuevo rumbo en la Programación de Piano: el

Reglamento para los exámenes de Grado de 1968 [152]

4.3. Los conservatorios en la Ley General de Educación de 1970 [ 160 ]

\section{Transición democrática y reformas del sistema educativo [ 163 ]}

5.1. La Transición y la España democrática [163 ]

\subsubsection{Transición y Democracia [ 164 ]}

5.1.2. Los gobiernos de la España democrática [ 170 ]

5.2. La contribución de la Transición y Democracia española a la política educativa musical hasta 1990 [ 178 ]

5.2.1. La Constitución de 1978 y las leyes orgánicas de Educación en Democracia [ 179]

5.2.2. Leyes de Educación durante los gobiernos del Partido Socialista: LODE, LOGSE, LOPEG y LOE [184]

5.2.3. Leyes de Educación durante los gobiernos del Partido Popular: LOU, LOCE y LOMCE [195 ]

5.2.4. La LOGSE: el modelo curricular y la programación didáctica de Piano [198]

5.2.5. El absentismo de la administración pública respecto a las enseñanzas artísticas de música [214]

5.3. La convergencia de las Enseñanzas Artísticas con el Espacio Europeo de Educación Superior [217]

5.3.1. El marco jurídico de los Centros Superiores de Enseñanzas Artísticas [221] 
5.3.2. Investigación en los centros superiores de música [227]

\section{LOMCE 2013, final de trayecto. Leyes de educación musical en democracia después de la LOGSE [ 233 ]}

6.1. Los pilares de una nueva educación [233]

6.2. Las enseñanzas de música en la LOCE, LOE y LOMCE [237 ]

6.3. El proceso de concreción del currículo de las Enseñanzas Artísticas Superiores, en la LOE [253 ]

6.3.1. El proceso de Bolonia y su influencia en las EEAASS [254]

6.3.2. El Real Decreto 1614/ 2009 [ 260 ]

6.3.3. El Real Decreto 631/2010 [264]

6.3.3.1. El Real Decreto 631/2010 y su relación con los Descriptores de Dublín y los Learning Outcomes de la Asociación Europea de Conservatorios [265]

6.3.3.2. El diseño del Currículo de los planes de estudio de enseñanzas superiores de Música en las Comunidades Autónomas [269]

6.4. El EEES y su adaptación al último nivel de concreción. El trabajo de los equipos docentes [272]

6.4.1. Ingredientes del cambio de paradigma en la Enseñanza Superior Musical [ 275 ]

\subsubsection{El ECTS [ 276]}

6.4.1.2. El aprendizaje por Competencias:

Definición y Debate [ 284 ] 
6.4.1.3. El nuevo rol del profesor [289]

\section{Las enseñanzas superiores de música en Europa [ 297 ]}

7.1. Del nacimiento de Europa a la creación de las redes académicas, o de la Comisión Europea al Grupo Polifonía [297]

7.2. «Bologna in Music»: el papel de las Asociaciones educativas artísticas europeas [302]

7.3. Estructuras auxiliares para la implantación del EEES: los marcos de cualificaciones, la Iniciativa Conjunta de Calidad (JQI), y el proyecto Tuning [307]

7.4. Los Descriptores de Dublín y la metodología Tuning en el Espacio de Educación Superior de Música [311]

Conclusiones [ 323 ]

Bibliografía [ 337 ]

Apéndices [ 369 ] 



\section{1 \\ Prólogo}

$\mathrm{D}$

ESDE LOS TIEMPOS DEL BRILLANTE reinado de Carlos III, -con los lógicos límites que imponía el Antiguo Régimen al reformismo borbónico-, la Educación siempre ha sido un caballo de batalla entre distintos estamentos políticos, sociales y religiosos. Un rocín difícil de cabalgar, con constantes cambios de jinetes. El forcejeo entre la política educativa carlotercista y los organismos eclesiásticos encargados de la Enseñanza en España se saldó, -de manera indirecta-, con la dimisión forzosa del ministro Esquilache, primero, y con la expulsión de la Compañía de Jesús de los dominios hispánicos de la Corona, -de manera más visible-, después.

El doctor Jorge Luís Moltó Doncel, docente y pianista de profesión, realiza un estudio muy riguroso, partiendo de los debates alrededor de la Constitución de Cádiz, -en donde se alude a las escuelas particulares, encargadas de impartir las enseñanzas musicales-, y pasando por una compleja panoplia legislativa, hasta llegar a la LOMCE del ministro Wert. 
La fundación de los conservatorios nace al pairo del impulso de la reina regente, Doña María Cristina de Borbón Parma, y con la presencia destacada de Franceso Piermarini, cantante italiano de ópera, como profesor de canto, y Pedro Albéniz, como maestro de piano y acompañamiento. La presencia del canto destinado a la ópera no es baladí, por cuanto la hija de la regente, la reina Isabel II, fue cantante de ópera en su juventud, con un repertorio consagrado a los compositores belcantistas, en particular, Bellini y Donizetti.

La Ley Moyano, -Ley de Instrucción Pública de 9 de septiembre de 1857-, desarrollada por el Ministro de Fomento in illo tempore, significó un paso adelante a la hora de regular las enseñanzas artísticas, siempre dentro del régimen general del sistema educativo.

En la historia de la enseñanza del piano, las medidas legislativas del Sexenio Democrático supusieron un paso de gigante. Nunca olvidarán los conservatorios aquellas programaciones de todas las asignaturas impartidas en la Escuela Nacional de Música y Declamación promulgadas el primer día de las calendas de diciembre de 1871, todo un referente Ab Conservatoria Condita.

Las medidas legislativas de la Restauración y, luego, de la II República Española, expresan dos visiones antitéticas de la enseñanza musical.

Jorge Luís Moltó Doncel prosigue su análisis legislativo hasta nuestros días, adentrándose en el proceloso mundo de la normativa europea, hasta el proyecto Tuning, ya en el Espacio de Educación Superior en Música.

Toda esta primera parte de su Tesis Doctoral es una reflexión que abre el camino hacia la investigación artística. Una reflexión necesaria y documentada, que constituye un documento imprescindible para encarar con seriedad el futuro de la enseñanza e investigación del piano, ahora felizmente publicada.

Francisco Carlos Bueno Camejo
Universitat de València
Editor de Cuadernos de Bellas Artes 


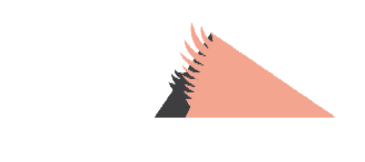

\section{Introducción}

\section{Seguir a hombros de gigantes frente a una modernidad líquida}

TIVIR UNA ÉPOCA DE CRISIS en la que el agotamiento de viejas estructuras y modelos trae consigo cambios a velocidad de vértigo, vaivenes tan rápidos que los individuos apenas tienen tiempo a acomodarse antes de que les sorprenda la siguiente transformación, parece haberse convertido en uno de los atributos de nuestras sociedades posmodernas y globalizadas. Enfrentarse a los retos tecnológicos que permiten a la ciudadanía acceder a un volumen de información jamás visto en ningún tiempo pretérito, tiene sin lugar a dudas sus ventajas, aunque mucho nos tememos que conlleva también ciertas vicisitudes.

Este modo hipervelocidad que parece haber tomado nuestra cultura actual, produce efectos secundarios como la transitoriedad y la precariedad, una vida líquida en un tiempo sin certezas, como ha 
expresado acertadamente Zygmunt Bauman. ${ }^{1}$ La figura de la liquidez utilizada por el sociólogo polaco para describir la sociedad actual, extiende su influjo sobre nuestra cultura, la construcción de los vínculos humanos o la educación.

Las políticas educativas de algunos países europeos, conscientes de los efectos de este contexto, están obrando cambios importantes en los esquemas formales de sus sistemas educativos, como por ejemplo mediante la adaptación de nuevos principios más dinámicos como es el Aprendizaje a lo largo de la vida (Lifelong Learning), desarrollado por la Dirección General de Educación de la Comisión Europea.

Por esta razón, intentar comprender las transformaciones acaecidas a nivel educativo y más concretamente en la educación musical impartida a través de los conservatorios, ${ }^{2}$ florece ante nuestros ojos como un acontecimiento con la suficiente entidad como para ser examinado con más detenimiento. Frente a este contexto de imparable fluidez en el que parece no existir ningún asidero al que agarrarse, sugerimos una estrategia para reconducir las mareas.

La propuesta gravita entorno a la importancia de conocer y revisar nuestro pasado no para quedarnos atrapados en él melancólicamente y acabar como expresa el pasaje bíblico con la mujer de Lot, convertidos en una estatua de sal inerte, sin vitalidad y capacidad de reacción, sino para encontrar precisamente los procesos e hitos acaecidos más remarcables que nos ayuden a discriminar entre

${ }^{1}$ Bauman, Zygmunt: Modernidad líquida, Buenos Aires, Fondo de Cultura Económica, 2003.

${ }^{2}$ Adoptamos la descripción de la Asociación Europea de Conservatorios en este estudio, para referirnos al término conservatorio, entendido como toda aquella institución especializada, ya sean Conservatorios, Academias, Escuelas o Universidades de Música, en el que el objetivo principal de sus enseñanzas es fomentar en el estudiante, el desarrollo práctico y creativo de la Música. Véase: Aec-Polifonia, Tuning Project: Reference Points for the Design and Delivery of Degree Programmes in Music, Bilbao, Publicaciones de la Universidad de Deusto, 2009, p. 21, [documento en línea]

$<$ http://www.unideusto.org/tuningeu/images/stories/Publications/tuningMusic2011.pdf $>$ [consultado el 19-8-2014]. 
todo el macrovolumen actual de información, sobre qué hechos merece la pena detenerse y meditar. Para contrapesar el axioma de Bauman, partimos de la hipótesis que de entre el actual torrente de información en el que nos encontramos sumergidos, pocos elementos son realmente remarcables y presentan la densidad necesaria para ser profundamente estudiados, por lo que nos parece adecuado adoptar una mirada crítica y atenta que nos permita sintetizar y separar lo que es realmente provechoso de lo puramente anecdótico, distinguir lo esencial de lo accesorio.

Dicho esto, echar una mirada al pasado buscando aquellos elementos que proporcionen solidez y dirección a nuestra sociedad volátil, justificaría a nuestro modo de ver, una tarea realmente útil. Zweig se refirió a estos momentos como "Momentos estelares", hitos inesperados, puntos de inflexión en la historia que marcan un antes y un después en el devenir de la humanidad: "cada uno de estos momentos estelares marca un rumbo durante décadas y siglos". 3

Más recientemente el historiador granadino José Enrique RuizDomènec, nos sugiere un itinerario similar al propuesto por Zweig, a través de un estudio histórico en el que destaca diecisiete momentos que han variado el rumbo de la historia de nuestro mundo. $\mathrm{Al}$ destacar estos momentos decisivos de la historia, estas "semillas del pasado" a las que hace referencia Ruiz-Domènec, o "miniaturas históricas" en el caso de Zweig, lo que procuramos es aprender de nuestros errores para poder tomar decisiones en el futuro que nos eviten tener que repetir las mismas conductas, e impedir así caer atrapados en una eterna infancia. Compartimos la opinión de RuizDomènec cuando afirma que "estamos viviendo un momento decisivo", y por tanto la situación demanda "el derecho de los hombres y de las mujeres a ser dueños de su destino, libre y democráticamente." 4

3 ZWEIG, Stefan: Momentos estelares de la humanidad. Catorce miniaturas históricas, Barcelona, Acantilado, 2002, p. 9.

${ }^{4}$ Ruiz-Domènec, José Enrique: La Trama del Pasado. Diecisiete momentos que cambiaron la historia del mundo, librosdevanguardia, 2014, p. 16. 
De manera que para confrontar esta hipótesis inicial, a lo largo de las páginas siguientes nos embarcaremos en un estudio panorámico de la evolución de la organización de la educación en España, centrando nuestra atención en la regulación de las enseñanzas de música, más concretamente, en la especialidad instrumental de Piano.

Pero, ¿por qué tomar como base la normativa musical? Sencillamente porque partimos de la teoría que los hitos de la legislación desplegada en materia educativa de un país en cada época determinada, hacen de espejo de su tiempo y de la comunidad de individuos que la protagonizaron, razón que nos lleva a emprender este repaso a la ordenación de las enseñanzas de música en los conservatorios desde la óptica de la Educación General y su regulación a través de los Sistemas Educativos, un modelo que comienza en España, coincidiendo con el inicio de su historia constitucional en las Cortes de Cádiz, en 1812. Este primer hito de la Educación General se convertirá por tanto en el punto de partida de nuestro viaje, un trayecto que nos conducirá hasta la aplicación de la última ley de educación hoy por hoy vigente, la Ley Orgánica 8/2013, de 9 de diciembre, para la mejora de la calidad educativa.

Sin embargo, no solo la necesidad de auscultar el pasado es la causante de estimular el comienzo de este trabajo. El reto que empezaba a plantear al final de la década de los noventa, la adaptación de las universidades y centros superiores de enseñanzas artísticas de España y del resto de Europa, al nuevo Espacio Europeo de Educación Superior, conocido comúnmente como Plan Bolonia, acabó confluyendo en otra de las principales fuerzas motrices para iniciar este viaje a través de la reglamentación musical en los conservatorios. La oleada de prescripciones legislativas que empujaron a las enseñanzas artísticas hacia un nuevo horizonte, determinado por el marco legislativo de la educación superior en España y el Espacio Europeo de Educación Superior, suscitó en nosotros el interés y la necesidad de emprender una reflexión positiva sobre la acción programadora en la especialidad de Piano, área instrumental que por otra parte, compone actualmente la materia prima de nuestra labor docente. 
Por consiguiente, la excursión comentada que se despliega en los sucesivos capítulos de este libro, explora los sucesos musicales más significativos, indaga en el pasado musical para arrojar luz y discernimiento, e intenta desterrar en la medida de nuestras posibilidades ilusiones fantásticas sobre la realidad musical, todo ello con el propósito de ir reemplazando paulatinamente interpretaciones apócrifas por argumentos verosímiles y de algún modo también útiles. Como reza la antigua expresión de la oratoria escolástica medieval, nuestra revisión compone en definitiva, esos hombros de gigantes sobre los que nos aupamos modestamente como investigadores para poder otear el horizonte musical propuesto, lo que nos recuerda que las posibles conquistas logradas, lo son gracias a las obras de nuestros antepasados.

\section{Algunos aspectos metodológicos sobre esta obra}

Nuestros esfuerzos intentan responder por tanto, a cuestiones tales como: ¿existen "momentos estelares" dentro del período acotado para nuestro estudio, en los que dividir la regulación de las enseñanzas de música? ¿Cuáles han sido las principales tendencias metodológicas que han caracterizado cada uno de los distintos modelos de acción programadora empleados en la enseñanza de la especialidad de Piano, y cómo ha discurrido su evolución?

Por otra parte, aclararemos en los límites de nuestras demarcaciones, los factores que han caracterizado cada una de las etapas presentadas, prestando especial atención a aquellas que hayan demostrado tener una mayor influencia en la reglamentación musical. Estudiaremos los factores contextuales históricos así como los desafíos a los que se enfrentaron en cada etapa la ordenación de los estudios musicales, interesándonos de forma particular las aportaciones depositadas por cada una de ellas al conjunto de estas enseñanzas.

Para ir desgranando todas y cada de una de estas cuestiones, los siete capítulos que articulan la estructura interna de nuestra tesis, plantean una diseño de trabajo que responde de forma general a la siguiente combinación dispuesta en tres niveles descendentes: 
contexto histórico; análisis de la legislación desarrollada en el periodo estudiado; y descripción de las principales consecuencias para la enseñanza de la especialidad de Interpretación de Piano.

En efecto, al inicio de cada capítulo durante el recorrido a través de los sistemas educativos, presentaremos una breve contextualización histórica intentando describir el período en el que se desarrolló dicha normativa. Los autores consultados para la elaboración de estas miniaturas iniciales, han sido por una parte manuales de primera mano que tratan la historia de España de forma compendiada, como la Historia mínima de España, de Juan Pablo Fusi, o la Breve historia de España de Fernando García de Cortázar y José Manuel González Vesga, a las que podemos añadir España. Una historia única, de Stanley Payne, o el volumen ya citado anteriormente de José Enrique Ruiz-Domènec, La Trama del Pasado. Diecisiete momentos que cambiaron la historia del mundo. Junto a estos textos han sido asimismo examinadas obras enciclopédicas como la Historia de España de Ramón Menéndez Pidal, o la Historia de España de Marqués de Lozoya.

Posteriormente, esta lista de títulos que tan fructíferamente nos ha servido para emprender el estudio panorámico de cada etapa, nos facilitó también el paso para consultar aquellas obras de referencia que nos han sido provechosas en la presentación de la visión general de la regulación de las enseñanzas de música, dentro del contexto de la educación general en España. Entre estos textos destacamos los dos volúmenes de la Historia de la educación de España de Alfonso Capitán Díaz, así como el libro de Manuel Puelles Benítez, Política, legislación y educación, obras como decimos a medio camino todavía entre la contextualización histórica y la tradición educativa en España y que nos han servido de nexo con las enseñanzas impartidas en los conservatorios.

Ya metidos más de lleno en el centro medular de nuestra materia sobre normativa musical, destacaríamos las aportaciones del interesante examen jurídico de Marzal Raga, El régimen jurídico de las enseñanzas musicales; de Fernando Agüerría Cueva, subrayaríamos su Historia de la educación musical en la España contemporánea. Un estudio de 
política legislativa; o de Embid Irujo y Gurrea Casamayor, su texto la Legislación sobre enseñanza. Enseñanzas de Régimen Especial.

Finalmente, junto a estas obras recalcaríamos las tesis doctorales de: $\mathrm{M}^{\mathrm{a}}$ Angeles Sarget Ros, Evolución de los conservatorios de música a través de las disposiciones legales: la Comunidad Autónoma de Castilla-La Mancha; Fernando Delgado García, Los Gobiernos de España y la Formación del Músico (1812-1956); María Luisa Martínez Díaz, El desarrollo de las Enseñanzas Superiores de Arte Dramático, Danza y Música en la Comunitat Valenciana. Antecedentes históricos, situación actual y perspectiva de futuro; o María del Mar Gutiérrez Barrenechea, La formación de intérpretes profesionales en los conservatorios en el marco de la reforma educativa: Madrid como paradigma.

No obstante, convendría precisar que al realizar esas pequeñas incursiones en el contexto histórico al inicio de cada uno de los capítulos, no deseábamos llenar un vacío en la historia de la regulación musical, por lo que consideramos que nuestro planteamiento no contiene en sentido estricto un punto de vista histórico. El objetivo no ha consistido en ningún momento exponer una nueva historia de la educación musical de nuestro país o plantear un examen desde un punto de vista legal. A pesar de haber utilizado para la persecución de nuestras intenciones fuentes provenientes de la normativa reglamentaria, el lector no se topará aquí con un trabajo de derecho administrativo que suministre a sus lectores un concienzudo y exacto análisis jurídico de la legislación que regula las enseñanzas musicales. Así que, si traemos a colación estos aspectos, es únicamente porque mientras estas particularidades pueden ser las características más relevantes de los estudios mencionados, nosotros sólo pretendemos utilizar estas contribuciones para dirigirnos hacia nuestro verdadero objetivo expuesto al inicio de la introducción y cuyo trasfondo tiene que ver, en último término, con la Interpretación musical y la docencia de esta actividad en el marco de las enseñanzas de la especialidad instrumental de Piano.

En este sentido, encontramos trabajos más cercanos a nuestro punto de vista ligado al mundo pianístico y su investigación, en las tesis doctorales de Gemma Salas Villar o Mariano Vázquez Tur, versando sobre El piano romántico español 1830-1855, y El piano y su 
música en el siglo XIX en España, respectivamente. El piano y su enseñanza es asimismo tratado en la tesis doctoral de Rocío Lorenzo Martín, Los contenidos de la educación pianística en los conservatorios de música: una propuesta integrada, en donde se nos muestra una interesante referencia sobre el estado de la cuestión del tratamiento del programa y su implantación en la LOGSE y la LOE. Siguiendo con el Piano pero relacionado con la interpretación y la creatividad encontramos a Elena Esteban Muñoz y su tesis, La versión pianistica. Defensa de la buella estético estilística del pianista en su interpretación en función de sus habilidades, conocimiento y creatividad. También sobre creatividad e interpretación aunque sin centrarse en ningún instrumento en concreto, destaca el trabajo de Francisco Higueras $\mathrm{Mu}$ ñoz, Interpretación musical y creatividad. Construcción del discurso social a través del pensamiento social y la investigación contemporánea.

En definitiva, el lector comprobará por sí mismo parte de la evolución de la enseñanza en España a través de sus sistemas educativos, deteniéndose especialmente en la reglamentación musical y sus consecuencias para la docencia de la especialidad instrumental del Piano durante prácticamente los últimos dos siglos. Un repaso en el que cada capítulo irá jalonando nuestro periplo a través de las diferentes etapas de la historia de la organización musical, hasta llegar a la actualidad con el último de los sistemas educativos sancionado en 2013.

La obra recurre por tanto al empleo de una metodología históricocrítica para desarrollar la indagación, en el sentido en que esta técnica nos ha permitido realizar un repaso como decimos a más de dos siglos de la historia de España y efectuar una estimación sobre la evolución normativa de sus planes de estudios. En conjunto, el trabajo se vale de esta metodología deductiva basada en un proceso analítico-sintético, esto es, asentado en la presentación de unas evidencias principalmente basadas en textos legislativos, con la esperanza de obtener respuestas a las preguntas planteadas al inicio de este apartado.

Este enfoque nos permitirá mostrar el modo en el que aspectos que son examinados por separado y que en principio parecían inconexos, posteriormente se relacionan entre sí como parte de un 
proceso en el que cada uno tiene relación con el resto, floreciendo en las conclusiones finales la aportación de una nueva consideración original.

Así por ejemplo, por medio de esta técnica accederemos al descubrimiento de relaciones que a priori nos parecen tan alejadas en el tiempo, como es el modo en que influiría la entrada de España en la Comunidad Económica Europea en 1986, a las enseñanzas de interpretación en la especialidad de piano veinte años más tarde. $\mathrm{O}$ descubrir con fascinación la manera en la que los modelos programáticos de esta especialidad, al aparecer como capas superpuestas las unas sobre las otras revelan el curso de su evolución con mayor nitidez, dejando la puerta abierta para pronosticar nuevos planteamientos en el futuro.

Para llevar a cabo el estudio comparativo de las diferentes programaciones de la asignatura de piano, de la legislación educativa musical de nuestro país, así como de la normativa europea encargada de regular el proceso de convergencia de la educación superior artística, fue necesaria la recolección de documentos así como la localización de programas y reglamentos en diferentes instituciones como es el caso del Archivo Histórico del Real Conservatorio Superior de Música de Madrid o la Biblioteca Nacional de España. Mención especial merece de hecho el descubrimiento del Reglamento Orgánico del Real Conservatorio de Música y Declamación MSS/12971/6, custodiado en esta última, documento del que no teníamos ningún tipo de referencia bibliográfica y cuya presentación en este estudio se debe gracias al fruto del trabajo de campo realizado directamente sobre el catálogo de la Biblioteca.

En el caso de los sistemas educativos más antiguos, constituciones y diversa legislación, llevamos a cabo su recopilación a través de la Colección legislativa oficial de España. Su localización varió considerablemente, dependiendo de las distintas etapas históricas a las que pertenecían los documentos consultados. Así, encontramos parte del material examinando los fondos de la biblioteca de la Universitat de València, a través de la Biblioteca Històrica, Biblioteca d'Humanitats "Joan Reglà", Biblioteca de l'Escola Universi- 
tària de Magisteri "Ausiàs March" y la Biblioteca de Ciències Socials "Gregori Maians".

Algunas leyes educativas y normativa general, fueron descargadas directamente de la web del Boletín Oficial del Estado y del Diario Oficial de la Comunidad Valenciana, para la normativa educativa autonómica correspondiente. Asimismo, obtuvimos material pertinente a través del Servicio de Información Legislativa del Boletín Oficial del Estado y el Servicio de Documentación, Biblioteca y Archivo, del Centro de Investigación y Documentación Educativa del Ministerio de Educación y Ciencia. También mediante correo electrónico y diferentes recursos de internet, reunimos documentación de la Biblioteca Central del Ministerio de Economía y Hacienda, la Hemeroteca Digital de la Biblioteca Nacional y la Biblioteca Digital de Derecho, "PixeLegis", de la Universidad de Sevilla.

Por lo que respecta a la legislación europea y el proceso de convergencia europea de educación superior, accedimos a la página web EUR-Lex y la página oficial del proceso de Bolonia en el Espacio Europeo de Educación Superior respectivamente, así como a los sitios web oficiales de la Unión Europea, que contenían información relevante sobre la historia, organismos y funcionamiento de la UE.

Igualmente ha sido de gran utilidad para el acceso a diversas revistas, publicaciones y diccionarios musicales, la aportación de colecciones privadas como la del profesor y amigo ya tristemente fallecido, Don Luís Blanes Arqués.

Realizadas estas aclaraciones metodológicas, recordar por última vez so pena de parecer reiterativos, la demanda de base que dinamiza el fondo de la investigación que a continuación exhibimos y que podría quedar fácilmente condensada en la siguiente interpelación, a saber: ¿cómo podemos optimizar en la actualidad, la enseñanza de interpretación en la especialidad de piano impartida en los conservatorios? Responder a esta cuestión no es un tema baladí y en nuestro caso particular, nos ha empujado a mirar atrás repasando nuestra propia historia antes de dar un paso en falso hacia delante. En este sentido, la célebre sentencia del filósofo norteame- 
ricano George Santayana "quien no conoce su pasado corre el peligro de repetirlo" ${ }^{5}$ cobra especial relevancia y sintetiza muy oportunamente nuestra invitación.

Para concluir, hacer caer en la cuenta al lector que este libro forma parte de la Tesis Doctoral defendida por el autor en febrero de 2015, e incorpora las oportunas sugerencias y comentarios de la Dra. Dña. $\mathrm{M}^{\mathrm{a}}$ Isabel Osuna Lucena, el Dr. D. Antonio Notario Ruiz y la Dra. Dña. Gloria Camarero Gómez, todos ellos miembros del tribunal examinador que la evaluó y a quienes estoy profundamente agradecido. Un proyecto, en fin, que no habría sido posible sin la ayuda y el apoyo de numerosas personas a las que quisiera expresar mi más sincero reconocimiento y gratitud aunque no aparezcan sus nombres de forma detallada. En primer lugar, destacaría el conjunto de profesionales al frente de algunas de las Bibliotecas y Servicios de Préstamo que he consultado, por su excelente profesionalidad y atención en lo concerniente a la recolección de buena parte de la bibliografía aquí consultada. Y finalmente a mis directores de Tesis, los Doctores D. Román de la Calle y a D. Francisco Carlos Bueno Camejo, que pertrechados con su dilatada experiencia y sabiduría, avalaron con entusiasmo desde el principio mi propuesta.

${ }^{5}$ SANTAYANA, George: The Life of Reason: or The Phases of Human Progress, vol. I, Reason in Common Sense, New York, Charles Scribner's Sons, 1920, p. 284. 



\section{Los orígenes}

\subsection{Génesis de los sistemas educativos}

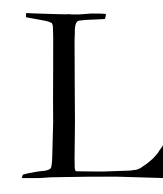

A EVOLUCIÓN HISTÓRICA DE LA ORGANIZACIÓN y reglamentación de las enseñanzas, que actualmente conocemos como enseñanzas artísticas, ${ }^{6}$ se exhibe como un largo proceso cuajado de desigualdades y altibajos. Una primera muestra de esta aseveración, se manifiesta de manera ostensible al comprobar el modo en el que estas enseñanzas se han visto vinculadas con el resto del conjunto jurídico-legislativo, en lo que a materia educativa concierne. $^{7}$ En consecuencia, resulta inevitable contextualizar el

${ }^{6}$ Ley Orgánica 2/2006, de 3 de mayo, de educación (B.O.E, de 4 de mayo de 2006, Título I, Capítulo VI).

${ }^{7}$ Como ejemplo ilustrativo de lo que aquí se expone, se pueden consultar los preámbulos de la Ley 17/2003, de 24 de marzo, por la que se regula la organización de las enseñanzas artísticas superiores en Aragón, (B.O.E. de 7 de mayo), o la Ley 8/2007, de 2 de marzo, de la Generalitat, de Ordenación de Centros Superiores de Enseñanzas Artísticas y de la creación del Instituto Superior de Enseñanzas Artísticas de la Comunitat Valenciana (D.O.G.V. de 8 de marzo). 
principal y verdadero objetivo substancial de nuestro trabajo, dentro de un planteamiento global más amplio que incluya, a través de las disposiciones y referencias legislativas más relevantes, un compendio de lo que ha sido la ordenación general educativa hasta nuestros días.

Uno de los principales objetivos que persigue todo Sistema Educativo, consiste en responder de la manera más acertada y exacta posible, a las necesidades de la realidad social y política a la que pertenece y en la cual se desenvuelve. Invariablemente, en cada momento histórico los sistemas educativos han ido adecuándose a los diferentes acontecimientos, intentando dar repuesta a los heterogéneos retos y exigencias que planteaba la sociedad.

Como iremos viendo, las sucesivas ordenaciones en materia educativa toman diferentes matices, dependiendo de las circunstancias socio-políticas en las que se desarrollan. De tal modo, que una reforma educativa puede significar el quebrantamiento decisivo con el anterior marco legislativo, o por el contrario, puede concebirse como una lógica prolongación reelaborada de su predecesor, como es el caso de la Ley Orgánica 2/2006, de 3 de mayo, de Educación.

Para averiguar el origen de los sistemas educativos en España, es imprescindible remontarnos al último período del siglo XVIII y primera década del XIX. Al parecer los sistemas educativos españoles inaugurales, ${ }^{8}$ no fueron impermeables a uno de los acontecimientos históricos más trascendentales acaecidos en nuestro continente durante este ciclo:

"La cultura intelectual y la educación en la España de finales del siglo XVIII y comienzos del XIX recibieron el influjo benefactor del espíritu francés de la Revolución. La presencia de los 'nuevos aires' revolucionarios y post-revolucionarios

\footnotetext{
${ }^{8}$ La historia de nuestros sistemas educativos se inicia conjuntamente a nuestra historia constitucional: "La preocupación por la regulación de la Educación General con validez oficial comienza en nuestra historia constitucional en las Cortes de Cádiz." (MARZAL RAGA, Consuelo de los Reyes: El régimen jurídico de las enseñanzas musicales, Valencia, Institució Alfons el Magnànim, 2010, p. 24)
} 
fue decisiva en el pensamiento pedagógico liberal que inspiró prácticamente todo el sistema educativo español a lo largo del siglo XIX".

No obstante, las influencias sobre un proceso tan complejo como es la creación de una estructura y ordenación educativa, dentro del contexto histórico de un país, vienen siempre compuestas y afectadas por diversos semblantes:

“El 'afrancesamiento' de la cultura española constituyó un proceso plural y complejo, manifiesto ya a lo largo del siglo XVIII, singularmente en su segunda mitad, durante los reinados de Carlos III y Carlos IV. Las teorías educativas se incluyen en el contenido de una especie de 'mentalización' cultural, lenta, que sin herir sentimientos nacionales y con los mínimos recelos, va incorporando el 'esprit-français' a la cultura española". ${ }^{10}$

Posteriormente, el crisol donde coexistirían las bases pedagógicas del liberalismo francés, con los modelos educativos de los ilustrados en España, sería el constitucionalismo español. Efectivamente en 1812 las Cortes de Cádiz, sumergida España en plena contienda contra la invasión napoleónica, concibieron entre otros tantos textos legislativos, la Constitución de 19 de marzo.

Se trata de la primera constitución de la historia española, consecuencia del frágil equilibrio entre los dos principales frentes políticos, liberales y absolutistas, al mismo tiempo que representa el primer texto legal organizativo de la administración educativa, dedicándole por entero el título IX del documento ${ }^{11}$ a la instrucción pública:

\footnotetext{
${ }^{9}$ CAPITÁN DÍAZ, Alfonso: Historia de la educación de España. I De los orígenes al Reglamento General de Instrucción Pública, Madrid, Dykinson, 1991, p. 974. ${ }^{10}$ Ídem, p. 975.

${ }^{11}$ Constitución española de 1812, Título IX. De la Instrucción Pública. Capítulo Único. [documento en línea]

$<$ http://www.cervantesvirtual.com/portal/1812/> [consultado el 17-42008].
} 
"El antecedente más remoto de organización administrativa de la Instrucción Pública en España, dentro del Estado constitucional, se halla en la Constitución de Cádiz de 19 de marzo de 1812, cuyo artículo 369 crea una Dirección General de Estudios para la inspección de toda la enseñanza pública bajo la autoridad del Gobierno, y el régimen de las Universidades antes autónomas. El 'plan general de enseñanza' había de ser uniforme en todo el Reino -artículo 368- y se reservaba a las Cortes, por medio de planes y estatutos especiales, arreglar cuanto pertenecía al importante objeto de la instrucción pública -artículo 370-. A pesar de la identidad terminológica, la Dirección General de Estudios no era un órgano igual a las direcciones generales que van a arraigar después en nuestra organización administrativa". ${ }^{12}$

En esta referencia podemos distinguir de igual forma, las principales consecuencias que tuvo para la educación este documento. La enseñanza debía de llegar a todas partes y a todos, es decir tenía que ser uniforme y universal, al tiempo que las Cortes se instituían como organismo reformador y reformista de la instrucción pública.

El 9 de septiembre de 1813, se presentaba ante la cámara de los diputados, el Informe de la Junta creada por la Regencia para proponer los medios de proceder al arreglo de los diversos ramos de instrucción pública. El documento incorpora los fundamentos que salvaguardan el pensamiento ilustrado y liberal en materia educativa, y viene refrendado por D. Martín González de Navas, D. José Vargas Ponce, D. Eugenio de Tapia, D. Diego Clemencia, D. Ramón Gil de la Cuadra y D. Manuel José Quintana, quienes componían la Comisión de Instrucción Pública, creada ésta a su vez por las Cortes. Según el

${ }^{12}$ DíAz, Joaquín: La administración educativa en España (1812-1939), [documento en línea]

$<$ http://www.educacion.gob.es/cide/jsp/plantilla.jsp?id=arch03a\&contenido $=/$ espanol $/$ archivo $/$ docheducacion/adeducativa/adeducativa01.htm $>$ [consultado el 26-8-2014]. 
informe, la instrucción pública debe ser, universal, igual, uniforme, pública, gratuita y libre. ${ }^{13}$

La trascendencia del documento es reveladora, a juzgar por la repercusión y el efecto que tuvo en textos posteriores. En efecto, el Informe de la Junta establece las bases del posterior Dictamen y Proyecto de Decreto sobre el arreglo general de la Enseñanza Pública, presentado en las Cortes el 7 de marzo de 1814, por la comisión de Instrucción Pública y que en último lugar se materializaría, esta vez con carácter de texto legislativo, mediante el Reglamento General de Instrucción Pública, ${ }^{14}$ publicado el 10 de julio de 1821 y aprobado por Decreto de las Cortes de 29 de junio de 1821.

El Reglamento, como ya hiciera el Dictamen y Proyecto de Decreto de 1814, divide el régimen de enseñanza en tres niveles: primera, segunda y tercera enseñanza. A estos tres grados hemos de añadirles las Escuelas especiales - Escuelas particulares en el Dictamen - fundamentales para nuestro trabajo como demostraremos más tarde.

Todos estos adelantos experimentaron un severo estancamiento en 1814. Efectivamente, el 22 de marzo del susodicho año y tras la derrota napoleónica en su ofensiva contra España, vuelve Fernando VII de su exilio en Valençay instaurando la monarquía absoluta. La decisión más nefasta para el desarrollo de la instrucción pública en ese momento, se resume en la derogación de todos los acuerdos y avances legislativos decretados por las Cortes de Cádiz. $^{15}$

${ }^{13}$ QuinTANA, Manuel José: "Informe de la Junta creada por la Regencia para proponer los medios de proceder al arreglo de los diversos ramos de Instrucción Pública", en Obras Completas, Madrid, B.A.E. Atlas, T. XIX, pp. 175191.

${ }^{14}$ Decreto LXXXI, de 29 de junio de 1821, en Colección de los decretos y órdenes generales expedidos por las Cortes Ordinarias de los años 1820 y 1821, en el segundo periodo de su Diputación, que comprende desde 25 de febrero hasta 30 de junio del último año impresa de orden de las mismas. Tomo VII, Madrid, Imprenta Nacional, 1821, p. 362.

${ }^{15}$ Ahora el objetivo prioritario es reestablecer de nuevo el antiguo régimen, comenzando un período comprometido para los liberales: "Comenzaba una época absolutista que duraría hasta 1820; en este período todos los que ha- 
El letargo absolutista daría un nuevo giro hacia el denominado trienio constitucional. La sublevación militar protagonizada por el teniente coronel Rafael de Riego en 1820, proporcionaría una nueva oportunidad a los liberales para gobernar el país y reemprender los proyectos interrumpidos en 1814.

El Reglamento General de Instrucción Pública de 1821 representa sin lugar a dudas, un hito en la marcha histórica-educativa española de esta etapa:
"su importancia radica en que sentó las bases del nuevo sis- tema educativo preconizado por el liberalismo español, hasta tal punto que sus características fundamentales, aunque no todas, pueden verse en la mítica Ley Moyano de 1857”.

Nos encontramos delante del primer sistema liberal de educación, que se desenvolvió con paso firme hasta alcanzar el territorio del ámbito legislativo desde el Informe de Quintana de 1813. Al mismo tiempo el Reglamento sirvió de plataforma para futuras leyes de ordenación educativa como son, el Plan General de Estudios de 1845 (Plan Pidal) y sobre todo para la Ley de Instrucción Pública de 1857 (Ley Moyano).

"La educación liberal asumía la herencia del pensamiento ilustrado, las aportaciones procedentes de otras fuentes tan diversas, como el constitucionalismo político doceañista, el utilitarismo moral anglosajón, el romanticismo literario y social... y se implicaba en una realidad histórica animada de tensiones y oposiciones entre tradicionalismo y liberalismo, entre afrancesados y reaccionarios, entre liberales moderados (afrancesados, carlotercistas y 'doceañistas') y liberales pro-

bían elaborado la Constitución fueron considerados no gratos y peligrosos para el bien público, se vuelve a la antigua ideología, al desequilibrio político y económico del país" (CAPITÁN DíAz, Alfonso, op. cit, p. 1016).

${ }^{16}$ Historia de la Educación en España, Madrid, Servicio de Publicaciones del Ministerio de Educación, tomo II, 1979, p. 16 (cita extraída de CAPITÁN DíAZ, Alfonso, op. cit., vol. I, p. 1009). 
gresistas (radicales y demócratas) entre la Iglesia y el Estado". ${ }^{17}$

No obstante y a pesar de su señalado alcance, fue un texto con poco margen de representación histórica, desplegándose su desarrollo pedagógico en el lapso de tiempo enmarcado por el trienio constitucional desde 1821 a 1823.

El 7 de abril de 1823, tras el fracaso del trienio, Fernando VII respaldado por el Duque de Angulema, jefe del destacamento francés, bautizado con el sobrenombre de los "Cien mil hijos de San Luís" vuelve a España y con él, un nuevo capítulo en la historia conocido comúnmente como la década ominosa o absolutista, que dará paso a la crisis dinástica de 1833 tras el fallecimiento del monarca.

La Constitución de Cádiz y toda su actuación llevada a cabo durante el trienio constitucional sería nuevamente derogada. ${ }^{18}$

Por razón del Real Decreto de 19 de noviembre de 1823, queda constituida la organización del nuevo gobierno, al que se le transfiere la denominación de Consejo de Ministros:

"He venido en resolver, que vos, con los demas" (sic) "mis Secretarios de Estado y del Despacho D. José García de la Torre, del de Gracia y Justicia; D, José Sanjuán, del de Guerra; D. Luis María Salazar, del de Marina, y Don Juan de

${ }^{17}$ Capitán Díaz, Alfonso: Historia de la educación en España II Pedagogía Contemporánea, Madrid, Dykinson, 1994, p. 29.

18 "Manifiesto de S. M. declarando que por haber carecido de entera libertad desde el dia 7 de Marzo de 1820, hasta el $1^{\circ}$ de Octubre de 1823, son nulos y de ningún valor todos los actos del gobierno llamado constitucional: y en cuanto á lo decretado y ordenado por la Junta provisional y la Regencia, aquella creada en Oyarzun, y esta en Madrid, lo aprueba S. M., entendiéndose interinamente", en Decretosy Resoluciones de la Junta Provisional, Regencia del Reino y los expedidos por su Majestad desde que fue libre del tiránico poder revolucionario, comprensivo al año de 1823. Por D. Fermin Martin de Balsameda, Intendente del Ejército Honorario, Tomo Séptimo, Madrid, Imprenta Real, 1824, p. 147. 
Erro, del de Hacienda, formeis" (sic) "un Consejo, que se denominará Consejo de Ministros". ${ }^{19}$

En esta primera agrupación no se hallan todavía las dos figuras emblemáticas representantes clave y contrapuestos, de la organización pública y educativa de ese período. Nos estamos refiriendo a las personalidades de Francisco Tadeo Calomarde de Retascón y Arriá (1773-1842) y a la de Luís López Ballesteros Varela (17821853).

Calomarde fue nombrado conjuntamente Secretario de Estado y del Despacho, a la vez que era escogido para la secretaria de Gracia y Justicia mediante Real Decreto de 18 de enero de $1824 .{ }^{20}$ A través de este segundo secretariado, Calomarde llevó a cabo una importante reforma de la Instrucción pública, dejando claramente manifiesto su peculiar estilo personal:

"Ministro hasta 1832, representó el más estricto absolutismo conservador frente al 'aperturismo' liberal del período constitucional". ${ }^{21}$

Bajo este signo comienza Tadeo Calomarde su tarea administrativa como ministro de Gracia y Justicia, que comprendía paralelamente la organización de la Instrucción Pública, desplegando el siguiente repertorio en el lapso de tres años: Plan literario de estudios y arreglo general de Universidades del Reino de 14 de octubre de 1824; ${ }^{22}$ Plan y

19 "Real decreto: ordena S. M. para el acierto en sus deliberaciones la formacion de un Consejo que se denominará de Ministros, siendo estos los Secretarios de Estado y del Despacho", en Decretos y Resoluciones de la Junta provisional,..., p. 192.

20 "Real Decreto nombrando S. M. secretario del Estado y del Despacho, y Secretario de Gracia y Justicia. [En 18]", en Decretos del Rey Nuestro Señor don Fernando VII, y Reales Ordenes, resoluciones y reglamentos generales expedidos por las secretarias del despacho universal y consejos de S.M. en los seis meses contados desde $1^{\circ}$. de enero hasta fin de junio de 1824. Por don Josef Maria de Nieva. Tomo VIII, Madrid, Imprenta Real, 1824, p.73.

${ }^{21}$ CAPITÁN DíAZ, Alfonso, op. cit., vol. II, pp. 41-42.

${ }^{22}$ Decretos del Rey Nuestro Señor don Fernando VII, y Reales Ordenes, resoluciones y reglamentos generales expedidos por las secretarias del despacho universal y consejos de $S$. M. En los seis meses contados desde $1^{\circ}$. De julio hasta fin de diciembre de 1824. Con un 
Reglamento de Escuelas de Primeras Letras de 16 de febrero de 1825; ${ }^{23}$ Reglamento general de Escuelas de Latinidad y Colegios de Humanidades de 16 de enero de $1826 .{ }^{24}$

Con todo, el conjunto de reformas que llevó a cabo el político aragonés, designado corrientemente "Plan Calomarde", figura en la historia educativa, a pesar de su inmovilismo, como uno de los planes mejor acabados y exhaustivos del momento:

"El plan anterior fue modificado por el de 14 de octubre de 1.824 y el de 16 de febrero de 1.825 , de los que se puede decir que fueron los más acabados y completos que regían en toda Europa en aquella época". ${ }^{25}$

\subsection{La música en los sistemas de enseñanza de 1812 a 1836}

¿Cuál fue el desenvolvimiento de la música dentro de los sistemas de ordenación educativa, según los textos legislativos expuestos hasta el momento?

La primera referencia que encontramos es bastante enigmática, dejando suficiente margen a la interpretación individual, nos estamos refiriendo al artículo 367 de la Constitución de Cádiz de 1812:

apéndice. Por don Josef Maria de Nieva. Tomo Nono, Madrid, Imprenta Real, 1825, p. 233.

${ }^{23}$ Decretos del Rey Nuestro Señor don Fernando VII, y Reales Ordenes, resoluciones y reglamentos generales expedidos por las secretarias del despacho universal y consejos de $s$. M. En los seis meses contados desde $1^{\circ}$. De enero hasta fin de diciembre de 1825. Por don Josef Maria de Nieva. Tomo Décimo, Madrid, Imprenta Real, 1826, p. 51.

${ }^{24}$ Decretos del Rey Nuestro Señor Don Fernando VII, Y Reales Ordenes, resoluciones y reglamentos generales expedidos por las secretarias del despacho universal y consejos de $S$. M. en los seis meses contados desde $1^{\circ}$. de enero hasta fin de diciembre de 1826. Por Don Josef Maria de Nieva. Tomo Undecimo, Madrid, Imprenta Real, 1827, p. 6.

${ }^{25}$ Díaz, Joaquín, op. cit., [documento en línea] $<$ http://www.mec.es/cide/jsp/plantilla.jsp?id=arch03a\&contenido=/espa$\mathrm{nol} /$ archivo/docheducacion/adeducativa/adeducativa01.htm $>$ [consultado el 26-8-2014]. 
“ART.367. Asimismo se arreglará y creará el número competente de universidades y de otros establecimientos de instrucción, que se juzguen convenientes para la enseñanza de todas las ciencias, literatura y bellas artes", ${ }^{26}$

Es opinión de algunos autores ${ }^{27}$ descifrar este artículo, englobando la regulación de las enseñanzas musicales dentro de la circunscripción de las bellas artes. Se trata de una aseveración ciertamente significativa, ya que la música no sólo se encuentra estipulada como objeto de materia a reglamentar dentro de la instrucción pública, sino que lo hace además con el rango de enseñanzas superiores equiparables a las universitarias.

Mucho más claras y elocuentes son las referencias que encontramos en materia musical en los documentos subsiguientes.

Encauzándonos directamente en el Dictamen y Proyecto de Decreto sobre el arreglo general de la Enseñanza Pública de 1814 y dejando a un lado el Informe de la Junta de 1813, encontramos en aquel un número considerables de noticias.

Ya hemos introducido cómo el Informe de 1813 y el presente Dictamen, abordaron entre sus principales objetivos la uniformidad y universalización de la enseñanza:

${ }^{26}$ Constitución española de 1812, Título IX, art. 367. [documento en línea] $<$ http://www.cervantesvirtual.com/portal/1812/> [consultado el 26-82014].

${ }^{27}$ Perelló DOMÉneCh, Vicente: La enseñanza musical en la Comunidad Valenciana, Valencia, Generalitat Valenciana. Conselleria de Cultura i Educació, 2003, p. 24. También BLANES ARQUÉS, Luís, Discurso de investidura Doctor Honoris Causa por la Universidad Politécnica de Valencia, 19 de enero de 2005, [documento en línea]

$<$ https://www.upv.es/organizacion/la-institucion/honoris-causa/luis-blanes/discurso-es.html $>$ [consultado el 29-7-2014]. 
"Quizá entre las causas que se han opuesto hasta ahora á" (sic) "su reforma y mejoramiento, no ha habido otra mas" (sic) "dañosa que la falta de uniformidad en la enseñanza". ${ }^{28}$

Sólo unas líneas más adelante encontramos la primera alusión a las escuelas particulares, encargadas como veremos de impartir las enseñanzas musicales:

"Diferente era el método, diferentes los libros, opuestos muchas veces los principios que se enseñaban, y diversos siempre: de manera que invirtiendo el Estado inmensas sumas en la educación de sus súbditos, la abandonaba á la arbitrariedad de cuerpos ó individuos; pagaba aquí para que se enseñasen verdades útiles, allí para perpetuar errores, allá en fin para sostener los caprichos o antojos de escuelas particulares; resultando de esta falta de uniformidad tal desconcierto, tal contradicción, que nada mas frecuente que ver en la Nación establecimientos tan adelantados como los mejores de Europa, y otros apegados aun á los absurdos de la edad media". ${ }^{29}$

$\mathrm{Al}$ parecer ciertas enseñanzas, profesores o escuelas, que se desarrollaban al margen de la educación reglada, van asociadas a una práctica menos generalizada, poco común y de la que se puede prescindir en un primer nivel de ordenación en la instrucción pública, por cuya razón van acompañadas de ese halo especial, que en cualquier caso el Estado respeta y ve con buenos ojos, pero cuya situación entiende que han de asumir o al menos compartir con los propios interesados.

Se trata en consecuencia de una excepción al principio de instrucción pública gratuita que plantea el Estado, para que todos los ciudadanos tengan acceso a una enseñanza sin cortapisas.

${ }^{28}$ Dictamen y proyecto de decreto sobre el arreglo general de la enseñanza pública; presentado a las Cortes por su Comisión de Instrucción Pública y mandados imprimir de orden de las mismas, Madrid, Cortes, 1814, p. 4

$<$ http://mdc.cbuc.cat/cdm4/document.php?CISOROOT=/guerraInd\&CI SOPTR $=3862 \&$ CISOSHOW $=3826>$ [consultado 24-04-2008].

${ }^{29}$ Ibidem, pp. 4-5. 
"Estos son los principios en que debe estribar la enseñanza costeada por el Estado; pero al mismo tiempo es necesario dexar" (sic) "en libertad á" (sic) "los que quieran enseñar ó" (sic) "aprender en escuelas particulares. Nada más contrario á" (sic) "los más preciosos derechos del hombre, y al mismo tiempo al adelanto en las ciencias, que ese empeño de entrometerse el Gobierno en señalar el camino que han de seguir los que quieran dedicarse á" (sic) "enseñar por su cuenta, y los que anhelen instruirse con maestros que ellos mismos costeen". 30

Por otro lado, no sabemos de qué "caprichos" y "antojos" habla el documento $^{31}$ cuando se refiere a las escuelas particulares y si la crítica va dirigida a las enseñanzas musicales en concreto o las artísticas en general. Motivos no nos faltan para sospechar - no creemos ir del todo desencaminados - de que la música es, a tenor de la siguiente observación, una clara candidata:

"La música, como arte de luxo," (sic) "y que tanto se mejora con la concurrencia de profesores extrangeros," (sic) "se enseñará en una Academia establecida en esta corte; pudiéndose formar otras dos semejantes en México y Lima". ${ }^{32}$

Lo que resulta innegable y enigmático a un tiempo es, que las enseñanzas musicales aparecen regladas y organizadas aunque no sabemos con exactitud qué quiere expresar el texto, al adjudicar las enseñanzas de música a una Academia. Tal vez podamos arrojar un poco más de luz sobre esta cuestión continuando con nuestro análisis.

En primer lugar, resulta evidente que lujosas o no, existe el firme propósito de organizar igualmente este tipo de enseñanzas:

"y repite la Comisión, que con las sumas empleadas hoy día en la enseñanza pública, entiende que se costeará sobrada-

\footnotetext{
30 Ídem, p. 5.

31 Ibidem.

${ }^{32}$ Ídem, p. 16.
} 
mente todas las universidades, escuelas particulares y demás establecimientos propuestos", 33

Ya inmersos de lleno en el Dictamen, varios son los artículos que hacen referencia a la regulación de las enseñanzas musicales. Dejando a un lado los artículos 13 y 14 que hablan sobre la situación de los maestros en las escuelas particulares, mucho más interesantes y elocuentes se presentan los artículos 36 y 37, puesto que asignan a las escuelas particulares, junto con las universidades mayores y colegios, el compromiso de proporcionar los estudios de tercera enseñanza:

"ART. 36. La tercera enseñanza comprehende" (sic) "aquellos estudios que se llaman de carrera ó" (sic) "facultad, y son necesarios para algunas profesiones de la vida civil.

ART. 37. Estos estudios se proporcionarán, unos en universidades mayores, y otros en colegios ó" (sic) "escuelas particulares". ${ }^{34}$

Llegamos finalmente al Título VII dedicado íntegramente a los colegios o escuelas particulares. El Título está compuesto por cinco artículos. Los dos primeros tienen por objeto revelar el por qué de estas escuelas y su justificación, alegando que son necesarias "para algunas profesiones de la vida civil, y que no se proporcionan en las universidades mayores", ${ }^{35}$ de ahí la necesidad de acudir, o establecer en el caso de que no existan, estas escuelas. En el artículo 64 se expone de qué manera y en qué número se constituirán estos colegios y escuelas, descubriendo finalmente de manera explícita que se fundará "Para la enseñanza de la música, una escuela que se establecerá en Madrid". ${ }^{36}$

Los tres últimos artículos no son de menor trascendencia para nuestra investigación, puesto que se encargan de desplegar los

\footnotetext{
${ }^{33}$ Ídem, p. 21.

${ }^{34}$ Ídem, Título V, arts. 36, 37.

35 Ídem, Título VII, art. 63.

${ }^{36}$ Ídem, art. 64, 50.
} 
puntos concernientes a la creación de los reglamentos, que regirán estos establecimientos educativos. El artículo 66 formula textualmente:

“ART. 66. La Dirección general de estudios deberá formar estos reglamentos con presencia de los ya existentes, y tomando informes de los profesores mas" (sic) "aventajados en la ciencia ó" (sic) "facultad de que se trate".

Se trata por tanto del primer paso para la elaboración de los futuros reglamentos de enseñanzas musicales. Este anuncio es un arranque, el primer empuje de un movimiento llamado a convocar, no solamente el levantamiento de establecimientos que alberguen las enseñanzas musicales, sino también y como es obvio la plasmación de los reglamentos y disposiciones que hagan falta para organizar estas instituciones convenientemente. Si bien es cierto que nos queda aún un extenso periplo para llegar al siguiente nivel de concreción, las programaciones de las asignaturas, es innegable que estamos más próximos a alcanzarlo desde esta orientación.

Finaliza así nuestro recorrido por el Dictamen y Proyecto de Decreto sobre el arreglo general de la Enseñanza Pública. Se trata de un documento sin parangón en este período, puesto que como veremos a continuación el Reglamento de Instrucción Pública es prácticamente una reproducción sin demasiadas modificaciones en lo que atañe a la organización de la enseñanza musical. Por otro lado, la colección de planes educativos desarrollados por Calomarde, sorprendentemente, no presenta ningún tipo de regulación en materia musical. Lo más paradójico de esta cuestión yace, en que será justamente durante su vigencia, cuando se erija al fin el primer establecimiento destinado propiamente al aprendizaje de las enseñanzas musicales.

Pero enfoquemos nuestra atención sobre un último documento, antes de volcarnos sobre esta interesante cuestión.

El 16 de junio de 1820, podíamos leer en un Artículo de Oficio de la Gaceta de Madrid, lo siguiente:

${ }^{37}$ Ídem, Título VII, art. 66. 
"El Rey se ha servido expedir el decreto siguiente:

'Convencido de que el medio mas seguro de cimentar con la mayor solidez los gobiernos representativos es el promover todos los ramos de la instrucción pública, y deseo de que se adelanten los trabajos preparatorios para el establecimiento de un plan uniforme y general de enseñanza en todo el reino con arreglo á" (sic) "lo que prescribe la Constitución; tuve á" (sic) "bien mandar que se recogiesen noticias puntuales y exactas de los establecimientos de instrucción de todas clases que existen en los pueblos, con expresión de su instituto, rentas y estado en que se hallan, y que estas noticias, comunicadas por los ayuntamientos á" (sic) "los Gefes" (sic) "políticos, y por estos" (sic) "al Gobierno supremo con su informe y el de las diputaciones provinciales, tuviesen una forma comun" (sic) "para que sea mas fácil la deducción de los resultados generales sobre el estado actual en esta materia." $" 38$

Este pasaje simboliza el propósito de Fernando VII, después de jurar la Constitución el 9 de julio de 1820, de contribuir a la instauración de un sistema monárquico de tipo constitucional, que pese a la tentativa acabaría siendo insostenible.

El Real Decreto plantea un plan uniforme y general de enseñanza, proceso de reforma que cristalizaría en el ya consabido Reglamento general de instrucción pública de 1821.

Las diferencias con el Dictamen y Proyecto, en el que se inspira, no son substanciales y se reduce sencilla y primordialmente a una cuestión de terminología. Allí donde el dictamen hablaba de escuelas particulares, aparecen ahora como escuelas especiales. Por lo que se refiere al resto del documento encontramos pocas diferencias.

\footnotetext{
38 "Real decreto sobre el establecimiento de un plan uniforme y general de enseñanza en todo el reino con arreglo á lo que prescribe la Constitución", en Gaceta de Madrid de 17 de Junio de 1820, nº 95, pp. 697-698.
} 
La tercera enseñanza se desglosa en el Título IV, y comprende "los estudios que habilitan para ejercer alguna profesión particular", proporcionándose estos estudios "en cátedras agregadas á" (sic) "las Universidades de provincia, que después se designará, y otros en escuelas especiales". 39

Las universidades y escuelas especiales continúan quedando aglutinadas en el mismo rango dentro de la tercera enseñanza, designadas todas ellas para instruir en alguna profesión particular.

El Título V se ocupa por entero de la regulación de estas escuelas especiales. Contiene 26 artículos y es en el número 63, en el que encontramos la referencia a la música. Aparece aquí una importante variación, ya que esta vez no serán una sino dos las escuelas a fundar:

“63. Para la enseñanza de la música se establecerá una escuela en Madrid y otra en Barcelona". 40

Por último y antes de acabar el presente capítulo, desearíamos destacar el Título IX del Reglamento, en el que se hace referencia a la constitución de una Academia Nacional.

Ésta que ya aparecía con anterioridad en los textos precedentes, la sacamos ahora a relucir por el noble interés que perseguía en todas las áreas del saber y lo que quería encarnar, nada menos que el último peldaño y más alto rango del conocimiento, donde "se reunirán los sabios, los literatos y los profesores de bellas artes mas eminentes de los ramos á" (sic) "que debe dedicar la Academia sus importantes tareas".

\footnotetext{
${ }^{39}$ Decreto LXXXI. de 29 de junio de 1821, en Colección de los decretos.... Tomo VII, Título IV, arts. 36, 37.

${ }^{40}$ Ídem, Título IV, art. 63.

${ }^{41}$ Ídem, Título IX, art. 109.
} 
En ellas se refundirían todas las academias existentes, a excepción de la Academia de San Fernando, "la cual subsistirá como escuela especial de nobles artes", ${ }^{42}$

\subsection{Fundación del primer establecimiento de Música en España}

El 15 de julio de 1830, representa sin lugar a dudas, un hito en la historia de la ordenación de los estudios musicales en España, ya que se establece en la Corte por Real Orden, un "Conservatorio de Música, titulado de $\mathrm{M}^{\mathrm{a}}$ Cristina, marcando el Director, Profesores y Empleados de que se ha de componer, y sus correspondientes dotaciones anuales". 43

La Real Orden viene refrendada por López Ballesteros, a quien ya hemos nombrado con anterioridad y que fue elegido Ministro de Hacienda en diciembre de $1832 .^{44}$

Ballesteros aparece en la escena política, como una figura moderada que intentó suavizar las polarizaciones y tensiones de la década absolutista, reduciendo al mínimo las maniobras despóticas, supliéndolas con nuevos giros renovadores:

"los ministros de Fernando VII - con las excepciones de Ugarte y Calomarde - no apoyaban las 'depuraciones' - 'purificaciones’ - e intentaban por todos los medios a su alcance lenificar la persecución generalizada limitándose en ocasiones a lo estrictamente propio de trámite sin efecto alguno: frente al "imnovilismo" (sic) "del Duque del Infantado o de Tadeo

${ }^{42}$ Ídem, Título IX, art. 116.

${ }^{43}$ Real Orden por la cual S. M. se ha dignado disponer se establezca en la Corte un Conservatorio de Música titulado de $M^{a}$ Cristina, marcando el Director, Profesores y Empleados de que se ha de componer, y sus correspondientes dotaciones anuales (Archivo Histórico del Real Conservatorio Superior de Música de Madrid, 15 de julio de $\left.1830, \operatorname{Leg} 1 / 1^{\circ}\right)$.

44 "Real Decreto: nombra S. M. los individuos que han de servir en propiedad el empleo de Secretario de Estado y del Despacho en cada uno de los Ministerios", en Decretos y Resoluciones de la Junta Provisional,..., p. 210. 
Calomarde se hallaba el 'reformismo' aperturista de Ballesteros, Zambrano, o Salazar". ${ }^{45}$

Al parecer el Ministro de Hacienda supuso una inestimable ayuda para el desarrollo de las enseñanzas artísticas y su personal talante "aperturista", simbolizó una valiosa aportación al levantamiento definitivo del Conservatorio.

“Así, pues, creáronse por él varios establecimientos cuya tendencia era favorecer las ciencias positivas. La Escuelas de Minas y el Cuerpo de Ingenieros que en ella se formó, abrian" (sic) "una nueva era á" (sic) "la geologia," (sic) "en la que se hicieron algunos trabajos importantes. El Conservatorio de Artes con sus sucursales en las provincias, sentó las bases de la enseñanza industrial, y suplia" (sic) "con sus cátedras en algunos puntos lo que las ciencias fisico-matemáticas" (sic) "pedian" (sic) "en vano á" (sic) "las universidades. Los Consulados y Juntas de Comercio recibieron nuevo impulso, permitiéndoseles establecer escuelas de diferentes clases; y hasta el Conservatorio de Música y Declamación fue una prueba de que aquel ministro se apartaba de las rancias doctrinas y necias preocupaciones". ${ }^{46}$

El documento está dirigido al Director general del Real Tesoro y al Contador general de Distribución, y prosigue de la siguiente manera:

"El Rey N. S. se ha servido mandar que se establezca en esta Corte un Conservatorio Real de Música que llevará el augusto nombre y gozará de la escelsa" (sic) "proteccion" (sic) "de la Reina $N^{a} . S^{a} . "{ }^{47}$

Efectivamente estamos hablando del origen del actual Real Conservatorio Superior de Música de Madrid, primer y único estable-

${ }^{45}$ CAPITÁN DíAz, Alfonso, op. cit., vol. II, p. 44-45.

${ }^{46}$ Gil de ZÁrate, Antonio: De la Instrucción Pública en España, Oviedo, Pentalfa, 1995, vol. 1, pp. 98-99.

${ }^{47}$ Real Orden por la cual S. M..... (Archivo Histórico del Real Conservatorio Superior de Música de Madrid, Leg 1/1º). 
cimiento oficial existente de semejantes características en esta época, ${ }^{48}$ y que como iremos vislumbrando, se convirtió en el modelo de referencia a seguir, tanto en su funcionamiento como en su estructura organizativa, por la mayoría de los conservatorios de posterior creación. $^{49}$

Se designa como director y maestro de estilo de canto a Francisco Piermarini, cantante italiano de ópera en la época y a Pedro Albéniz, como maestro de piano y acompañamiento, dos figuras especialmente destacadas para nuestro trabajo, como demostraremos más adelante.

Nos parece atrayente la cuestión planteada por algunos investigadores, ${ }^{50}$ concerniente a la influencia recibida en la Corte de Madrid,

${ }^{48}$ Le sigue en el tiempo, el Conservatorio del Liceo de Barcelona, que se erige en 1838. Posteriormente, ya en 1879 se funda el Conservatorio de Música de Valencia.

${ }^{49}$ La creación de éste y otros conservatorios sucesivos, no supuso la panacea ni el remedio definitivo a los desafíos de la época romántica, pero sí que representa el principio organizativo generador de la enseñanza musical reglada en España: "Después de las guerras napoleónicas, sufrió la música española otro colapso, mayor que los anteriores. R. Carnicer fue obligado a dejar Barcelona para dirigir el teatro de la corte. Éste, junto con Pedro Albéniz y Baltasar Saldoni, formaron la trinidad de los buenos maestros del Conservatorio de Madrid, fundado en 1830, al cual siguió, en 1838, el de Barcelona. En honor a la verdad, debemos añadir que, con la fundación de ambos conservatorios, no se levantó mucho el nivel, tan decaído, de la música española religiosa y profana, que no supo aprovecharse de los clásicos vieneses ni de los románticos, tan estimados en el mundo". (ANGLÉs, Higinio: La música española desde la Edad Media hasta nuestros dias: catálogo de la exposición bistórica, celebrada en conmemoración del primer centenario del nacimiento del maestro Felipe Pedrell/ por Higinio Anglés, Barcelona, Diputación Provincial de Barcelona, Biblioteca Central, 1941, p.73).

${ }^{50}$ MONTES, Beatriz: "La influencia de Francia e Italia en el Real Conservatorio de Madrid", en Revista de Musicología, vol. XX, no 1, Madrid, Sociedad Española de Musicología, 1997, pp. 467-478. Sobre la creación del Conservatorio de Madrid en 1830, y los proyectos anteriores véase: ROBLEDO ESTAIRE, Luís: "La creación del Conservatorio de Madrid", en Revista de Musicología, vol. XXIV, n 1-2, Madrid, Sociedad Española de Musicología, 1997, p. 189223, y Robledo Estaire, Luís: "El Conservatorio que nunca existió: El proyecto de Melchor Ronzi para Madrid (1810)", en Música. Revista del Real 
por los Conservatorios establecidos en Nápoles y París, sobre todo, en lo que respecta al desarrollo y organización de las enseñanzas impartidas en el Conservatorio español.

Un factor importante sí conocemos. Por Reales Órdenes de 4 de agosto, 6 de octubre y 4 de noviembre, todas ellas del año 1830, es decir, a escasos meses de la inauguración del Conservatorio español, se ordena solicitar una copia de los reglamentos empleados no solo en Nápoles, París y Milán, ${ }^{51}$ sino también los de Suecia, Estocolmo, ${ }^{52}$ Sajonia ${ }^{53}$ o Gran Bretaña. ${ }^{54}$

No obstante, y aunque se trata de una interesante teoría, no vamos a adentrarnos a discutir en este momento tal hipótesis, al no formar la cuestión parte substancial de nuestras inquietudes y objetivos.

El 7 de enero de 1831, comienza la apertura del curso. El centro no se encuentra totalmente listo y todavía se llevarían a cabo obras para su remate final hasta el mes de marzo. ${ }^{55}$ Definitivamente, el

Conservatorio Superior de Música de Madrid, $\mathrm{n}^{\circ}$ 7-8-9, Madrid, Real Conservatorio Superior de Música de Madrid, 2000-2002, pp. 13-25.

${ }^{51}$ Real Orden, mandando remesar los Reglamentos que rigen en los Conservatorios de Música de Nápoles, París y Milan, Madrid, 4 de agosto de 1830 (Archivo Histórico del Real Conservatorio Superior de Música de Madrid, Leg 1/2).

${ }^{52}$ Real Orden, acompañando adjuntos $1^{\circ}$ : el Reglamento del establecimiento de instrucción de la Academia Real de Música de Suecia y $2^{\circ}$. El Reglamento de la - Sociedad Harmónica de Stockolmo, Madrid, 6 de octubre de 1830 (Archivo Histórico del Real Conservatorio Superior de Música de Madrid, Leg 1/11).

${ }^{53} \mathrm{Rl}$. Orden, acompañando adjunto un proyecto de un Conservatorio de Música escrito por el maestro Morlachi 1er.Mstro.de la Capilla de S. M. el Rey de Sajonia, Madrid, 4 de noviembre de 1830 (Archivo Histórico del Real Conservatorio Superior de Música de Madrid, Leg 1/16).

${ }^{54} \mathrm{Rl}$. Orn. acompañando adjunto un ejemplar del Reglamento interior de la Academia de Música de la Capital de la Gran Bretaña, Madrid, 4 de noviembre de 1830 (Archivo Histórico del Real Conservatorio Superior de Música de Madrid, Leg $1 / 17)$.

${ }^{55}$ OrTiz BALLESTERos, Consuelo: "Un paseo por palacio a través del Real Conservatorio Superior de Música de Madrid”, en Música. Revista del Real Con- 
Conservatorio se inaugura de modo oficial con gran boato y solemnidad, el 2 de abril de 1831, festejando posteriormente en el mismo, el nacimiento de la Infanta Luisa Fernanda, ${ }^{56}$ hija menor del rey Fernando VII y de María Cristina.

Tal vez lo que resulta más paradójico de todo este asunto sea, que el primer Conservatorio de la historia educativa española hace su aparición al margen de la ley, aunque conviene aclarar con más calma esta aseveración.

Ya hemos comprobado cómo el Conservatorio viene avalado legalmente por Real Orden de su Majestad el Rey Fernando VII. Sin embargo, quien realmente amparó y protegió su creación, fue su esposa la Reina Maria Cristina, con quien había contraído matrimonio en $1829 .^{57}$

Es por tanto la decisión y el empuje de la soberana, quien estimula verdaderamente el nacimiento del Conservatorio. Así nos lo recuerdan algunas publicaciones de la época en un parte no oficial:

"Esta empresa de interes" (sic) "moral y económico se debe á" (sic) "nuestra ilustrada y amable REINA, en cuyo corazon" (sic) "magnánimo se abrigan los deseos del mayor lustre y prosperidad del pueblo español: en cuyo augusto seno se encierran las mas halagüeñas esperanzas. Bajo su Real nombre y auspicios se ha decretado por nuestro Soberano, incansable para la ventura de sus pueblos, la ereccion" (sic) "del Real Conservatorio de música en la corte". ${ }^{58}$

servatorio Superior de Música de Madrid, $\mathrm{n}^{\circ}$ 10-11, Madrid, Real Conservatorio Superior de Música de Madrid, 2005-2006, p. 14.

${ }^{56}$ SOPEÑA IBÁÑEZ, Federico: Historia del Real Conservatorio de Música de Madrid, Madrid, Ministerio de Educación y Ciencia. Dirección General de Bellas Artes, 1967, p. 35.

57 “Noticias Extranjeras. España. Madrid 11 de Diciembre", Gaceta de Madrid. 12 de Diciembre de 1829, n 172, p. 645.

58 "Parte no Oficial. España. Real Conservatorio de Música de Maria Cristina”, Gaceta de Madrid. 24 de Julio de 1830, n 89, pp. 363-364. 
Un mes más tarde encontramos el siguiente Artículo de Oficio, confirmando la noticia:

"El Rey nuestro Señor se ha dignado mandar que se establezca en esta corte un Conservatorio Real de música con el título de María Cristina, en obsequio del nombre de la Reina nuestra Señora, y bajo su protección augusta". ${ }^{59}$

Lo que queremos mostrar con estas indicaciones es que el Conservatorio nace bajo el empuje y la decisión individual de personalidades vinculadas a la institución, con todo lo que ello significa, sin aparecer en cualquier caso el Conservatorio, dentro del marco reglamentario de la organización general educativa.

Recordemos al respecto que el Reglamento general de instrucción pública de 1821 contemplaba en su Título V, la regulación por entero de estas enseñanzas a través de las escuelas especiales, y el artículo 63 establecía dos de estas escuelas, una en Madrid y otra en Barcelona, para la enseñanza de la música. En contraposición a este Reglamento, nos hallamos en 1830 con el plan de ordenación de la Instrucción Pública de Tadeo Calomarde, y sorprendentemente, a lo largo de los tres planes desarrollados durante 1824, 1825 y 1826, por el político aragonés, no encontramos ninguna pauta ni modelo de organización para las enseñanzas musicales. En honor a la verdad hemos de señalar que el Reglamento general de Escuelas de Latinidad y Colegios de Humanidades de 16 de Enero de 1826, prevé en el currículum de estos últimos, las enseñanzas de Música, Baile y Esgrima, para todos aquellos alumnos que quieran y puedan costeárselo por cuenta propia,${ }^{60}$ advirtiendo en el caso de la Música, que se enseñará solamente la teoría de la misma, no la práctica, de tal modo que si algún alumno quisiera estudiar algún instrumento, co-

\footnotetext{
59 "Artículo de Oficio", Gaceta de Madrid. 26 de Agosto de 1830, no 103, p. 421.

${ }^{60}$ Decretos del Rey Nuestro Señor don Fernando VII, y Reales Ordenes, Resoluciones y Reglamentos generales expedidos por las secretarás del despacho universal y consejos de $S$. M. desde I ${ }^{\circ}$ de Enero hasta fin de Diciembre de 1826. Por Don Josef María de Nieva. Tomo Undécimo, Madrid, Imprenta Real, 1827, arts. 65, 73, 76.
} 
rrerá de su cuenta y pago los profesores que necesite, dando las clases en horas de recreo. ${ }^{61}$

Es esta la razón por la que el Conservatorio, con un telón de fondo legislativo caracterizado por el vacío normativo que regule las enseñanzas de música, surge finalmente de las iniciativas particulares de personajes vinculados a la entidad. ${ }^{62}$

Concluyendo, este primer trayecto nos ha encaminado hacia los orígenes de las primeras intenciones educativas tocante al establecimiento y organización de las enseñanzas de música. Hemos contemplado el nacimiento del primer establecimiento que llevó a cabo dichas enseñanzas y su particular marco reglamentario, ya es hora por tanto de abordar los reglamentos encargados de organizar este centro y sus enseñanzas. Estamos por lo tanto ante la primera célula primigenia, que dirige y orienta nuestra investigación, y aunque todavía queda mucho camino por recorrer, estos primeros pasos representan los pilares sobre los que aparecerán las futuras programaciones de las asignaturas que conforman el currículo de las enseñanzas de música. En consecuencia, este primer capítulo nos ha permitido recorrer el viaje que nos conduce directamente a la creación de los primeros reglamentos sobre música y subsiguientemente a la programación de sus asignaturas.

${ }^{61}$ Ídem, art. 83.

${ }^{62}$ Desgraciadamente esta desafortunada desconexión entre los diferentes derroteros asumidos por los sistemas educativos por un lado, y la regulación de las enseñanzas musicales por otro se convertirá en una característica de estas enseñanzas que vamos a poder comprobar a lo largo de nuestro viaje: "En suma, encontramos a través de estos textos un surgimiento en nada planificado de una endeble estructura de la enseñanza musical que, además, en absoluto está conectada con el sistema educativo. La presencia de las enseñanzas musicales en los planes de estudio de la enseñanza reglada es más que tenue y no está asegurada". (EMBID IRUJO, Antonio: Un siglo de legislación musical en España. Y una alternativa par la organización de las enseñanzas en su grado superior, Zaragoza, IFC Edición especial para ACESEA, 2000, p. 85. Disponible en el URL:

$<$ http://www.acesea.es/www/files/unsiglodelegislacionmusical.pdf> [consultado el 21-07-2014]). 


\subsection{Las bases de 1830 y la revisión de 1838. Los reglamentos de Francisco Piermarini y Cándido Nocedal}

Una vez levantado el Conservatorio, en su inaugural emplazamiento de la Plaza de los Mostenses de Madrid, ${ }^{63}$ la primera regulación que organiza la actividad académica del establecimiento, la encontramos en forma de bases generales en la Real orden concerniente al arreglo y mejor enseñanza del Conservatorio de Música. ${ }^{64}$

El escrito está dirigido al director del Conservatorio y de nuevo aparece firmado por el Ministro Luís López Ballesteros.

Las plazas creadas para la estructura del centro y la adjudicación de las distintas enseñanzas son las siguientes:

"un Administrador; un Rector espiritual; un maestro de composicion;" (sic) "uno de piano y acompañamiento; uno de violin" (sic) "y viola; uno de solfeo; uno de violoncello; uno de contrabajo; uno de flauta, octavin" (sic) "y clarinete; uno de oboé" (sic) "y corno inglés; uno de fagot; uno de trombon;" (sic) "uno de trompa; uno de clarín" (sic) "y clarin" (sic) "de llave; uno de harpa;" (sic) "uno de lengua castellana, Secretario de la Direccion;" (sic) "uno de lengua italiana; uno de baile; una Directora, una Subdirectora, una Ayudanta, para el departamento de alumnas". ${ }^{5}$

En un primer instante, puede resultar extraño que la plaza de piano y acompañamiento se presenten de manera conjunta como única especialidad, cuando en realidad no hace sino reflejar de manera evidente el papel que asumió durante este período. El piano no se había asentado aún como instrumento independiente de un modo

${ }^{63}$ Ortiz Ballesteros, Consuelo, op. cit, pp. 14-15.

${ }^{64}$ Decretos del Rey nuestro señor Don Fernando VII, y reales ordenes, resoluciones y reglamentos generales expedidos por las secretarias del despacho universal y consejos de $S$. M. desde 1. ${ }^{\circ}$ de enero hasta fin de diciembre de 1830.Por Don Josef Maria de Nieva. Tomo decimoquinto, Madrid, Imprenta Real, 1831, pp. 412-413. También se encuentra en: "Artículo de Oficio", Gaceta de Madrid. 25 de Noviembre de 1830, n $^{\mathrm{o}} 144$, pp. 581-582.

${ }^{65}$ Ibidem. 
estable y desempeñaba principalmente un rol de acompañamiento, tanto en el repertorio vocal primordialmente, como en el instrumental, interpretando incluso en algunas ocasiones arreglos operísticos como solista. En efecto, como así nos lo confirma un programa de audición de 26 de marzo de 1832, efectuado en el nuevo salón del trono del Conservatorio, de las diez piezas que componen el programa la gran mayoría son arias, dúos o conjuntos operísticos, y la única obra para piano que aparece en el programa, consiste no en una pieza del repertorio original para piano, sino en un Rondó sobre un tema de Il Crociato in Egitto de Giacomo Meyerbeer. ${ }^{66}$ No obstante, nos equivocaríamos pensando que este papel subsidiario del piano es una tarea en exclusividad, ${ }^{67}$ ya que lo era toda la música instrumental.

Otro aspecto a destacar es la titulación que se obtiene al finalizar los estudios. El alumno alcanza el nombramiento de profesor-dis-

66 "Primeros ensayos de su aplicación que ofrecen todos los alumnos internos y externos del Real Conservatorio de Música de María Cristina en el Nuevo Salón del Trono a los RR. PP. de sus augustos fundadores y protectores el Señor don Fernando VII y Señora doña María Cristina en loor de S. A. R. la idolatrada Princesa doña María Isabel Luisa el día 26 de marzo de 1832", en Memoria acerca de la Escuela Nacional de Música y Declamación de Madrid escrita para ser presentada en la Exposición Universal de la Música y del Teatro que ha de verificarse en Viena en el año de 1892, Madrid, Imprenta de José M. Ducazcal, 1892.

${ }^{67}$ Realmente, durante este período el piano constituye junto a la música instrumental e incluso la sinfónica, un conglomerado sometido a la primacía de la música vocal. Como señala Sopeña: "Es indudable que la preferencia por el italianismo se marca claramente en la sociedad, en los músicos, en el Conservatorio. Basta pensar lo siguiente: las sinfonías de Beethoven tardan medio siglo en conocerse en Madrid; hasta 1866 no se oye una de ellas completa -la séptima-, dirigida por Barbieri en la «Sociedad de Conciertos». Vemos, sí, en las veladas del Conservatorio el nombre de Haydn, incluso el de Weber, pero no ya la música sinfónica sino la estrictamente instrumental aparece en claro segundo término. Sin embargo buena parte de lo que se hace es realidad gracias al Conservatorio" (SOPEÑA IBÁÑEZ, Federico, op. cit, p. 67). 
cípulo del Real Conservatorio, asistiendo gratuitamente a la orquesta del mismo, siempre que para ello sean convocados. ${ }^{68}$

Pero sin duda alguna, el aspecto más relevante para nuestro estudio hallado en el documento, es el que aparece en el artículo número 20, pues por fin descubrimos una alusión clara sobre el modo de organizar las distintas asignaturas que se imparten en el centro:

"20. Los métodos ó" (sic) "tratados para la enseñanza de cada ramo de la música en el Conservatorio, se presentarán por cada maestro al Director, sin cuya aprobacion" (sic) "no podrán usarse". ${ }^{69}$

Efectivamente, como desarrollaremos en el siguiente capítulo, la llegada de los distintos métodos y tratados, tanto para instrumentos como para las materias teórico-prácticas, simbolizó la fundación y establecimiento de la principal herramienta pedagógica de la enseñanza musical en la época, y su hegemonía se prolongó en el tiempo hasta rebasar la primera mitad del siglo XX.

Sin embargo, aunque la etapa Piermarini parecía augurar un futuro lleno de posibilidades y prosperidad, la realidad histórica a través de su escenario político-social se impuso de manera inexorable. Los acontecimientos que se amontonan a ritmo vertiginoso precipitan al Conservatorio hacia una nueva situación, cuyas nefastas consecuencias no se harán esperar.

La muerte de Fernando VII en 1833 origina una crisis dinástica al proclamar reina con apenas tres años a su sucesora Isabel II. María Cristina se hace cargo de la regencia desde 1833 hasta 1840, administración que asumiría como trágico telón de fondo la guerra civil de los siete años. En efecto, la primera guerra carlista finaliza conjuntamente a la regencia de María Cristina de Borbón, dando paso al gobierno del general Espartero.

${ }^{68}$ Decretos del Rey nuestro señor Don Fernando VII, y reales ordenes, resoluciones y reglamentos generales expedidos por las secretarias del despacho universal y consejos de $S$. M. desde 1. ${ }^{\circ}$ de enero hasta fin de diciembre de 1830. Por Don Josef Maria de Nieva. Tomo decimoquinto,..., arts. 7, 8 .

69 Ídem, art. 20. 
La crisis económica provocada por la guerra, afecta severamente la estabilidad del país y muy directamente a la sensible organización de las enseñanzas musicales, sumiendo al Conservatorio en un duro trance. ${ }^{70}$ Por Real Orden de 29 de agosto de 1838, se dicta nueva organización para el Conservatorio, con el principal objetivo de afrontar esta dura situación:

"Por Real órden” (sic) “de 29 del próximo Agosto se ha dignado S. M. mandar que se dé una nueva organizacion" (sic) "al conservatorio de música y declamación que lleva su augusto nombre, procurando conciliar su existencia con la rigorosa" (sic) "economía que exigen las circunstancias, reduciendo el establecimiento solamente á" (sic) "una escuela de alumnos externos". ${ }^{71}$

Piermarini es destituido y en su lugar aparece el Conde de Vigo, encomendado de estrenar el reciente cargo de viceprotector. Este puesto de nueva creación suplanta al de director y tiene como principal finalidad asentar los lazos necesarios entre el establecimiento académico y la corte, siendo comúnmente acaparado por personajes políticos que en ningún caso forman parte del claustro de profesores del Conservatorio ni se tratan de músicos profesionales.

La doble lectura que podemos extraer de esta nueva reorganización, no puede ser más contradictoria. Por un lado representa la solución que impide afortunadamente, la total desaparición del Conservatorio del horizonte musical, ${ }^{73}$ al tiempo que esta misma medida, lo aleja de un proceso de regularización definitiva capaz de otorgarle la dignidad profesional que se merece, contraria al tradicional formulismo de enseñanza de lujo.

${ }^{70}$ Para profundizar sobre esta cuestión, recomendamos las obras citadas de Federico Sopeña, Consuelo Ortiz y Fernando Delgado.

71 "Noticias Nacionales. Madrid 30 de setiembre", Gaceta de Madrid. 30 de Septiembre de 1838, no 1414, p. 2.

72 Así nos lo recuerda Federico Sopeña: "Son en realidad «protectores», puente social entre la corte y el Conservatorio”. (SOPEÑA IBÁÑEZ, Federico, op. cit, p. 59).

${ }^{73}$ Gil de ZÁrate, Antonio, op. cit., vol. 3, p. 353. 
La etapa de peregrinaje que vivió la entidad musical, ${ }^{74}$ hasta la inauguración el 19 de noviembre de 1851 del Teatro Real y el asentamiento en este lugar del Real Conservatorio de Música y Declamación, ${ }^{75}$ permitió finalmente al establecimiento educativo disfrutar de un entorno más adecuado, aunque este nuevo contexto lo encadenaría todavía más a su obediencia palaciega. ${ }^{76}$

Sin embargo, el cambio más relevante que está a punto de sobrevenir en esta segunda mitad de siglo XIX es la nueva regulación del sistema educativo con la Ley de Instrucción Pública de 9 de septiembre de 1857, desarrollada por el entonces ministro de fomento, Claudio Moyano. Esta Ley, como veremos próximamente, significará un nuevo esfuerzo por regular las enseñanzas artísticas dentro del régimen general del sistema educativo, proporcionándoles una categoría acorde con su integridad formativa.

Pero antes de abordar esta interesante cuestión, hemos de afrontar aún, algunos hechos fundamentales para nuestra investigación. Siguiendo con el recorrido por los distintos niveles que comporta el proceso legislativo, llegamos al último estadio de nuestro viaje, en el que hacen su aparición los reglamentos e instrumentos pedagógicos encargados de organizar el Conservatorio y las distintas enseñanzas que lo componen.

En efecto, esta primera etapa de ordenación de las enseñanzas musicales, que cristaliza a través de la fundación y progreso del Conservatorio Real de Música María Cristina, y que se encuadra en el momento histórico que discurre desde su creación en 1830 hasta la aparición de la Ley Moyano en 1857, viene a su vez delimitada por los dos únicos reglamentos existentes en esta época situados

\footnotetext{
${ }^{74}$ Los recortes económicos provocaron la necesidad de buscar un alquiler más asequible: "Para el Conservatorio, como ya adelantamos, fue una época de recortes y de cambios. En 1847, siendo viceprotector D. Juan Martínez Almagro, éste se ve obligado a buscar otro emplazamiento para la institución, lo suficientemente amplio como para albergar a trescientos jóvenes, los instrumentos musicales, las decoraciones y demás muebles que posee". (OrTiz BAllesteros, Consuelo, op.cit, p. 23).

${ }^{75}$ Ídem, p.26.

${ }^{76}$ SOPEÑA IBÁÑEZ, Federico, op. cit, p. 59.
} 
curiosamente en los polos de este período. Se trata del Reglamento de 16 de septiembre de 1830, firmado por su Director Francisco Piermarini y el Reglamento de 5 de marzo de 1857, rubricado por el Viceprotector, Cándido Nocedal.

El nombramiento de Francisco Piermarini como primer director del Conservatorio es según algunos autores, el resultado de una malograda elección que trajo consigo cierto malestar, ${ }^{77}$ haciendo responsable al italiano de la falta de proyección e influjo social que emanaba el centro, derivado de su administración.

En cualquier caso, el reglamento nos suministra indicios nada despreciables, que permiten concebir una imagen más precisa, sobre la metodología empleada en las materias que se impartían durante aquella época en el Conservatorio.

El Capítulo VII del reglamento de Piermarini, se dedica por completo a puntualizar las funciones a desempeñar por los maestros del centro.

En el artículo $1^{\circ}$ volvemos a tropezar, como ya hemos informado anteriormente en las bases generales, con los métodos o tratados que ha de presentar cada profesor, previo visto bueno del Director. El "Método de Piano" se presenta como principal recurso organizativo de las enseñanzas y es propuesto libremente por el profesor, permitiendo que cada educador elija o cree su particular procedimiento de trabajo para impartir las clases a condición, eso sí, de notificar cualquier cambio o alteración que se lleven a cabo en los mismos. $^{78}$

Los sistemas y criterios de evaluación también resultan interesantes. El maestro debe realizar un seguimiento de asistencia del alumno anotando las siguientes observaciones adicionales:

${ }^{77}$ GÓmez Amat, Carlos: Historia de la música española, Madrid, Alianza Editorial, 2007, p. 257. También SOPEÑA IBÁÑEZ, Federico, op. cit, p. 21.

${ }^{78}$ PIERMARINI, Francisco: "Reglamento Interior aprobado por el Rey N. S. (Q. D. G.) para el gobierno económico y facultativo del Real Conservatorio de Música de María Cristina", Capítulo VII, art. $7^{\circ}$, en Memoria acerca de la Escuela Nacional de..., p. 34. 
"asistente ú" (sic) "omiso: aplicado ó” (sic) "negligente: perspicaz ó” (sic) "torpe: quieto ó” (sic) "inquieto". 79

Pero a parte de estas curiosidades, es en el Capítulo IX del Reglamento donde encontramos información más exacta sobre las calificaciones, exámenes y premios:

"Artículo $1^{\circ}$. Las notas diarias de los Maestros en las listas de sus clases, son para el Director un examen continuo de confianza en los mismos Maestros; pero en razón de su propia superior responsabilidad, llamará eventualmente á” (sic) "examen á" (sic) "cada clase, de cuyo estado necesite cerciorarse más; y así no habrá día establecido de examen mensual. En este acto reconoce también el Director la imparcialidad ó" (sic) "parcialidad con que los Maestros hayan puesto sus notas en las listas diarias; de suerte que á" (sic) "un tiempo inspecciona á" (sic) "los Maestros, y reconoce el estado de los discípulos". 80

Son varias las conclusiones que podemos extraer de este artículo. Por un lado tenemos los diferentes controles diarios y mensuales sorpresa, pensados para verificar tanto el progreso del alumno como el de los profesores. Además resulta inevitable para nosotros pensar en la actual evaluación continua, como método parejo renovado de las primitivas "listas diarias".

Los artículos $2^{\circ}$ y $3^{\circ}$ del reglamento hacen referencia a los exámenes anuales que se celebran en el Conservatorio como recompensa a los progresos y méritos obtenidos durante el curso. Los premios se distribuyen en premios de "mérito moral" y premios de "mérito facultativo". Evidentemente, los primeros van dirigidos a recompensar la actitud decorosa del alumnado, mientras que los premios al mérito facultativo tienen por objeto gratificar los esfuerzos y progresos intelectuales clásicos.

Por último, el artículo $4^{\circ}$ nos recuerda que el alumno que finalice su carrera obtendrá como reconocimiento a su trayectoria y dedi-

\footnotetext{
${ }^{79}$ Ídem, Capítulo VII, art. $4^{\circ}$.

${ }^{80}$ Ídem, Capítulo IX, art. $1^{\circ}$.
} 
cación, el título de Profesor-discípulo del Real Conservatorio, quedando obligados a auxiliar gratuitamente a la orquesta del Establecimiento, cuando sean requeridos a tal efecto. Pero a pesar de todas estas referencias seguimos sin saber: ¿Cuál es la duración de la carrera? ¿Cuántos años ha de cursar un alumno de piano, para obtener su título de Profesor-discípulo del Real Conservatorio?

No encontramos en el reglamento ninguna aclaración concluyente al respecto, pero tal vez podamos encontrar algún indicio examinando el siguiente artículo:

"Art. 14. Como el elemento esencial de la buena ejecución en la Música es la exactitud, unidad y repetición exclusiva de las lecciones determinadas para la enseñanza, es prohibido á" (sic) "todo alumno del Conservatorio el practicar sin expreso permiso del Maestro ni con la voz, ni con los instrumentos, aunque sea á" (sic) "pretexto de estudio o de ejercicio de agilidad, ni un solo compás ajeno de las lecciones que les estén señaladas, ó" (sic) "de las que ha hayan pasado. Esta falta, que es gravemente perjudicial al alumno y contraria á” (sic) "la responsabilidad y crédito del Conservatorio y de los Maestros será reprendida severamente cuando se averigüe, y aun podrá, si se reitera, ocasionar la exclusión absoluta del alumno que así desprecia su propio interés, y el concepto de quien con la autoridad de la experiencia y el legítimo celo de la responsabilidad se compromete con S. M. y con el publico á" (sic) "guiarlo por el camino más llano, corto y seguro desde el primero hasta el último paso de la carrera clásica". ${ }^{81}$

Aunque el artículo gravita entorno a la advertencia de no ejecutar "ni un solo compás ajeno a las lecciones" que no sean las que se estén estudiando bajo la supervisión del Maestro, con el ultimátum de exclusión definitiva del centro en caso de repetir la infracción, encontramos en el mismo "celo" pedagógico un dato de especial interés, el objetivo primordial de la carrera es la "buena ejecución en la Música", entendida como aquella que se mantiene dentro de los parámetros de "exactitud, unidad y repetición exclusiva de las

${ }^{81}$ Ídem, Capítulo XVI, art. 14. 
lecciones determinadas para la enseñanza". El alumno ha de realizar con la máxima corrección de ejecución, las lecciones y ejercicios que aparecen en su Método oficial de piano. ¿Y cuánto tiempo tiene para llevar a cabo estos ejercicios? ¿ ¿, 5, 6 años? Lo único que sabemos es que el Maestro se "compromete" ante su Majestad y ante el público, en guiar al alumno por el camino "más llano, corto y seguro desde el primero hasta el último paso de la carrera", he aquí la exacta temporalización de los estudios de piano.

Obviamente, en la actualidad no deja de asombrarnos una planificación educativa diseñada con este procedimiento. Al lado de nuestros planes de estudio con 14 cursos hasta alcanzar la licenciatura en la especialidad de Piano, resulta insólito. ${ }^{82}$ Pero esto no hace sino evidenciar que nos encontramos ante la primera regulación de las enseñanzas artísticas en la historia educativa, al mismo tiempo que descubrimos cómo una mirada atenta al pasado, permite redescubrir la actualidad y vigencia atesoradas en estas aportaciones históricas.

Finalizamos aquí nuestra revisión al reglamento de Piermarini, para abordar a continuación el último de los escritos elaborado antes de la reforma educativa de 1857.

Se trata del reglamento compuesto el 5 de marzo de 1857 por Nocedal, Viceprotector del Real Conservatorio de Música y Declamación en esa época.

Hasta entonces varios son los Planes de Estudio y Viceprotectores que se han sucedido. Como veremos en el capítulo siguiente, el Plan general de Instrucción Pública de 4 de agosto de 1836, impulsado por el Duque de Rivas y el Plan General de Estudios de 17 de septiembre de 1845 promovido por el Ministro de Gobernación, Pedro José Pidal, no aportan ningún aspecto relevante para la regulación de la enseñanza musical.

\footnotetext{
${ }^{82} \mathrm{El}$ plan de estudios diseñado por la LOGSE, contempla 4 años para grado elemental, 6 para grado medio y 4 para el grado superior, en la especialidad de Piano.
} 
Mientras tanto las autoridades que ocupan sucesivamente el cargo de Viceprotector, tampoco aportan cambios significativos en lo que a la organización de las enseñanzas del Conservatorio se refiere. Conde de Vigo, José Arnaldo, Juan J. Martínez Almagro, Marqués de Tabuérniga, Joaquín María Ferrer y finalmente Ventura de la Vega nombrado Director el 24 de octubre de 1856, van sucediéndose uno tras otro en su cargo sin aportar grandes novedades. ${ }^{83}$ No obstante, bajo el mandato de este último, aparece el reglamento de Nocedal. Cándido Nocedal i Rodríguez de la Flor (1833-1903) fue ministro de Gobernación desde octubre de 1856 hasta el mismo mes de 1857, coincidiendo con el lapso de tiempo que estuvo en la presidencia Ramón María Narváez, período que da comienzo al denominado bienio moderado (1856-1858). ${ }^{84}$

Nos hallamos frente a un período de transición, donde confluyen sucesos heterogéneos. De un lado, Claudio Moyano, ministro de Fomento durante la misma presidencia de Narváez y ocupando Nocedal la cartera de Gobernación, está a pocos meses de presentar su Ley de Bases de Instrucción Pública, acontecimiento que sobrevendrá el 17 de julio de 1857, y que sirvió de plataforma para el desarrollo definitivo de la Ley de 9 septiembre. A esto hemos de añadirle la disfunción que presenta el reglamento de Nocedal, al presentar un escrito discordante con la realidad. Si por un lado el reglamento continúa señalando en su artículo $5^{\circ}$ al Viceprotector, como "Jefe superior del Conservatorio" responsable de su "orden administrativo y de sus progresos artísticos", la realidad es muy distinta ya que el 24 de octubre de 1856 había sido nombrado Director, Ventura de la Vega, produciéndose la concentración de dos figuras administrativas, encargadas del gobierno de un mismo establecimiento, situación que acabaría normalizándose con la Ley Moyano y el Reglamento de Pedro Salaverría.

En verdad esta situación no era desconocida ni inusual. El mismo Ventura había sido elegido como miembro integrante de la comi-

${ }^{83}$ Memoria acerca de la Escuela Nacional de Música y Declamación de Madrid..., p. 319.

${ }^{84}$ VV.AA.: Enciclopedia de Historia de España. Diccionario biográfico, vol. IV, Madrid, Alianza Editorial, 1991, pp. 616-617. 
sión encargada de reorganizar el Conservatorio para hacer frente a la crisis de la primera Guerra Carlista durante los mandatos de Piermarini y Conde de Vigo. ${ }^{85}$

Toda esta situación queda reflejada en el reglamento, a través de un texto de nula trascendencia para las enseñanzas musicales. El documento no aporta ninguna novedad significativa y constituye un fiel reflejo del tránsito institucional y burocrático que están coexistiendo, a escasos meses de estrenar un nuevo sistema educativo.

$\mathrm{Al}$ realizar un breve examen del documento, tropezamos con que la titulación obtenida al final de los estudios es la misma que con Piermarini, y los Métodos siguen en plena vigencia a la hora de sistematizar la programación de las asignaturas eso sí, aparece una salvedad que pudiendo pasar inadvertida, encierra una visión de gran importancia, se insiste junto a la presentación de los métodos, en que se ha de dar a los profesores las "instrucciones convenientes para que haya la unidad y correlación indispensables" en la enseñanza de las materias. Casi de modo accidental, lo que se está propiciando con esta actuación es la organización lógica y congruente de la programación de la asignatura, describiendo una cualidad esencial de la acción docente: la planificación. Se trata por tanto de un detalle que aparece de soslayo, como si fuera un aspecto accesorio, pero que en realidad contiene el germen de una idea novedosa y vigente en la actualidad, que contrasta al mismo tiempo con la monotonía y redundancia del resto del texto. ${ }^{86}$

Continuando con nuestro análisis, unas líneas más adelante, concretamente en el artículo 34 del reglamento, encontramos otra información con un mensaje no menos sugestivo:

${ }^{85}$ Ovilo y OTERO, Manuel: Manual de biografía y de bibliografía de los escritores españoles del siglo XIX por Manuel Ovilo y Otero, Tomo II, Paris, librería de Rosa y Bouret, 1859, [documento en línea]

<http://es.wikisource.org/wiki/Manual_de_Biograf\%C3\%ADa:_Ventura_ de_la_Vega $>$ [consultado el 26-8-2014].

${ }^{86}$ Nocedal, Cándido: "Reglamento Orgánico del Real Conservatorio de Música y Declamación aprobado por S. M.", Capítulo II, art. 5, en Memoria acerca de la Escuela Nacional de Música y Declamación de Madrid..., pp. 48-55. 
"Art. 34. Los aspirantes á" (sic) "alumnos han de saber leer u" (sic) "escribir, y han de tener las cualidades físicas necesarias para el estudio á" (sic) "que han de dedicarse". ${ }^{87}$

La circunstancia que atrae esta vez nuestra atención es la sensibilidad que demuestra el texto para describir la importancia de poseer unas "cualidades" para dedicarse al estudio de las enseñanzas musicales, sobre todo en el caso de la práctica instrumental. Evidentemente no es tarea fácil reconocer y determinar esas cualidades, a las que comúnmente definimos como talento o condiciones especiales, pero estamos convencidos de que es necesario poseerlas, racionalizarlas de modo objetivo y desarrollarlas con mayor profundidad, a medida que avanza el nivel de profesionalización en los estudios. A esta idea le acompaña la observación de que junto a las condiciones musicales, los jóvenes estudiantes han de saber ciertamente, leer y escribir.

Por último, resulta interesante advertir que las dos plazas de piano aparecen desligadas de la de acompañamiento, síntoma del despegue y protagonismo paulatino que está conquistando el instrumento como solista. ${ }^{88}$

\subsection{Los Métodos Oficiales de Piano como herramienta programadora}

Ya hemos introducido en capítulos anteriores, el significativo florecimiento que tuvieron los métodos y tratados de música dentro del panorama educativo, sobre todo como procedimiento didáctico primordial para racionalizar las enseñanzas artísticas, aportando su particular lectura del aprendizaje y práctica musical.

Los Métodos son escritos didácticos profundamente ligados a la realidad musical y pedagógica de su tiempo, que intentan dar una respuesta eficaz a las necesidades educativas del momento y en no pocas ocasiones representan un modo seguro de conocer la música

\footnotetext{
${ }^{87}$ Ídem, p. 52.

${ }^{88}$ Ídem, p. 50.
} 
compuesta en la época. Después de la aparición de los primeros métodos, los nuevos textos y sucesivas revisiones soportaron el paso del tiempo, hasta el punto de que bien entrada la segunda mitad del siglo XX, todavía existían algunos de ellos en escuelas y conservatorios, ${ }^{89}$ antes de verse finalmente arrinconados por los nuevos planes de estudios.

$\mathrm{Al}$ comienzo de nuestro discurso, hemos expuesto la influencia que tuvo la Revolución francesa y su fundamento filosófico en el origen de los sistemas educativos. Una vez más encontramos en la revuelta gala, el origen de esta sistemática basada en los "Métodos Oficiales”. Efectivamente entre 1802 y 1814, el Conservatorio de París, con el propósito de unificar criterios por todo el territorio en materia de enseñanza musical, elaboró un proyecto basado en la confección de unas obras de texto que sirviesen de referente en todos los conservatorios y escuelas regionales..$^{90}$ De esta manera nacerían los Métodos, a fin de convertirse en una herramienta capaz de organizar y sistematizar la materia musical, sea cual sea la especialidad a reglamentar.

Creemos importante recalcar y coincidimos a este respecto con otros autores que son los tratadistas quienes van por detrás de los genios creadores y no al revés, pues son aquellos quienes después de examinar la obra maestra, extraen todo tipo de reglas y conclusiones con el afán de comprenderla. ${ }^{11}$ Una muestra ilustrativa de lo que acabamos de exponer, sincrónico en el tiempo con la aparición de los métodos, lo encarnaría el proceso de esclarecimiento e instauración de la forma Sonata durante el siglo XIX que nos propone Charles Rosen. ${ }^{92}$ El autor defiende la hipótesis de que la razón principal por la que conocemos la forma sonata tal cual se nos presenta hoy en día, es porque teóricos como Antonin Reicha, Adolph

${ }^{89}$ La Escuela elemental de piano y su prolongación la Escuela superior de piano, editadas ambas por la Sociedad Didáctico-Musical, son un claro ejemplo de lo que aquí se enuncia.

${ }^{90}$ Citado en MONTES, Beatriz: "La influencia de Francia e Italia en el Real Conservatorio de Madrid”, ..., p. 473.

${ }^{91}$ GÓmez AMAT, Carlos, op. cit, p. 247.

${ }^{92}$ Rosen, Charles: Formas de sonata, Barcelona, Labor, 1994, p.15. 
Bernhard Marx y Carl Czerny, nos dejaron en sus respectivos tratados de composición, los procedimientos compositivos más provechosos utilizados por Beethoven.

España se suma por tanto a esta tendencia pedagógica, llevando a cabo su particular reelaboración de los Métodos didácticos. Para ello nos ha parecido conveniente diferenciar el grueso de los diversos textos publicados en la época, de otro conjunto mucho más reducido al que podemos clasificar como, "Métodos Oficiales".

Los Métodos Oficiales consisten principalmente, en aquellas publicaciones destinadas a convertirse en obra de texto para la enseñanza de los alumnos del conservatorio, desmarcándose en este sentido del resto de volúmenes. El primero de los métodos para piano adoptado en el Real Conservatorio tras su inauguración, fue extranjero y tenemos noticias de ello a través de la Gaceta de 16 de abril de $1831 .{ }^{93}$ En efecto el método aprobado es el Cours complet pour l'enseignement du forté piano conduisant progrefsivement des premiers eléments aux plus grandes difficultés, obra escrita en tres volúmenes por la pianista y profesora del Conservatorio de París, la marquesa Hélène de Montgeroult. ${ }^{94}$

Habrá que esperar al menos una década, para encontrar el primer texto oficial de autor español. En mayo de 1840, se publica el Método completo de Piano del Conservatorio de Música, compuesto por el único profesor de piano existente en el Conservatorio por entonces, Pedro Albéniz y Basanta. ${ }^{95}$ A éste le seguirían los de José Miró, ${ }^{96}$ José Aranguren ${ }^{97}$ y Manuel de la Mata, ${ }^{98}$ como textos oficia-

93 Avisos. Con Real aprobación, dada á propuesta del director del Real conservatorio de música Maria Cristina, se ha becho en el establecimiento el arreglo siguiente, Gaceta de Madrid. 16 de Abril de 1831, n 48, p. 198.

${ }^{94}$ Montgeroult, Hélène: Cours complet pour l'enseignement du forté piano, conduisant progrefsivement des premiers éléments aux plus grandes difficultés, 3 vols., Paris, Chez Launer/Gravé et imprimé chez Marquerie frères, [ca. 1825].

95 Albéniz, Pedro: Método completo de Piano del Conservatorio de Música, 3 vols., Madrid, Almacén de Carrafa/ Librería de Hermosos/ Almacén de Lodre, 1840.

${ }^{96}$ MirÓ, José: Método completo de Piano, Madrid, Zozaya, 1856. 
les reconocidos por la Junta facultativa. Recordemos que la Junta facultativa estaba instituida en un principio por el Director y los maestros de contrapunto, clave y violín, ${ }^{99}$ a los que con el tiempo se les fueron añadiendo más profesores del claustro, ${ }^{100} \mathrm{y}$ entre sus funciones se encontraba la aprobación, o no, junto con el director, de los métodos didácticos elaborados o presentados por los profesores.

Como veremos posteriormente, después de estos métodos el espíritu pedagógico fue evolucionando y los nuevos aires trajeron consigo una organización más ecléctica de la enseñanza del piano, basándose principalmente en un programa compuesto por obras y estudios combinados simultáneamente de diversos autores, pasando progresivamente los ejercicios técnicos a un segundo plano. Coincidiendo con el inicio del sigo XX aparece un nuevo tipo de publicación basado en este sistema, que consistía en reunir bajo un mismo volumen, una selección escogida de ejercicios, estudios y obras de nivel progresivo. Bajo este signo surge la Escuela elemental de piano elaborada por la Sociedad Didáctico-Musical, ${ }^{101}$ que aparece como una serie de volúmenes con carácter recopilatorio, adecuados a cada curso.

Pero dirijamos nuevamente nuestra atención sobre los citados métodos oficiales. Realizando un breve examen sobre los textos mencionados, podemos descubrir como primera característica el cordón umbilical que une a casi todos ellos. En efecto, el Método de Manuel de la Mata es una trascripción del de Pedro Albéniz,

${ }^{97}$ Aranguren, José: Método completo de Piano, Bilbao, Casa Dotesio, [ca. 1890].

${ }^{98}$ De La Mata, Manuel: Método completo de Piano, Madrid, Pablo Martín editor, 1871.

${ }^{99}$ Piermarini, Francisco, op.cit, Capítulo X, art. 4.

${ }^{100}$ NOCEDAL, Cándido: op. cit, Capítulo IV, art. 9.

${ }^{101}$ Un ejemplo del trabajo desarrollado por este grupo lo vemos en: SOCIEDAD DIDÁCTICO-MUSICAL: Escuela elemental de piano. Dividida en cinco volumenes, correspondientes a los cinco años de dicha enseñanza, Madrid, J. M. Sardá, Pascual González y Eusebio Fernández, 1903. 
quién a su vez se inspiró en el de su maestro Hernri Herz. ${ }^{102}$ A pesar de todo, la obra de Albéniz es con diferencia la más interesante y trascendente del conjunto. Interesante, puesto que en sus tres volúmenes encontramos un vasto repertorio de ejercicios, compilando en una misma obra a diversos pianistas como Herz, Pleyel, Adam, Müller, Humel y Kalkbrenner. Y trascendente, porque su magisterio acabaría marcando a varias generaciones de pianistas a lo largo de su carrera como profesor en el Conservatorio, desde 1830 hasta su cese por defunción en 1855.

Aunque estamos de acuerdo con algunos autores, al atestiguar que el Método de Albéniz se encuentra desubicado respecto de la actividad pianística centroeuropa del momento, ${ }^{103}$ no es menos cierto que la sistemática llevada a cabo por el pianista madrileño, resulta totalmente inusual y actualizada si la comparamos con el ambiente predominantemente operístico que reinaba en el Conservatorio y la práctica inexistencia de recitales instrumentales.

Consiguientemente, los tres volúmenes de Albéniz dejan poco margen a los tratados de Miró y Aranguren. Miró también estudió en París con Kalkbrenner y con su método, poco añade a las tan precisamente expuestas teorías de Albéniz, situación con la que nos tropezamos nuevamente en Aranguren. Hemos de advertir además con este último, que su ocupación en el Conservatorio, fue finalmente como profesor numerario de armonía en 1880.

No obstante, no desearíamos mostrar en ningún caso una visión reduccionista, parcial o fraccionada de estos pedagogos del piano, cuya obra y vida por sí solas, constituyen objeto de estudio e investigación. ${ }^{104}$ Nuestra posición aquí no desea dictaminar sentencia

102 Herz, Henri: Méthode complète de Piano op. 100, Les fils de B. Schott, Maguncia y Amberes/ J. Meissonnier, Paris/ Dalmaine et C.ie., London, 1838.

${ }^{103}$ Chiantore, Luca: Historia de la técnica pianística, Madrid, Alianza, 2001, p. 252.

${ }^{104}$ Para profundizar sobre el tema consultar la tesis inédita: SALAS VILLAR, Gemma: El piano romántico español 1830-1855, Universidad de Geografía e Historia de Oviedo, 1997. También de la misma autora, "La enseñanza para piano durante la primera mitad del siglo XIX: los métodos para piano" en 
sobre cuestiones espinosas y peliagudas, que exigen un tratamiento más exclusivo y pormenorizado de lo hechos. Los Métodos de piano de este ciclo, constituyen una colección de escritos cuyo legado no podemos obviar, si deseamos comprender la evolución de la didáctica pianística. Desde las primeras adaptaciones de los Métodos franceses de Viguerie ${ }^{105}$ o Adam, ${ }^{106}$ pasando por los textos de Eduardo Compta, ${ }^{107}$ Roberto Segura, ${ }^{108}$ José Tragó, ${ }^{109}$ Pere Tintorer, ${ }^{110}$ Juan Bautista Pujol ${ }^{111}$ y Santiago de Masarnau, ${ }^{112}$ todos estos

Nassarre: Revista aragonesa de musicologia, Zaragoza, vol. 15, no 1-2, 1999, pp. 956.; "Aproximación a la enseñanza para piano a través de la cátedra de Pedro Albéniz en el Real Conservatorio de Madrid" en Revista de musicologia, Madrid, vol. 22, no 1, 1999, pp. 209-246.; "Pedro Pérez de Albéniz: en el segundo centenario de su nacimiento" en Cuadernos de música iberoamericana, Madrid, vol. 1, 1996, pp. 97-126.

${ }^{105}$ Viguerie, Bernard: Método completo de piano, GonZALO, José (ed.), Madrid, Manuel Jiménez, 1873.

${ }^{106}$ Sobejano AyAla, José: El Adam español o lecciones metódico-progresivas de forte piano. Por el profesor armonista D. $n$ J. Sobejano Ayala, Madrid, Calcografía de D. Bartolomé Wimbs, 1826.

${ }^{107}$ COMPTA Y TORReS, Eduardo: Método Completo de piano, Madrid, Imp. de Enrique Abad, 1873.

${ }^{108}$ Segura, Roberto: Método elemental de piano por Roberto Segura. Primera parte, Valencia, Casa de los Sres. Prosper y Laviña, 1879.

${ }^{109}$ Tragó, José: Escuela de piano. Estudios, Madrid, Almagro y Ca , 1899. También del mismo autor: Escuela de piano. Seis sonatinas, Madrid, Almagro y $\mathrm{C}^{\mathrm{a}}$, 1899.

110 Tintorer, Pere: Curso completo de piano, Barcelona, [S.i., ca. 1878].

111 Bautista Pujol, Juan: Nuevo mecanismo de piano, Barcelona, Tip. de J. B. Pujol, 1895.

${ }^{112}$ MASARNAU, Santiago : Llave de la ejecución : seis modelos de pasos para el pianoforte, que, ejecutados sucesivamente por los doce tonos mayores desarrollan en breve tiempo la ejecución de la mano asegurando de paso su buena posición y contribuyendo también a la formación del oido, Madrid, A. Romero, 1862. También del mismo autor: Tesoro del pianista, Madrid, Romero y Marzo, 1862. 
autores y sus manuscritos, componen el núcleo generador de un sistema pedagógico pianístico, representativo de este período. ${ }^{113}$

¿Cuál es la herencia que nos dejaron todos ellos? ¿Podemos establecer las características generales de su legado? Como ya hemos comentado anteriormente, necesitaríamos un espacio más adecuado para contestar a estas cuestiones con propiedad y exactitud. Sin embargo, para nuestra disertación global sobre la evolución de la acción programadora en la asignatura de Piano, esta primera aproximación nos brinda la oportunidad de esgrimir los siguientes argumentos.

Los Métodos y tratados teóricos permanecen actualmente, como el primer intento auténtico e indiscutible por racionalizar y sistematizar la técnica pianística, mediante la presentación de cientos de ejercicios técnicos que intentan abarcar la totalidad del juego pianístico, combinado a su vez y por si fuera poco, con otro número similar de estudios de diversos compositores, todo ello con el sano propósito de equipar al alumno con un mecanismo lo más preciso y desarrollado posible, a pesar de las limitaciones que pueda encerrar cada texto. Consultando el índice de cualquiera de los tres Método oficiales mencionados, encontramos ejercicios de posición fija, posición libre, notas dobles, paso de pulgar, las escalas y sus digitaciones, escalas en 3 as. y 6as., arpegios en todas las posiciones, trinos, notas repetidas, saltos, técnica de 8as. y todo un largo etcétera de gimnasia al teclado, acompañado de explicaciones sobre elementos de Música y un corolario de consejos pianísticos, como a qué edad debe empezarse a estudiar o sobre la elección del instrumento. ${ }^{114}$ Sin lugar a dudas, esta avalancha de ejercicios resulta abrumadora.

La lista de estudios y obras propuestas como complemento al trabajo de los ejercicios, aunque varía sensiblemente de unos a otros autores, suele coincidir en la exposición de los principales nombres

113 Sin olvidar el sello pedagógico que imprimieron pianistas como Teobaldo Power: "Fue autor de una obra didáctica que aplicó para su enseñanza en Madrid". (GÓmEZ AmAT, Carlos, op. cit, p. 78).

${ }^{114}$ AlBÉNIZ, Pedro, op. cit., vol. $1^{\circ}$, p. 9. 
de "referencia" del universo pianístico. Por ejemplo, Miró presenta estudios de Theodore Döhler y fugas de J. G. Albrechtsberger, ${ }^{115}$ que no figuran en los otros textos, mientras que Mata, ofrece autores españoles que no muestra el gaditano. Tomando como referencia el Método de Manuel de la Mata, por ser el más tardío en su publicación, podemos conocer de primera mano, qué tipo de programa se concebía para completar la formación del pianista. El encabezamiento del pasaje no puede ser más alentador:

\section{“OBRAS CLÁSICAS QUE ES CONVENIENTE TOCAR Y CONOCER, SIQUIERA SEA EN PARTE, PARA LLE- GAR Á" (sic) "SER UN PERFECTO PIANISTA". 116}

El repertorio para convertirse en ese "perfecto pianista" consiste en estudios, fugas, sonatas y obras de estilo romántico para piano solo, ${ }^{117}$ a cuyo inventario hay que añadir obras a cuatro manos, música de cámara, ejercicios de armonía y hasta partituras de orquesta, todo un esfuerzo recopilatorio que en la actualidad abarcaría la programación de al menos tres asignaturas.

Desearíamos resaltar un último apunte de José Miró en su texto, como aportación de inestimable valor en la que se describe elocuentemente, el estilo y concepción netamente fortepianístico, en el que se encuentran hondamente sumergidos todos estos autores y sus escritos:

"Las obras de este último autor" [refriéndose a Beethoven] "no deben sin embargo ejecutarse hasta no estar muy seguro de poseer un mecanismo perfecto, pues este genio inmortal siguiendo siempre el impulso de sus sublimes inspiraciones se cuidaba rara vez del manejo de los dedos; por consiguiente el

\footnotetext{
${ }^{115}$ MirÓ, José, op. cit., p. 122.

${ }^{116}$ DE LA MATA, Manuel, op, cit., p. 115.

117 Al Método le acompaña el siguiente elenco de compositores: estudios de Bertini, Czerny, Cramer, Clementi, Kalkbrenner, Moscheles, Herz, Kessler, Prudent, Ravina, Thalberg, Liszt, Chopin, y los españoles Ledesma y Gómez; sonatas de Field, Ries, Dussek, Haydn, Mozart; fugas de Bach, Czerny, Haendel y Cherubini y obras de Weber, Mendelssohn, Beethoven y Chopin.
} 
alumno que emprendiese demasiado pronto este estudio se espondrá” (sic) "á” (sic) "contraer graves defectos". ${ }^{118}$

Este discurso nos conduce directamente a nuestro siguiente postulado. Es necesario ubicar a todos estos tratados decimonónicos en su justo territorio pedagógico, si no queremos incurrir en abusos tanto por defecto como por exceso. Si aceptamos, como hemos expuesto en nuestra primera conclusión, los contenidos técnicos propuestos en los Métodos de piano de este período, como la primera tentativa por normalizar y reglamentar los estudios pianísticos, tan injusto sería tacharlos de anacrónicos, como pretender descubrir en ellos el último grito de la técnica pianística. De hecho, nada mejor que valorar el equilibrio exhibido entre estos dos polos, para apreciar hasta qué punto un manual pianístico está al corriente de las últimas novedades. ${ }^{119}$

Finalmente, los Métodos aparecen como primer sistema organizativo de la enseñanza de Piano, asumiendo el difícil equilibrio dentro de la evolución de la formación pianística, de aglutinar los contenidos fundamentales de la práctica interpretativa, a la vez que establecen el punto inaugural para futuros progresos.

El período romántico, en definitiva, se manifiesta como un período de especial tensión bipolar, entre la fuerza creadora del artista y las pautas docentes encargadas de establecer y organizar normas coherentes que expliquen el trabajo de aquél.

\footnotetext{
${ }^{118}$ Miro, José, op. cit., p. 122.

${ }^{119}$ SOPEÑA, Federico op. cit., p.156
} 



\section{De la Ley Moyano a la revolución de 1868}

\subsection{Marco Legislativo: el Plan Duque de Rivas, el Plan Pidal y la Ley de Instrucción pública de 1857}

S

I EN EL PRIMER CAPÍTULO de nuestro trabajo confesábamos, que la trayectoria de las enseñanzas artísticas se había caracterizado por continuos vaivenes legislativos durante su transcurso histórico, a continuación llega el momento de dar paso a uno de esos puntos álgidos, en el que la reglamentación musical acusó un apreciable desarrollo.

El 9 de septiembre de 1857, en un clima político de consenso fruto del pacto alcanzado entre moderados y liberales, se publica la Ley de Instrucción Pública también conocida como Ley Moyano. Claudio Moyano Samaniego (1809-1890), fue ministro de la cartera de Fomento durante la presidencia de Ramón María Narváez, quien junto a Francisco Armero de Peñaranda y Francisco Javier de Istúriz, fueron relevándose sucesivamente en la presidencia, durante el 
período comprendido entre el 12 de octubre de 1856 al 30 de junio de 1858, definido también como el bienio moderado.

Moyano había articulado en julio de ese mismo año la Ley de Bases de Instrucción Pública, texto que le abrió la puerta al posterior desarrollo de la Ley de 9 de septiembre. La Ley encarnó la consolidación de un sistema educativo liberal estable, después de las numerosas tentativas llevadas a cabo, y supuso la primera y única Ley de Instrucción pública que se redactó durante las regencias y posterior reinado de Isabel II. Atrás quedan el Informe Quintana (1813), el Reglamento de La Instrucción Pública (1821), el Plan Duque de Rivas (1836) y el Plan Pidal (1845). Sin embargo, todos ellos prepararon y garantizaron la instauración de un sistema educativo en 1957, cuyo diseño marcaría el desarrollo de la enseñanza en España durante todo el resto de siglo XIX y primer tercio del XX, dejándose notar su influencia hasta la Ley General de Educación de 1970.

Además, la Ley de Instrucción Pública de 1857, marca un hito en el ámbito reglamentario de las enseñanzas artísticas, ya que representa un salto cualitativo respecto de sus predecesores el Plan General de Instrucción Pública de 1836 y el Plan General de Estudios de 1845.

Los planes de estudios del Duque de Rivas y José Pidal, constituyen dos contrafuertes en el conjunto de estatutos y códigos planteados desde el Dictamen y Proyecto de Decreto sobre el arreglo general de la Enseñanza Pública de 1814, hasta la Ley de Instrucción Pública de $1857 .^{120}$

Inmersos de lleno en plena contienda carlista y bajo el gobierno provisional de Francisco Javier Istúriz, aparece el 4 de agosto de 1836 el Plan General de Instrucción Pública, elaborado por Antonio Gil de Zárate, Cristóbal Bordiú, Vicente Vázquez Queipo y Ángel Saa-

${ }^{120}$ A éstos habría que añadirles el Proyecto de Ley sobre instrucción secundaria y superior (1838) del Marqués de Someruelos, y el Proyecto de Ley sobre organización de la enseñanza intermedia y superior (1841) de Facundo Infante. (Reproducidos en Álvarez De Morales, Antonio: Génesis de las Universidad Española Contemporánea, Madrid, Instituto de Estudios Administrativos, 1972, pp. 589-702, 611-620). 
vedra Ramírez de Baquedano, duque de Rivas y ministro de Gobernación durante la presidencia de Istúriz. ${ }^{121}$

El plan representó un nuevo intento liberal, después del Reglamento de 1821, por establecer un sistema educativo, pero corrió peor suerte que aquél al no entrar nunca en vigor.

En lo tocante al ámbito musical, el panorama no puede ser menos halagüeño. La única correspondencia posible con las enseñanzas artísticas, la encontramos en el artículo 42, donde se especifican los estudios que integran la tercera enseñanza:

“Art. 42. La tercera enseñanza comprende: $1^{\circ}$ Las facultades de Jurisprudencia, Teología, Medicina y cirugía, Farmacia y Veterinaria. $2^{\circ}$. Las escuelas especiales de Caminos y canales, Minas, Agricultura, Comercio, Bellas Artes, Artes y oficios, y las que el Gobierno juzgue conveniente establecer en lo sucesivo, según lo requieran las necesidades públicas. $3^{\circ}$ Estudios de erudición: Antigüedades o arqueología, Numismática y Bibliografía". ${ }^{122}$

No sabemos si el Conservatorio, inaugurado en 1830, y su instrucción se recogen dentro de las Bellas Artes, pero en cualquier caso, la consagración del documento a las enseñanzas musicales son meros supuestos, tanto más si lo comparamos con el despliegue exhibido en el Reglamento de 1821.

Y lo mismo podemos agregar del Plan General de Estudios de 17 de septiembre de $1845 .{ }^{123}$

${ }^{121}$ CAPITÁN DÍAZ, Alfonso, op. cit., vol. II, p. 56.

122 "Real Decreto por el que se aprueba el Plan General de Instrucción Pública", Gaceta de Madrid, suplemento de 9 de agosto de 1836, n 600.

123 "Real Decreto de 17 de septiembre de 1845. Plan General de Estudios" en Colección de Decretos, t. XXXV, pp. 197-246. También en "Real Decreto aprobando el plan general de estudios para la instrucción pública del reino en la parte relativa á las enseñanzas secundaria y superior", Gaceta de Madrid, 25 de septiembre de $1845, \mathrm{n}^{\circ} 4029$. 
Enmarcado por el gobierno del general Ramón María Narváez durante la denominada década moderada, surge la aludida reforma educativa planteada por Pedro José Pidal, ministro de Gobernación, con el auxilio de Antonio Gil de Zárate, dramaturgo y figura significativa de la escena política y educativa española de este período. ${ }^{124}$

La aportación musical de esta nueva ordenación del sistema educativo, es igual de estéril que la de su predecesor. De nuevo encontramos, esta vez en el artículo 40 del documento, la misma referencia a las Bellas Artes, sin mencionar por ningún lado, las enseñanzas musicales. ${ }^{125}$

Consecuentemente y como acabamos de comprobar, ante este panorama de por medio, el advenimiento de la nueva reforma de la Instrucción pública en 1857 marcó una distancia abismal con sus antecesores, caracterizándose esta última, por el cuidado y atención acreditados en materia musical y su adecuado planteamiento general:

"Hay que convenir en que fue un diseño bastante acabado y, quizá, el mejor posible para su tiempo - por la estructura material y formal y por la coherencia de contenido, muestra de su valía y capacidad de aplicación". ${ }^{126}$

La Ley de Instrucción Pública de 1857, se articula en cuatro secciones: sección primera, "De los estudios"; sección segunda "De los estableci-

${ }^{124}$ CAPITÁN DíAZ, Alfonso, op. cit., vol. II, p. 72.

125 “Art. 40. Son estudios especiales los que habilitan para carreras y profesiones que no se hallan sujetas á la recepcion de grados académicos. El Gobierno costeará por ahora los necesarios para La construcción de caminos, canales y puertos. El laboreo de las minas. La agricultura. La veterinaria. La náutica. El comercio. Las bellas artes. Las artes y oficios. La profesion de escribanos y procuradores de los tribunales." "'Real Decreto aprobando el plan general de estudios,...", en Gaceta de Madrid, 25 de septiembre de 1845, $\mathrm{n}^{\circ} 4029$, p. 4).

${ }^{126}$ CAPITÁN DÍAZ, Alfonso, op. cit., vol. II, p. 100. 
mientos de enseñanza"; sección tercera "Del profesorado público", y cuarta sección "Del gobierno y administración de la instrucción".

El primer aspecto a remarcar, tocante al contexto musical y su organización, lo encontramos en el artículo 55:

"Art. 55. En la carrera de Bellas Artes se comprenden las de Pintura, Escultura, Arquitectura y Música". ${ }^{128}$

A diferencia de sus antecesores de 1836 y 1845, la nueva Ley de Instrucción, sí que detalla y enumera qué enseñanzas agrupa la carrera de Bellas Artes, indicando la Música como una de las disciplinas integrantes del conjunto.

Seguidamente los artículos 56, 57 y 58, especifican cuales son a su vez los estudios de los que consta cada una de estas enseñanzas, dedicándole el último de ellos a las enseñanzas musicales:

“Art. 58. Los estudios de Maestro compositor de Música son los siguientes:

Estudio de la Melodía.

Contrapunto.

Fuga.

Estudio de la Instrumentación

Composición religiosa.

Composición dramática.

Composición instrumental.

Historia crítica del Arte musical.

127 “Ley de Instrucción pública de 9 de septiembre de 1857”, en Gaceta de Madrid, 10 de septiembre de 1857, $\mathrm{n}^{\circ}$ 1710. También aparece reproducida en la Colección legislativa de España, Madrid, Imprenta del Ministerio de Gracia y Justicia, 1857, t. LXXIII tercer trimestre, pp. 266-319.

${ }^{128}$ Ley de instrucción..., Sección primera, Título III, Capítulo II, art. 55. 


\section{Composición libre.}

Un reglamento especial determinará todo lo relativo a las enseñanzas de Música vocal é instrumental y Declamación, establecidas en el Real Conservatorio de Madrid, como asimismo a los estudios preparatorios, matrículas, exámenes, concursos públicos y expedición de los títulos propios de estas profesiones". ${ }^{129}$

El artículo termina haciendo referencia a los reglamentos como documento regulador de las enseñanzas de música, asunto especialmente interesante que abordaremos con más calma en el próximo apartado.

La Ley se hace asimismo eco de la existencia del Conservatorio de música, como establecimiento de referencia ineludible para desempeñar su cometido:

“Art. 137. Habrá en Madrid una Escuela de Bellas Artes para los estudios superiores de Pintura, Escultura y Grabado además de los elementales; otra de Arquitectura, y un Conservatorio de Música y Declamación".

Pero lo realmente interesante de todo este despliegue, reside en que por primera vez en la historia educativa española, encontramos una descripción detallada y exacta, explicando en qué han de consistir las enseñanzas musicales. Si bien es cierto que el diseño propuesto es insuficiente y parco en ideas, al considerar única y exclusivamente como disciplina de rango superior la carrera de Maestro compositor, y descartar de forma automática al resto de especialidades musicales de dicha clasificación, resulta innegable descubrir en este preciso momento, el inicio de un proceso que se adivinará arduo y complejo, consistente en el esclarecimiento, definición y despliegue, de los principios reguladores fundamentales de la educación musical, con el propósito de lograr su plasmación definitiva en el marco reglamentario.

${ }^{129}$ Ley de instrucción..., Sección primera, Título III, Capítulo II, art. 58.

${ }^{130}$ Ley de instrucción..., Sección segunda, Título I, Capítulo IV, art. 137. 
Un ejemplo ilustrativo de lo que exponemos aparece reflejado en la sección tercera de la Ley, referente a las normas reguladoras del profesorado público. Dejando a un lado cierto tipo de salvedades, como es el hecho de no necesitar la nacionalidad española, para desempeñar el cargo de profesor en las enseñanzas de Música vocal e instrumental, ${ }^{131}$ llaman fundamentalmente nuestra atención, contextos especialmente significativos como los siguientes:

“Art. 207. Para aspirar a cátedras de instituto se requiere:

Primero. Tener veinticuatro años cumplidos.

Segundo. Tener título correspondiente.

Este será, en los Estudios generales de segunda enseñanza, el grado de Bachiller en la facultad a que corresponda la asignatura.

En las enseñanzas de aplicación los reglamentos determinarán para qué asignaturas se ha de exigir el mismo grado de Bachiller, y para qué otras el título superior o profesional de la carrera a que correspondan los respectivos estudios.

Los Profesores de Lenguas vivas y Dibujo, y los de Música vocal é instrumental y Declamación no necesitan titulo" (sic). ${ }^{132}$

Resulta sintomático que los docentes de música sean los únicos, junto con los de Lenguas vivas y Dibujo, que no precisen de titulación alguna para desempeñar sus tareas. Y con ello no estamos sosteniendo que estas disciplinas carezcan de un personal cualificado para transmitir su magisterio, pero sí argumentamos que esta disposición denota primeramente, la falta de tradición histórica de la que adolecían estas disciplinas en su ordenación y arreglo aca-

131 “Art. 167. Para ejercer el Profesorado en todas las enseñanzas se requiere: Primero. Ser español, circunstancia que puede dispensarse a los Profesores de Lenguas vivas y a los de Música vocal e instrumental. Segundo. Justificar buena conducta religiosa y moral." (Ley de instrucción..., Sección tercera, Título I, Capítulo I, art. 167).

${ }^{132}$ Ley de instrucción..., Sección tercera, Título I, Capítulo III, art. 207. 
démico hasta entonces y en segundo lugar como quedará patente más adelante, la dificultad intrínseca a la propia naturaleza de las enseñanzas artísticas, para llevar a cabo una ordenación académica en toda regla.

Desgraciadamente tendrá que cumplirse holgadamente un siglo de subsistencia en este contexto, para reconocer a estos docentes y sus actividades, con la misma equidad que al resto de profesionales. ${ }^{133}$

\subsection{El Reglamento de Salaverría. Las Instrucciones de 1863}

Si bien es cierto que Cándido Nocedal y Claudio Moyano, compartieron ministerios de Gobernación y Fomento respectivamente, durante el primer gobierno del "bienio moderado" presidido por Narváez, fue la siguiente administración la encargada de aplicar en materia musical, los nuevos estatutos desplegados en la reciente Ley de Instrucción de 1857.

Merece la pena detenerse unos instantes, para no perder de vista el curso de los acontecimientos. Como vimos en el capítulo anterior, el Reglamento orgánico del Conservatorio redactado por el ministro de Gobernación y viceprotector del mismo, Cándido Nocedal, viene rubricado con fecha de 5 de marzo de 1857. Como es obvio, aunque Nocedal compartiera administración con Moyano, no tuvo tiempo de reflejar los avances propuestos por la nueva Ley de Instrucción pública, por el simple hecho de que ésta apareció seis meses después. Desconocemos los verdaderos motivos que impulsaron la redacción del reglamento de 5 de marzo, a escasos meses de estrenarse un nuevo sistema educativo, pero lo que sí sabemos es que el reglamento quedó desfasado a los pocos meses de su publicación, convirtiéndose irreversiblemente en un estatuto más propio del trámite burocrático, que el fruto de una verdadera regulación educativa.

${ }^{133}$ La Ley Orgánica 1/1990, de 3 de octubre, de Ordenación General del Sistema Educativo (B.O.E. de 4 de octubre), establece en su artículo 42, la equivalente a todos los efectos, del título superior correspondiente a los estudios de grado superior de conservatorios, al de licenciado universitario. 
Reemplazando en la presidencia a Narváez, el 15 de octubre de 1857 toma posesión de su nuevo cargo, don Francisco Armero de Peñaranda, Marqués de Nervión (1804-1867). El nuevo gabinete del gobierno está compuesto por los siguientes ministerios y sus secretarios: Estado, Francisco de Paula Martínez de la Rosa; Hacienda, Alejandro Mon y Pidal; Gracia y Justicia, Joaquín José Casaus; Gobernación, Manuel Bermúdez de Castro; Guerra, Joaquín Armero; Marina: José $\mathrm{M}^{\mathrm{a}}$ Bustillo (Conde de Bustillo); Fomento, Pedro Salaverría y Charitu. ${ }^{134}$

Obra de este último, fue la redacción del Reglamento Orgánico Provisional del Real Conservatorio de Música y Declamación. ${ }^{135}$ En esta ocasión y a diferencia de la fórmula de Nocedal, el nuevo reglamento sí que contiene las nuevas actualizaciones propuestas por la Ley, presentando numerosas novedades en comparación con su antecesor.

La primera modificación que nos presenta el texto, es la nueva clasificación de las enseñanzas musicales impartidas en el Conservatorio divididas en dos clases, a saber: los "estudios superiores" y los “estudios de aplicación”. ${ }^{136}$ No hemos de llevarnos a engaño, deduciendo que esta clasificación regula dos niveles de una misma especialidad, por ejemplo "Piano aplicación" y seguidamente "Piano superior". No, no es este el caso. El reglamento habla de "estudios superiores" para referirse a la especialidad de Maestro compositor, y de "estudios de aplicación" para describir el resto de especialidades. $^{137}$

${ }^{134}$ Burriel I Floria, Guillem (dir.): Crónica de España, Barcelona, Plaza y Janés, [documento en línea]

$<$ http://www.xtec.es/ jrovira6/governs1/govern3.htm> [consultado el 26-8-2014].

${ }^{135}$ SAlaverRíA, Pedro: "Reglamento Orgánico Provisional del Real Conservatorio de Música y Declamación" en Memoria acerca de la Escuela Nacional de Música y Declamación de Madrid..., pp. 59-67.

${ }^{136}$ Ídem, art. 1.

137 Concretamente los "estudios de aplicación" comprenden las siguientes especialidades: "Canto.- Declamación.- Órgano.- Harmonía elemental y superior.- Piano y acompañamiento elemental y superior.- Solfeo preparatorio 
Sin embargo, y esto sí que es un importante paso adelante, la ordenación en niveles de la carrera instrumental se ha llevado finalmente a término, estipulando en el caso de la especialidad pianística, cuatro cursos para la enseñanza elemental y fijando el límite de cursos totales para estudiar la carrera, en seis años como máximo. $^{138}$

Los artículos 16, 17 y 18, establecen un conjunto de normas y condiciones, para cumplir correctamente con los estudios instrumentales, aspectos que serán considerados con mayor atención en las instrucciones complementarias trazadas por el director, Ventura de la Vega. Regresaremos más adelante, sobre esta interesante cuestión.

En relación con los métodos y tratados, es el Gobierno quién indicará, previa propuesta del Director y la Junta consultiva, los textos a impartir en las clases del establecimiento. ${ }^{139}$

Aflora como observamos, un cambio gubernativo substancial al recaer sobre la administración central, la tutela y supervisión del conservatorio. Una consecuencia directa de este giro estatal, la hallamos en la transformación de los cargos dirigentes. Substituyendo a la antigua figura del Viceprotector, surge la de Director como nuevo garante del correcto funcionamiento del establecimiento musical, cuyo designación es propuesta por el Gobierno. Para socorrer al Director en el desempeño de sus tareas continúa existiendo la Junta consultiva, manteniéndose apenas invariable en su constitución y funciones.

Como vemos, el nuevo Reglamento aporta valiosas y en ocasiones, inesperadas revelaciones, y aunque estos datos son sin lugar a dudas, un claro reflejo de los hábitos y costumbres de la época, resulta poco menos que sorprendente a nuestros ojos, encontrar reflexiones como la que proponemos a continuación:

para canto.- Solfeo general.- Lengua italiana.- Piano.- Instrumental de cuerda.- Instrumental de viento" (Ídem, art. 5).

138 Ídem, art. 15.

139 Ídem, art. 22. 
"Art. 31. En las enseñanzas de piano, harpa" (sic) "y solfeo, podrá haber clases desempeñadas por Profesoras." "140

Pero al margen de estas manifestaciones, lo primordial es que con la presente regulación de las enseñanzas, podemos trazar, en contraste con el reglamento de Nocedal, las pautas generales de los estudios de piano.

El alumno, o alumna, que desease empezar sus estudio de piano, debía presentar la siguiente documentación: fe de bautismo; certificado que atestigüe la "buena vida y costumbres" del aspirante, firmada por el cura o autoridad local pertinente, y por último la documentación pertinente que acredite haber concluido la primera enseñanza elemental. ${ }^{141}$ Además el educando debía poseer "las cualidades físicas convenientes" para la enseñanza que iba a comenzar, ${ }^{142}$ no tener menos de ocho años ni más de catorce para emprender las enseñanzas de solfeo, ${ }^{143}$ y no exceder de veinte para emprender cualquier otra enseñanza del Conservatorio. ${ }^{144}$

También cambia la denominación del título respecto al reglamento anterior, y ahora el alumno que finaliza sus estudios recibe el grado de "Profesor del Real Conservatorio". Para ello el aspirante tendrá que obtener un primer o segundo premio en su concurso.

Un aspecto importante que desearíamos recalcar consiste en que, para emprender las enseñanzas superiores de Maestro compositor, ${ }^{145}$ el reglamento señala la necesidad de haber cursado los estudios que se indican en el artículo 27 de la Ley de Instrucción Pública, equivalente al bachillerato en Artes, ${ }^{146}$ mientras que como acaba-

\footnotetext{
140 Ídem, art. 31.

${ }^{141}$ Ídem, art. 38.

142 Ídem, art. 39.

143 Ídem, art. 40.

${ }^{144}$ Ídem, art. 41.

145 Ídem, art. 3.
}

146 “Art. 27. Para ingresar en las Escuelas superiores, los reglamentos determinarán si ha de exigirse el mismo grado, o en su lugar una preparación equivalente de estudios generales o de aplicación de la segunda enseñanza. 
mos de exponer, para comenzar los estudios de aplicación, por ejemplo los de piano, solamente es necesaria la preparación elemental reflejada en el artículo 2, de la citada Ley. ${ }^{147}$

No obstante, y a pesar del agravio comparativo que podría desprenderse de una primera lectura, lo realmente esencial es que con los estudios de composición, se sienta un precedente en la ordenación académica musical, abriendo el acceso a las restantes especialidades, para una regulación superior equivalente en el futuro.

Todo este conjunto de aspectos y singularidades, nos demuestra las prerrogativas que puede ofrecer una adecuada reglamentación de las enseñanzas, cuando se encuentra secundada por el marco legislativo oportuno. Prueba de lo que aquí exponemos, nos lo confirma el siguiente testimonio de Sopeña:

"Esta reglamentación supone un paso importantísimo: dentro del espíritu general de la leyes 'moderadas', la centralización, la ligadura con el rector y con Fomento, la división de las enseñanzas, fueron un bien y además un primer paso para la ordenación de la enseñanza". ${ }^{148}$

Una última demostración, del esfuerzo reorganizador que se está llevando a cabo en las enseñanzas musicales durante esta etapa, lo ilustra el documento que a continuación presentamos. Acompañando al Reglamento de Salaverría, aparecen con fecha de 30 de enero de 1861, y rubricadas por el entonces director del estableci-

Estos estudios no durarán menos de los seis años que se requieren para el bachillerato en Artes." (Ley de instrucción..., Sección primera, Título III, art. 27).

147 “Art. $1^{\circ}$. La primera enseñanza se divide en elemental y superior. Art. $2^{\circ}$ La primera enseñanza elemental comprende: Primero. Doctrina cristiana y nociones de Historia sagrada, acomodadas a los niños; Segundo. Lectura; Tercero. Escritura; Cuarto. Principios de Gramática castellana, con ejercicios de Ortografía; Quinto. Principios de Aritmética, con el sistema legal de medidas, pesas y monedas; Sexto. Breves nociones de Agricultura, Industria y Comercio, según las localidades." (Ley de instrucción..., Sección primera, Título I, arts. $\left.1^{\circ}, 2^{\circ}\right)$.

${ }^{148}$ SOPEÑA IBÁÑEZ, Federico, op, cit., p. 65. 
miento Ventura de la Vega, las Instrucciones para el buen desempeño de las enseñanzas y para el régimen y disciplina del Real Conservatorio de Música y Declamación. ${ }^{1}$

Como el propio de la Vega expone al inicio del documento, las Instrucciones aparecen para completar lo expuesto en el artículo 87, apartado segundo, del Reglamento orgánico, en el que se especifican las tareas y responsabilidades del Director al frente del Conservatorio. Dice así:

"Segundo: Dictar las instrucciones convenientes para el buen desempeño de las enseñanzas y para el régimen y disciplina del Establecimiento". ${ }^{150}$

Por este motivo las Instrucciones afloran como un documento de inestimable valor, al aportar una gran cantidad de información inédita, con capacidad para despejar algunas cuestiones substanciales.

El texto se articula en diecinueve capítulos, cada uno de los cuales expone de forma descriptiva, asuntos específicos de la enseñanza musical. Los primeros trece capítulos tratan cada uno sucesivamente las diferentes asignaturas ofrecidas en el conservatorio, describiendo en último lugar el orden y disposición en que se han de llevar a cabo las mismas. Este último matiz es de suma importancia ya que el modelo propuesto, cimentado en la superación de determinados cursos y asignaturas como condición indispensable para seguir progresando en los estudios, se perpetuará en las siguientes reformas de enseñanza empleadas en los conservatorios.

Los capítulos V y VI, encabezados con el título de "Enseñanza de piano" y "Clases elementales de piano y preparatoria de órgano" respectivamente, son los encargados de desarrollar las instrucciones pertinentes a la especialidad de Piano.

${ }^{149}$ DE LA VEGA, Ventura: "Instrucciones para el buen desempeño de las enseñanzas y para el régimen y disciplina del Real Conservatorio de Música y Declamación", en Memoria acerca de la Escuela Nacional de Música y Declamación de Madrid..., pp. 305-317.

${ }^{150}$ SALAVERría, Pedro, op.cit., art. 87. 
Comencemos con el capítulo VI en el que se regulan los primeros cursos de piano. El él se abordan las "Clases elementales", exponiendo en su primer artículo el objetivo principal hacia el que se encaminan estas enseñanzas:

"Art. 42. El objeto de la clase de piano elemental, es: 1. ${ }^{\circ}$ que los alumnos que sigan la carrera de pianista se preparen para las clases superiores, á" (sic) "las que podrán pasar cuando hayan adquirido la instrucción que previene el art. 34; 2. , que los dedicados al Canto y á" (sic) "la Composición, adquieran la instrucción conveniente en el piano; y 3. ${ }^{\circ}$, que los que, habiendo estudiado el Solfeo en el Conservatorio, no tengan las disposiciones que reclama la carrera artística, adquieran el grado de instrucción á" (sic) "que puedan aspirar".

Tres son las necesidades a cubrir por estos estudios. Dejando al margen los dos itinerarios, consistentes en una formación básica para cantantes y compositores y el de ofrecer unas nociones del instrumento a aquellos menos dotados - como si se tratara de una formación amateur - nos interesa especialmente la primera de las opciones, en la que se preparan y seleccionan a aquellos alumnos, con capacidad suficiente como para desarrollar una carrera pianística en cursos o clases superiores.

El nivel que ha de adquirir el alumno para acceder a estos cursos, viene estipulado en el artículo 34, y no es otro que el cimentado en un grado de destreza, suficiente como para poder emprender los 42 estudios de Cramer. En realidad Johann Baptist Cramer (17711858), compuso 84 estudios divididos en dos series de 42 estudios cada una, publicadas en 1804 y 1809 respectivamente. ${ }^{152}$ Sospechamos que se refieren en este caso a la primera de las series. El artículo 46 vuelve a confirmar la noticia, pero esta vez con la intención de expresar el límite de tiempo del que disponen los alumnos para culminar este primer ciclo:

${ }^{151}$ DE LA VEGA, Ventura, op. cit., art. 42.

152 DE Place, A.: “Johann Baptist Cramer”, en François-René de Tranchefort, (dir.): Guia de la música de piano y de clavecín, Madrid, Taurus, 1990, p. 285. 
“Art. 46. El Límite de la enseñanza en estas clases será el de los 42 estudios de Cramer, y el máximun" (sic) "de tiempo el de cuatro años". 153

Finalizamos nuestro recorrido por este primer ciclo, añadiendo que el número de inscripciones de alumnos para asistir a estas clases era ilimitado, ${ }^{154}$ y que el examen para acceder al siguiente ciclo dentro del apartado de "mecanismo", consistía en que el alumno debía ejecutar un ejercicio elegido por el profesor y otros designados por el tribunal calificador, entre aquellos cuya dificultad había sido ya superada; posteriormente, en el apartado de "inteligencia" debían tocar un estudio y una lectura a primera vista, de 16 a 20 compases de duración. ${ }^{155}$

Una vez superado el examen con éxito, el alumno podía finalmente iniciar, su "Enseñanza de piano" propiamente dicha. El capítulo V consta de ocho artículos comprendidos entre los números 34 al 41, ambos inclusive, y desglosa los pormenores de la enseñanza pianística en el último de sus ciclos.

Comienza el capítulo con el artículo 34, al que ya nos hemos referido anteriormente, y con el que se establece el nivel que ha de poseer un alumno para iniciar estos estudios:

"Art. 34. Para ser admitido un alumno en esta enseñanza necesita tener el grado de instrucción necesario para emprender los 42 estudios de Cramer"'. ${ }^{156}$

Le siguen a continuación los artículos 35, 36 y 37, con unas revelaciones que nos sorprenden, por la novedosa estructuración pedagógica de sus argumentos:

${ }^{153}$ DE LA VEGA, Ventura, op. cit., art. 46.

${ }^{154}$ Ídem, art. 48.

155 Ídem, art. 49.

156 Ídem, art. 34. 
"Art. 35. La enseñanza del piano se divide, como la instrumental de orquesta, en tres partes que son: mecanismo, inteligencia y expresión.

Art. 36. El mecanismo abraza la posición del cuerpo, brazos, manos y dedos; la correcta pulsación, la práctica de los matices, de las articulaciones, de la agilidad, y de todo lo que hace á" (sic) "los sonidos lentos y rápidos, fuertes y débiles, sueltos y ligados, en ambas manos.

Art. 37. La inteligencia y la expresión comprenden cuanto se ha dicho en los artículos 28 y $29 " .{ }^{157}$

Reproducimos seguidamente la trascripción de los artículos mencionados, para facilitar la comprensión global del pasaje:

"Art. 28. La inteligencia abraza la teoría de todo lo que pertenece al mecanismo, las reglas del colorido, fraseo, de las respiraciones y de las condiciones diversas que deben observarse en la ejecución de una pieza instrumental, según su aire y naturaleza.

Art. 29. La expresión comprende todo lo que pertenece á la manifestación del sentimiento con el calor, entusiasmo y buen gusto que conviene al carácter de la pieza que el alumno aprende; pero no dependiendo esta parte de reglas escolares, sólo al Profesor incumbe guiar al discípulo, aconsejarle, alentarle y cooperar al desarrollo del genio que posea". ${ }^{158}$

Nos encontramos realmente ante un hito de la enseñanza pianística y su organización. En efecto se trata de la primera redacción en forma de estatuto reglamentario, procurando una elucidación de los elementos de la técnica pianística, desde una perspectiva pedagógica, a la vez que establece el principio generador de la programación didáctica de la asignatura.

\footnotetext{
${ }^{157}$ Ídem, art. 37.

${ }^{158}$ Ídem, ${ }^{\text {art }}$ s. 28, 29.
} 
Continúa el capítulo con la enumeración de los Métodos y estudios aceptados para las enseñanzas de piano:

“Art. 38. Las obras de texto adoptadas, son: los Métodos de Albéniz, Miró, Aranguren, Bertini, Czerni, Moscheles, Kalbrener y Herz, y los Estudios de Bertini, Concone, Ledesma, Czerni, Cramer, Moscheles, Kalbrener, Doler, Kesler, Thalberg y Herz". ${ }^{159}$

Por lo que respecta a los métodos de autores nacionales aparecen los textos habituales ya presentados en el primer capítulo de nuestro trabajo, a los que hemos de añadirles los tradicionales textos $y$ estudios de Carl Czerny, Johann Baptist Cramer o Friedrich Wilhelm Kalkbrenner, presentes todavía en las programaciones de gran número de conservatorios.

Finaliza el capítulo dedicado a la "Enseñanza de piano", añadiendo diversas observaciones respecto a los exámenes y ejercicios de concurso, a la vez que se determina un total de 16 alumnos de cada sexo, como límite máximo permitido en cada clase.

Es el momento de abordar a continuación el capítulo XIII, por el que se plantean las normas para la correcta consecución de las asignaturas a lo largo de la especialidad escogida. El capítulo titulado, "Del orden que debe observarse en los estudios que constituyen las diversas carreras", ${ }^{160}$ expone su contenido a través de las diferentes especialidades, correspondiendo al artículo 103, las observaciones pertinentes a las especialidades instrumentales. Dice así:

"Art. 103. El dedicado á" (sic) "la carrera instrumentista, simultaneará el último año de solfeo con el primero del instrumento á" (sic) "que se dedique.

${ }^{159}$ Ídem, art. 38.

${ }^{160}$ Ídem, p. 312. 
En el segundo año de la enseñanza instrumental, terminados los tres de solfeo, estudiará Harmonía” (sic) "elemental". ${ }^{161}$

Si aplicamos estas consideraciones a las enseñanzas de piano, obtendríamos como resultado el esquema del apéndice 4.

Recordemos que el plan de estudios establece un límite de cuatro cursos para superar el ciclo elemental y seis para finalizar los estudios.

Finalizamos nuestro recorrido a través de estas instrucciones, realizando un último análisis sobre los restantes capítulos del documento. Y lo obramos, fijando nuestra atención sobre tres aspectos principales.

El primero de ellos constituye una prueba evidente, de hasta qué punto el discurrir habitual de las clases, se había asentado hasta entonces en la propia creatividad e iniciativa del profesor. $\mathrm{Y}$ así creemos que debe ser ciertamente, sin embargo el texto siguiente vuelve a sorprendernos con una nueva aportación que habla por sí sola:

“Art. 114 Desde la publicación de las presentes Instrucciones, todo Profesor clasificará sus respectivos alumnos, colocando á" (sic) "cada uno según el grado de instrucción que tenga, en el curso que le corresponde, con arreglo al programa de aquella clase". ${ }^{162}$

Estamos asistiendo a un nuevo giro de tuerca en la ordenación educativa, al impulsar una organización del alumnado que evidenciaba la desorganización pedagógica existente. Para solucionar esta situación, se toma una medida de lo más elemental, consistente en ubicar a cada alumno, según su nivel de progreso, "en el curso que le corresponde". Esta particularidad nos introduce de lleno en las dos siguientes cuestiones a tratar.

\footnotetext{
161 Ídem, art. 103.

${ }^{162}$ Ídem, art. 114.
} 
El procedimiento planteado tiene su explicación y queda en cierta medida justificado por una cuestión puramente metodológica, representativa del contexto educativo en el que se desenvolvían las clases. Nos estamos refiriendo al carácter esencialmente colectivo que reinaba en las aulas de piano de esta época. Recordemos rápidamente que las clases se organizaban en turnos diarios de dos horas, con un máximo de 16 alumnos por turno en el segundo ciclo y número ilimitado de alumnos en la clase elemental. Sin embargo, el nuevo reglamento es muy claro al respecto y prevé que todas las materias sean impartidas individualmente, a excepción de la de Solfeo, ${ }^{163}$ otro rasgo novedoso que lo distingue de su predecesor. Los nuevos procedimientos a emplear ante esta nueva situación son los siguientes:

"Art. 146. Para el orden de las lecciones individuales establecerán los Profesores un turno equitativo, á" (sic) "fin de que ningún alumno salga perjudicado en la enseñanza que debe recibir.

Art. 147. A fin de que los alumnos aprovechen debidamente, no sólo en la lección individual que cada uno debe recibir, sino también presenciando atentamente las que los demás reciban, el Profesor, como encargado del orden de su respectiva clase, observará las reglas siguientes: $1{ }^{\mathrm{a}}$, hacer que todos los alumnos concurran exactamente desde el principio de la clase; $2 .^{\mathrm{a}}$, disponer que se coloquen de modo que pueda observarlos y cerciorarse de que siguen con atención las advertencias y correcciones generales y particulares que tenga lugar, para lo cual se prohibe" (sic) "completamente todo género de labores, de lectura ó" (sic) "cualquiera" (sic) "otra ocupación ajena á" (sic) "la clase, aun cuando sea relativa á" (sic) "Otro ramo de enseñanza; 3. , no permitir la entrada ni la permanencia en la clase á" (sic) "personas extrañas ni alumnos del Conservatorio que á" (sic) "ella no pertenezcan". ${ }^{164}$

${ }^{163}$ Salaverría, Pedro, op.cit., art. 23.
${ }^{164}$ De la VeGA, Ventura, op. cit., arts. 146, 147. 
No sabemos con exactitud cual era el "turno equitativo" empleado por cada profesor en su aula, aunque no resulta difícil imaginar la dinámica de las clases, a medio camino entre la enseñanza individual y la colectiva. Basta con pensar en la praxis adoptada, en cualquiera de los cursos y "Máster-clases" que se imparten hoy en día.

La tercera y última de las aportaciones se revela posiblemente, como la más trascendental de las tres, ya que discurre y profundiza en torno a la cuestión principal de la acción programadora en la especialidad de Piano.

Volviendo a la primera de las cuestiones planteadas, sobre la nueva organización de los alumnos conforme a sus respectivos cursos, el artículo 114 especifica al final de su redacción, que el ajuste se llevaría a término "con arreglo al programa de aquella clase". Por otro lado, en el artículo 145 encontramos la siguiente declaración:

“Art. 145. Los Profesores observarán en la enseñanzas el orden establecido en los programas que hubieren presentado y recibido la aprobación, y no podrán variarlos ni modificarlos sino en el período que media entre el fin de un curso y el principio del siguiente, con aprobación de la Dirección". ${ }^{165}$

Nuevamente reaparece la mención a unos "programas", que los profesores “observarán” para el desarrollo de sus enseñanzas. Para finalizar y por si nos cabía alguna duda, las Instrucciones concluyen su exposición con la siguiente nota final:

"Nota. Los programas detallados de las enseñanzas que en la actualidad se dan en esta Escuela, se hallan publicados en una edición especial". ${ }^{166}$

El texto no se presta a vacilaciones ni titubeos. Se trata de la última de las aportaciones de todo este despliegue reglamentario. ${ }^{167} \mathrm{La}$ Ley

\footnotetext{
${ }^{165}$ Ídem, art. 145.

166 Ídem, p. 317.

${ }^{167}$ Desgraciadamente, no conservamos ninguna de estas programaciones hoy en día. Si se trataban de documentos rudimentarios, elaborados por el profe-
} 
de Instrucción Pública de 9 de septiembre, el Reglamento Orgánico Provisional de Pedro Salaverría y las presentes Instrucciones para el buen desempeño de las enseñanzas y para el régimen y disciplina de Ventura de la Vega, constituyen un sistema escalonado, que irrumpiría con fuerza hasta el último nivel de la cadena educativa.

\subsection{La crisis sociopolítica de 1865 y las reformas educativas de Manuel de Orovio. Un Reglamento inédito}

Tras finalizar el bienio moderado protagonizado por los gobiernos de Narváez, Armero e Istúriz, el 30 de junio de 1858 sobreviene un nuevo cambio político a manos del principal dirigente de la Unión Liberal, el general Leopoldo O' Donnell y Jornis (1809-1867). Entre los hombres que conforman su ejecutivo, encontramos de nuevo a Pedro Salaverría, aunque en esta ocasión, haciéndose cargo del ministerio de Hacienda.

O'Donnell mantuvo un largo gobierno si lo comparamos con su siguiente mandato, comprendido entre los meses de junio de 1865 a julio de 1866, por lo que su administración simboliza la última gestión estable y duradera, antes de producirse la crisis sociopolítica que agitará al estado español a partir de este momento. Finalizada su gestión el 2 de marzo de 1863, los gobiernos y sus respectivas presidencias, se suceden a ritmo vertiginoso, reflejo de la convulsión y el malestar que está viviendo la población: Marqués de Miraflores, diez meses; Lorenzo Arrazola, tres meses; Alejandro Mon y Pidal, seis meses; Ramón $\mathrm{M}^{a}$ Narváez, diez meses; Leopoldo O' Donnell y Jornis un año; Ramón $\mathrm{M}^{a}$ Narváez, diez meses, y finalmente Luís González Bravo, que no llegaría a los seis meses de mandato, al estallar la "Gloriosa" revolución septembrina de 1868. Es el final de reinado de Isabel II y el inicio del sexenio revolucionario, periodo que recogerá los acontecimientos acaecidos en el país durante los años 1868 a 1874.

sor para su propio régimen y gobierno en las aulas, o simplemente nunca se materializaron, es algo que no podemos confirmar. 
El recuento final de este periodo Isabelino, nos conduce a través de un tiempo histórico marcado por las guerras carlistas, dos en total, y un sinfín de asonadas y levantamientos, sumiendo al país en la bancarrota económica.

Podemos abrir esta última etapa de desintegración del reinado, a partir de los hechos acaecidos durante la noche del 10 de abril de 1865. En aquella madrugada (noche de San Daniel), la Guardia Civil cargó violentamente contra una manifestación de estudiantes, resultando nueve muertos y numerosos heridos a consecuencia del encontronazo. El origen de la movilización, fue la de manifestar públicamente su disconformidad con el gobierno, ante la medida adoptada de apartar a Emilio Castelar de su cátedra universitaria. En efecto Castelar acababa de publicar El Rasgo, artículo en el que ponía en tela de juicio la solución propuesta por Isabel II, para hacer frente al déficit presupuestario existente en la administración. El Gobierno reaccionó destituyendo al profesor de su cargo y sofocando duramente las voces disconformes. En este tira y afloja caracterizado por "la subversión permanente" y "la represión sistemática", 168 Narváez constituye su último gabinete de gobierno el 10 de julio de 1866, en pleno ambiente dominado por la crispación y ante la sospecha de una revuelta inminente. Tras la desaparición de este último ya no habría marcha atrás:

"Desde la muerte de Narváez la situación política se hizo insostenible. La línea de represión seguida por Gonzáles Bravo resultaba inútil y desesperada: la revolución llegaba de modo incontenible". ${ }^{169}$

¿Cómo influyó todo este clima sociopolítico al sistema educativo y más concretamente a la cuestión musical?

Existen tres documentos que responden de manera clara y directa a esta interesante cuestión. Se tratan del proyecto de decreto y Real

168 TOMÁs Villarroya, Joaquín: "El proceso constitucional. Capítulo VIII. La descomposición del régimen. El fin de la Constitución", en La era isabelina y el Sexenio Democrático, Historia de España fundada por don Ramón Menéndez Pidal, Madrid, Espasa-Calpe, 1981, T. XXXIV, pp. 345 y ss.

169 Ídem, p. 363. 
Decreto de 9 de octubre de 1866, ${ }^{170}$ el proyecto de decreto y Real Decreto de 15 y 17 de junio de 1868, ${ }^{171}$ y finalmente el Reglamento Orgánico del Real Conservatorio de Música y Declamación, ${ }^{172}$ de autor y fecha desconocidas y cuyo anonimato representa, uno de los múltiples secretos que esconde este enigmático documento.

El equipo ejecutivo que acompañó al último gobierno de Narváez, trajo consigo el nombramiento de don Manuel de Orovio y Echagüe (Marqués de Orovio, 1817-1883), como secretario al frente del ministerio de Fomento. Mediante otro Real Decreto diferente, aunque con igual fecha de 9 de octubre de 1866, Orovio confeccionó un conjunto de reformas que recomponían el Real Consejo de Instrucción Pública:

"Era una forma de «controlan» desde el poder toda la instrucción pública a través de un organismo colectivo, constituido por los amigos y los fieles al Ministro o al Gobierno de S. M.". 173

Realmente, en este nuevo contexto de irritabilidad política, la medida representa la solución drástica y a la desesperada, de atajar un tema que siempre había estado vigente: la libertad de cátedra. ${ }^{174}$

La Ley Moyano había encontrado una solución intermedia a este asunto, ${ }^{175}$ basándose en un sistema de listas, en las que el Gobierno

170 "Real decreto reformando las Escuelas del Notariado, Diplomática, Ingenieros industriales, Profesores mercantiles, Real Conservatorio de Música y Declamación, Bellas Artes, Náutica y Veterinaria.", en Gaceta de Madrid, 13 de octubre de 1866, nº 286.

171 "Real decreto reorganizando el Real Conservatorio de Música y Declamación", en Gaceta de Madrid, 20 de junio de 1868, n 172.

${ }^{172}$ Reglamento Orgánico del Real Conservatorio de Música y Declamación, s.l., s.d. El manuscrito original que comentamos en nuestro análisis se halla en la Biblioteca Nacional de Madrid, MSS/12971/6.

${ }^{173}$ CAPITÁn DíAz, Alfonso, op. cit., t. II, p. 166.

${ }^{174}$ García Trobat, Pilar: "Libertad de cátedra y manuales en la facultad de derecho (1845-1868)", en Cuadernos del Instituto Antonio de Nebrija de estudios sobre la universidad, no 2, Madrid, Universidad Carlos III, 1999, pp. 37-58. 
proponía una enumeración de libros de texto que se iban renovando cada tres años. En último lugar, el profesor elegía de entre los libros propuestos por la administración. Más tarde, el Reglamento general de instrucción pública, de 20 de julio de $1859,{ }^{176}$ remataba la cuestión, dedicándoles los artículos comprendidos del 10 al 19. Con la revolución del 68, desaparecerían las listas definitivamente.

Las reformas de Orovio y su política interventora originaron un total de seis nuevos decretos, todos con idéntica fecha de 9 de octubre:

“1) sobre la reforma de los estudios de segunda enseñanza; 2) reglas para llevar a cabo dicha reforma; 3) nueva organización de la Facultad de Filosofía y Letras; 4) reforma de los estudios de la Facultad de Derecho; 5) reforma de la Escuelas de Notariado, Diplomática (Archivos y Bibliotecas), Ingenieros industriales, Profesores mercantiles, Real Conservatorio de Música y Declamación, Bellas Arte, Náutica y Veterinaria, que se llamarían 'Escuelas especiales' en lugar de Escuelas superiores y profesionales; 6) reforma de la enseñaza de la Escuelas normales para el estudio y preparación de los aspirantes al Magisterio". ${ }^{177}$

Ante esta avalancha de reales decretos promulgados en el mismo día, conviene precisar la situación, para evitar posibles malentendidos. Como ya hemos expuesto anteriormente, el documento que a nosotros nos interesa y que a continuación vamos a examinar, es el Real Decreto de 9 de octubre de 1866, por el que se reforman las Escuelas del Notariado, Diplomática, Ingenieros industriales, Profesores mercantiles, Real Conservatorio de Música y Declamación, Bellas Artes, Náutica y Veterinaria.

${ }^{175}$ Ley de instrucción.... Sección primera, Título V, art. 86. (Seguimos aquí el texto aparecido en la Colección legislativa de España, Madrid, Imprenta del ministerio de gracia y justicia, 1857, t. LXXIII, tercer trimestre, p. 283).

176 "Reglamento General de Instrucción Pública, 20 de julio de 1859”, Colección legislativa de España, Madrid, Imprenta del Ministerio de Gracia y Justicia, 1859, T. LXXXI, pp. 157-181.

${ }^{177}$ CAPITÁn DíAZ, Alfonso, op. cit., vol. II, p. 167. 
En la exposición de motivos que plantea el ministro a la reina Isabel II, encontramos las causas principales que dieron pie, a la reforma de estas enseñanzas y sus establecimientos. Comienza, recordando la equiparación a Escuela superior que posee el Conservatorio, desde la Ley de Instrucción pública del 57, añadiendo a continuación que este planteamiento y su realización son inviables:

"Si la experiencia no hubiera acreditado que semejante fusion" (sic) "es de todo punto anómala é" (sic) "insostenible, bastaría considerar que la índole excesivamente reglamentaria de la expresada ley es incompatible con el desarrollo y tendencias diversas de cada una de aquellas Escuelas, que á" (sic) "tan distintos fines se dirigen y de tan diferente organización han menester. El buen sentido reconoce sin gran esfuerzo que, si bien las Escuelas todas tienen de comun" (sic) "el objeto final de la enseñanza, no pueden hermanarse bajo prescripciones idénticas el Ingeniero y el Músico, el Piloto y el Jurisconsulto, el Pintor y el Veterinario. Tiempo es ya, Señora, de que se haga la luz en este caos, y de que se ordenen y regularicen los establecimientos de enseñanza con provecho de las ciencias de las artes y de la industria, y con alivio no insignificante del presupuesto de gastos". ${ }^{178}$

Junto a la incompatibilidad organizativa esbozada por Orovio, el gobernante plantea una segunda cuestión definitiva, que empalma con el contexto sociopolítico que presentábamos al comienzo, determinado por la crisis económica. Por este motivo se proponen un conjunto de medidas, relacionadas con la regularización del profesorado y sus retribuciones, con la intención de paliar el trance financiero en el que se encuentra inmerso el país. Finaliza la exposición, recordando las consabidas justificaciones, que motivan la reforma:

178 "Real decreto reformando las Escuelas del Notariado, Diplomática, Ingenieros industriales, Profesores mercantiles, Real Conservatorio de Música y Declamación, Bellas Artes, Náutica y Veterinaria.", en Gaceta de Madrid, 13 de octubre de $1866, \mathrm{n}^{\circ} 286$, p. 1. 
“También el Real Conservatorio de Música y Declamación exige con urgencia una reforma que regularice sus enseñanzas y las haga provechosas y fecundas.

A satisfacer tantas y tas notorias necesidades de la instrucción pública en ramos muy interesantes, combinando lo mejor con lo menos costoso, tiende le adjunto proyecto de Real decreto que el Ministro de Fomento, de acuerdo con el Consejo de Ministros, somete á" (sic) "la soberana aprobación" (sic) "de V. M.". ${ }^{179}$

Es este sin duda alguna, un dato que revela claramente las intenciones de la reforma, combinar "lo mejor con lo menos costoso". Ahora solo faltaba definir qué iba a ser lo mejor para la enseñanza musical.

El Real Decreto no constituye un mandato de larga extensión, apenas lo componen seis artículos. Comienza el primero de ellos informándonos del cambio de denominación de los establecimientos, que pasarán a designarse Escuelas especiales, en vez de Escuelas superiores o profesionales como se llamaban hasta el momento, materializando esta reforma un paso atrás en el progreso educativo musical, ya que como el propio artículo indica, retrocedemos a la calificación que tenía el Conservatorio, en el Reglamento general de instrucción pública de 1821:

“Artículo 1. Las Escuelas del Notariado,, de Diplomática, de Ingenieros industriales y Profesores mercantiles, el Real Conservatorio de Música y Declamación, las de Bellas Artes, Náutica y Veterinaria dejan la denominación de Escuelas superiores y profesionales, para tomar la de Escuelas especiales que tenían antes de la ley de 9 de Setiembre de 1857”. ${ }^{180}$

En el artículo segundo se abordan los aumentos salariales de los profesores. El tercer artículo es especialmente relevante para el contenido de nuestro trabajo, ya que dictamina la creación de los

\footnotetext{
${ }^{179}$ Ibidem.

${ }^{180}$ Ibidem.
} 
reglamentos que han de ordenar la nueva situación de estas escuelas:

"Art. $3^{\circ}$ Se formarán inmediatamente los reglamentos de todas las expresadas Escuelas para determinar su régimen y respectivos estudios". ${ }^{181}$

En el artículo quinto, encontramos la figura del Comisario Regio, como nuevo representante encargado de la gestión y gobierno del conservatorio, en substitución del antiguo cargo de Director. ${ }^{182}$

Concluye aquí el arreglo educativo perpetrado por el Ministro Manuel de Orovio en lo tocante a materia musical, sin embargo el tema no está zanjado. Ya hemos introducido cómo el advenimiento del último gobierno de la Unión liberal, encarnado en la persona de Luís González Bravo (1811-1871), perpetuó durante cinco agónicos meses, la implacable dinámica restrictiva iniciada por Narváez, ante el inminente estallido revolucionario. Acompañando a González Bravo en la presidencia aparece la figura del conquense Severo Catalina del Amo (1832-1871), encargado durante este corto gobierno, de los ministerios de Marina y Fomento. ${ }^{183}$ Desde este segundo despacho, Catalina acabaría de rematar la tarea iniciada por su predecesor. A las diferentes medidas y parches aplicados por Orovio a la Ley de Instrucción Pública, hemos de sumarle el proyecto de decreto y Real Decreto de 15 y 17 de junio de 1868 respectivamente, desplegados por Catalina durante su corta administración. Veamos a continuación las cuestiones más sobresalientes, relacionadas con estos documentos.

${ }^{181}$ Ibidem.

182 "Art. 5' Para entender en lo relativo á Escuelas de Bellas Artes y conservación de Museos de pintura se nombrará una Comision Régia compuesta de personas de elevada posicion, amantes de nuestras glorias artísticas. Tambien podrá nombrarse un Comisario Régio para el Real Conservatorio de Música y Declamación” ("Real decreto reformando las Escuelas del Notariado...", en Gaceta de Madrid, 13 de octubre de 1866, n 286, p. 1., art. 5).

${ }^{183}$ Bleiberg, Germán (dir.): Diccionario de Historia de España, Madrid, Revista de Occidente, 1968-1969, 3 vols., I, p. 786. 
El proyecto de decreto ofrece una exposición, sobre la que gravitan las principales razones y motivos que justifican la nueva reorganización. Comienza la exposición, repasando el Real Decreto de 9 de octubre de Manuel de Orovio, en el que se dispone que las Escuelas superiores dejen esta clasificación, para volver a la de Escuelas especiales, abandonando consecuentemente el régimen universitario y ajustándose de ahora en adelante a una nueva estructuración y reglamentación, acorde con la "índole respectiva de sus enseñanzas". ${ }^{184}$ ¿Y cuál es la índole o idiosincrasia particular de las enseñanzas artísticas? Tal vez estas palabras, nos den la contestación:

"Si esta medida era razonable y conveniente tratándose de establecimientos como las Escuelas de Pintura y Arquitectura, las del Notariado y Veterinaria, hacíase" á" (sic) "todas luces indispensable en cuanto á" (sic) "la Música y Declamacion," (sic) "cuya naturaleza y aplicaciones artísticas se alejan tanto de la organizacion" (sic) "y vida universitarias, como difieren y se alejan los vuelos de la imaginacion" (sic) "y las creaciones de la fantasía del pausado procedimiento y discurso de la razon" (sic) "serena". ${ }^{185}$

No acaba de quedar claro cuál es la posición exacta del ministro Catalina respecto a la Música y su régimen de enseñanzas, aunque una posible interpretación que se desprende de esta exposición, es la de la clara desventaja por parte de la enseñanzas musicales respecto a las universitarias, al versar aquellas sobre materias relacionadas con la "imaginación" y la "fantasía", alejadas por tanto de la organización y sistematización propias de la "razón serena". Se trata de una aseveración controvertida, que se revela a todas luces discutible.

Prosiguiendo con nuestro recorrido, encontramos rápidamente el origen y fundamento de toda esta regulación, que no es otro que la consabida crisis económica que asola al país en estos momentos. Por este motivo es necesario replantearse el funcionamiento del

\footnotetext{
184 "Real decreto reorganizando el Real Conservatorio de Música y Declamación”, en Gaceta de Madrid, 20 de junio de 1868, n 172, p.1.

${ }^{185}$ Ibidem.
} 
Conservatorio, sobre todo en lo que respecta a la regulación del personal docente. Al final el proyecto de decreto no propone otra cosa que el necesario recorte presupuestario del Conservatorio mediante su consiguiente reducción de plantilla:

"la cifra total de gastos del establecimiento exige rebaja; y porque la exige, y en este como en todos los ramos hay el propósito inquebrantable de realizar toda las economías posibles, el Ministro que suscribe, autorizado por la ley vigente de presupuestos, tiene el honor de aconsejar á" (sic) "V. M. la reforma de la planta y régimen del Conservatorio". ${ }^{186}$

Con la nueva reforma quedarían excedentes trece profesores, los cuales pasarían a percibir las dos terceras partes de su nómina, más el complemento de las matrículas libres.

Finalizada la exposición, comienza el Real Decreto propiamente dicho, con fecha de 17 de junio, desplegándose a través de 12 artículos.

La novedad más destacada para nuestro estudio, la encontramos en el último artículo. En él se recoge, la orden de redactar un nuevo reglamento interno para el gobierno de la Escuela especial, así como la elaboración de los diferentes documentos, necesarios para el correcto avance de las enseñanzas:

“Art. 12. En el término más breve posible elevará el Comisario Régio" (sic) "al Gobierno un proyecto de reglamento que determinará todo lo concerniente á" (sic) "oposiciones y concursos, exámenes de ingreso, número de admisibles á" (sic) "cada asignatura, matrículas, duración del curso, exámenes generales, certificados de aptitud, ejercicios prácticos, premios, pensiones etc., y cuanto se refiera al mayor provecho de la enseñanza y buen régimen de la Escuela". ${ }^{187}$

Por lo que se refiere al resto del decreto, en los artículos cuarto y quinto, hallamos reflejada la organización de la sección de Decla-

${ }^{186}$ Ibidem.

${ }^{187}$ Ídem, p. 2, art. 12. 
mación. Esto es consecuencia de la nueva división que asumirá la Escuela repartida en tres secciones, aunque la estructura general de las enseñanzas, no acaba de estar claramente definida en lo concerniente a los estudios de composición y las enseñanzas instrumentales:

“Art. 2. ${ }^{\circ}$ Esta Escuela especial comprenderá las enseñanzas elementales de los estudios superiores y las aplicaciones más generales de la Música y la Declamacion," (sic) y "se dividirá en tres secciones: Música, Declamacion" (sic) "general y Declamacion" (sic) "lírica". ${ }^{188}$

En verdad estos vacíos reglamentarios, desenmascaran el talante general del Real Decreto, marcado por el apresuramiento y la precariedad del momento.

Desearíamos a continuación, hacer un paréntesis en nuestro análisis e introducir un documento de excepcional interés. Es posible que su valor habite más en las estimaciones proyectadas desde nuestra actual perspectiva, que en la poca o nula trascendencia que pudiese haber tenido el propio documento en su tiempo.

El manuscrito original que comentamos consecutivamente muestra en su segunda página el título de Reglamento Orgánico del Real Conservatorio de Música y Declamación (véase apéndice 1). Se trata de un texto confuso en su exposición, al contener numerosos borrones y enmiendas con lápiz rojo que tachan parte del texto primigenio y en ocasiones la totalidad del mismo. El documento, que contiene un total de 45 páginas, presenta al final del mismo cuatro hojas añadidas con más correcciones y comentarios.

En verdad, y aquí empiezan las curiosidades, se trata de dos documentos solapados. El primero de ellos, al que podríamos llamar reglamento original, posee como acabamos de revelar 45 páginas, nueve capítulos y 141 artículos, y es una versión extendida y optimizada del reglamento de Salaverría. Así nos lo demuestran los cuatro primeros artículos del texto, en donde aparece la división de las enseñanzas del Conservatorio en dos secciones, Música y De-

${ }^{188}$ Ídem, art. 2. 
clamación, subdividiendo a su vez las enseñanzas de música en estudios superiores correspondientes a la carrera de maestro compositor y los de aplicación, enumerando seguidamente, y esto sí que es una novedad organizativa, las especialidades que contienen esta segunda sección. ${ }^{189}$ En la lista aparecen dos nuevas asignaturas que no existían hasta entonces, a saber: Conjunto instrumental y Conjunto vocal.

Sin embargo, donde localizamos una novedad substancial para las enseñanzas de piano es en la organización que se hacen de las mismas en las páginas once y doce del reglamento. Los artículos 37 y 38 describen la "Clase elemental de piano", y sus antecesores 35 y 36, los de la "Enseñanza de Piano". Es en este último artículo en donde encontramos un dato sumamente revelador:

"Art. 36. Los estudios que constituyen esta enseñanza se harán en ocho años y en la forma que marca las Instrucciones" ["que marcan las Instrucciones" aparece tachado y en su lugar se halla escrito encima, la expresión "siguiente"]. ${ }^{190}$

Este reglamento habría regulado por primera vez, en caso de haberse ejecutado, los estudios de piano en ocho años, a diferencia del resto de instrumentos que lo hacían en seis, o siete como es el caso del violín. Si recordamos el reglamento de Salaverría, el piano se desarrollaba a lo largo de seis años de estudio. En definitiva lo que este reglamento inédito prevé, es una ampliación de los estudios pianísticos en dos años más de duración. Proyecto totalmente novedoso para la época que de hecho no se verá cumplido hasta comienzos del siglo XX.

189 Biblioteca NACIONAL DE MADRID: Reglamento Orgánico del Real Conservatorio de Música y Declamación, s.l., s.d., MSS/12971/6, arts. 1, 2, 3, 4. (Texto manuscrito sin autor, ni fecha de publicación con abundantes correcciones, y la mayoría de las hojas tachadas con lápiz rojo. En el título de la página 1, aparece tachado Real Conservatorio, y añadido de otra mano, "de la Escuela Especial de...". También presenta tres hojas sueltas al final, de otra mano, con correcciones).

190 Ídem, p. 12. 
Hemos comentado la hipótesis acerca de que el reglamento comprendía dos escritos paralelamente. El segundo texto consiste realmente en todo ese conjunto de correcciones y notas incorporadas que desfiguran y emborronan el reglamento original. El suplemento de cuatro hojas que encontramos al final forma parte de este agregado.

La primera modificación con la que tropezamos se aprecia en el encabezamiento de la primera página. En efecto podemos leer, justo debajo de donde antes decía "del Real conservatorio" y que ahora aparece finalmente tachado, la enmienda que indica "de la Escuela especial". ${ }^{191}$ La Biblioteca Nacional, lugar donde se conserva el manuscrito actualmente, data el documento en el siglo XIX. Sin embargo, esta simple anotación que acabamos de apuntar es suficiente por sí sola para encuadrar más exactamente el tiempo de circulación del documento, ya que la única vez en todo el transcurso de su historia desde su fundación hasta nuestros días, que el Conservatorio de Madrid ha adoptado esta designación de Escuela especial, fue precisamente en el contexto que abordamos en este capítulo. Como ya hemos expuesto, ${ }^{192}$ las reformas de Manuel de Orovio decretaron en octubre de 1866 el cambio de nombre del Real Conservatorio de Música y Declamación por el de Escuela especial, no volviendo a adoptar el establecimiento esta denominación una vez transcurrido este período.

Existen todavía algunas evidencias más que encuadran el escrito en este período comprendido entre los años 1966 a 1968. Nos referimos a las correcciones a lo largo del manuscrito, ${ }^{193}$ en donde aparece tachada la palabra "Director" y encontramos en su lugar la de "Comisario Regio". ${ }^{194}$ Una última evidencia en esta misma dirección y ya para concluir con la hipótesis expuesta, la encontramos

${ }^{191}$ Ídem, p. 1.

192 Vid. supra, p. 82, cita 177.

${ }^{193}$ Reglamento Orgánico del Real Conservatorio de Música y Declamación,..., pp. 2021.

${ }^{194}$ Recordemos que este cambio de designación se regula en el artículo $5^{\circ}$, del Real Decreto de 13 de octubre de 1866. (Vid. supra, p. 84, cita 182). 
en el primero de los artículos, corregido y enmendado, en el que leemos la nueva división en tres secciones que adoptará la Escuela, ${ }^{195}$ distribución que fue prevista por Catalina en el artículo segundo del Real Decreto de 17 junio de 1868.

Concluimos aquí el examen de este significativo Reglamento, y con él nuestro viaje por una fase educativa marcada por las persistentes circunstancias restrictivas del momento. Las reformas educativas de Manuel de Orovio, la normativa desplegada por Severo Catalina, y el reglamento inédito aquí expuesto que apuntaba hacia un realidad educativa musical más próspera, ${ }^{196}$ nunca llegaron a tener vigencia en el marco educativo musical, ${ }^{197}$ sin embargo los recortes impuestos al Conservatorio y sus enseñanzas, no se remediaron con la entronización del nuevo sistema político. Para devolver a los estudios musicales su reconocimiento de enseñanzas superiores queda un largo trecho jalonado por continuas reformas y transformaciones, comenzando por las sufridas durante el sexenio democrático, cuyo contenido presentamos en nuestro siguiente capítulo.

${ }^{195}$ Reglamento Orgánico del Real Conservatorio de Música y Declamación,..., art. 1.

${ }^{196}$ Ante las diferentes posibilidades y disyuntivas que la historia plantea, en ocasiones las evidencias tienen la virtud pedagógica de enseñarnos agriamente la crudeza de la opción finalmente adoptada: "La historia real de un país se hace sobre todo contando con la constatación de lo que efectivamente ha sucedido, pero también con los testimonios de que ha habido vectores que empujaban en otra dirección." (EMBID IRUJO, A.: Un siglo de legislación..., p. 86)

${ }^{197}$ De La MATA, Manuel: "Reseña histórica", en Memoria acerca de la Escuela Nacional de Música y Declamación de Madrid..., p. 11. 



\section{El sexenio democrático y los inicios del siglo $\mathrm{XX}$}

3.1. Reglamentación de las enseñanzas de Música durante el Sexenio democrático. Un hito en la historia de la Programación de Piano

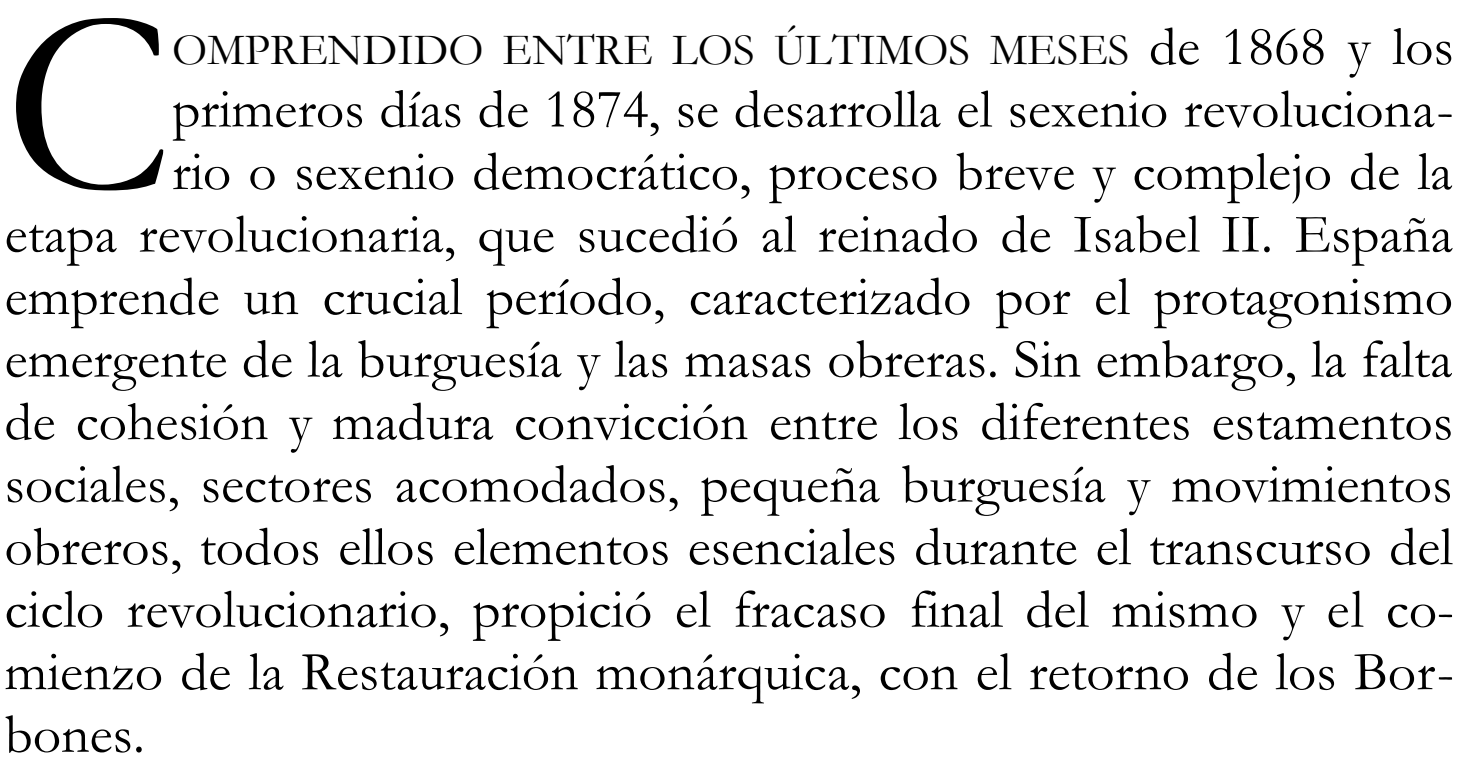


A lo largo del territorio español, el fenómeno de las Juntas provisionales de gobierno, se erige como nuevo sistema de régimen administrativo. Bajo este cuño discurre la regencia de Francisco Serrano y Domínguez, Duque de la Torre (1810-1885), a la que seguirá la monarquía democrática de Amadeo de Saboya (1845-1890) en 1871 y la constitución de la primera república en 1873, cuya quiebra final cerrará este período.

Las novedades que trae consigo el período revolucionario, asoman sobre el horizonte de las enseñanzas musicales a manos del nuevo ministro de fomento, Manuel Ruiz Zorrilla (1833-1895). Las medidas en materia educativa no se hacen esperar y con la llegada del sexenio, se restablecen nuevos parámetros educativos, inversos a los planteados por Narváez y González Bravo, durante sus gobiernos prerrevolucionarios. Girando entorno a temas como la libertad de enseñanza, Zorrilla presenta nuevos decretos que derogan las disposiciones promulgadas por Severo Catalina, ya que según el ministro, aquellas leyes atentaban contra los deberes esenciales de los maestros. Efectivamente, la libertad de enseñanza es anunciada durante esta época con brío y contundencia, considerándose en esta ocasión, una cualidad y un derecho inherentes al ser humano. $^{198}$

La primera noticia significativa que nos llega de este período consiste en un Decreto con fecha de 15 de diciembre de 1868, en el que se declara disuelto el Conservatorio de Música y Declamación para erigir en su lugar una Escuela Nacional de Música. La elucidación de tal maniobra, la encontramos nada más abordar el texto:

"Deseando el Ministro que suscribe organizar sobre bases racionales el establecimiento conocido con el nombre de Real Conservatorio de Música y Declamacion," (sic) "y la enseñanza de aquellas asignaturas, cuyo estudio puede contribuir á" (sic) "suavizar las costumbres y cultivar en sentido provechoso á" (sic) "los fines morales el espíritu del hombre, ha creido" (sic) "conveniente la disolucion" (sic) "de aquel centro de enseñanza y la creacion” (sic) "de una Escuela de Mú-

${ }^{198}$ CAPITÁN DíAZ, Alfonso, op. cit., vol. II, p. 170. 
sica, que responda á" (sic) "la verdad del arte y satisfaga las exigencias de sus progresos y adelantamientos". ${ }^{199}$

Se trata por tanto, de organizar las enseñanzas musicales partiendo de postulados coherentes o "bases racionales" como indica el Decreto, con la finalidad de atender convenientemente las necesidades educativas de las enseñanzas artísticas. Para cumplir con este noble propósito, aparece nuevamente la libertad de enseñanza, esta vez para exponer que tal principio ejemplar, no se opone en absoluto a la existencia de estas enseñanzas y sus establecimientos, aunque eso sí, el compromiso del Estado para sufragar y amparar estos estudios tiene unos límites muy claros que encontramos resumidos en los siguientes términos:

"Estas ideas que han presidido á" (sic) "las reformas hechas hasta ahora en Instruccion" (sic) "pública, y presidirán á" (sic) "las que se hagan en los sucesivo, aconsejan que se concrete la enseñanza pública á" (sic) "sus principios fundamentales, dejando á" (sic) "la vocacion," (sic) "esfuerzo y constancia individuales los estudios y la práctica necesarios para alcanzar la especialidad en cualquiera de sus ramos y aplicaciones. Sería un absurdo pretender que el Estado debe costear la enseñanza de todas las especialidades y aplicaciones, teniendo una Cátedra y un Profesor por cada una de las infinitas subdivisiones de la ciencia y del arte". ${ }^{200}$

El mensaje es claro, no se puede abordar la total regulación de las enseñanzas musicales. Y no se puede, porque además de las razones argumentadas, el país todavía no se ha recuperado del colapso económico sufrido. Así lo explica el propio ministro a continuación, cuando plantea los estudios de declamación y las dificultades que encierra su regulación educativa:

"Ni esta enseñanza especialísima pertenece en rigor al Estado, ni seria prudente en estos momentos, cuando atencio-

199 "Decreto declarando disuelto el Conservatorio de Música y Declamación, y creando en Madrid una Escuela Nacional de Música", en Gaceta de Madrid, 20 de diciembre de 1868, no 355.

200 Ídem, p. 2. 
nes urgentísimas y de interés universal reclaman su atencion" (sic) "y un lugar más preferente en el Presupuesto". ${ }^{201}$

Lo que no es "prudente" plantear, no es otra cosa que la instauración de un establecimiento en correctas condiciones, para desarrollar los estudios de declamación, por la sencilla razón de que "en estos momentos" no hay caudal administrativo suficiente para este tipo de proyectos.

Finalizada la exposición de motivos inicial, aparecen los seis artículos que conforman el Decreto. En los dos primeros, como ya hemos comentado, se declara disuelto el Conservatorio para fundar la Escuela Nacional de Música, y aparte de esta información, sólo cabe resaltar el retorno de la figura del Director, sustituyendo a la del Comisario regio, nombramiento que efectuará el gobierno y que recaerá sobre uno de los profesores más antiguos del centro.

El segundo y último documento que encontramos de esta época corresponde a la redacción de un nuevo Reglamento para la recién creada Escuela Nacional de Música. Aprobado por el mismo ministro de fomento Manuel Ruiz Zorrilla, el escrito aparece reflejado en el Decreto de 22 de diciembre de $1868 .{ }^{202}$ Dejando a un lado las exiguas medidas de Severo Catalina, si comparamos el Reglamento de Zorrilla con el de su predecesor Pedro Salaverría, las diferencias saltan a la vista. Nos encontramos ante un Reglamento de emergencia, donde sus 32 artículos, distan mucho de la ordenación ejecutada durante el bienio moderado, con los 103 artículos del Reglamento de Salaverría, más los 163 desplegados por Ventura de la Vega en las Instrucciones del Conservatorio.

Este hecho explica por sí solo la situación en la que se encontraban las enseñanzas artísticas durante la regencia de Serrano, a la vez que confirma la trascendencia que alcanzó la regulación musical en los conservatorios apenas una década anterior.

${ }^{201}$ Ibidem.

202 "Decreto aprobando el reglamento para la Escuela nacional de Música", en Gaceta de Madrid, 27 de diciembre de 1868, nº 362. 
Con la entronización de Amadeo de Saboya, designado Rey por las Cortes españolas el 16 de noviembre de 1870, comienza la segunda etapa del sexenio democrático, sucediendo en la jefatura de gobierno al general Prim. Durante su corto reinado, desde diciembre de 1870 hasta febrero de 1873, acontece un suceso capital en la regulación de las enseñanzas musicales estrechamente vinculado con el contenido de nuestro trabajo: el hallazgo de la primera programación de la enseñanza de piano. ¿Cuáles fueron los hechos que propiciaron la aparición del documento?

En primer lugar aflora un nuevo Reglamento aprobado por Decreto de 2 de julio de $1871 .{ }^{203}$ En sí el nuevo estatuto no incorpora ninguna novedad importante, a excepción de algún apunte anecdótico, como la creación de la asignatura de mímica aplicada al canto. ${ }^{204}$ No obstante, y a pesar de que a nivel organizativo falten aspectos por pulir, ${ }^{205}$ será el Reglamento que se mantendrá vigente hasta 1901.

El empuje definitivo para la elaboración de las diferentes programaciones que componen el cuadro de asignaturas de la reciente Escuela Nacional, no lo encontramos en el reglamento aludido, sino que tiene su origen en otra fuente.

Es la Real Orden de 18 de octubre de 1871 la que dictamina coordinar y unificar las asignaturas de todas las Facultades, Escuelas e Institutos. El texto lo firma Telesforo Montejo y Robledo (18181896), ministro de Fomento en 1871, ${ }^{206}$ durante el breve gobierno de José Malcampo y Monge.

Lo que la Real Orden establece concretamente consiste en la estipulación exacta de los conocimientos a calificar, y que esta acción se lleve a cabo con igualdad de criterio tanto para las enseñanzas

203 "Decreto aprobando el Reglamento de la Escuela Nacional de Música", en Gaceta de Madrid, 5 de julio de 1871, nº 186.

204 Ídem, Capítulo I, art. $2^{\circ}$.

205 SOPEÑA IBÁÑEZ, Federico, op.cit., p. 80.

${ }^{206}$ BLEIBERG, Germán (dir.): Diccionario de Historia de España, Madrid, Revista de Occidente, 1968, vol. II, p. 1109. 
libres como para las oficiales, por lo que la libertad de enseñanza vuelve a cobrar protagonismo una vez más:

"Las ventajas que la libertad de enseñanza planteada en España, merced á la revolucion" (sic) "de Setiembre, proporciona á" (sic) "los jóvenes escolares, permitiéndoles hacer sus estudios libremente y donde más pueda convenirles, y abreviar lo términos de las carreras científicas y profesionales en razon" (sic) "de su aplicacion" (sic) "y de su ingenio, ni pueden ni deben subsistir un solo momento sin que los exámenes de asignaturas y los ejercicios necesarios para conceder los diversos grados académicos constituyan para las familias y para la sociedad una sólida y firme garantía de la aptitud de los examinandos".207

Ante esta situación académica, el Ministerio de Fomento expone el siguiente planteamiento:

"Hoy más que nunca es absolutamente necesario que las pruebas á" (sic) "que deben sujetarse los que estudian lo mismo en las Facultades, Escuela é" (sic) "Institutos oficiales que en lo libres, reunan" (sic) "tales condiciones para la califiacion," (sic) "se hallen de tal manera coordinadas y coadyuven con tan rígida severidad á" (sic) "la consecución de aquel fin, que sean prenda segura é" (sic) "irrevocable comprobante de la suficiencia de la juventud que concurre á" (sic) "recibir su instruccion" (sic) "en aquellos establecimientos". 208

Realmente, lo que propone la disposición, expresándonos en términos actuales, no es ni más ni menos que una unificación de los contenidos y criterios de evaluación, para las diferentes pruebas y exámenes a los que concurren los alumnos durante sus estudios.

207 “Orden disponiendo que los claustros de las Facultades y el Profesorado de las Escuelas é Institutos propongan las modificaciones que consideren procedentes en la legislación que actualmente rige para exámenes de asignaturas y para ejercicio de pruebas de títulos académicos", en Gaceta de Madrid, 19 de octubre de 1871, no 292, t. III, p. 207.

208 Ibidem 
Planteadas las necesidades, corresponde consecuentemente proponer las soluciones:

"Por estas razones, es la voluntad de S. M. que V. S. pida á" (sic) "los respectivos Cláustros" (sic) "de las Facultades y al Profesorado de las Escuelas é" (sic) "Institutos que dependen de esa Universidad, razonado informe en que propongan las modificaciones que consideren procedentes en la legislación" (sic) "que actualmente rige en España para exámenes de asignaturas y para los ejercicios de prueba necesarios para conceder los diversos títulos académicos". ${ }^{209}$

La respuesta no se hace esperar, y el 1 de diciembre de 1871, se redactan los programas de todas y cada una de las asignaturas impartidas en la Escuela Nacional de Música y Declamación. Estos manuscritos se alzan como un referente en la organización pedagógica de las enseñanzas musicales, ya que son las primeras programaciones halladas desde la fundación del Conservatorio. En sentido estricto, no simbolizan el primer ensayo organizativo de las enseñanzas musicales, este puesto les está reservado a los Métodos de piano, sin embargo unos y otros, nacen de una misma motivación común: la unificación de criterios.

Ya vimos durante el primer capítulo, cómo después de la Revolución francesa de 1789, el Conservatorio de París elaboró los Métodos de piano con la finalidad de reunir y presentar en un solo texto los contenidos fundamentales de la práctica instrumental, para difundir ulteriormente la estandarización de estos conocimientos y su verificación al resto de establecimientos educativos repartidos por el territorio. La Real Orden de 18 de octubre y sus "ramificaciones", si entendemos así las programaciones de 1 de diciembre de la Escuela Nacional de Música, son la versión hispánica del mismo fenómeno.

Para el siguiente análisis encontramos tres ejemplares diferentes de la programación oficial. El primero de ellos, el más antiguo de los tres, es una copia manuscrita del original con fecha 1 de diciembre de 1871, y firmado por el entonces secretario de la Escuela, Manuel

209 Ibidem 
de la Mata. La programación se presenta compilada junto a otros manuscritos y documentos, en la Memoria presentada por la Escuela de Música y Declamación en la Exposición Internacional de Filadelfia. ${ }^{210} \mathrm{El}$ segundo de los ejemplares se trata de un Cuadernillo independiente, también manuscrito y copia del original, con fecha 1 de agosto de 1875. ${ }^{211}$ La última de las muestras consiste en un texto impreso de 1891. ${ }^{212}$ Puesto que los dos ejemplares iniciales presentan idénticos contenidos, centraremos nuestra atención exclusivamente sobre el primero de ellos.

El documento comienza mostrando un índice general de las programaciones incluidas, tropezando prontamente con la de Piano en la página 11. Después del índice, encontramos el siguiente escrito:

"Dichos programas han sido hechos por los profesores respectivos y revisados por comision" (sic) "facultativa, para cumplimentar la R.l orden de 18 de octubre de 1871, transmitida á" (sic) "esta Escuela por el Elmo. Sr. Rector de la Universidad Central con fecha 28 del mismo, con el objeto de uniformar y coordinar los estudios y exámenes de los alumnos procedentes de la enseñanza oficial y libre, sirviendo de sólida garantía, respecto á" (sic) "la actitud de los examinados, conforme el espíritu demostrado en dha. R.l orden. Madrid $1^{\circ}$ de Diciembre de 1871. Es Copia. El Secretario. Manuel de la Mata". ${ }^{213}$

210 "Escuela de Música y Declamación. Programas de las enseñanzas de la misma" en Memoria presentada por la Escuela de Música y Declamación en la Exposición Internacional de Filadelfia. Madrid, Imp. y Fundición de J. Antonio García, 1876.

${ }^{211}$ Escuela Nacional de Música y DeClamación: Programa de las enseñanzas. 1 de agosto de 1875 Archivo Histórico del Real Conservatorio Superior de Música de Madrid, Doch. Bco. 1/3

${ }^{212}$ Escuela Nacional de Música y Declamación: Programa oficial de la enseñanz̧a de piano 3, Madrid, Imp. de J. M. Ducazcal, 1891.

213 "Escuela de Música y Declamación. Programas de las enseñanzas de la misma," en Memoria presentada por la Escuela de Música y Declamación en la Exposición Internacional de Filadelfia,... 
La nota habla por sí sola. Las programaciones surgen para "uniformar y coordinar" los trabajos y ejercicios de los estudiantes libres y oficiales, según lo dispuesto en la Orden de 18 de octubre de 1871.

Centrados ya en el núcleo de la programación, la relación de contenidos que se describen en cada curso no representa ningún descubrimiento por sí mismo. En honor a la verdad lo que allí encontramos no es ni más ni menos que una trascripción de los Métodos oficiales, concretamente y para ser más exactos, del método de Manuel de la Mata. Para confirmar esta hipótesis basta con efectuar un repaso al inventario de cuestiones proyectadas para el primer curso de piano:

" 1 ' . y $2^{\circ}$. Cuaderno del método del Sr. Mata (declarado obra de texto) página 1. a hasta la 56)"214 "que contienen:

Conocimiento del teclado y posición” (sic) "del cuerpo y manos.

Ejercicios sobre cinco teclas en diferentes tonos.

Ejercicios en mayor estension," (sic) "e instrucciones para las diferentes formas de digitacion," (sic) "como son: elisiones sustituciones articuladas y mudas ó" (sic) "ligadas en notas sencillas y dobles; pasos del pulgar por debajo de los otros dedos, y estos por encima de aquel [aparecen unas abreviaturas de difícil interpretación, que contrastando con su método equivalen a etc., etc.,].

Ejercicios y arpegios en todos los tonos con sujecion (sic) á" (sic) "metrónomo.

Estudios de Bertini (op. 100.)". ${ }^{215}$

Esta descripción de los contenidos pianísticos tal y como se nos presenta, es prácticamente una copia literal del texto elaborado por de la Mata en su Método para piano. ${ }^{216}$

${ }^{214}$ Falta el primer paréntesis en el original.

${ }^{215}$ Ibidem. 
No obstante, los Métodos oficiales de este período abarcaban tres o cuatro volúmenes por término general, ${ }^{217}$ mientras que los estudios de piano se desarrollan a lo largo de siete cursos. Consiguientemente, es natural que a partir del quinto año no hallemos referencia alguna a ningún Método oficial, y en su lugar encontremos cursos enteros monopolizados principalmente por estudios, a la vez que aparecen como novedad significativa, fugas de Bach y práctica del transporte. Hemos de convenir que el punto débil de esta clasificación se encuentra en el apartado dedicado a la interpretación del repertorio pianístico. Durante el cuarto, quinto y sexto año, la programación invita a estudiar obras de Dussek, Field, Ries, Hummel, Mozart, Weber y Mendelsshon. A excepción de estos tres últimos, el resto ocupa un segundo plano en la actualidad, prueba concluyente de lo que encarnan estas figuras dentro del repertorio pianístico. Por otro lado, echamos en falta las obras maestras del piano y sus creadores. Junto a Mendelsshon es inevitable pensar en Schumann, y entre los clásicos desearíamos ver las sonatas de Haydn junto a las de Mozart, y las de este último con un protagonismo más relevante y no de un modo tan tímido, sólo se pide una sonata de Dussek o de Mozart en cuarto curso. Prolongándonos en el tiempo deberíamos tropezarnos con Beethoven y Schubert, pero desgraciadamente no es así.

Peor parados salen aún los dos maestros del piano romántico por excelencia. Liszt no aparece por ningún lado, pese haber estado en España en $1844,{ }^{218}$ y de Chopin se presentan los 12 estudios op. 10, eso es todo, nada de Nocturnos, Baladas ni Scherzos. Tal vez el último de los apartados propuesto para el séptimo curso, en el que se deja vía libre para la interpretación de obras de elevado nivel

${ }^{216}$ DE LA MATA, Manuel, op. cit., p. 3.

${ }^{217}$ El método de Manuel de la Mata, que revisamos para este trabajo, contiene cuatro cuadernos.

${ }^{218}$ Ortiz BALLeSTERos, Consuelo, op, cit., p. 23. 
técnico, constituya una posible medida de emergencia a esta cuestión. $^{219}$

Pese a la certidumbre de estos hechos, no podemos dilapidar radicalmente el alcance y magnitud del conjunto de la programación, tanto en el terreno pedagógico como en el reglamentario. Existe una voluntad didáctica clara, presentando los estudios de cada curso, conforme a una escala de dificultad progresiva. Podríamos cuestionarnos, entablando un interesante debate, sobre la idoneidad pedagógica de los ejercicios técnicos y su "sujeción a metrónomo". Pero lo que resulta evidente, es que la programación de 1871, codifica gradualmente los objetivos a desempeñar en cada uno de los siete cursos de que constan los estudios de piano, cruzando la línea marcada por los Métodos oficiales que sistematizaban las enseñanzas durante los primeros tres o cuatro cursos a lo sumo, y presentando aunque sea con deficiencias, el primer ordenamiento de las enseñanzas musicales en toda su longitud.

Damos por finalizado aquí nuestro recorrido, a través de un documento histórico, que subsiste en la actualidad como la primera programación de Piano en la historia educativa reglada. El último ejemplar de la programación que hemos mencionado, correspondiente al año 1891, no presenta grandes transformaciones con respecto a sus predecesores. La incorporación al programa de nuevos estudios de compositores españoles como Zabalza, Quesada o Teobaldo Power, y el hecho de que se trate básicamente del mismo documento pero en versión impresa, procurando un aspecto más oficial a la programación, son prácticamente las notas más remarcables de esta ultima muestra.

219 "Escuela de Música y Declamación. Programas de las enseñanzas de la misma," en Memoria presentada por la Escuela de Música y Declamación en la Exposición Internacional de Filadelfia,... 


\subsection{Comienzos del siglo XX: los reglamentos de 1901, 1911 y 1917}

El primer tercio del siglo XX traerá consigo valiosas transformaciones para los conservatorios y Escuelas de música del territorio español. En efecto, durante este periodo se confeccionarán las medidas responsables de clausurar el final de un ciclo y su correspondiente formulación legislativa, y abrir una nueva etapa que a pesar de hundir sus raíces sobre las mismas bases y principios de siempre, al menos en la forma aportará un nuevo semblante, fruto de la nueva naturaleza del entorno.

La apertura de todo este contexto comienza con el Real Decreto de 16 de junio de $1905,{ }^{220}$ en el que el Estado, procura su conformidad a todas aquellas Corporaciones populares, Diputaciones y Ayuntamientos, que soliciten el reconocimiento oficial de las enseñanzas impartidas en sus respectivas Escuelas provinciales y conservatorios de música, siempre y cuando cumplan los requisitos necesarios. El 25 de agosto de 1917 se confecciona el Reglamento para el gobierno y régimen del Real Conservatorio de Música y Declamación, ${ }^{221}$ floreciendo como la última de las disposiciones reglamentarias que se exprese en términos tan circunscritos y delimitados para regular la organización, tanto del propio Conservatorio de Madrid como la del resto de nuevos establecimientos oficiales. Ciertamente después de este último Reglamento, lo que hallaremos serán los planes generales de 1942 y 1966, concernientes a la organización y reglamentación general de los conservatorios de todo el estado español. Descubramos gradualmente los hechos acontecidos hasta la aparición de este nuevo horizonte reglamentario.

A caballo entre el último cuarto del siglo XIX y primer tercio del $\mathrm{XX}$, se desarrolla el período que conocemos como la Restauración.

220 "Real decreto disponiendo que las Corporaciones provinciales que sostengan Conservatorios y Escuelas de Música y deseen que los estudios en ellos cursados tengan validez académica, soliciten su incorporación al Conservatorio de Madrid", en Gaceta de Madrid, 17 de junio de 1905, nº 168.

221 "Real decreto aprobando el Reglamento para el gobierno y régimen del Real Conservatorio de Música y Declamación", en Gaceta de Madrid, 30 de agosto de 1917, n 242. 
El pronunciamiento del general Arsenio Martínez Campos (18311900) en Sagunto, traería consigo el arribo de la dinastía borbónica y el desvanecimiento de la primera República. Comienza así este largo ciclo de la historia española que encuadra sucesivamente los reinados de Alfonso XII (1874-1885), la regencia de Maria Cristina de Habsburgo-Lorena (1885-1902), el reinado de Alfonso XIII (1902-1923), y bajo la supervisión de este último, la dictadura de Primo de Rivera (1923-1931).

Después del sexenio democrático y el fracaso de los ideales revolucionarios de 1868, Alfonso XII, a quien su madre Isabel II le había cedido los derechos de la Corona, hizo uso de su potestad como soberano mediante una monarquía constitucional en la que se pretendía garantizar las libertades de todas las clases y grupos sociales del estado español. Sin embargo, el plan de gobierno diseñado por Antonio Cánovas del Castillo (1828-1897), preveía la alternancia en el poder de los partidos conservador y liberal, marginando al resto de las fuerzas políticas y radicalizando el liberalismo doctrinal representado en la burguesía conservadora y latifundista, a la que se había hecho frente durante 1868. Este hecho provocaría el desarrollo de los movimientos obreros, y la aparición de un anarquismo cada vez más virulento que se recrudecería con los problemas económicos y sociales de la época, llegando al paroxismo con el asesinato de Cánovas del Castillo.

Si a esto añadimos la pérdida de Cuba, Puerto Rico, Guam y Filipinas, en la fugaz contienda contra Estados Unidos, obtendremos como resultado un panorama político-social dominado por el pesimismo y la crisis del sistema bipartidista, que encarnaría en 1917, uno de los períodos más oscuros y difíciles de la historia española. El 12 de septiembre de 1923, el capitán general Miguel Primo de Rivera (1870-1930), con el beneplácito de Alfonso XIII, condujo el golpe de estado que acabaría con la Constitución de 1876, el cual tenía por objeto devolver el orden público, sin embargo esta solución a la desesperada no ayudaría a resolver el conflicto. La dimisión el 28 de enero de 1930 de Primo de Rivera preludiaba el fin de la monarquía, última etapa de la Restauración, que tuvo como antesala en 1930 y 1931 los gobiernos transitorios de Dámaso Berenguer y Fusté y Juan Bautista Aznar Cabanas respectivamente. 
Durante el gobierno de este último se convocaron las elecciones municipales de 12 de abril de 1931, cuyo resultado dio pie a la proclamación de la segunda República española, el 14 de abril del mismo año. En este período se alternan en el poder tres gobiernos: un primer ciclo a cargo del denominado bienio reformista, desde 1931 a 1933 con Niceto Alcalá-Zamora como Presidente de la República y Manuel Azaña Díaz como Presidente del Gobierno; un segundo gobierno conocido como el bienio radical-cedista desde 1933 a 1936, en el que se turnan en la presidencia Alejandro Lerroux García, Ricardo Samper e Ibáñez y Joaquín Chapaprieta y Torregrosa, que frenaría las reformas iniciadas por el ejecutivo anterior; y finalmente las elecciones generales de febrero de 1936, que trajeron la victoria del Frente Popular, el nombramiento nuevamente de Manuel Azaña como presidente de la república y tras unos pocos meses de gestión, el descarrilamiento final de la república en el conflicto bélico que asoló España desde 1936 a 1939.

Vinculado al ámbito musical, se consignarán durante el primer cuarto del siglo XX, tres reglamentos diferentes que encauzarán la organización de los conservatorios hacia nuevos horizontes. Se dará un paso importantísimo en el reconocimiento oficial de las enseñanzas musicales de ámbito nacional, y asistiremos como consecuencia de todo este adelanto a las lógicas transformaciones sufridas por las correspondientes programaciones de Piano.

El primero de los reglamentos mencionados aparece en septiembre de 1901, y emprendió como objetivo prioritario la reforma de su homólogo predecesor. Como ya estudiamos en el capítulo anterior, el último reglamento vigente hasta la fecha era el de 1871, implantado durante la dirección de Emilio Arrieta al frente del Conservatorio en pleno sexenio democrático. En efecto Arrieta sostuvo un largo mandato como principal encargado del centro, desde 1868 hasta 1894, protagonizando la transición entre el período revolucionario y la restauración borbónica. A continuación le siguieron en el cargo Jesús del Monasterio (1894-1897), e Ildefonso Jiménez de Lerma (1897-1901). ${ }^{222}$ Durante la etapa de Monasterio se llevaron a cabo reformas en el reglamento de 1871, ya que este se ha-

${ }^{222}$ SOPEÑA IBÁÑEZ, Federico, op.cit., p. 225. 
llaba parcheado de tal manera, que demandaba la creación de un nuevo documento que lo substituyese. A la espera de un nuevo texto, se redacta el Real Decreto de 11 de diciembre de 1896 en cuya exposición podemos advertir lo siguiente:

“SEÑORA: El reglamento de 2 de Julio de 1871, por el cual se rige la Escuela Nacional de Música y Declamación, apenas si está en vigor, así en lo relativo á" (sic) "las enseñanzas como en cuanto al personal técnico se refiere, pues una serie de reformas, sin plan fijo, le han ido modificando de tal suerte, que hoy puede considerarse anulado por aquéllas.

La importancia de este Establecimiento docente, único en España, reclama que el Gobierno de V. M. estudie una reorganización completa á" (sic) "fin de ponerle, en cuanto las fuerzas del Erario lo permitan, á" (sic) "la altura de sus similares". 223

Una vez más, encontramos en la frágil situación económica del país uno de los principales factores de riesgo para la correcta organización de las enseñanzas musicales. En cualquier caso, el Real Decreto de 11 de diciembre que prosigue a la exposición citada, se centra única y exclusivamente en la reorganización técnica del profesorado, dividiendo a los profesores en numerarios y supernumerarios, ${ }^{224}$ y estableciendo turnos de oposición y concurso para los ascensos y provisión de vacantes, entre otros aspectos, ${ }^{225}$ teniendo que esperar todavía unos cuantos años hasta tropezar con un nuevo estatuto que contemple todas las reformas reglamentarias adecuadas. En verdad, esta reforma no constituía el primer amago por mejorar el estado general de la Escuela Nacional de Música. A pocos meses de su nombramiento como director, Monasterio fue seleccionado junto a D. Gaspar Núñez de Arce, D. Manuel Tamayo y Baus, D. Federico Balart, D. Tomás Bretón, D. Gabriel

223 "Real decreto dictando reglas relativas á la reforma de la organización de la Escuela Nacional de Música y Declamación", en Gaceta de Madrid, 12 de diciembre de $1896, \mathrm{n}^{\circ} 347$.

224 Ídem, art. 1.

225 Ídem, art. 3. 
Rodríguez y Balart y el Sr. Conde de Morphy, para formar parte de una Comisión, encargada de proponer las reformas necesarias para la optimización y mejora de la Escuela. ${ }^{226}$ Con este escenario como telón de fondo aparece el Reglamento del Conservatorio de Música y Declamación de 14 de septiembre de $1901 .{ }^{227}$

Nos encontramos en el período de regencia de Maria Cristina bajo la presidencia de Práxedes Mateo Sagasta (1827-1903), cabeza visible del partido liberal y a Álvaro de Figueroa y Torres, Conde de Romanones (1863-1950), al frente del ministerio de Instrucción Pública. ${ }^{228}$ La Gaceta de 15 de septiembre de 1901, publica junto al reglamento, un segundo Real Decreto con fecha 14 de septiembre, en el que figura el nombramiento del nuevo Comisario Regio al frente del Conservatorio, D. Tomás Bretón y Hernández, por lo que el estreno del siglo XX comportará novedades no sólo en el terreno reglamentario, sino también en lo pertinente a la administración del establecimiento musical que pasará ahora a llamarse Conservatorio de Música y Declamación.

En la exposición del proyecto de decreto que antecede al reglamento encontramos una vez más los objetivos principales que originan esta reforma. Lo que se pretende con esta nueva ordenación es una actualización de las disposiciones reglamentarias acorde con los nuevos tiempos que corren, ya que la anterior legislación de 1871 había quedado obsoleta:

"Es menester que sustituya á" (sic) "las arcaicas disposiciones, hasta ahora vigentes, un plan de estudios más en armonía con los creciente progresos que en nuestro tiempo alcan-

226 "Real orden nombrando una comisión para que en el plazo de tres meses proponga á la Dirección general las reformas que deban introducirse en la organización de la Escuela Nacional de Música y Declamación”, en Gaceta de Madrid, 17 de junio de 1894, no 168.

227 "Real decreto reformando la Escuela Nacional de Música y Declamación y aprobando el adjunto reglamento orgánico del Conservatorio de Música y Declamación”, en Gaceta de Madrid, 15 de septiembre de 1901, nº 258.

228 BurRel I FlORIA, Guillem (dir.), op. cit., [documento en línea] < http://www.xtec.es/ jrovira6/governs1/govern8.htm $>$ [consultado el 268-2014]. 
zan las enseñanzas de índole artística, y un reglamento interior cuya ejecución no pueda ser eludida en manea alguna, á" (sic) "fin de que resulten eficaces los trabajos que se propongan, asegurando las ventajas de posibles innovaciones al par que se afiancen las conveniencias que desde antiguo están reconocidas". 229

El Ministerio se pregunta consecutivamente cuál es el origen que ha encaminado a la Escuela Nacional a su actual situación:

"Atento el Ministro que suscribe á" (sic) "remediar en cuanto le fuera posible el presente estado de cosas, una de sus más vivas preocupaciones fue la de conocer las causas principales de la postración en que se encuentran los estudios de música y declamación en nuestra Patria". ${ }^{230}$

Entre las nuevas soluciones formuladas para la mejora del establecimiento, dos propuestas merecen especial atención. La primera de ellas tiene por objeto regular las diferentes pruebas de ingreso a la Escuela, centrándose sobre todo en el control de acceso a los niveles superiores:

"Efectúase el ingreso de la Escuela de Música y Declamación con una descuidada facilidad que á" (sic) "ningún otro establecimiento de enseñaza es extensiva. Las puertas de la Escuela de Música y Declamación están completamente abiertas aun para los más desprovistos de la conveniente preparación. Para evitar los deplorables efectos que esto ocasiona, el Ministro que suscribe ha pensado en la necesidad de exigir un examen de ingreso á" (sic) "los que hayan de ser alumnos de la misma, análogamente á" (sic) "los exigidos á" (sic) "los alumnos de los Institutos generales y técnicos y otros establecimientos de enseñanza, á" (sic) "fin de que al entrar en las

229 "Real decreto reformando la Escuela Nacional de Música y Declamación y aprobando el adjunto reglamento orgánico del Conservatorio de Música y Declamación",..., p. 1359.

${ }^{230}$ Ibidem. 
aulas donde han de estudiar difíciles materias lleven ya los alumnos la preparación previa que les es indispensable". ${ }^{231}$

En segundo lugar y como lógica consecuencia de lo expuesto, se procede a una nueva clasificación de los estudios, distribuyéndolos en dos nuevos niveles: elementales y de perfeccionamiento. Lejos queda por tanto aquella desafortunada ordenación que dividía las enseñanzas musicales en estudios de composición y estudios de aplicación, reemplazándose por ésta última propuesta más coherente didácticamente, en consonancia con los diferentes niveles de adelanto y dificultad adquiridos por el alumno a lo largo de su carrera musical:

"Por lo que dice relación al orden de desenvolvimiento de los estudios, imponíase por imperiosas razones de carácter propiamente pedagógico la clasificación de las enseñanzas que en la Escuela hayan de darse, conforme á" (sic) "un plan basado en la natural de la diferenciación de los grados de enseñanza. Propónese el Ministerio que suscribe la división de las enseñanzas de la Escuela Nacional de Música y Declamación en dos grados perfectamente definidos: estudios elementales y estudios de perfeccionamiento. Esta clasificación concilia las dos ventajas de extender y propagar la cultura artística de un modo discreto y facilitar la selección de las inteligencias aptas para el ejercicio de las profesiones artísticas. Limitado el número de alumnos en las clases de perfeccionamiento, á" (sic) "las cuales se pasará por el orden correlativo seguido en los exámenes, los alumnos que á" (sic) "tales clases pertenezcan habrán de ser forzosamente aquellos que hayan demostrado más definida vocación y mejores aptitudes para el ejercicio de la profesión artística á" (sic) "que hayan de consagrarse". ${ }^{232}$

Es interesante apreciar, el celo que manifiesta la normativa a la hora de seleccionar los alumnos en función de las "aptitudes" necesarias para el "ejercicio de la profesión artística". No se trata de una mera observación. Bretón en su nueva responsabilidad como

\footnotetext{
${ }^{231}$ Ibidem.

${ }^{232}$ Ibidem.
} 
Comisario Regio del Conservatorio tomaría el firme compromiso de combatir y remediar la laxitud en que había caído la Escuela respecto a los niveles de exigencia requeridos para la consecución con éxito de los estudios. De este singular modo nos lo recuerda Federico Sopeña:

"En sus primeros discursos, el Comisario Regio ataca, una vez más, el vicio heredado de la no exigencia por una parte y de la prodigalidad en los premios por otra; la no exigencia aparece cada día más grave porque la titulación intenta abrirse camino «profesional» a través de las clases particulares y porque no hay, como en Barcelona, la autocrítica y la noble emulación de las Academias privadas bien organizadas". ${ }^{233}$

Da comienzo a continuación el Real Decreto de 14 de septiembre de 1901 que se articula en dos partes principalmente. La primera de ellas contiene los nueve artículos que desglosan la disposición propiamente dicha, para mostrar seguidamente la publicación del nuevo Reglamento del Conservatorio de Música y Declamación. Los artículos enumeran las diferentes novedades que hemos ido aportando en nuestro análisis: el cambio de denominación de Escuela Nacional por el de Conservatorio de Música y Declamación; el anuncio de la nueva administración del centro a cargo del Comisario Regio o la aprobación del reglamento orgánico como nuevo estatuto de gobierno.

Sin duda alguna, la averiguación más relevante que responde al objeto de nuestro trabajo, la descubrimos en el artículo 10 del Reglamento. Dice así:

"Art. 10. Los Profesores supernumerarios de las asignaturas de Piano y Violín tendrán á” (sic) "su cargo la enseñanza de los cuatro primeros años, pasando los alumnos desde el quinto á las clases de los numerarios, en las cuales no podrán

${ }^{233}$ SOPEÑA IBÁÑEZ, Federico, op.cit., p. 105. 
admitirse más que los siguientes, previa oposición: En la clase de Violín, 16: en las tres de Piano, 30 en cada una". ${ }^{234}$

Con esta noticia podemos confirmar cuántos cursos abarcaban cada uno de los dos ciclos, verificándose cuatro para nivel elemental y disponiendo el resto de los cursos $5^{\circ}, 6^{\circ}$ y $7^{\circ}$, en el nivel de perfeccionamiento. Quedaban excluidos de realizar el examen de paso de grado aquellos alumnos que iban a comenzar durante ese mismo curso escolar los estudios superiores de Violín y Piano. ${ }^{235}$

La siguiente disposición que nos sale al encuentro es el Real Decreto de 16 de junio de 1905, del que ya hemos hablado al comienzo de este capítulo, refiriéndonos a él como un nuevo hito en el desarrollo de las enseñanzas musicales y su regulación, extensible en esta ocasión al resto del país.

El Real Decreto viene firmado por Alfonso XIII, dando luz verde al proyecto de decreto de igual fecha propuesto por Carlos María Cortezo (1850-1933), ministro de Instrucción pública y Bellas Artes, durante la breve presidencia del dirigente de signo conservador, Raimundo Fernández Villaverde (1848-1905).

El plan lanzado por el Ministro de Instrucción, no es otro que el de otorgar el reconocimiento oficial de las enseñanzas a todas aquellas escuelas y conservatorios, que hallándose sujetas a otras Corporaciones, Diputaciones o Ayuntamientos diferentes del de Madrid, así lo soliciten. Los requisitos necesarios para autorizar este reconocimiento se centran esencialmente en la necesaria preparación académica del profesorado, y la correcta adaptación de los planes de estudio. A este respecto resulta interesante el siguiente punto contenido en el segundo artículo del decreto:

"4. "Que los programas de enseñanzas se ajusten á" (sic) "los oficiales del Conservatorio de Música y Declamación, si se solicita validez de los estudios de Solfeo y los elementales de

\footnotetext{
234 "Real decreto reformando la Escuela Nacional de Música y Declamación y aprobando el adjunto reglamento orgánico del Conservatorio de Música y Declamación",.., p. 1360.

235 Ídem, disposición general 3ª p. 1361.
} 
Piano y Violín. Para conceder la validez académica de los estudios de los demás instrumentos, cursos y asignaturas que constituyen la enseñaza de la Música, habrán de someterse á" (sic) "los planes, programas y condiciones especiales que formule el Claustro de Profesores del Conservatorio de Madrid y apruebe el Consejo de Instrucción pública". ${ }^{236}$

Este observación, nos da una ligera idea, de hasta qué punto el resto de escuelas y conservatorios del estado español, se veían sujetos a los preceptos y mandatos del establecimiento madrileño. Pese a todo, la normativa encarna una nueva mejora en el ámbito de la educación musical, apareciendo en los reglamentos subsiguientes aunque sea de manera muy tímida la nueva tarea de revisar el correcto funcionamiento de los conservatorios y escuelas de música españoles con validez académica reconocida, labor que no se había contemplado hasta entonces.

Los reglamentos elaborados en 1911 y 1917 presentan varias novedades significativas en cuanto a contenido y formato al tener que desempeñar la doble tarea de organizar, no solamente las enseñanzas del Conservatorio de Música de la capital, sino que a partir de ahora tendrán que tutelar igualmente los establecimientos musicales oficiales repartidos por el resto de la geografía española.

Abordamos a continuación el primero de los dos reglamentos citados, aprobado según Real Decreto de 11 de septiembre de 1911, a propuesta del Ministro de Instrucción Pública y Bellas Artes, Amalio Gimeno Cabañas (1852-1936). El Reglamento se desarrolla bajo la dirección de D. Cecilio de Roda y López al frente del Conservatorio, ${ }^{237}$ y constituye una prueba fehaciente de la gestión reali-

236 "Real decreto disponiendo que las Corporaciones provinciales que sostengan Conservatorios y Escuelas de Música y deseen que los estudios en ellos cursados tengan validez académica, soliciten su incorporación al Conservatorio de Madrid",..., p. 1108.

237 "Real Decreto nombrando Director del Conservatorio de Música y Declamación á D. Cecilio de Roda y López", en Gaceta de Madrid, 25 de enero de $1911, \mathrm{n}^{\circ} 25$. 
zada durante el breve lapso de tiempo transcurrido, poco más de dos años, entre los dos mandatos de Bretón. ${ }^{238}$

El comienzo de la exposición efectuado en el proyecto de decreto revela las principales intenciones que persigue el nuevo documento:

"SEÑOR: Si se compara la organización actual de nuestro Conservatorio de Música y Declamación con la de los principales Conservatorios extranjeros, bien pronto se hecha de ver la diferencia radical que existe entre ellos.

Los Conservatorios alemanes y austriacos tienden á" (sic) "formar músicos, imponiendo una verdadera educación, determinada por lo que ellos llaman cursos paralelos, y así obligan á" (sic) "todos los alumnos, sea cualquiera la enseñanza que cultiven, á" (sic) "que cursen los estudios elementales de piano, los principios de Armonía, la Estética y la Historia de la Música, á (sic) que asisten á" (sic) "las clases de Conjunto coral primero, y á" (sic) "las de Conjunto instrumental después, apoyando la enseñanza de algunas ramas del arte en conocimientos para ellas necesarios, como la Declamación para los alumnos de Canto, la Danza, la Mímica y la Esgrima para los alumnos de Declamación. Tienden también todos esos Conservatorios á" (sic) "formar Profesores, en una Escuela especial, donde el estudio de la Pedagogía se une á" (sic) "conocimientos culturales, indispensable para todo Maestro". ${ }^{239}$

La supuesta inspiración en los planes de estudios de Conservatorios centroeuropeos origina en este reglamento el refuerzo e insistencia de la enseñanza sobre los citados "cursos paralelos", o lo que es lo mismo, sobre todas aquellas asignaturas que acompañan y

${ }^{238}$ Tomás Bretón fue Comisario Regio en 1901. Tras su dimisión le siguieron Enrique Fernández Arbós y Cecilio de Roda. Bretón volvería de nuevo como Director el 15 de febrero de 1913.

239 "Real Decreto aprobando el Reglamento para el funcionamiento del Conservatorio de Música y Declamación", en Gaceta de Madrid, 14 de septiembre de 1911, no 257, p. 690. 
complementan los estudios de la especialidad escogida. Hasta tal punto llega la inquietud que se plantea crear una Escuela especial para la enseñanza de Pedagogía como materia indispensable para los Profesores. Con todo este planteamiento lo que se pretende es proporcionar una educación artística más sólida abrazando disciplinas de carácter humanístico y musical que completen la práctica instrumental.

Comienza el Real Decreto, y los primeros contrastes significativos que advertimos en comparación con sus predecesores no se hacen esperar. Para empezar, no aparece ningún epígrafe en el que se aluda de manera expresa al Conservatorio de Música de Madrid, muestra del carácter distintivo que define al texto como documento organizador de un plan general. Un segundo aspecto que llama también nuestra atención es su extensión. Nos hallamos ante un estatuto que se desarrolla a lo largo de cinco títulos y 132 artículos, más las disposiciones transitorias.

Encabeza el Capítulo primero la presentación de los objetivos y deberes que ha de desempeñar el Conservatorio de la capital española, localizando en el apartado e), del segundo artículo, una de las primeras novedades ya comentadas al presentar este documento. Hablamos de la tarea que deberá cumplir el Conservatorio de Música y Declamación de Madrid, supervisando la correcta actividad del resto de Conservatorios y Escuelas oficiales de la península:

“e) Vigilar el régimen y funcionamiento de los conservatorios y Escuelas de música españolas, donde el Estado reconozca validez oficial á" (sic) "los estudios". 240

Al continuar con los capítulos II y III de la disposición aparece reflejada la nueva tipificación de las enseñanzas. Éstas incluyen la instrucción de la asignatura especial de la que el alumno se matricula, más el resto de asignaturas. ${ }^{241}$ Las enseñanzas del Conservatorio siguen dividiéndose en las secciones de Música y Declamación, pero con la novedad de que aquellas se subdividen a su vez en dos

\footnotetext{
${ }^{240}$ Ídem, Título I, Capítulo I, art. 2.e.

${ }^{241}$ Ídem, Título I, Capítulo II, art. 3.
} 
clases, elemental o preparatoria y superior. ${ }^{242}$ Ha habido una nueva reestructuración de estos niveles respecto al Reglamento de 1901. Ahora la enseñanza elemental de Piano abarca los cinco primeros cursos, a diferencia de los cuatro que eran antes, y la enseñanza superior incluyen los cursos $6^{\circ}, 7^{\circ}$ y $8^{\circ}$, lo que significa la aparición de un nuevo curso para la conclusión de la carrera. ${ }^{243}$

Todas estas novedades ya suponen de por sí cambios substanciales en lo que a la enseñanza de piano y su programación respecta. Sin embargo, es en el capítulo III del Decreto donde vamos a encontrar la nueva estructura organizativa de las enseñanzas de música. En efecto, todo este capítulo se encarga de explicar y articular cuál va a ser la metodología a seguir para la obtención del correspondiente diploma de capacidad tras la finalización con éxito de los estudios musicales. Comienza aquí el nuevo esquema organizativo del que hablábamos al presentar los reglamentos de 1911 y 1917, basado en la enunciación de un conjunto de premisas y condicionantes que regulan la sucesión de los estudios musicales hasta su consecución definitiva. Los estudios se dividen en enseñanzas principales y enseñanzas accesorias obligatorias, ${ }^{244}$ estableciéndose que para emprender los estudios de las enseñanzas principales es necesario cursar el resto del conjunto de enseñanzas accesorias, conforme a un plan de ordenación establecido. Según este planteamiento, los estudios de Piano considerados como enseñanza principal, han de contemplar la instrucción del resto de asignaturas accesorias conforme al esquema del apéndice 5 .

La verificación de los progresos de los alumnos oficiales se realiza conforme a dos tipos de prueba. Un examen con el profesor para pasar de un curso a otro dentro de un misma sección, y otro ejercicio esta vez con tribunal, tanto para acceder a la sección de enseñanzas superiores como para la finalización de los estudios. ${ }^{245}$

\footnotetext{
${ }^{242}$ Ídem, Título I, Capítulo II, art. 4.

243 Ídem, Título I, Capítulo II, art. 6.

${ }^{244}$ Ídem, Título I, Capítulo III, art. 7.

${ }^{245}$ Ídem, Título III, Capítulo IV.
} 
Es cierto que la presente ordenación académica adolece de importantes lagunas reglamentarias. Por ejemplo no tenemos noticia alguna sobre cuántos cursos componen cada una de las enseñanzas accesorias, e incluso como el propio reglamento reconoce en su artículo número 13, existen estudios preparatorios que no aparecen comprendidos en la presente organización, tal vez por esta razón, no encontremos mención alguna a los estudios de acompañamiento dentro del plan de estudios contemplado para la especialidad de Piano. Sin embargo, este vacío pedagógico se ve compensado casi de soslayo por razón de la penúltima de las disposiciones transitorias contenidas en el documento, una referencia de incuestionable valor para nuestro análisis, consistente en la agrupación de todas las programaciones del conservatorio en una sola obra pedagógica con la finalidad de que aparezcan reflejados los cursos y conocimientos a trabajar de cada una de las materias que conforman el plan de estudios:

"7. a Durante el próximo curso y antes de que termine el mes de Mayo, se revisarán los programas de todas las enseñanzas del Conservatorio, para que dentro de un solo tipo de unidad didáctica se especifiquen en cada asignatura y cada año los conocimientos que cada curso comprende, las obras cuyo estudio es obligatorio y las demás que el alumno puede estudiar, ó” (sic) "el Profesor elegir, según las condiciones del discípulo y lo que exija su disposición especial". ${ }^{246}$

Finalizamos aquí nuestro repaso por este singular documento, símbolo de la nueva transformación que estaban sufriendo las enseñanzas musicales durante este período. La organización de las enseñanzas de 1911 representan un hito que establece los lazos de conexión pertinentes entre los reglamentos aparecidos hasta entonces y los futuros planes de estudios musicales que surgirán durante la segunda mitad del siglo XX.

El 30 de agosto de 1917 se publicaba en la Gaceta de Madrid el Reglamento para el gobierno y régimen del Real Conservatorio de Música Decla-

${ }^{246}$ Ídem, p. 701, Disposición transitoria $7^{\mathrm{a}}$. 
mación. ${ }^{247}$ Mediante Real Decreto de 25 de agosto, Alfonso XIII daba vía libre al proyecto de reforma del Conservatorio propuesto por el Ministro de Instrucción Pública y Bellas Artes, Rafael Andrade y Navarrete (1855-1928). Corren tiempos difíciles para la estabilidad política española, en los que Eduardo Dato Iradier (1856 1921), presidente del gobierno en este instante, tuvo que aceptar las condiciones estatutarias de las recién nacidas Juntas de Defensa, movimiento castrense surgido a finales de 1916, que se enfrentaba a no pocos sectores parlamentarios y que acrecentó la tensión creada por la huelga general sindicalista. Era el final de los partidos liberal y conservador, y la política española había perdido el norte buscando en la dictadura de Primo de Rivera la solución al conflicto.

En medio de este oscurecido horizonte aparece el reglamento de 1917 repitiendo prácticamente el mismo esquema y contenidos que su predecesor. No obstante, el nuevo texto contiene valiosas sorpresas. De entre todas ellas pasamos a continuación a examinar las más relevantes. Es en la exposición de motivos llevada a cabo por el ministerio donde localizamos la primera novedad:

"SEÑOR: La organización actual del Real Conservatorio de Música y Declamación fue á" (sic) "no dudarlo, un paso seguro en el camino de su desenvolvimiento pedagógico, orientado á" (sic) "crear verdaderos artistas dentro de las tendencias modernas, pero la obra quedó incompleta y por ende defectuosa, por no llegar hasta una consecuencia necesaria, que lógicamente se impone cuando integran una entidad elementos diversos: la especialización.

Debiese esta omisión de concepto, en la parte musical, á” (sic) "no tenerse en cuenta las tres tendencias que en el Conservatorio se manifiestan, de una manera precisa entre los que allí acuden en busca de la educación especial y que responden á" (sic) "la diferencia de los temperamentos artísticos que impulsados por el mismo propósito no se sienten impeli-

247 “Real Decreto aprobando el Reglamento para el gobierno y régimen del Real Conservatorio de Música y Declamación”, Gaceta de Madrid, 30 de agosto de 1917, no 242. 
dos á" (sic) "conseguirlo por idénticos medios. Esas tres tendencias, claramente delimitadas en la práctica, son las de Maestro compositor, Cantor é" (sic) "Instrumentista. A formarlos con entera independencia y propio carácter tiende el Reglamento que ahora se eleva á" (sic) "la alta consideración de Vuestra Majestad". 248

Con la nueva clasificación de las enseñanzas musicales en Compositores, Cantantes e Instrumentistas, estamos asistiendo a la aparición de las asignaturas instrumentales como nueva área de especialización musical. Pero veamos detenidamente el modo en el que se desarrolló esta idea dentro del Reglamento del Conservatorio.

Al igual que la ordenación de 1911, el actual Reglamento en su segundo artículo, apartado e), vuelve a enumerar entre sus principales tareas el cuidado y correcto funcionamiento del resto de conservatorios y escuelas de Música oficiales para introducir a continuación, en los capítulos II y III, la ordenación de las enseñanzas ofrecidas en el Conservatorio.

Los artículos $4^{\circ}$ y $5^{\circ}$ del segundo capítulo son los encargados de mostrarnos los nuevos cambios acontecidos. Las enseñanzas del Conservatorio se siguen dividiendo en dos Secciones, Música y Declamación, pero la primera de ellas, se subdividirá en enseñanzas de Compositores, de Instrumentistas y de Cantores, especificando por último que la enseñanza de Piano y Violín se separarán ambas en elemental y superior, comprendiendo cinco cursos la primera y tres la segunda.

El artículo quinto nos explica cuáles serán las asignaturas de cada una de las tres nuevas clasificaciones, decretando lo siguiente para las enseñanzas instrumentales:

"La carrera de Instrumentista comprenderá las enseñanzas siguientes:

Solfeo y Teoría de la Música, Curso compendiado de Harmonía" (sic) "Música de salón, conjunto vocal é" (sic) “ins-

${ }^{248}$ Ibidem. 
trumental Historia de la Música y especialmente de la española y Estética, y la enseñanza completa del instrumento correspondiente". ${ }^{449}$

Mucho menos transparente se nos muestra el Capítulo III, en el que se plantean la organización y distribución de las enseñanzas. El artículo 6, el único que posee el capítulo, va descifrando paulatinamente el plan trazado para la obtención de los distintos títulos académicos. Sin embargo, al finalizar el capítulo quedan todavía algunos cabos sueltos. Por ejemplo, faltan por organizar las asignaturas de Conjunto vocal y Música de salón en el planteamiento general de la carrera de Piano, mientras que el grado superior de la misma aguarda dos cursos de Acompañamiento que no aparecían en las materias contempladas para los estudios de Instrumentista. Detalles subsanables, que traslucen en cualquier caso, la falta de unión y remate final emanados del documento.

En relación con el avance y progreso de las programaciones, el reglamento no aporta ninguna reforma innovadora al respecto. Se remite a ellas en los artículos 77 y 79 como instrumento de consulta para orientar a los alumnos libres en sus exámenes. Con este último tanteo al reglamento de 1917 finaliza también nuestra revisión a los estatutos elaborados durante la Restauración borbónica.

Proclamada la Segunda República, se funda durante el bienio reformador (1931-1933) la Junta Nacional de Música. ${ }^{250}$ Ésta tenía como misión crear y administrar entre otros organismos públicos, las Escuelas nacionales de Música, estableciendo por Decreto de 3 de febrero de 1932 un Plan general de enseñanza ${ }^{251}$ en el que el Conservatorio de Madrid tendría que ser transformado en una Es-

\footnotetext{
${ }^{249}$ Ibidem.
}

250 "Decreto creando la Junta Nacional de la Música y Teatros líricos", en Gaceta de Madrid, 22 de julio de 1931, nº 203.

251 “Decreto disponiendo que la Junta Nacional de Música y Teatros líricos formule un Plan general de enseñanza, con el fin de transformar los Conservatorios y Escuelas actuales que se juzguen convenientes en Escuelas Nacionales de Música, vinculando su función a la del Conservatorio Nacional de Madrid, que se transformará asimismo en Escuela Superior de Música”, en Gaceta de Madrid, 4 de febrero de 1932, nº 35. 
cuela Superior de Música. Por otra parte, en noviembre del mismo año se propone una reforma del reglamento del Conservatorio $\mathrm{Na}$ cional de Música y Declamación, a lo que la Junta Nacional responde con una negativa dada la inminente reestructuración de los estudios musicales que se está preparando para toda España. ${ }^{252}$ Presenciamos por tanto, una interesante trama por encumbrar las enseñanzas musicales al más alto rango académico, pero con planes e intereses bien distintos y enfrentados. ${ }^{253}$ Finalmente, el asunto quedaría en agua de borrajas; los sucesos sociopolíticos se precipitan y el estallido del conflicto bélico zanjaba un capítulo en el que se pierde, según algunos autores, ${ }^{254}$ una nueva oportunidad de incorporar los conservatorios de Música en el régimen de las enseñanzas superiores.

Del Reglamento de 1917 pasaremos por tanto a la organización de los conservatorios efectuada en 1942. Un cuarto de siglo de sequía reglamentaria en materia musical en el que la Segunda República no tuvo ocasión de materializar ninguna reforma legislativa profunda y en el que se confirma el dramático trance sufrido posteriormente por España a lo largo de todo este tiempo.

\subsection{Restauración y Segunda República, dos programaciones análogas en mundos opuestos}

No podemos concluir el presente capítulo sin verificar el estado y evolución de las programaciones de Piano durante este ciclo histórico. Dos Programaciones Oficiales para Piano, pertenecientes cada una de ellas a los períodos de la Restauración y la segunda República, nos servirán de prueba para resolver esta interesante

252 "Orden resolviendo el expediente incoado sobre modificación del Reglamento del Conservatorio Nacional de Música y Declamación", en Gaceta de Madrid, 29 de noviembre de 1932, nº 334.

${ }^{253}$ Para una visión más completa sobre el tema recomendamos la lectura de Delgado García, Fernando: Los Gobiernos de España y la Formación del Músico (1812-1956), Sevilla, Servicio de Publicaciones de la Universitat de Sevilla, 2003, (microficha).

${ }^{254}$ Sopeña IBÁÑEZ, Federico, op.cit., p. 151. 
cuestión. Ninguno de los dos ejemplos muestra fecha alguna capaz de ofrecernos una evidencia de su localización exacta en el tiempo. Sin embargo, como veremos a continuación, gracias a la información contenida en el propio documento podemos llegar a relacionarlas con las etapas señaladas en este capítulo.

El primero de ellos trae rotulado en su primera página el título de Programa oficial de la Enseñanza de Piano adoptado en el Conservatorio de Música y Declamación. ${ }^{255}$

La denominación de "Conservatorio de Música y Declamación" surge por vez primera en el reglamento de 1901 y estuvo vigente hasta la reorganización de 1911, a partir de la cual, el establecimiento aparece en las distintas resoluciones administrativas de la época, nombrado indistintamente como "Conservatorio de Música" o "Real Conservatorio" para acabar adoptando esta última designación en el Reglamento de 1917. El programa presenta ocho cursos para las enseñanzas de piano, esquema que aparece por primera vez en una ordenación reglamentaria en la organización de 11 de septiembre de 1911. No obstante, esta división de los estudios pianísticos en 8 cursos había sido ya emprendida con anterioridad a la aparición del Reglamento de 1911. En efecto, al leer con atención el título que aparece en los Métodos de piano editados por la Sociedad Didáctico-Musical, observamos lo siguiente:

"Escuela elemental de piano. Dividida en cinco volúmenes, correspondientes a los cinco años de dicha enseñanza.- Volumen de tercer año, por la Sociedad Didáctico-Musical"'. ${ }^{256}$

Si además repasamos con detenimiento la portada de cualquiera de los volúmenes reeditados a lo largo de su dilatada vida editorial, podremos encontrar una interesante información:

${ }^{255}$ Programa oficial de la Enseñanza de Piano adoptado en el Conservatorio de Música y Declamación. Ofrecido por la casa Antonio Matamala editor y almacenista de Música, s.d., Archivo Histórico del Real Conservatorio Superior de Música de Madrid, Doc. Bca. $C^{o} 2(6, b)$.

${ }^{256}$ Citado en IgLeSIAs MARTíneZ, Nieves (dir.): La música en el Boletín de la Propiedad Intelectual, 1847-1915, Madrid, Ministerio de Educación y Cultura; Biblioteca Nacional, 1997, p. 384. 
"Ajustada al programa de $1^{\circ}$ de octubre de 1903, del Real Conservatorio de Música y Declamación de Madrid”. ${ }^{257}$

El Conservatorio llevó a cabo una programación de las enseñanzas en octubre de 1903, donde se establecieron los cinco cursos de grado elemental y los tres de grado superior para los estudios de piano, esquema que adoptaría el Método de la Sociedad DidácticoMusical, pero que no vería la luz en forma de estatuto oficial hasta la reorganización de 1911.

En conclusión, todas estas averiguaciones nos permite ubicar el Programa oficial de la Enseñanza de Piano adoptado en el Conservatorio de Música y Declamación alrededor del lapso de tiempo que abarca desde 1903 a 1911, situándonos de lleno en plena Restauración borbónica.

El segundo de los documentos lleva por título Programa oficial de la Enseñanza de Piano del Conservatorio Nacional de Música y Declamación. ${ }^{258}$ La designación de "Conservatorio Nacional" no deja lugar a dudas, ya que se trata de la denominación empleada durante la segunda República.

Un rápido análisis comparativo entre ambas programaciones nos lleva a una primera conclusión en la que se demuestra la práctica inexistencia de diferencias substanciales entre ambas. El mismo número de cursos, con el mismo número de obras e idénticos autores.

El esquema de los cursos se dividen en dos partes principales: una con la relación de estudios y obras programadas para el curso, y otra donde se muestra la compilación de ejercicios técnicos suplementarios a realizar. La presentación de esta segunda sección, difiere sensiblemente en ambas programaciones. Mientras en la pri-

257 SOCIEDAD DIDÁCTICO-MUSICAL: Escuela elemental de piano. Dividida en cinco volumenes, correspondientes a los cinco años de dicha enseñanza, Madrid, J. M. Sardá, Pascual González y Eusebio Fernández, 1903.

${ }^{258}$ Programa oficial de la Enseñanza de Piano del Conservatorio Nacional de Música y Declamación, s.d., Archivo Histórico del Real Conservatorio Superior de Música de Madrid. 
mera aparecen los autores y sus ejercicios técnicos: Schmidt, Czerny, Hanon o Kullak, en la programación perteneciente a la etapa republicana aparece el apartado encabezado con el epígrafe de "Medios auxiliares de mecanismo", ${ }^{259}$ sugiriendo los diferentes ejercicios técnicos a efectuar cada año, e indicando la obra de texto donde podemos encontrarlos. En verdad, y esta es una de las primeras diferencias con las que nos topamos, estos ejercicios y sus autores, lo que han hecho sencillamente es desbancar a los Métodos oficiales de Albéniz, Miró, Aranguren o Mata, presentes en las anteriores programaciones.

A pesar de que en espíritu el esquema de todas ellas sigue siendo el mismo, se distinguen diferencias todavía más evidentes entre estas programaciones del siglo XX y su antecesora de 1891. El eje central sobre el que gravitan todas ellas son los ejercicios técnicos y los estudios, pero aflora un nuevo semblante en estas últimas que no había aparecido hasta entonces, a saber: la incipiente aparición de obras representativas del repertorio pianístico dentro del cómputo general de ejercicios y estudios propuestos para el curso.

Así por ejemplo, a partir del quinto año encontramos programadas tres piezas que suelen consistir en: un solo de concierto; un primer tiempo de Sonata y una pieza romántica. A veces aparece el solo de concierto, reemplazado por otro primer tiempo de Sonata. Este nuevo semblante es decisivo, ya que gracias a él, hacen su aparición en los estudios pianísticos autores como Schumann, Beethoven o Liszt.

Evidentemente, aunque queda todavía un largo recorrido por hacer, estas particularidades mostradas añaden nuevos aires a la programación de Piano, fruto de la progresiva ordenación académica realizada durante este período. El aumento de un nuevo año prolongando los estudios de piano hasta el $8^{\circ}$ curso, y la nueva subdivisión en dos grados, elemental y superior, son algunos ejemplos demostrativos del incesante afán renovador que requieren las enseñanzas musicales.

${ }^{259}$ Ibidem. 


\section{4}

\section{La ordenación académica de los conservatorios de Música durante el régimen franquista}

\subsection{La nueva ordenación académica de los conservatorios de}

Música: la organización de 1942 y la reglamentación de 1966

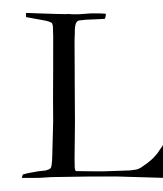

A CAÍDA DEL GOBIERNO de Manuel Azaña el 8 de septiembre de 1932 ponía punto y final al bienio reformador de la segunda República. El 19 de noviembre del siguiente año, tras la disolución de las Cortes, se convocaron elecciones generales. Las primeras en las que la mujer tenía derecho a voto. Las urnas dieron una clara victoria a la derecha, encabezando el nuevo gobierno Alejandro Lerroux (1864-1949). Comenzaba así el bienio negro de la república. El nuevo gobierno alimentó la sublevación izquierdista de octubre de 1934, que junto a la aprobación de Ley de Amnistía y las huelgas convocadas por C.N.T. y U.G.T., provocaría el estado de guerra en todo el país, practicándose una dura represión militar contra los insurrectos. La gravedad del conflicto provocó el final del bienio radical-cedista y la dimisión de Lerroux, 
disolviéndose las Cortes por segunda vez durante la República, y convocando nuevamente elecciones generales el 16 de febrero de 1936. La victoria recaería esta vez sobre el Frente Popular, y Azaña sería el encargado de formar nuevo gobierno, pasando posteriormente a responsabilizarse de la presidencia de la República.

A pesar del nuevo cambio de signo la situación es irreconciliable. Los partidos se encuentran totalmente fragmentados, constituyendo una compleja red de agrupaciones que imposibilitan el encuentro entre las distintas fuerzas políticas. El golpe militar del General Franco, el 18 de julio de 1936, da origen a la Guerra Civil española.

Probablemente el conflicto bélico no se habría dilatado tanto en el tiempo si éste no se hubiese internacionalizado. A pesar de la creación en Londres del Comité de No Intervención, al que se adhirieron Francia, Gran Bretaña, la Unión soviética, Italia y Alemania entre otros países, los apoyos a ambos bandos no se hizo esperar, evidenciando la total inoperancia de los controles del Comité. El 28 de marzo de 1939, Franco entra en Madrid, sin hallar resistencia alguna. Entre los asesinatos de José Castillo y Calvo Sotelo durante la República, y la firma del fin de la guerra el 1 de abril de 1939, queda la terrible impronta del trauma bélico, tres años de cruenta lucha que darían paso al régimen dictatorial del general Franco.

El régimen franquista vivió dos etapas claramente diferenciadas. Un primer período (1939-1959) netamente marcado por la posguerra: crisis económica y reconstrucción del país, ostracismo político internacional, clima social represivo acentuado por las continuas ejecuciones, encarcelamientos y depuraciones, nulo crecimiento económico debido a una política equivocada basada en la autarquía, lo que implica la concentración del capital en el sector público limitando al máximo las exportaciones.

La segunda etapa del régimen (1860-1975), se caracterizó principalmente por el despegue económico del país, gracias al éxito cosechado por el Plan de Estabilización económica (1959) y los Planes de Desarrollo (1964-1975). A este repentino despegue económico habría que añadir los tímidos y paulatinos escarceos aperturistas que cristalizarían con la admisión de España en 1955 en el seno de 
la ONU. No obstante, habrá que esperar a la desaparición del régimen dictatorial y el advenimiento del sistema democrático para ver la incorporación definitiva del país en el conjunto de la comunidad internacional.

Al amparo de estos dos períodos, se concentra el desarrollo de toda una legislación educativa que define por sí misma el estado sociopolítico del momento. Durante la primera etapa se promulgan los siguientes estatutos: la Ley sobre ordenación de la Universidad espanola; ${ }^{260}$ Ley sobre Educación Primaria, ${ }^{261}$ y la Ley de Bases de Enseñanza Media y Profesional, ${ }^{262}$ reforma educativa realizada bajo la inspección técnica del Ministro de Educación Nacional, José Ibáñez Martín (1898-1969). El nuevo gabinete compuesto el 18 de julio de 1951, el cuarto durante el gobierno de Franco, daría muestras de los primeros desequilibrios manifestados por el sistema, atrayendo sobre sí los presagios de aperturismo. Ocupa el Ministerio de Educación Nacional Joaquín Ruiz-Giménez Cortés (1913-2009). Durante su dirección al frente de la administración educativa se dicta la Ley sobre Ordenación de la Enseñanza Media, ${ }^{263}$ que reforma la normativa que sobre el mismo nivel de enseñanza se había desarrollado el 20 de septiembre de $1938,{ }^{264}$ en plena guerra civil, y la Ley de 20 de julio de 1955 sobre «Formación Profesional Industrial». ${ }^{265}$

Las últimas reglamentaciones estatutarias más destacables en materia educativa serían la Ley sobre ordenación de las enseñanzas técnicas ${ }^{266}$

${ }^{260}$ Ley de 29 de junio de 1943, sobre ordenación de la Universidad española (B.O.E. de 31 de julio).

${ }^{261}$ Ley de 17 de julio de 1945, sobre Educación Primaria (B.O.E. de 18 de julio).

${ }^{262}$ Ley de 16 de julio de 1949 de Bases de Enseñanza Media y Profesional (B.O.E. de 17 de julio).

${ }^{263}$ Ley de 26 de febrero de 1953 sobre Ordenación de la Enseñanza Media (B.O.E. de 27 de febrero).

${ }^{264}$ Ley Reguladora de los estudios del Bachillerato (B.O.E. de 23 de septiembre de 1838)

${ }^{265}$ Ley de 20 de julio de 1955 sobre «Formación Profesional Industrial» (B.O.E. de 21 de julio).

${ }^{266}$ Ley de 20 de julio de 1957 sobre ordenación de las enseñanzas técnicas (B.O.E. de 22 de julio) 
durante el ministerio de Jesús Rubio García-Mina (1908-1976), y la Ley 14/1970, de 4 de agosto, General de Educación y Financiamiento de La Reforma Educativa, ${ }^{267}$ también conocida como "Ley Villar", ${ }^{268}$ símbolo representativo de la expansión económica y el acentuado cambio general experimentado en la sociedad española del momento. En verdad la Ley de educación de 1970 nace con el objetivo de solucionar las disonancias de índole pedagógica, administrativa y social existentes, justificando una reforma que diese respuesta a los nuevos interrogantes planteados por la ciudadanía.

Asociadas al mundo musical y su ordenación académica, localizamos el Decreto de 15 de junio de 1942 sobre organización de los Conservatorios de Música y Declamación, ${ }^{269}$ y el Decreto 2618/1966, de 10 de septiembre sobre Reglamentación general de los Conservatorios de Música, ${ }^{270}$ dos estatutos que como muy bien dejan ver sus fechas de aparición, se hallan enmarcados cada uno de ellos en diferentes períodos del régimen franquista. A caballo entre ambos, surge el Decreto de 14 de marzo de 1952 por el que se separan las enseñanzas de Música y Declamación de los actuales Conservatorios, ${ }^{271}$ resolución que como su propio nombre revela, separaría las enseñanzas de una y otra sección, apareciendo en el panorama de las enseñanzas artísticas las Escuelas de Arte Dramático. En honor a la verdad, la separación de ambas disciplinas sobre el terreno sólo se llevó a cabo en la comunidad de

267 Ley 14/1970, de 4 de Agosto, General de Educación y Financiamiento de la Reforma Educativa (B.O.E. de 6 de agosto).

268 Manuel Lora-Tamayo Martín (1904-2002), fue relevado de su cartera en el Ministerio de Educación, el 18 de abril de 1968, por el valenciano José Luís Villar Palasí (1922-2012), impulsor de la reforma educativa de 1970, que culminó con la Ley de 4 de agosto.

${ }^{269}$ Decreto de 15 de junio de 1942 sobre organización de los Conservatorios de Música y Declamación (B.O.E. de 4 de julio)

${ }^{270}$ Decreto 2618/1966, de 10 de septiembre, sobre Reglamentación general de los Conservatorios de Música (B.O.E. de 24 de octubre).

${ }^{271}$ Decreto de 14 de marzo de 1952 por el que se separan las enseñazas de Música y Declamación de los actuales Conservatorios (B.O.E. de 1 de abril). 
Madrid, y hubo que esperar hasta los años ochenta para asistir a la ejecución del plan en el resto de los conservatorios. ${ }^{272}$

El Decreto de 15 de junio de 1942, refrendado por José Ibáñez Martín, Ministro de Educación Nacional al que ya nos hemos referido con anterioridad, nos proporciona en el preámbulo una muestra del ideal educativo adoptado en este período para las enseñanzas de música en los conservatorios:

"Es preocupación primordial del Gobierno el resurgimiento de la cultura y del arte patrios y la educación de la sensibilidad pública con una sólida formación espiritual y artística, mediante una enseñanza bien organizada. Para contribuir a tales fines es preciso abordar de una vez y a fondo el problema de la educación musical, del arte dramático y de las danzas artísticas y folklóricas, tal como en los Conservatorios oficiales ha de plantearse.

Estas enseñanzas no han tenido en nuestra Patria, a pesar de laudables intentos, un plan orgánico, eficaz y bien determinado. El único Centro docente regulado por el Estado fue el Real Conservatorio de Madrid, por el que desfilaron las personalidades más gloriosas entre los músicos y actores españoles. Surgieron después en varias provincias, por iniciativa privada las más de las veces, Centros de enseñanza musical y de declamación que, si bien obedecían a un buen deseo, no se hallaban debidamente fiscalizados por el Estado ni siguieron en sus planes aquellas normas de orientación obligadas en establecimientos de esta naturaleza". ${ }^{273}$

La regulación académica deja entrever sus propias limitaciones, ${ }^{274}$ quedando a merced de las posibilidades reales del presupuesto ge-

${ }^{272}$ Pérez Gutiérrez, Mariano: "Los Conservatorios Españoles. Historia, reglamentaciones, planes de estudio, centros, profesorado y alumnado" en Música y Educación, no 15, Madrid, Musicalis, 1993, p. 43.

${ }^{273}$ Decreto de 15 de junio de 1942, ...(B.O.E. de 4 de julio)

274 "DISPOSICIONES TRANSITORIAS. Primera.- Las enseñanzas de los Conservatorios se acomodarán al plan fijado en este Decreto, a medida que lo permitan las dotaciones del Presupuesto, utilizándose, para implantar de 
neral. En efecto, la ordenación es el punto de partida para sucesivas reestructuraciones, de ahí que se nos descubra, desde el punto de vista curricular, insuficiente, escaso y deshilachado, no sabiendo cuántas asignaturas conforman cada especialidad ni el plan organizativo de las mismas. $Y$ es que nos encontramos frente a un texto de apenas tres páginas y 15 artículos, más las disposiciones transitorias.

Pese a todo, el Decreto prevé cambios significativos. Encontramos por primera vez la clasificación de los conservatorios en Elementales, Profesionales y Superiores, ${ }^{275}$ dando un nuevo paso en el reconocimiento oficial de las Enseñanzas Artísticas Superiores (EEAASS) después del malogrado intento ensayado durante la segunda República. Esta clasificación tiene repercusiones directas en los estudios de piano, ya que el conjunto de enseñanzas encuadradas dentro de este último nivel superior, les atañe directamente:

"Cursos superiores de último grado. Virtuosismo del piano. Virtuosismo del violín. Dirección de Orquesta. Musicología. Canto gregoriano. Rítmica y Paleografía. Dirección, realización y presentación teatral". 276

El Decreto no especifica en qué consisten estas enseñanzas superiores de piano, aunque sí señala que deberán estar impartidas por Catedráticos numerarios. Las primeras noticias que encontramos sobre estos nuevos estudios es a través de una Orden emitida en 1943, por la que el pianista y profesor del Conservatorio de Madrid, José Cubiles Ramos pasa a desempeñar estas enseñanzas:

"Ilmo. Sr: Vista la instancia suscrita por el Profesor numerario del Real Conservatorio de Música y Declamación de Madrid don Antonio José Cubiles Ramos, en la que solicita ser nombrado Profesor numerario de «Virtuosismo del Piano» en el expresado Centro docente, y teniendo en cuenta las cir-

un modo inmediato las reformas más urgentes, los créditos consignados en el actual que figuren sujetos a reorganización." (Ibidem).

275 Ídem, art. 1.

276 Ídem, art. 3. 
cunstancias personales y artísticas que concurren en el solicitante.

Este Ministerio, de acuerdo con lo informado por el Director del Centro, ha tenido a bien disponer que el Profesor numerario de «Piano» del Real Conservatorio de Música y Declamación de Madrid don Antonio José Cubiles Ramos pase a explicar la enseñanzas de «Virtuosismo del Piano» en el citado Real Conservatorio, conservando el carácter de Profesor numerario y haciéndose constar esta modificación por medio de diligencia en el título administrativo del interesado". ${ }^{277}$

Los primeros laureados de la nueva enseñanza no tardan en aparecer, Antonio Iglesias y Rafael Vázquez, obtienen sus preciados galardones en $1945 .^{278}$

Se aplica por tanto en los conservatorios, dentro del límite de las posibilidades económicas y sociales del país, la organización académica de 1942, proyecto que aprovechó como plataforma su sucesor en el tiempo, el popular "Plan del 66".

Durante el séptimo gobierno de Franco comprendido entre los años 1965 y 1969, aparece la segunda de las reglamentaciones efectuada sobre los conservatorios, coincidiendo con el avance del I Plan de Desarrollo aprobado en diciembre de $1963 .{ }^{279}$ Corren otros tiempos diferentes a los años cuarenta, respaldados principalmente por el desarrollo económico y el progresivo aperturismo social. Manuel Lora Tamayo (1904-2002) es el nuevo ministro de Educación y Ciencia, cargo que desempeñó desde julio de 1962 hasta abril de 1968, siendo consecuentemente el encargado de dar luz verde a la nueva organización de los conservatorios.

${ }^{277}$ Orden de 2 de julio de 1943 por la que se dispone que don Antonio José Cubiles Ramos, Profesor numerario del Real Conservatorio de Música y Declamación de Madrid pase a explicar las enseñanzas de "Virtuosismo del Piano», en dicho Centro (B.O.E. de 21 de julio).

${ }^{278}$ SOPEÑA IBÁÑEZ, Federico, op, cit., p. 255.

${ }^{279}$ Ley 194/1963, de 28 de diciembre, por la que se aprueba el Plan de Desarrollo Económico y Social para el periodo 1964/1967 y se dictan normas relativas a su ejecución (B.O.E. de 31 de diciembre). 
Comienza el Decreto 2618/1966 de 10 de septiembre, advirtiéndonos en su exposición que la actual organización es la suma del Plan y reforma de 1942 y 1952 respectivamente, actualizados según las "modernas orientaciones" en materia de educación musical:

"En los propios textos de ambos Decretos se reconoce su carácter de punto de partida para una futura y general reorganización de los conservatorios, que es la que ahora se trata de conseguir, reduciendo a un texto único las disposiciones vigentes en esta materia, a la vez que se regulan aspectos nuevos de acuerdo con los dictados de la experiencia acumulada, en la aplicación de la reglamentación actual, en la que se habían revelado lagunas y deficiencias, y en armonía asimismo con las modernas orientaciones en la organización de las enseñanzas de Música". 280

Según nos informa el Decreto, estas orientaciones se han realizado conforme a los planes de estudio existentes en otros países y Conservatorios extranjeros, sin embargo y a pesar de las novedades perceptibles, muchas de las "lagunas" y "deficiencias" continuaron después de su aprobación. ${ }^{281}$

280 Decreto 2618/1966, de 10 de septiembre, sobre Reglamentación general de los Conservatorios de Música (B.O.E. de 24 de octubre).

${ }^{281}$ El Reglamento, según algunos autores, no cumplió al parecer con las expectativas previstas: "La Reglamentación General de los Conservatorios de Música de 1966, que intentó ampliar la organización del decreto de 1942, nace lamentablemente maltrecha desde sus orígenes. Me explico: El Ministerio de Educación y Ciencia convocó a todos los directores de los Conservatorios de España para que en varias sesiones elaborasen unieran criterios tendentes a elaborar un reglamento de todas las enseñanzas musicales que sería el resultado del balance de unos criterios puestos a debate y lograr unas conclusiones prácticas" [...] "Concluido el trabajo aparece en el Boletín Oficial del Estado del 24 de octubre el Decreto 218/1966 con el título Reglamento general de los Conservatorios de Música pero oh! sorpresa, la publicación de aquel órgano oficial es un engendro del reglamento nada parecido a lo redactado en aquellas sesiones." (BLANES ARQUÉS, Luís: Discurso de investidura...). 
También se hace hincapié en que el nuevo reglamento contempla los cursos y planteamiento a seguir para cada una de las especialidades:

"Se determinan los cursos que comprenden las diversas enseñanzas de los Conservatorios, así como los estudios previos necesarios para la admisión de matrícula en cada una de aquéllas". 282

Volvemos por tanto al esquema planteado por los reglamentos de 1911 y 1917, aunque mejor acabado. En efecto, el capítulo II presenta las enseñanzas impartidas en los conservatorios y su nueva clasificación. Los estudios se dividen en cursos y éstos a su vez, en grados: elemental, medio y superior. ${ }^{283}$ A raíz de este diseño los estudios de piano quedaron configurados del siguiente modo: cuatro cursos para grado elemental; cuatro para grado medio; y dos para el grado superior, sumando un total de diez años como mínimo para cursar los estudios pianísticos al completo.

El artículo séptimo describe el modo en el que han de cursarse las distintas asignaturas, siempre y cuando se tengan en cuenta ciertos requisitos. Este tipo de planteamiento académico se erige como una de las cuestiones más originales y representativas del plan de 1966. El área de autonomía proporcionada por la libre elección de matrícula en las asignaturas a estudiar para cada año, cedía al alumno la oportunidad de ordenar y confeccionar, dentro de los límites establecidos, su propio diseño educativo, aspecto metodológico que desentonaría drásticamente con el modelo curricular propuesto en la LOGSE.

Perteneciente a la cuestión de las programaciones, el artículo veintitrés presenta la siguiente indicación:

"Artículo veintitrés. - Uno. Los programas de los exámenes que constituyan el final del grado o asignatura serán iguales en todos los conservatorios y determinados por orden mi-

${ }^{282}$ Decreto 2618/1966, ...(B.O.E. de 24 de octubre).

${ }^{283}$ Ídem, Capítulo II, art. 5. 
nisterial. Los cambios de programa deberán ser publicados antes de empezar el curso académico.

Dos. Los demás programas, tanto de estudios como de examen, serán determinados por el director de cada conservatorio, de acuerdo con el claustro o con las juntas que designe a tal efecto". ${ }^{284}$

El primer apartado del artículo responde al mismo espíritu que presentaban los Métodos oficiales en el siglo pasado, pero en su versión actualizada, buscando esta vez la unificación de criterios en los exámenes de final de grado. Con la intención de desempeñar este propósito, aparece la Orden de 21 de junio de 1968 por la que se dispone la publicación del Reglamento para los exámenes de Grado en los Conservatorios de Música oficiales y se aprueban los programas de cada especialidad. $^{285}$

Podemos ver el plan de estudios en el apéndice 6.

La Orden se compone de dos anexos precedida de una breve exposición. El primero de ellos consiste en el Reglamento para los exámenes de Grado de los Conservatorios de Música oficiales, ${ }^{286}$ mediante el cual se dictan las instrucciones generales que han de contemplarse para el correcto desarrollo de los exámenes de fin de grado o asignatura.

Las instrucciones más estrechamente relacionadas con las especialidades instrumentales las encontramos en los apartados cuatro, cinco y catorce:

“4. Dos, por lo menos, de las composiciones correspondientes al último curso de un instrumento y todas las que correspondan a Canto serán interpretadas de memoria. Estas últi-

\footnotetext{
${ }^{284}$ Ídem, Capítulo IV, art. 23.

285 Orden de 21 de junio de 1968 por la que se dispone la publicación del Reglamento para los exámenes de Grado en los Conservatorios de Música oficiales y se aprueban los programas de cada especialidad (B.O.E. de 27 de septiembre).

${ }^{286}$ Ibidem.
} 
mas, además en su idioma original, cuando se trate del castellano, francés, italiano, alemán o inglés.

5. En el acto el examen de Canto o de un instrumento se ejecutará íntegra una obra de cada apartado, salvo cuando la composición conste de varios tiempos o partes, caso en que podrán omitirse los que decida el Tribunal. La obra se determinará a la suerte, siempre que en el apartado figuren varias. $[\ldots]$

14. Tanto los «Estudios» que figuran en la mayoría de programas instrumentales, como las «Lecciones» de práctica solfística pertenecientes a libros de texto integradas en el programa de Solfeo y Teoría de la Música, serán seleccionadas en Junta de Profesores, de la cual se levantará acta. La selección no podrá ser idéntica en dos convocatorias de examen inmediatas ni dada a conocer hasta que sea hecha pública en la tablilla del Conservatorio, lo cual deberá ser antes de abrirse la matrícula, salvo en aquellos Conservatorios que prefieran demorarlo hasta dos mese previos al periodo de exámenes, en cuyo caso, lo mismo el número de «Estudios» que de «Lecciones», se reducirá a la mitad del que conste en el programa de exámenes". ${ }^{287}$

El anexo II se encuentra publicado separadamente en el Boletín Oficial del Ministerio de Educación y Ciencia de 29 de julio, ${ }^{288}$ y en él se halla la lista de obras del repertorio correspondiente al programa de los exámenes de fin de grado.

${ }^{287}$ Ibidem.

288 Orden de 21 de junio de 1968 por la que se dispone la publicación del Reglamento para los exámenes de Grado en los Conservatorios de Música oficiales y se aprueban los programas de cada especialidad. Anexo II. Programas correspondientes a los exámenes de fin de grado de los conservatorios de Música (B.O.M.E.C. de 29 de julio de 1968). 


\subsection{Un nuevo rumbo en la Programación de Piano: el Reglamento para los exámenes de Grado de 1968}

La Orden de 1968, y en especial el anexo II, es una disposición de inestimable alcance, ya que de un lado sienta las bases sobre las que se desarrollarán las programaciones del resto de los cursos que componen los estudios, a la vez que fija una nueva dirección en el rumbo de las ordenamientos académicos que se originarán a partir de entonces.

Dada la cantidad y calidad de obras maestras que contiene el repertorio pianístico éste irá cobrando protagonismo paulatinamente, desnivelando la balanza que hasta ahora había estado del lado de los ejercicios técnicos y estudios. Las obras irán monopolizando la práctica totalidad de la programación de Piano, hasta el punto de desplazar casi por completo a los ejercicios de mecanismo, del mismo modo que éstos lo habían estado haciendo hasta ahora con las piezas de repertorio. La consigna es clara y se asienta en el hecho de aprehender y desarrollar la técnica pianística a través de las obras, dando origen así a un prototipo de programación basada en el "programa", valga la redundancia. Esto significa que la metodología fundamental adoptada en la práctica pianística gravitará esencialmente alrededor de un repertorio constituido a su vez por un número determinado de obras, que el alumno habrá de interpretar al final del curso académico para conseguir su correspondiente certificado de aptitud. Valorando el hecho de que algunas de las teorías más sobresalientes sobre la técnica pianística ya habían visto la luz hace más de medio siglo, ${ }^{289}$ no deja de traslucir al menos cierta inverosimilitud la circunstancia de que se adopte una metodología tan desnivelada, como consecuencia del especial hincapié efectuado sobre la nueva fórmula aplicada.

Considerando la magnitud de las conclusiones aportadas en el campo teórico, alumbradas y enraizadas siempre, eso sí, en las obras maestras del repertorio pianístico y sus ejecutantes, es ahora

${ }^{289}$ Rudolf Maria Breithaupt, publicó la segunda edición de su Die natürliche Klaviertechnik, en 1905, mientras que Tobias Matthay y su obra teórica The Act of Touch in all its Diversity. An Analysis and Synthesis of Piano-forte Tone-Production, vio la luz en 1903. 
como decimos cuando esta actividad didáctico-especulativa desaparece de la organización educativa, para dar vía preferente al repertorio pianístico, asentado éste primordialmente en la habilidad, destreza, intuición y perspicacia innatas, o no, del alumno. La continua actualización e incorporación de los sucesivos avances y descubrimientos técnicos, es una tarea que no conviene descuidar. ${ }^{290}$

Dirigiendo nuevamente nuestra atención sobre los programas de fin de Grado de 1968, detectamos las siguientes particularidades. $\mathrm{Al}$ igual que sucedía con los Métodos oficiales y las diferentes programaciones que hemos ido presentando, el objetivo primordial de los programas aprobados en el anexo II, reflejado en la Orden de 21 de junio, es el de establecer unos niveles de estandarización en las materias de los cursos de final de grado o de asignatura, iguales para todos los conservatorios. En el caso de la especialidad de Piano se trata de los cursos cuarto, octavo y décimo, correspondientes a los finales de grado elemental, medio y superior, respectivamente. Los tres cursos poseen una estructura bastante afín, cada una con sus correspondientes singularidades y articulada en apartados que responden en mayor o menor medida al siguiente esquema:

1. Ejercicios de mecanismo y estudios.

2. Obras del período barroco (Particularmente de J. S. Bach)

3. Obras del repertorio clásico (Sonatas).

4. Piezas del período romántico.

\footnotetext{
${ }^{290}$ Sobre todo si no se quiere incurrir en el apoltronamiento y anacronismo metodológico: "El defecto de fondo en lo que a enseñanzas de piano se refiere - ya comentaremos los tímidos pero bien dirigidos aspectos de la reforma en las enseñazas del solfeo- defecto examinado por mí largamente y antes por Tomás Andrade y Teresa Alonso, viene de su doble inactualidad: la presencia del «estudio» sobre la «pieza» que aparece como paréntesis y que la misma técnica de los «estudios» supusiera ya, en el momento de salir, un estancamiento, un retraso. Una vez más debemos recordar que el tratado no puede caminar con la lengua afuera detrás de la novedades pero ya puede recoger como «escuela» lo que veinte años antes era novedad" (SOPEÑA IBÁÑEZ, Federico, op, cit., p.156).
} 
5. Obras de estilo contemporáneo.

6. Repertorio de compositores españoles.

7. Conciertos con orquesta.

Si comparamos este nuevo esquema con el programa prescrito durante la segunda República, revisado en el segundo capítulo de nuestro trabajo, evidenciamos rápidamente los transformaciones acaecidas, a saber: aparecen los nuevos apartados de música española y contemporánea, los conciertos con orquesta cobran mayor protagonismo y relieve, encontramos por fin programadas, las sonatas de Beethoven, Haydn y Clementi e incluso en décimo curso, aunque echamos en falta las sonatas de Schubert, descubrimos las de Chopin, Schumann, Liszt y Brahms; a excepción del $4^{\circ}$ curso, los ejercicios técnicos auxiliares prácticamente han desaparecido.

Una de las novedades que más poderosamente llaman la atención en esta nueva clasificación, es el inventario de obras propuestas. El número de obras dispuestas para cada curso ha aumentado considerablemente, en comparación con las programaciones precedentes. No se trata evidentemente de una enumeración exhaustiva del repertorio pianístico. Tampoco es esa su finalidad. Es una herramienta metodológica, no una guía o manual de consulta. Además la enumeración de las obras presentadas deja la puerta abierta a nuevas sugerencias:

"8. Cualquiera de las obras (sea cual sea su clase) citadas en los «programas de examen» - y pruebas prácticas que se hallen en igual caso - podrá ser sustituida por otra de características semejantes que el Conservatorio examinador tenga incluida en sus "programas generales de curso», si éstos las contienen en mayor número que aquéllos y han sido aprobados por la Dirección General de Bellas Artes. En los citados «programas generales de curso» habrán de figurar, concretamente determinadas las obras instrumentales o vocales que en los «programas de examen» se dejan a libre elección sin 
mencionar título ni autor. Ninguna composición podrá figurar en más de un curso". ${ }^{291}$

Pero, ¿hasta qué punto estos programas influyeron verdaderamente en la configuración de las futuras ordenaciones de la programación de Piano? Al fin y al cabo, la Orden de 1968, ¿no presenta unos proyectos encaminados, de manera muy concreta, a los exámenes de final de Grado o asignatura? ¿Qué sucede con el resto de cursos de la especialidad? La mejor manera de responder a estos interrogantes es explorando, una vez más, las programaciones elaboradas durante este período.

El artículo veintitrés del plan de 1966 establecía en su segundo apartado que: "los demás programas, tanto de estudios como de examen, serán determinados por el director de cada conservatorio, de acuerdo con el claustro o con las juntas que designe a tal efecto". ${ }^{292}$ A continuación examinaremos el Programa de la Enseñanza de Piano, ${ }^{293}$ adoptado de modo oficial ${ }^{294}$ en el Real Conservatorio Superior de Música de Madrid, el 1 de octubre de 1973.

${ }^{291}$ Orden de 21 de junio de 1968... (B.O.E. de 27 de septiembre), Anexo I, apartado 8 .

${ }^{292}$ Decreto 2618/1966,... (B.O.E. de 24 de octubre), Capítulo IV, art. 23.

293 Real Conservatorio SuPERIOR DE MúsiCA: Programa de la Enseñanza de Piano vigente desde $1 .^{\circ}$ de octubre de 1973. Archivo Histórico del Real Conservatorio Superior de Música de Madrid.

${ }^{294}$ Hemos consultado dos documentos más en el que se exhibe la misma programación que a continuación presentamos. Uno de ellos está fechado en agosto de 1973, mientras que el otro no presenta inscripción alguna que permita ubicarlo en el tiempo, aunque con toda probabilidad se trata del documento más antiguo, a juzgar por su apariencia y presentación, más rudimentaria, esquemática y menos elaborada que la de los otros dos originales. El texto que hemos elegido para llevar a cabo nuestro análisis, es el último en aparecer y el mejor confeccionado de los tres, circunstancia que nos permite tener una visión más completa, al incorporar las posibles revisiones llevadas a cabo sobre la programación desde que se aplicara el plan de estudios de 1966. 
Comienza el documento con la redacción de nueve "Disposiciones Generales", en las que se presentan las principales pautas acordadas en la elaboración del programa oficial. El apartado número dos muestra las partes de que consta el examen de los diez cursos de los estudios de Piano:

“2. En la programación general de exámenes para los cursos de Piano que se redacta en las páginas siguientes, constan:

a) El programa de las obras a presentar.

b) El número total de las mismas.

c) Forma de examen." 295

Como podemos comprobar, aflora aquí la primera de las particularidades que compondrá el nuevo estilo de la programación pianística. Nos estamos refiriendo al criterio basado en el número de obras. La primera condición indispensable para culminar con éxito el curso académico es la de "montar" un número determinado de obras, que en general son un total de doce piezas, a excepción de tercero y cuarto curso, que se exigen catorce. Así nos lo recuerda convenientemente el apartado número 8:

“8. En el momento del examen cada alumno habrá de presentar una relación, completa y detallada, de las obras y estudios trabajados, correspondientes al curso de que se trate, de acuerdo con el programa oficial". ${ }^{296}$

En el apartado noveno encontramos el esquema propuesto para el desarrollo de los exámenes, basado en la interpretación de tres obras como mínimo de entre todas las presentadas por el aspirante:

“9. La fórmula general de examen consistirá en:

a) Interpretación de la obra obligada.

${ }^{295}$ Real CONSERVATORIO SuPERIOR DE MúsiCA: Programa de la Enseñanza de Piano vigente desde 1. ${ }^{\circ}$ de octubre de 1973, Archivo Histórico del Real Conservatorio Superior de Música de Madrid.

296 Ibidem. 
b) Interpretación de una obra que será sorteada de entre los grupos: contrapuntística o polifónicas, clásicas, románticas, modernas y concierto con orquesta (en los cursos en que exista este último apartado) de la lista presentada por el alumno.

c) Interpretación de una o varias obras (incluido estudios) elegidas por el Tribunal"'. ${ }^{297}$

La elección de la obra obligada a la que se refiere el subapartado a), viene regulada en los párrafos tercero y cuarto de las disposiciones:

"3. Al comienzo de cada curso, durante el mes de octubre, se publicará, en el Real Conservatorio Superior de Música de Madrid, una lista de las obras que serán de obligatoria presentación a examen para todos los alumnos, libres y oficiales, de Plan Antiguo y Plan Moderno, haciéndose constar en el anuncio de las mismas, las sustituciones o permutas que la inclusión de la obra obligada diere lugar.

4. La obra obligada de cada curso será elegida de entre los grupos contrapuntísticas o polifónicas, clásicas, románticas, modernas, conciertos para piano y orquesta (en los cursos en que exista este último apartado) y su elección implicará, según lo expuesto en el párrafo anterior, la eliminación de una obra del grupo correspondiente". ${ }^{298}$

Especialmente interesante se nos revela el séptimo apartado, en el que aparecen los factores que se determinan para la correcta valoración del programa interpretado por los alumnos:

“7. El Tribunal juzgará especialmente, junto a la corrección técnica, la fidelidad del examinado con respecto a las indicaciones que se refieren al aire o «tempo» de cada obra musical, al fraseo, matices y uso del pedal". ${ }^{299}$

\footnotetext{
297 Ibidem.

298 Ibidem.

299 Ibidem.
} 
A tenor de lo expuesto, las evidencias no dejan lugar a dudas. El modelo de programación que se sobrepondrá a partir del nuevo plan de estudios, se cimentará distintivamente sobre un programa establecido de obras para cada curso, confirmando la hipótesis que planteábamos con anterioridad, a raíz de la publicación de la Orden de 21 de julio de 1968. Se consolida de esta manera un modelo de programación en los conservatorios, de fuerte raigambre en el conjunto de las especialidades instrumentales, cuya consistencia ha soportado el paso del tiempo hasta el punto de mantenerse plenamente vigente en nuestros días, encarando los nuevos retos y planteamientos propuestos por los sucesivos avances en materia educativa.

Finalizadas las disposiciones generales, prosiguen a continuación los diversos programas pertenecientes a cada uno de los diez cursos de que constan los estudios de Piano. El programa o repertorio propuesto para cada curso se arregla por apartados semejantes a los que proponíamos en la Orden de 1968, consolidándose así otra de las características distintivas de esta programación inspirada en una fórmula que ya se asomaba de manera tácita en los modelos precedentes de 1911 y 1917, y que responde al siguiente diseño:

1. Obras de Estudio

2. Obras Contrapuntísticas

3. Obras Clásicas

4. Obras Románticas

5. Obras Modernas

6. Obras para Piano y Orquesta (A partir del sexto curso)

En el sexto año apreciamos la aparición del aparatado dedicado al repertorio de obras para piano y orquesta. La recopilación de obras y autores propuestos para cada curso es satisfactoria y queda abierta a la adición de nuevos títulos. La tercera de las secciones dedicadas al período clásico se fundamenta sobre todo en la interpretación completa de alguna de las Sonatas de Haydn, Mozart, Beethoven o Clementi. En el apartado de Obras Modernas se 
puede apreciar a su vez la subdivisión comprendida entre maestros del siglo XX españoles, y el resto de compositores extranjeros. La diferencia más substancial la encontramos en la desaparición de los ejercicios de mecanismo, ocupando su lugar los diferentes estudios programados en el primer apartado para cada curso.

El giro que supone el modelo de programación utilizado en los planes anteriores a la organización de 1942 e incluso durante la vigencia de este mismo, y el nuevo planteamiento concebido por la reglamentación de 1966, es un reflejo sintomático de las diferentes visiones adoptadas en cada período en lo concerniente a la planificación de los estudios de piano. Este hecho viene avalado por una evidencia de trascendental interés. Gracias a un Programa de la enseñanza de Piano, ${ }^{300}$ en el que aparecen reflejados los contenidos de los exámenes privados trimestrales de cada curso, correspondiente a una ordenación académica que podemos situar en la década de los cincuenta, logramos contrastar claramente la evolución sufrida en la programación de la asignatura durante todo este espacio de tiempo.

Como indicamos, en este Programa perteneciente al Real Conservatorio de Madrid, se muestran los programas de examen de cada trimestre para cada uno de los cursos, y lo que define a estos exámenes trimestrales es el estilo de las piezas propuestas para los mismos. En efecto resulta interesante comprobar cómo los dos primeros trimestres aparecen monopolizados por Estudios, acompañados de alguna pieza de J. S. Bach, y solamente al final de tercer trimestre, después de trabajar unos cuantos Estudios más, asoman tímidamente en el programa dependiendo de los cursos, una o dos obras. Qué paisaje tan opuesto al diseño esbozado durante la ordenación de 1966 que acabamos de examinar, en el que las obras del repertorio han desplazado a los estudios técnicos que protragonizaban la programación apenas una década antes.

300 Real CONSERvatorio De MúsiCa: Enseñanza Oficial. Programa de la enseñanza del Piano para los exámenes privados trimestrales que tendrán lugar del 15 al 20 de diciembre, del 15 al 20 de Marzo, y del 25 al 30 de Mayo, s.d., Archivo Histórico del Real Conservatorio Superior de Música de Madrid. 


\subsection{Los conservatorios en la Ley General de Educación de 1970}

No desearíamos finalizar el presente capítulo sin realizar una última observación sobre lo que sin duda fue una nueva oportunidad de adelanto y mejora en la regularización de los estudios musicales de los conservatorios durante el ciclo histórico que hemos desarrollado. Además de las organizaciones de 1942 y 1966, los Conservatorios de Música y sus enseñanzas tuvieron una tercera ocasión para reformar su estructura educativa gracias a la Ley 14/1970, de 4 de agosto, General de Educación y Financiamiento de La Reforma Educativa que estaba llamada a protagonizar un hito significativo en la regulación de las enseñanzas artísticas:

"los cambios en la configuración de la enseñanza de la Música comienzan a suceder con la aparición de la LGE en 1970, aun cuando las transformaciones decisivas deberán esperar a la LOGSE de 1990."301

A pesar de que la Ley preveía en la disposición transitoria segunda, cuarto punto, su incorporación a las enseñanzas universitarias:

"Cuatro. Las escuelas superiores de bellas artes, los conservatorios de música y las escuelas de arte dramático se incorporaran a la educación universitaria en sus tres ciclos, en la forma y con los requisitos que reglamentariamente se establezcan", ${ }^{302}$

el plazo previsto por la Ley para la aplicación de la reforma fue transcurriendo, ${ }^{303}$ y a excepción de las Escuelas de Bellas Artes, ${ }^{304}$

${ }^{301}$ EMbid Irujo, A.: Un siglo de legislación..., p. 90.

302 Ley 14/1970, de 4 de Agosto, General de Educación y Financiamiento de la Reforma Educativa (B.O.E. de 6 de agosto), Disposiciones Transitorias, $2^{\mathrm{a}}-4$.

${ }^{303} \mathrm{El}$ período anunciado se encuentra en las disposiciones transitorias: "El gobierno, a propuesta del Ministerio de Educación y Ciencia, acordara las medidas precisas para la implantación gradual, en el plazo de diez años, de las enseñanzas previstas en esta ley. Esta implantación podrá llevarse a efectos por niveles, etapas, ciclos y cursos de enseñanza, así como zonas territoriales o clases de centros; todo ello en atención a las disponibilidades de pro- 
los Conservatorios y Escuelas de Arte dramático no verían jamás consumado el proyecto:

"Se detuvo la negociación. Pasaron los 10 años que marca la ley, no se aplicaron los contenidos de la disposición y aquella y decisiva voluntad política de integración de los estudios superiores en la Universidad que podía haberse convertido en un hecho histórico resultó ser un espejismo efímero y fugaz". 305

fesorado, locales, dotaciones y demás condiciones que garanticen la eficacia de la educación". (Ídem, Disposiciones Transitorias, 1ª $^{\mathrm{a}}$-1).

${ }^{304}$ Orden de 26 de septiembre de 1979 por la que se aprueba el plan de estudios del primer ciclo de la facultad de bellas artes de la universidad politécnica de valencia (B.O.E. de 23 de octubre de 1979).

305 Blanes Arqués, Luís: Discurso de investidura... Ahondando sobre este mismo aspecto: "Sin embargo, las enseñanzas artísticas en su nivel superior quedan descolgadas de ese proceso de integración porque no se cumplirá lo que claramente indica la disposición transitoria segunda, apartado cuarto, de la LGE" [...] "Efectivamente, en ningún momento aparecerá esta regulación reglamentaria, lo que significa que ningún Gobierno se reclamará heredero del mandato tan claro de la Ley que acabamos de contemplar" (EMBID IRUJO, A.: Un siglo de legislación..., pp. 91-92). 



\section{Transición democrática y reformas del sistema educativo}

\subsection{La Transición y la España democrática}

$\mathrm{H}$

EMOS ALCANZADO CASI EL FINAL de nuestro recorrido histórico a través de la documentación legislativa musical, llegando la hora de abordar nuestra historia más reciente. Si el oráculo délfico "conócete a ti mismo" anima al hombre a indagar sobre su propia naturaleza, una posible manera de ayudar a este conocimiento como sujeto individual y colectivo, como integrante de una sociedad, consistiría en aquello que ya introducíamos al inicio de nuestra labor, cuando hablábamos de conocer y repasar el camino recorrido hasta ahora por aquellos que nos precedieron en nuestro mismo cometido.

Esta excursión comentada, que explora los sucesos musicales normativos más significativos, pretende indagar en el pasado musical para arrojar luz y discernimiento, en lugar de ilusiones fantásticas, reemplazando así interpretaciones apócrifas por argumentos vero- 
símiles y, esperemos que al menos hasta cierto punto también, útiles.

En consonancia con lo expuesto, nos sentimos plenamente identificados con el pensamiento del historiador y sociólogo alemán Max Weber cuando nos recordaba que:

"solo se puede saber lo que somos si se determina cómo hemos llegado a ser lo que somos." "306

Como hemos podido ir comprobando hasta ahora, la historia de la regulación académica musical en general y la de la enseñanza de la especialidad de Piano en particular, se presenta como un interesante recorrido que nos persuade y empuja a su estudio, planteando a su paso una extensa colección de temas a tratar.

La mirada sobre la historia de la acción programadora pianística, entendida ésta como las diferentes pautas y modelos empleados en la regulación académica de la especialidad a lo largo de dos siglos de reglamentación musical, constituye uno de los pilares sobre los que descansaremos para construir y proponer modelos alternativos más adelante. Según reza la antigua expresión de la oratoria escolástica medieval, nuestra revisión compone en definitiva, esos hombros de gigantes sobre los que nos aupamos modestamente como investigadores, para poder otear el horizonte que se proyecta hacia el futuro.

\subsubsection{Transición y Democracia}

Los últimos años del franquismo, caracterizado por la crisis interna en la que se encuentra inmerso el régimen dictatorial, resquebrajaba la escena política dominante sumergiendo al estado Español en un futuro incierto. Se abre una nueva oportunidad histórica para redefinir el cauce político de los acontecimientos, surgiendo dos nuevas

\footnotetext{
${ }^{306}$ La cita la extraemos nosotros concretamente del comentario realizado por el historiador Juan Pablo Fusi, cuyo análisis de la historia española actual nos servirá de referencia a continuación. (FUSI AIZPURUA, Juan Pablo: Historia minima de España, Madrid/Méxio D.F., Turner, 2012, p. 9).
} 
agrupaciones: la Junta democrática de España (JDE), establecida en julio de 1974 y la Plataforma nacional de Convergencia democrática (PCD), creada en junio de 1975, como opciones alternativas democráticas al régimen franquista. ${ }^{307}$ El fallecimiento del General Franco, el 20 de noviembre de 1975, conduciría al nombramiento de Juan Carlos I de Borbón y Borbón como Rey de España. Con la designación del monarca se suceden en el gobierno Carlos Arias Navarro y posteriormente Adolfo Suárez González, aflorando este último como figura clave de la transición española. Entre los hechos más relevantes que jalonan este delicado y frágil proceso se encuentran: la Ley de Reforma Política, estatuto que fue desmontando paulatinamente las estructuras del antiguo régimen, la convocatoria de elecciones democráticas el 15 de junio de 1977, como culminación del anterior proceso de desmantelamiento, y el nacimiento del Estado español como Monarquía parlamentaria, ${ }^{308}$ legitimado por la Constitución Española de 27 de diciembre de 1978, cuyo contenido fue aprobado en referéndum el 6 de diciembre del mismo año.

De manera que la desaparición del régimen dictatorial, dio lugar a uno de los momentos más interesantes y particulares de la historia política española que conocemos como Transición, denominado así por ser el período de tiempo que permitió a España caminar del franquismo a la democracia.

Existen varias circunstancias que definen especialmente a la transición española y la convierten en un período único con su propia especificidad, cuando los especialistas la comparan con las transiciones políticas acaecidas en otros países. No es nuestra misión analizar hondamente los procesos que caracterizaron esta peculiar etapa de la historia actual española, pero sí quisiéramos hacernos

${ }^{307}$ Entre las agrupaciones que conformaron la Junta democrática de España, se encontraban el Partido Comunista de España (PCE), el Partido Socialista Popular (PSP) o el sindicato filocomunista Comisiones Obreras (CC.OO.). Por lo que respecta a la Plataforma de Convergencia democrática, aparecen el Partido Socialista Obrero Español (PSOE) y la Unión General de Trabajadores (UGT), entre otros.

${ }^{308}$ Constitución Española de 27 de diciembre de 1978 (B.O.E. de 29 de diciembre de 1978, art.1). 
eco de algunos de los aspectos más representativos de este proceso que señalan los historiadores, por su especial relevancia.

Por ejemplo, la circunstancia que gira entorno a cómo la Transición fue un movimiento que se vio dinamizado obviamente desde la presión y fuerzas socio-políticas externas previsibles, que intentaban ese nuevo giro definitivo hacia un nuevo orden público y que no era sino el impulso cristalizado resultante a su vez de un cúmulo de factores precedentes como fue, verbigracia, la evidente crisis neurotizante que sufría el tardofranquismo desde 1969, al intentar compatibilizar el despegue económico que había trasformado al país, impregnando a su sociedad con nuevos aires de libertad que la alejaban de su ostracismo de posguerra, con el contraste que significaba la fuerte disonancia que presentaba la presencia del modelo dictatorial dentro del contexto internacional, disonancia que Juan Carlos I rectificaría al dirigir la monarquía hacia un régimen parlamentario.

Sin embargo, no son sólo estos sucesos lo específico de esta transformación de la política española, sino el hecho que hubiese una segunda fuerza dinamizadora desde dentro del propio régimen existente, lo que comportó la utilización de las leyes imperantes y de la propia normativa vigente en el gobierno de origen, para evolucionar e introducir los cambios pertinentes hacia un nuevo marco legislativo. Ésta parece ser que fue, en efecto, una de las circunstancias que marcó el proceso de la transición en España:

"La Transición española fue un caso de democratización desde dentro, en el que las leyes e instituciones del régimen autoritario se utilizaron para convertirlo totalmente en una democracia. Durante una conferencia de prensa celebrada en 1974 (poco antes de la muerte de Franco), al historiador Ricardo de la Cierva, entonces director general reformista de Cultura Popular, los periodistas le preguntaron si había existido alguna vez un caso así, y De la Cierva confesó, con bastante razón, que él no conocía ninguno. Durante la Transición el país pasó legalmente (de la ley a la ley, como se suele 
decir) y de forma relativamente pacífica de un dictadura a una democracia parlamentaria." 309

Otro aspecto que definió la Transición política española y en el que parecen coincidir los expertos, fue el hecho de que no se trató de un proceso plácido exento de tensiones y altibajos, sino que se convirtió más bien en un procedimiento arduo que requirió paciencia, flexibilidad e insistencia por todas la partes políticas involucradas, originando un movimiento que no se hallaba libre de dificultades imprevistas y con un futuro incierto. ${ }^{310}$ Un ejemplo de lo frágil y tensionado del proceso lo demuestra el ataque que sufrió el 23 de febrero de 1981, cuando una intentona golpista protagonizada por un sector del ejército contrario a la transición democrática, ocupó con un pelotón de la guardia civil el Congreso de los diputados, en un tentativa por desestabilizar completamente la ya de por sí difícil situación política del momento.

Entre los diversos sucesos políticos más representativos que caracterizaron el discurrir de la Transición, debemos destacar: la aprobación por las cortes en noviembre de 1977 y aprobada en referéndum al mes siguiente por la ciudadanía española de la Ley 1/1977, de 4 de enero, para la Reforma Política, ${ }^{311}$ disposición que jugó el papel de elemento legislativo reglamentario para transitar de la dictadura al sistema democrático; la celebración de las primeras elecciones constituyentes en junio de 1977, después de cuarenta años de sequía plebiscitaria en la sociedad española, que permitirían

309 Payne, Stanley G.: España. Una historia única, Madrid, Temas de Hoy, 2008, p. 393.

${ }^{310}$ Fusi Aizpuru aclara en su Historia minima de España que: "La transición a la democracia no fue, sin embargo, en ningún caso ni fácil ni lineal. El proceso tuvo mucho de improvisado, y su desenlace dependió en todo momento de muchos factores y circunstancias." (Fusi AizPURUA, Juan Pablo, op. cit., p. 239). Mientras que Casanova y Gil comentan que fue: "una transición compleja, sembrada de conflictos, de obstáculos previstos y de problemas inesperados, en un contexto de crisis económica y de incertidumbre política." (Puelles Benítez, Manuel: Política, legislación y educación, Madrid, UNED, 2012, p. 173).

${ }^{311}$ Ley 1/1977, de 4 de enero, para la Reforma Política (B.O.E. de 5 de enero de 1977). 
la paulatina fundación de las organismos democráticos; los Pactos de Moncloa que consistieron en los primeros acuerdos que tomaba el nuevo gobierno de la UCD con los sindicatos y partidos para hacer frente a la grave crisis del petróleo que protagonizó la recesión económica de 1974, y que gracias a los esfuerzos conjuntos de la nueva democracia tomando medidas urgentes, redundaría prontamente en la regularización económica del país; y la aprobación de nuevo por referéndum el 6 de diciembre de 1978 de la Constitución Española, ${ }^{312}$ en la que los españoles elegían libremente el texto legislativo como marco referencial organizativo del estado, quedando éste diseñado según sus artículos 1 y 2, como una monarquía parlamentaria cuyo territorio queda distribuido en comunidades autónomas. ${ }^{313}$

${ }^{312} \mathrm{La}$ trascendencia del texto constitucional tiene su origen en la fuerza que implicaba el equilibrio de todos los bloques parlamentarios sin imposiciones de ningún grupo mayoritario sobre el resto: "Fruto del consenso de las principales fuerzas parlamentarias, la Carta Magna de 1978 entraba en la historia de España como la primera Constitución pactada y no impuesta al país por el grupo dominante." (GARCíA DE CORTÁZAR, Fernando, GonZÁlez VesGA, José Manuel: Breve bistoria de España, Madrid, Alianza, 2012, p. 605).

Pérez Díaz añade: "la Constitución de 1978 simboliza la convivencia y la reconciliación nacional entre las derechas y las izquierdas, entre la iglesia y el anticlericalismo, entre el capitalismo y los movimientos sociales de reforma, y entre el centro y los nacionalismos periféricos" (PÉREZ DíAZ, Víctor: La primacia de la sociedad civil. El proceso de formación de la España democrática, Madrid, Alianza, 1993, p. 37, en Pueldes Benítez, Manuel, op. cit., p. 178).

${ }^{313} \mathrm{El}$ texto Constitucional exactamente es el siguiente:

"Artículo 1

1. España se constituye en un Estado social y democrático de Derecho, que propugna como valores superiores de su ordenamiento jurídico la libertad, la justicia, la igualdad y el pluralismo político.

2. La soberanía nacional reside en el pueblo español, del que emanan los poderes del Estado.

3. La forma política del Estado español es la Monarquía parlamentaria.

Artículo 2

La Constitución se fundamenta en la indisoluble unidad de la Nación española, patria común e indivisible de todos los españoles, y reconoce y garan- 
Esta nueva rotulación del estado en regiones autonómicas fue una de las principales novedades que trajo consigo la Constitución del 78 y la consolidación de la democracia, ya que representaba una transformación substancial y reorganización del modelo territorial español existente hasta la fecha. Sin embargo y pese a la lógica euforia inicial de los primeros años, con el tiempo parece que el diseño autonómico ha demostrado no estar exento de fisuras y problemáticas que se han prolongado hasta la actualidad. ${ }^{314}$

El traspaso de competencias del Estado a las administraciones locales de cada Comunidad Autónoma, se ha llevado a cabo a lo largo de todo este período democrático en el que algunos autores ${ }^{315}$ distinguen hasta cuatro etapas: Una primera fase preautonómica que se desarrolla durante la transición, en la que se elaboran los primeros estatutos de Cataluña y País Vasco; una segunda fase donde se firman los pactos autonómicos que permiten los traspasos competenciales de las comunidades denominadas de «vía rápida»; una tercera fase donde ocurre lo mismo que la fase precedente pero esta vez con las comunidades de «vía lenta»; y un último período donde se revisan y firman nuevos estatutos autonómicos en comunidades como: Cataluña (2006), Comunidad Valenciana

tiza el derecho a la autonomía de las nacionalidades y regiones que la integran y la solidaridad entre todas ellas." (Constitución Española de 27 de diciembre de 1978, B.O.E. de 29 de diciembre de 1978, arts. 1, 2).

${ }^{314}$ Sobre el cambio de fisonomía de la España autonómica García de Cortázar recalca: "Un nuevo Ministerio de Administración Territorial se encargaría, a partir de las elecciones de 1979, de supervisar el trasiego de poder a las regiones. Pasada la primera efervescencia, la fiebre autonómica disminuyó, dejando ver en toda su crudeza las contrapartidas negativas de una división, en gran parte artificial, donde prevalecieron los argumentos históricos sobre los económicos o geográficos y que ha hecho aumentar la burocracia y el gasto público." (GARCía de CorTÁZAR, Fernando, GonZÁlez VeSGA, José Manuel, op. cit., pp. 606-607).

${ }^{315}$ Para profundizar sobre el estado autonómico y su incidencia en la educación, consúltese por ejemplo "Tema XIV. Las Comunidades Autónomas y la Educación” en: Puelles BeníTEZ, Manuel, op. cit., pp. 269-282. 
(2006), Andalucía (2007), Islas Baleares (2007), Castilla y León (2007) o Aragón (2007). ${ }^{316}$

\subsubsection{Los gobiernos de la España democrática}

Si contabilizamos el tiempo transcurrido desde el final de la guerra civil española en abril de 1939 hasta la muerte de Franco en noviembre de 1975, y la subida al trono de Juan Carlos I en ese mismo año, hasta su abdicación y proclamación de su hijo Felipe VI como nuevo rey de España en junio del 2014, podemos apreciar que la sociedad española ya ha transitado el último período de su historia, entre transición y democracia, un período de similar duración al del régimen dictatorial anterior. Así pues, contrapesada desde el punto de vista estrictamente cronológico, la medida del régimen franquista, vivimos un momento favorable que aconseja hacer balance de lo que han significado estas ya casi cuatro décadas de democracia moderna, frente a su período inmediatamente precedente. ${ }^{317}$ La abdicación de Juan Carlos I, y el fallecimiento de Adolfo Suárez González el 23 de marzo de 2014, pueden servirnos como referencia para enmarcar probablemente el final de un período tras el cual, España se enfrenta a un nuevo horizonte.

${ }^{316}$ A lo largo de este dilatado período de traspaso de competencias y reformas de Estatutos, el modelo territorial autonómico como comentábamos anteriormente, ha generado no pocas disyuntivas de las que por poner sólo un ejemplo en el ámbito educativo que es el que a nosotros más nos incumbe, compartimos la siguiente: "Una vez conocidas las diferentes posibilidades de plasmar el modelo educativo a través del currículo, el Ministerio de Educación y Ciencia se encontró con la necesidad de llevarlo a cabo, esto es, de implantarlo en todo el territorio nacional. De inmediato surgirá el conflicto entre dos tipos de autoridades: la autoridad que emana del gobierno central y la autoridad de las diferentes comunidades autónomas ya que desde la Constitución de 1978 España se articula en un Estado dividido en diecisiete comunidades autónomas." (AGÜERRía CuEva, Fernando: Historia de la educación musical en la España contemporánea. Un estudio de política legislativa, Oviedo, FA, 2011, p. 197).

${ }^{317}$ Ley Orgánica 3/2014, de 18 de junio, por la que se hace efectiva la abdicación de Su Majestad el Rey Don Juan Carlos I de Borbón (B.O.E. de 19 de junio de 2014). 
Desde la entronización de Juan Carlos I como Rey de España en 1975 , en España han tenido lugar diez legislaturas ${ }^{318}$ cuyos períodos de mandato estuvieron a cargo de los partidos UCD, PSOE que posee la gestión más larga con cuatro legislaturas ininterrumpidas durante el mandato de Felipe Gonzáles Márquez - y PP. Como es de esperar los hechos que han sobrevenido a la sociedad española durante esta época, componen el escenario cuyo influjo calará en el desarrollo de la vida educativa del país y que estudiaremos en el capítulo siguiente.

La instauración de la monarquía permitía intuir la ilusión de un cambio de rumbo, ${ }^{319}$ una regeneración política que apuntaba hacia nuevos horizontes sin asomo ni referencia hacia la dictadura o la guerra civil, pero no como resultado de una amnesia autoinducida sino como fruto de la búsqueda de nuevas soluciones conjuntamente, para la dirección futura del país. Tal vez, una evidencia de esto que acabamos de exponer queda patente cuando una vez establecida la monarquía, el primer año de gobierno a cargo de Carlos Arias Navarro, político continuista del legado de Franco, se topó de bruces con el nuevo proyecto que el rey y sus asesores tenían en mente. El breve, de noviembre de 1975 a julio de 1976, y descorazonador gobierno de Arias Navarro daría paso tras su dimisión a la dirección del estado a cargo de Adolfo Suárez González, entrando de este modo la Transición política en una nueva línea de progreso. En efecto, la designación del nuevo presidente permitió tras su

${ }^{318}$ Para consultar las legislaturas que han tenido lugar durante este último período democrático, y todo tipo de información sobre el Congreso de los Diputados, consúltese su web:

<http://www.congreso.es/portal/page/portal/Congreso/Congreso/Diputados/Historia1977_2008> [consultado el 22-7-2014].

También se pueden consultar las elecciones generales, autonómicas y referendos en el portal temático que el Congreso creó con motivo de la celebración del 25 aniversario de la Constitución de 1978:

<http://www.congreso.es/consti/> [consultado el 22-7-2014].

${ }^{319}$ Este espíritu se puede intuir en el primer discurso de Juan Carlos I en el acto de su coronación. El evento se puede visualizar en:

<http://www.rtve.es/alacarta/videos/fue-noticia-en-el-archivo-dertve/discurso-juan-carlos-acto-coronacion/344072/> [consultado el 22-72014]. 
triunfo en las elecciones parlamentarias de 1977 y 1979, que España lograra su cambio de régimen pacíficamente:

"Al cumplirse un año de la muerte del Caudillo, el joven presidente ya había conseguido que las Cortes franquistas se hicieran el haraquiri programando un sistema bicameral en el sufragio universal. El franquismo moría como un samurai, con la espada de su propia ley, y autorizaba la transición hacia la democracia." ${ }^{320}$

Entre los propósitos conquistados durante las dos legislaturas del gobierno de la UCD con Suárez, destacamos como ya hemos comentado anteriormente la Ley de Reforma Política que representó el marco legislativo en el que se encuadró la Transición y la aprobación de la Carta Magna en las Cortes. Posiblemente otra de las consecuencias, resultado de la gestión de este momento tan intenso de la política española fue el desgaste sufrido durante el proceso, precipitando a Suárez a abandonar la escena política y dando paso a su sucesor en el Gobierno al ingeniero de caminos Leopoldo Calvo-Sotelo Bustelo, hombre ilustrado que no poseía sin embargo, el magnetismo político de su predecesor.

El breve mandato de Calvo-Sotelo de 1981 a 1982 lleva consigo acontecimientos remarcables como fue el intento de golpe de estado el 23 de febrero de 1981, operación perpetrada en el mismo acto de investidura del presidente, o la entonces polémica ${ }^{321}$ entrada de España en la OTAN. Después de las votaciones de 1977, las elecciones de 1979 proporcionaron la victoria por segunda vez consecutiva a la UCD, si bien se tratará de la última legislatura antes del relevo definitivo del gobierno centrista. Leopoldo Calvo Sotelo, sucesor de Adolfo Suárez en la presidencia, tras dimitir este

${ }^{320}$ García de Cortázar, Fernando, González VesGa, José Manuel, op. cit., p. 599.

${ }^{321}$ El 12 de marzo de 1986 se celebraba el referéndum que daba el sí a la permanencia de España en la OTAN. La polémica viene dada cuando al efectuarse las votaciones durante el gobierno socialista, éste movilizó su campaña a favor de la permanencia, después de la fuerte oposición que había mantenido antes de su entrada al Gobierno en el que utilizaba el eslogan "OTAN, de entrada no", defendiendo la posición contraria. 
último el 29 de enero de 1981, convocaría elecciones generales en octubre de 1982, otorgando las urnas una holgada victoria por mayoría absoluta al PSOE. España había materializado con éxito su tránsito hacia el sistema democrático, solventando paso a paso las diversas etapas y obstáculos surgidos en su trayectoria, sin embargo la última administración de la UCD, supuso un giro hacia el conservadurismo que desembocaría en la desintegración del partido y el triunfo por mayoría absoluta de los socialistas en las elecciones generales anticipadas de octubre de 1982:

"Normalizada la situación durante la etapa de gobierno de Leopoldo Calvo Sotelo (1981-1982), que sucedió a Suárez al frente del ejecutivo, la sociedad española asumió ya sin dificultad alguna el retorno de la izquierda al poder - por primera vez desde la Guerra Civil -, que se produjo tras la histórica victoria de los socialistas, dirigidos por Felipe González y Alfonso Guerra, en las elecciones de octubre de 1982." 322

En efecto, la histórica victoria de los socialistas que significaba la vuelta oficial de la izquierda al frente del estado desde la segunda república, cristalizó en un largo período de 14 años de gobierno articulado a lo largo de cuatro legislaturas, ratificadas en las elecciones generales de 1982, 1986, 1989 y 1993. Este hecho revela que su mandato fue determinante y su influencia social irremediable, ya que ningún otro grupo político en democracia se ha mantenido tanto tiempo en el poder como lo hizo el PSOE con Felipe Gonzáles Márquez a cargo de la dirección del partido. La firma del tratado de adhesión a la Comunidad Europea el 12 de junio de 1985, la prosperidad española y crecimiento económico del país desde ese mismo año hasta 1991, o las profundas reformas educativas en todos los niveles hasta el universitario, son sólo algunos ejemplos de la vasta gestión que ejerció el partido socialista obrero español durante su tarea al frente del ejecutivo. Sin embargo, no todo fue positivo, el largo mandato trajo consigo graves problemas de corrupción política dentro del partido, que junto a otros factores

${ }^{322}$ Fusi AizPURUA, Juan Pablo, op. cit., p. 245. 
desembocaría en el adelantamiento de las elecciones en 1996, con un ajustado triunfo del partido popular. ${ }^{323}$

El triunfo electoral de José María Aznar al frente de los populares en 1996, simbolizó el cambio de signo político después del amplio trabajo desplegado por los socialistas en la etapa precedente:

"La importancia del triunfo del PP en 1996 estaba ante todo en su significación. Representaba, simplemente, la alternancia política natural un una democracia consolidada.

El cambio de 1996 fue, así, un cambio político no traumático. Aznar y el Partido Popular, que gobernaron entre 1996 y 2004 - tras volver a ganar las elecciones en 2000 , esta vez por mayoría absoluta - dieron estabilidad a la acción del gobierno, mantuvieron (mejoraron, de hecho) el crecimiento económico y en buena manera el consenso social."324

Aznar llevó a España hacia el euro y la consiguiente desaparición de la peseta, en uno de los períodos económicos más prósperos de la historia española actual, después de una dura recuperación eco-

${ }^{323}$ Las elecciones generales de 1996 fueron posiblemente unas de los comicios más peleados del período democrático, ya que el Partido Popular se proclamaría vencedor de las mismas por un estrecho margen después de que el PSOE hubiese gobernado durante casi tres lustros, y a pesar de su peligrosa estrategia de destapar antiguos fantasmas del franquismo: "En líneas generales, todos los grandes partidos mantuvieron el rechazo consensuado a la politización de la historia de la Guerra Civil y la dictadura hasta 1993, cuando los socialistas se vieron en grave peligro de perder las elecciones generales por primera vez en más de una década. En ese momento, Felipe González puso un especial empeño en advertir de que votar al Partido Popular conllevaba el gran riesgo de restaurar algunos de los más sombríos aspectos del franquismo. Esto equivaldría a lo que en los Estados Unidos de las décadas posteriores a la guerra civil americana se denominó «agitar la camisa ensangrentada»»" (PAYNE, Stanley G., op. cit., p. 399). También en el mismo sentido: "Frente al reiterativo mensaje del PP de regeneración moral de España, un PSOE autosatisfecho inundó la campaña de referencias a sus logros sociales y asustó a los votantes con un futuro dominado por las dentelladas conservadoras al Estado del bienestar." (GARCÍA DE CORTÁZAR, Fernando, GONZÁlEZ VeSGA, José Manuel, op. cit., p. 623-624).

${ }^{324}$ Fusi AizPuruA, Juan Pablo, op. cit., pp. 250-251. 
nómica, a raíz de la crisis sufrida en la década de los 90, que exigía un esfuerzo presupuestario considerable hasta conseguir los índices monetarios marcados por Maastrich para entrar en la unión económica europea, objetivo que sería finalmente alcanzado con éxito al poner en marcha el plan de la moneda única junto con los restantes once países de la Unión, el 1 de enero de 1999.

La intensa campaña electoral de 2004 estuvo marcada trágicamente por el espantoso atentado terrorista en los trenes de cercanías de Madrid el 11 de marzo, cuando varias bombas estallaban causando centenares de muertes y miles de heridos. En medio de la aflicción, el país toma un nuevo rumbo político al dar las urnas la victoria a José Luís Rodríguez Zapatero candidato a la presidencia del partido socialista.

Esta segunda ronda de administración socialista se desarrolló durante la VIII y IX legislaturas de la democracia y tuvo dos derroteros bien distintos. Si la primera legislatura se distinguió por el fomento de políticas sociales y la continuidad en el plano económico marcado por la estabilidad de su predecesor, los tiempos de bonanza dieron paso después de las elecciones de 2008, a una de las peores crisis económicas sufridas desde la transición. ${ }^{325}$ Las medidas anticrisis y planes de ajuste se ponen en marcha bajo la inminente amenaza de la intervención europea que ya se ha practicado en países como Irlanda, Portugal o Grecia. El gobierno parece incapaz de resistir el azote de la crisis y la credibilidad de Zapatero empieza a entrar en caída libre. La convocatoria de las elecciones generales anticipadas parece mostrarse como la única solución posible a la desesperada, del presidente socialista.

El 20 de noviembre de 2011, se llevan a cabo las undécimas elecciones a la Cortes Generales de España, inaugurándose así la décima legislatura democrática. Victoria esta vez del partido popular con Mariano Rajoy Brey como presidente del estado y estrepitosa

325 Merece la pena reproducir algunos de los comentarios de la prensa especializada internacional describiendo el estado económico español: "The party is over, se acabó la fiesta, escribía el 11 de noviembre de 2008 The Economist, en un nuevo informe especial sobre España." (Ídem, p. 266). 
derrota de los socialistas que ven pagar en las urnas la indeterminación de sus estrategias. ${ }^{326}$

Algunos historiadores interpretan la crisis económica y el fin del gobierno de Zapatero, como un hito en la historia española que parece apuntar a algo parecido al fin de un ciclo político:

"El fin de la prosperidad y de la bonanza económica pareció también confirmar el fin de la transición. Cuando Mariano Rajoy, llegó al poder tras ganar las elecciones en noviembre de 2011, su gran tarea era nada menos que la reconstrucción de una economía en quiebra."327

Como decíamos al comienzo de este capítulo, en 2015 han pasado cuarenta años del comienzo de uno de los capítulos históricos más trascendentales de la vida política y social española. El giro que ha sufrido España en este período ha sido inmenso, con resultados valiosísimos al convertirse en un país democrático, consolidar su posición en Europa afianzándose como nación en el marco internacional y al ser capaz de adoptar una política económica desarrollada, aunque en ocasiones no suficientemente juiciosa a la hora de afrontar los desafíos y obstáculos de su tiempo. Es posible tal vez, que el uso de los modelos políticos veteranos tan legítimos y justificados en su momento, empiecen a mostrar signos de fatiga y reclamen la aplicación de nuevos patrones que exijan a su vez cambios estructurales, pero esto implica una ardua y delicada tarea que coloca a la generación actual ante un verdadero desafío. El repaso

${ }^{326}$ Aunque la proximidad a los acontecimientos relatados tal vez no nos permitan ver con perspectiva e imparcialidad lo sucedido, pueden no obstante extraerse algunas primeras lecturas de los hechos acaecidos: "La pérdida de poder local, la inestabilidad financiera y la dificultad de sacar adelante los presupuestos del Estado de 2012 fuerzan a Zapatero a anunciar en pleno verano la disolución de las Cámaras y la convocatoria de elecciones a celebrar el 20 de noviembre de 2011." [...] "El 20 de noviembre de 2011 se consumó el descalabro del PSOE." [...] "el partido socialista se quedaba huérfano por su indefinición durante la crisis y la falta de ideas atrayentes." (GARCÍA de CorTÁZAR, Fernando, GonZÁlEZ VESGA, José Manuel, op. cit., p. 715).

${ }^{327}$ Fusi AizPURUA, Juan Pablo, op. cit., p. 266. 
crítico, minucioso y sin precipitaciones de nuestro pasado para aprender de nuestros errores o releer nuestra historia a la luz de nuevos hallazgos científicos, creemos que no puede o no debe ser obviado $^{328}$ o substituido por un revisionismo histórico falaz que reinterprete los acontecimientos caprichosamente, en función de intereses y deseos vagamente argumentados. Políticamente la Democracia fue consecuencia de la Transición y ésta a su vez fue posible en parte, fruto del consenso político alcanzado por los principales partidos UCD, PSOE, PCE y PP (entonces AP) y otras fuerzas minoritarias, ratificadas en las Cortes constituyentes de 1977 por la ciudadanía española, que volvía a celebrar votaciones cuarenta años después del último sufragio y que sirven de ejemplo a las generaciones posteriores de cómo hacer frente a un nuevo ciclo:

"Zapatero supuso, pues, la ruptura de consensos básicos vigentes, tácita o explícitamente, desde la transición. El PSOE parecía identificar ahora democracia con izquierda y nacionalismos; la idea parecía ser que, treinta años después de la muerte de Franco, las circunstancias españolas no eran ya las circunstancias de la transición. Con su victoria en las elecciones el 9 de marzo de 2008, Rodríguez Zapatero y el PSOE lograron un segundo mandato para gobernar el país. Zapatero basó buena parte de su campaña electoral en la negación sistemática de que la economía española pudiera verse afectada por la crisis financiera y económica que en 2008 había empezado a manifestarse ya en Estado Unidos y en distintos países europeos - y que lo expertos temían podía tener dimensiones tan graves como la crisis de 1929 -". 329

\footnotetext{
328 Acerca del alcance y el olvido a la consideración del pasado: "La transición, las preocupaciones políticas, morales e históricas que habían impregnado a generaciones anteriores, y singularmente a las generaciones moldeadas por el espíritu de oposición al régimen de Franco, eran para la nuevas generaciones que emergían en los 90, si no inexistente, al menos progresivamente irrelevantes y, en todo caso, nada urgentes y muy poco significativas." (Ídem, pp. 261-262).

329 Ídem, p. 265.
} 
La crisis económica mundial surgida durante la primera década del siglo XXI de consecuencias en territorio nacional todavía por determinar, unida al posible cambio de ciclo que vive la política española después de cuatro décadas de Transición y Democracia, entrañan intensas transformaciones que necesitarán no poco esfuerzo, rigor y presteza en el futuro.

\subsection{La contribución de la Transición y Democracia española a la política educativa musical hasta 1990}

En consonancia con los capítulos anteriores, abordaremos a continuación cuáles han sido las medidas en política educativa que se han tomado durante este ciclo y cómo han afectado los acontecimientos ocurridos, en la configuración de la historia educativa musical contemporánea, partiendo de la hipótesis que la legislación desplegada en materia educativa de un país en una determinada época, refleja parte de la imagen de ella misma y de la comunidad de individuos que la protagonizaron. Como viene siendo habitual en nuestro estudio y siguiendo nuestro objetivo inicial, nos concentraremos en la articulación de las principales leyes y disposiciones educativas que han regulado la enseñanza de música en los conservatorios.

El interés en este aspecto de nuestra investigación se ha visto acrecentado a medida que avanzamos hasta llegar al tiempo presente, a causa como veremos en seguida, del amplio desarrollo reglamentario que las Enseñanzas Artísticas han sufrido consecuencia de varios factores que iremos descubriendo gradualmente, como por ejemplo, la trascendencia que ha supuesto a nivel educativo la inserción de España en Europa.

Estudiar el progreso de la reglamentación musical nos permitirá en conclusión, valorar en su justa medida los aciertos y errores que ha sufrido el Arte de la Música y su ordenación académica en España, para una vez llegados a este punto poder exponer vías de actuación que permitan la mejora y desarrollo de los procesos de enseñanzaaprendizaje, dirigidos especialmente a instrumentistas y en un paso 
más allá, que desarrollen su faceta interpretativa dentro de la especialidad pianística.

La triple dedicación profesional como docentes, intérpretes e investigadores a la que parece abocarnos la regulación académica en materia musical de la última década, nos invita a una revisión crítica de nuestros sistemas educativos y demás reglamentación de este período. Nuestro análisis buscará primeramente participar en la búsqueda de respuestas a las exigencias planteadas por una sociedad en continua evolución, pero también y en segunda instancia ponernos al día en nuestra tarea pedagógica, mediante la exploración de nuevos campos y metodologías que permitan profundizar en la interpretación pianística y su docencia en esta época de rápidos cambios. Al fin y al cabo, lo que se pretende es que la conjunción de estos tres frentes, el interpretativo, el docente y el investigador, redunden en el progreso de una actividad profesional que al dirigirse hacia el alumnado, pueda finalmente encarnar verdaderas propuestas pedagógicas de innovación y mejora educativa.

\subsubsection{La Constitución de 1978 y las leyes orgánicas de Educación en Democracia}

La Constitución española de 1978 asoma como el primer estatuto en arrojar los primeros ingredientes normativos en educación. Como hemos introducido en nuestra breve contextualización, la Transición tuvo entre sus pilares de base, la gestión en consenso de los partidos elegidos en las urnas en 1977, en especial UCD y PSOE, al no salir ningún partido político elegido en mayoría. Este hecho matizó el devenir sociopolítico y por extensión la educación de la sociedad española. ${ }^{330}$

330 Según Puelles Benítez, la historia española alimentada más por fuertes pasiones políticas y religiosas que por el pragmatismo, nos ha conducido a dobles lecturas de principios universales como la igualdad, la libertad o la educación: "A esa tradición dual respondían las posiciones de la derecha y de la izquierda: cada bloque polarizaba su posición en torno a uno de los dos principios de libertad e igualdad, vividos con carácter absoluto y, por tanto, irreconciliables." [...] "Esta antítesis no sólo tenía inevitables consecuencias 
El artículo 27 de la Constitución se encuentra dentro de esta coyuntura del consenso, y generó, posiblemente sin esperarlo, las bases de una actuación lo suficientemente holgadas como para generar un movimiento pendular, que oscilaría de un partido a otro según quién ocupase el gobierno de la nación en ese momento:

“el artículo 27, siendo un pacto escolar, era un pacto abierto a la alternancia política. Es decir, el pacto era lo suficientemente amplio para que cada partido, llamado a gobernar por imperativo de las urnas, pudiera subrayar unos aspectos más que otros, siempre que respetara el contenido esencial del pacto constituyente." [...] "Se aceptaba, pues, el consenso básico pero no el consenso político. La realidad mostraría de inmediato lo arduo que sería el desarrollo legislativo y político del artículo 27."

La carta constitucional dedica el contenido del artículo 27 en exclusiva a aspectos vinculados directamente con la educación:

“Artículo 27

1. Todos tienen el derecho a la educación. Se reconoce la libertad de enseñanza.

2. La educación tendrá por objeto el pleno desarrollo de la personalidad humana en el respeto a los principios democráticos de convivencia y a los derechos y libertades fundamentales.

3. Los poderes públicos garantizan el derecho que asiste a los padres para que sus hijos reciban la formación religiosa y moral que esté de acuerdo con sus propias convicciones.

4. La enseñanza básica es obligatoria y gratuita.

políticas para la educación, sino que alcanzaba al modelo mismo: mientras que en la UCD se defendía el pluralismo escolar sobre la base de centros y proyectos educativos propios, en su mayor parte de carácter confesional, en el PSOE se luchaba por una escuela pública autogestionada y con pluralismo interno.” (Puelles BeníTEZ, Manuel, op. cit., pp. 180-181).

331 Ídem, p. 183 
5. Los poderes públicos garantizan el derecho de todos a la educación, mediante una programación general de la enseñanza, con participación efectiva de todos los sectores afectados y la creación de centros docentes.

6. Se reconoce a las personas físicas y jurídicas la libertad de creación de centros docentes, dentro del respeto a los principios constitucionales.

7. Los profesores, los padres y, en su caso, los alumnos intervendrán en el control y gestión de todos los centros sostenidos por la administración con fondos públicos, en los términos que la ley establezca.

8. Los poderes públicos inspeccionarán y homologarán el sistema educativo para garantizar el cumplimiento de las leyes.

9. Los poderes públicos ayudarán a los centros docentes que reúnan los requisitos que la ley establezca.

10. Se reconoce la autonomía de las universidades, en los términos que la ley establezca". 332

Otros apartados de la Constitución, que apuntan igualmente hacia diferentes aspectos relacionados con la educación y la enseñanza, son los artículos: 20.1 y 20.4; 39; 43.3; 44; 148.1-17ª 149.1-15 a y 149.1-30a . Especial hincapié deseamos hacer sobre el artículo 148.1-15 al referirse explícitamente a los conservatorios como uno de los compromisos a asumir por las Comunidades Autónomas en el conjunto de sus competencias:

“Artículo 148

1. Las comunidades autónomas podrán asumir competencias en las siguientes materias:" [...]

332 Constitución Española de 27 de diciembre de 1978 (B.O.E. de 29 de diciembre de 1978, art. 27). 
“15. ${ }^{a}$ Museos, bibliotecas y conservatorios de música de interés para la comunidad autónoma". ${ }^{333}$

Es cierto que el semblante que se desprende de los conservatorios a raíz de este artículo, asociándolo con museos y bibliotecas, se encuentra más cercano al de las actividades propias de estos establecimientos dedicados a conservar el valor cultural de las artes, que al de un centro educativo consagrado a la enseñanza musical. ${ }^{334}$

El impulso procurado por la Constitución en cuestión de enseñanza, desembocaría en una combinación de leyes orgánicas destinadas a renovar el esquema general del sistema educativo, proyecto que se desarrolló principalmente durante el gobierno del partido socialista. Entre medias queda la LOECE, ${ }^{335}$ propuesta del ministro de educación José Manuel Otero Novas durante el período UCD, una ley que nunca llegaría a tener validez al fallar el Tribunal Constitucional en sentencia de 13 de septiembre de 1981, inconstitucionales varios de sus artículos. ${ }^{336}$ Algunas de las principales leyes de educación desarrolladas desde la fundación de España como Estado democrático hasta nuestros días, son las siguientes: Ley Orgánica de Reforma Universitaria ${ }^{337}$ (LRU)(1983); Ley Orgánica Reguladora del Derecho a la Educación ${ }^{338}$ (LODE)(1985); Ley Orgánica de Ordenación General del Sistema Educativo 339

333 Ídem, art. 148.1-15ª.

${ }^{334}$ Sobre la sorprendente alusión a los conservatorios en la Constitución del 78 y su significación, véase el interesante análisis de: EMBID IRUJO, Antonio: Un siglo de legislación..., pp. 93-96.

${ }^{335}$ Ley Orgánica 5/1980, de la Jefatura del Estado, de 19 de junio, por la que se regula el Estatuto de Centros Escolares (B.O.E. de 27 junio de 1980)

336 Sentencia 13 de febrero de 1981, del pleno del tribunal constitucional por el que se modifican determinados artículos del estatuto de centros escolares, aprobado por ley orgánica 5/1980, de 19 de junio (B.O.E. de 24 de febrero de 1981).

${ }^{337}$ Ley Orgánica 11/1983, de 25 de agosto, de Reforma Universitaria (B.O.E. de 1 de septiembre de 1983).

338 Ley Orgánica 8/1985, de 3 de julio, reguladora del Derecho a la Educación. (B.O.E. de 4 julio de 1985)

${ }^{339}$ Ley Orgánica 1/1990, de 3 de octubre, de Ordenación General del Sistema Educativo. (B.O.E. de 4 de octubre de 1990). 
(LOGSE)(1990); Ley Orgánica de la Participación, la Evaluación y el Gobierno de los Centros Docentes ${ }^{340}$ (LOPEG)(1995); Ley Orgánica de Universidades ${ }^{341}$ (LOU)(2001); Ley Orgánica de las Cualificaciones y de la Formación Profesional ${ }^{342}$ (LOCFP)(2002); Ley Orgánica de Calidad de la Educación ${ }^{343}$ (LOCE)(2002); Ley Orgánica de Educación ${ }^{344}$ (LOE)(2006) y Ley Orgánica para la mejora de la calidad educativa ${ }^{345}$ (LOMCE)(2013).

Este despliegue legislativo generó una expansión de la ordenación educativa de la que han ido brotando numerosas ramificaciones, creando invariablemente una red estructural reglamentaria que se esfuerza en proporcionar una respuesta válida a los continuos cambios y necesidades de una sociedad desarrollada. Desde esta óptica y ajustándonos a los márgenes distintivos de nuestro estudio, la organización de los estudios musicales, y más concretamente los nuevos diseños de la programación de Piano, van a verse sobre todo influenciados por los siguientes aspectos: primeramente, por el desglose de los estudios musicales en centros profesionales y superiores; en segundo lugar, por las innovaciones pedagógicas tocante a las nuevas propuestas de planificación educativa formuladas en la LOGSE y la aparición de la ordenación de los estudios de tercer ciclo y su correspondiente impacto en el grado superior de música; y finalmente, por el aumento burocrático-legislativo que se produce, al ampliarse las posibilidades de los centros educativos

340 Ley Orgánica 9/1995, de 20 de noviembre, de la Participación, la Evaluación y el Gobierno de los Centros Docentes (B.O.E. de 21 de noviembre de 1995).

341 Ley Orgánica 6/2001, de 21 de diciembre, de Universidades (B.O.E. de 24 diciembre de 2001). Algunos contenidos de esta Ley ha sido revisados por la Ley Orgánica 4/2007, de 12 de abril, por la que se modifica la Ley Orgánica 6/2001, de 21 de diciembre, de Universidades. (B.O.E. de 13 de abril de 2007).

${ }^{342}$ Ley Orgánica 5/2002, de 19 de junio, de las Cualificaciones y de la Formación Profesional (B.O.E. de 20 junio de 2002).

${ }^{343}$ Ley Orgánica 10/2002, de 23 de diciembre, de Calidad de la Educación (B.O.E de 24 de diciembre de 2002).

${ }^{344}$ Ley Orgánica 2/2006, de 3 de mayo, de Educación (B.O.E. de 4 de mayo de 2006).

${ }^{345}$ Ley Orgánica 8/2013, de 9 de diciembre, para la mejora de la calidad educativa (B.O.E. de 10 de diciembre de 2013). 
gobernados por las consejerías autonómicas, dentro del ámbito de autonomía pedagógica que posee cada una de las comunidades autónomas, para rematar los sistemas educativos en sus respectivos territorios por un lado, pero también al entrar España en Europa y formar parte del programa de convergencia europea para la educación superior.

\subsubsection{Leyes de Educación durante los gobiernos del Partido Socialista: LODE, LOGSE, LOPEG y LOE}

Con la llegada del Partido Socialista Obrero Español al poder en 1982, José María Maravall se haría cargo de la cartera del Ministerio de Educación y Ciencia desde 1982 a 1988 y los principales objetivos de su programa fueron garantizar el derecho a la educación de toda la ciudadanía y mejorar la calidad de la enseñanza. Persiguiendo estos objetivos se desarrollan durante el período de gobierno socialista las siguientes leyes citadas: la Ley Orgánica de Reforma Universitaria de 1983(LRU); la Ley Orgánica reguladora del Derecho a la Educación de 1985 (LODE); la Ley Orgánica de Ordenación General del Sistema Educativo de 1990 (LOGSE) y la Ley Orgánica de la Participación, la Evaluación y el Gobierno de los Centro Docentes de 1995 (LOPEG).

Evidentemente, el movimiento pendular hacia el lado opuesto del terreno político tras el mandato de la UCD trajo consigo la versión socialdemócrata de la educación que Capitán Díaz resume así:

"Con el cambio político cabía esperar la posible «lectura»socialista de la Constitución de 1978. Parecía que habían de venir nuevos modelos de estructura socioeconómica, reformas de la administración pública, de la educación, de los usos y modos culturales..., en fin, de todo lo que era considerado «tradicionalmente» identificable con el franquismo y/o con la «derecha española», según los propios socialistas. En el sector educativo se prometía la plena realización del derecho de todos los españoles a la educación (extensión), la mejora de la calidad de la enseñanza (cualidad) y la participación corresponsable, de derecho y de hecho, de los poderes públicos - 
Estado, Comunidades Autónomas, Diputaciones, Ayuntamientos... - y de la sociedad civil - alumnos, profesores, familia... - dado el carácter de la educación como «servicio público» (democratización como equilibrio efectivo de derechos y obligaciones y como autonomía relativa del sistema educativo)."346

Como ya hemos indicado, después de la Ley de Reforma Universitaria los socialistas abordarían el derecho a la educación, uno de los objetivos de su programa político en materia educativa, con la Ley Orgánica Reguladora del Derecho a la Educación.

El nuevo gobierno había mantenido una dura oposición con el ejecutivo predecesor y la LODE mostraba por fin públicamente su posicionamiento en lo tocante a la educación. Los populares interpondrían recurso de inconstitucionalidad contra la LODE, repitiendo la estrategia que los socialistas habían practicado anteriormente con la LOECE propuesta por la UCD. No obstante, la LODE sería sancionada finalmente el 3 de julio de 1985 tras modificarse el texto de algunos de sus artículos según sentenciaba el Tribunal Constitucional. Estos rifirrafes entre partido en el gobierno y oposición son los primeros signos muestra de lo difícil que iba a resultar materializar en el terreno político, el consenso acordado en el artículo 27 de la Constitución que apuntábamos anteriormente.

Según sus autores, la LODE ampliaba este artículo de manera más acorde al espíritu constitucional original, completando la visión parcial que había tenido la LOECE sobre dicho articulado y variando el rumbo tecnocrático de esta ley anterior, hacia el democrático y plural que defendía la nueva norma.

Sin embargo, hemos de agregar que los cambios legislativos sobre educación en España no sólo responden a esta situación comentada sino que como otros autores apuntan, son también resultado del esfuerzo por acomodarse a los cambios sociales de una nación, intentando mantenerse al día y no descolgándose del dinamismo de una sociedad moderna:

${ }^{346}$ CAPITÁN DíAz, Alfonso, op.cit., vol. II, p. 840. 
"Los sucesivos cambios legislativos, de enorme trascendencia para el desarrollo de la educación en España, no fueron debidos exclusivamente a la labor de los responsables políticos de cada partido en materia de educación. Antes al contrario, las actuaciones políticas que impulsaron estos cambios en nuestro ordenamiento jurídico fueron en gran medida consecuencia de los diferentes movimientos de renovación pedagógica que podríamos retrotraer hasta la reforma educativa de 1970 y que en la década de los años ochenta adquirieron un mayor protagonismo." 347

Prosiguiendo nuestro análisis por la LODE, comprobamos que la ley traería consigo importantes logros como el firme reconocimiento de la enseñaza pública, pero también de la privada, con conciertos públicos para aliviar las demandas de la gratuidad de ésta primera y de la privada no concertada, así como aspectos tan importantes como la democratización y participación de la comunidad educativa con la creación por ejemplo de los consejos escolares. En definitiva podríamos concluir que:

"La LODE nace como una norma que desarrolla cabal y armónicamente los principios de la Constitución española en materia de educación «respetando tanto su tenor literal como el espíritu que presidió su redacción», y garantizando «al mismo tiempo el pluralismo educativo y equidad»."348

Más tarde, el inicio de la década de los 90 traería consigo una de las leyes educativas de más impacto y trascendencia para la sociedad española desde que en 1812 se decidiese organizar la educación a través de los sistemas educativos, estamos hablando de la Ley Orgánica 1/1990, de 3 de octubre, de Ordenación General del Sistema Educativo, o LOGSE. La polémica que acompañó a la ley es una muestra de la importancia y calado de su propuesta.

Dicha ley vino precedida de un extenso y profundo debate político que se iniciaba con el Proyecto para la Reforma de la Enseñanza, docu-

\footnotetext{
347 AgüErría Cueva, Fernando, op. cit., p. 178.

${ }^{348}$ CAPITÁN DíAZ, Alfonso, op. cit., vol. II, p. 860.
} 
mento con el que el ministro José María Maravall proponía las líneas maestras para la reforma del sistema educativo. Más tarde, con la entrada en el ministerio en 1988 de Francisco Javier Solana de Madariaga, el proyecto vería su versión definitiva con el título Libro Blanco para la Reforma del Sistema Educativo, ${ }^{349}$ encontrándose listo para su debate público.

Como hemos comentado anteriormente con la LODE, la LOGSE no era simplemente la expresión a través de una ley de la opinión que tenía el gobierno respecto a la Educación y su gestión, sino que los tiempos habían cambiado y con ellos su sociedad y la década de los 90 proponía nuevos desafíos al antiguo sistema regulado por LGE de 1970:

"EI sistema educativo español había evolucionado cuantitativa y cualitativamente durante la década de los ochenta, sin solución de continuidad del progreso iniciado en los años setenta a partir del desarrollo de la Ley General de Educación (1970)."

En efecto, si la LODE y el derecho a la educación de toda la ciudadanía era el primer punto a cumplir del ideario socialista, el segundo objetivo venía a continuación con la conquista de la calidad educativa. La LOGSE intentaría observar ambos:

"La extensión del derecho a la educación y su ejercicio por un mayor número de españoles en condiciones homogéneamente crecientes de calidad son, en sí mismos, los mejores instrumentos para luchar contra la desigualdad."351

La Ley de Ordenación General del Sistema Educativo de 1990, supuso también una transformación profunda de las enseñanzas artísticas de música que veían con entusiasmo su integración en el conjunto de las enseñanzas generales del sistema educativo, al lo-

\footnotetext{
${ }^{349}$ MEC: Libro Blanco para la reforma del Sistema Educativo, Madrid, 1989.

${ }^{350}$ CAPITÁn DíAZ, Alfonso, op. cit, Voll. II, p. 875.

351 Ley Orgánica 1/1990, de 3 de octubre,...(B.O.E. de 4 de octubre de 1990, preámbulo de la Ley).
} 
grar una articulación uniforme y cabal que no conocían desde la Ley Moyano de $1857 .{ }^{352}$

Embid Irujo comenta así la magnitud del efecto de esta ley para las enseñanzas musicales:

"La trascendencia de la Ley que indico es innegable en cuanto que ha determinado una nueva estructura de la enseñanza, pero quizá sea todavía mayor esa trascendencia en el ámbito de las enseñanzas artísticas dada la nueva configuración que de ellas se ha realizado por la LOGSE, sin prácticas ataduras con el pasado. En este plano, por un lado, se puede apreciar un refuerzo de la presencia de las enseñanzas musicales dentro de lo que la LOGSE denomina «enseñanzas de régimen general»y, por otro, se configuran de forma completamente nueva las enseñanzas artísticas." 353

En consonancia con esto y como la propia ley reconoce en el preámbulo:

"La ley aborda, por primera vez en el contexto de una reforma del sistema educativo, una regulación extensa de las enseñanzas de la música y de la danza, del arte dramático y de las artes plásticas y de Diseño, atendiendo al creciente interés social por las mismas, manifestado singularmente por el incremento notabilísimo de su demanda. Diversas razones aconsejan que estén conectadas con la estructura general del sistema y que, a la vez, se organicen con la flexibilidad y especificidad necesarias para atender a sus propias peculiaridades y proporcionar distintos grados profesionales, alcanzando titulaciones equivalentes a las universitarias, que, en el caso de

\footnotetext{
352 Algunos autores destacan la trascendencia de esta ley como uno de los tres hitos más significativos de las enseñanzas musicales junto a la citada Ley de Instrucción pública de 1857 (Ley Moyano), y la Ley General de Educación de 1970 (LGE). Véase por ejemplo: MARZAL RAGA, Consuelo de los Reyes, op. cit., p. 79.; y sobre todo el interesante análisis de: EMBID IRUJO, Antonio: Un siglo de legislación....

${ }^{353}$ EMBID IRUjO, Antonio: Un siglo de legislación..., p. 96.
} 
la Música y las Artes Escénicas, que comprenden la Danza y el Arte Dramático, lo serán a la de Licenciado." 354

Como veremos seguidamente en nuestro análisis, la LOGSE contiene aspectos novedosos en comparación con el plan anterior, como son la regulación en cursos en vez de asignaturas o el aumento de los años de estudio. Pero donde encontramos a nuestro parecer los cambios más significativos es posiblemente en la sólida fundamentación de sus bases en principios psicológicos de la educación y en la reforma curricular con un modelo abierto.

La expresión de los objetivos con verbos en infinitivo que encontramos en el currículo, indican conductas a desarrollar conforme a criterios y clasificaciones establecidas previamente por especialistas.

Sobre la clasificación de las metas del sistema educativo, hay que destacar el trabajo que realizó Bloom y otros colaboradores, contenido en la obra: Taxonomía de los objetivos de la educación. ${ }^{355}$ Este trabajo que nace del esfuerzo conjunto de más de una veintena de especialistas norteamericanos en educación, reunidos en sesiones desde 1949 a 1953, emerge con la intención de crear un armazón racional común que posibilitase el intercambio entre los examinadores de este país. Es decir, al realizar una clasificación, o una taxonomía de los resultados de la educación, se pretendía entre otras cosas favorecer un esquema común que permitiese la intercomunicación principalmente entre los profesores, y de forma general entre la comunidad educativa.

La aportación de esta investigación influenciaría de manera notable el panorama educativo posterior. Así por ejemplo, la clasificación que realizaron estos autores en su taxonomía se articula en seis clasificaciones: Conocimiento; Comprensión; Aplicación; Análisis; Síntesis; y Evaluación. Si comparamos esta clasificación con los Descriptores de Dublín, que veremos más adelante en el apartado 7. 4. y que representan nuestro actual marco de cualificaciones del sistema educativo superior, encontramos una clasificación en estos

${ }^{354}$ Ley Orgánica 1/1990, de 3 de octubre,..., preámbulo de la Ley.

355 Bloom, Benjamín S. (ed): Taxonomía de los objetivos de la educación, Alcoy, Marfil, 1972. 
últimos en cinco categorías principales: Poseer y comprender conocimientos; Aplicación de conocimientos y comprensión; Capacidad de emitir juicios; Capacidad de comunicar; y Habilidades de aprendizaje.

Como podemos comprobar la afinidad entre ambas clasificaciones es notable. Tal vez la diferencia más considerable que aportan los actuales Descriptores de Dublín, sea la referencia que hacen a las Habilidades de aprendizaje, encaminadas al aprendizaje permanente y autónomo del estudiante, un asunto que trataremos con detenimiento más adelante.

Otro aspecto importante que introdujo Bloom y el grupo de investigadores, es que junto a la adquisición de conocimientos como objetivo principal del sistema educativo, la meta inmediatamente siguiente consistía en la aplicación práctica de esos conocimientos, y para ello introducen la distinción entre Destrezas y Aptitudes. Si la primera se reduce a la aplicación de una rutina o método ordinario aprendido a una nueva situación, la Aptitud implica un proceso más rico y complejo donde el estudiante combina conocimientos teóricos con prácticos para reestructurarlos a la nueva situación problemática de la vida:

"La circunstancia de que la mayor parte de nuestro aprendizaje se efectúa para hallarnos en condiciones de aplicarlo a las coyunturas problemáticas de la vida real es una demostración de la importancia de los objetivos de la aplicación en el programa general de la enseñanzas. Así, pues, la eficacia de una buena parte del programa docente se halla supeditada a lograr que el alumno se inserte lo mejor posible en las nuevas coyunturas con el fin de que pueda aplicar lo aprendido a problemas que nunca la" (sic) "habían salido durante el proceso de la enseñanza."356

Esta aplicación de los conocimientos propia de la aptitud, que la diferencia de la destreza, implica como decíamos conocimientos y conceptos concretos, pero también envuelve otras conductas más generales como pueda ser por ejemplo, la adopción por parte del

${ }^{356}$ Ídem, p 137. 
alumno de una actitud adecuada ante los problemas, fundamentada en el autocontrol o la confianza en las propias capacidades. De ahí que, esa visión más global del aprendizaje que introducen estos investigadores - abarcando varios aspectos como son el saber, el saber hacer, y el saber aplicar, unido a otros valores generales del individuo - se nos presente como una primera piedra del actual sistema educativo basado en competencias.

Por tanto, el giro copernicano que planteaba la LOGSE al entender la educación no como un cúmulo de contenidos y saberes que había que volcar sobre los alumnos y que estos debían aprender, sino como un conjunto de conductas que había que desarrollar conforme a un modelo basado en objetivos, contenidos y criterios de evaluación, fundamentado todo ello en las aportaciones científicas de la psicología del desarrollo, representó como decimos un desafío en su momento y el advenimiento de un modelo educativo que todavía hoy sigue vigente evolucionando con el tiempo.

Por el contrario, entre los posibles desaciertos de la Ley tal vez podemos destacar el hecho de que la novedad de la filosofía de su mensaje pedagógico, no llegó a propagarse de forma extensiva entre toda la comunidad educativa musical, al no encontrar un profesorado adecuadamente receptivo - posiblemente consecuencia de una insuficiente formación previa ${ }^{357}$ - y un alumnado que si bien es cierto soportaba una sobrecarga lectiva, ${ }^{358}$ se resistía en cambio a

${ }^{357}$ La LOGSE trajo consigo un nuevo perfil del profesor que todavía hoy está en discusión: "el papel del profesor ha cambiado sustancialmente: de ser un maestro ha pasado a convertirse en un técnico de la educación que asesora, orienta, coordina, pero que ya no es la fuente principal de conocimientos. Conceptos como aprender a aprender o método experimental adquieren relevancia, el protagonismo se desplaza del profesor al alumno para lo que se requiere una nueva preparación pedagógica y un reciclaje profundo del profesorado." (AgüERría CuEVA, Fernando, op. cit., p. 187)

${ }^{358}$ Los conservatorios durante la LOGSE, trasladaron el sistema de créditos universitarios directamente al currículo de música, sin tener en cuenta que el trabajo que realiza fuera del aula un estudiante de una especialidad instrumental de conservatorio, pongamos por caso en Piano, puede llegar a cuatriplicarse, sin embargo esta tarea fuera del aula no se contempló en el cómputo de los créditos anuales del curso, lo que sobrellevó un error en el cálculo de la carga lectiva de los cursos y por consiguiente una sobrecarga 
asumir que el estudio de la música requería el mismo trabajo y dedicación que la de cualquier otra licenciatura universitaria.

En definitiva, la LOGSE supuso ciertamente un verdadero adelanto para las enseñanzas artísticas pero el impulso de la normativa no llegó a rematar la reforma que con tan noble propósito expresaba su articulado, dejando importantes cabos sueltos por resolver como por ejemplo, la completa consolidación y estabilización de las enseñanzas artísticas musicales en su ciclo superior equivalente al universitario. ${ }^{359}$

En un último esfuerzo del gobierno por resolver los desajustes que la aplicación del sistema educativo iba demostrando en su funcionamiento sobre la práctica, los socialistas lanzan en 1995 la LOPEG, una norma que intentaba adecuar a los nuevos tiempos lo que la LOGSE y la LODE en 1985 había regulado en lo tocante a la participación, organización y funcionamiento de los Centros Educativos así como la mejora de los mecanismos de evaluación sobre el conjunto del sistema. Sin embargo, no hubo tiempo material para comprobar los efectos del "parche" que simbolizaba la LOPEG sobre la LOGSE ya que como muy bien resume Puelles:

para los educandos. De hecho, este es un error que intentaría paliar el ECTS en la LOE: "Una conclusión a la que se llega de forma generalizada desde la praxis que los distintos colectivos implicados viven diariamente, es que resulta evidente que la falta de tiempo de dedicación al estudio del instrumento, como consecuencia de la excesiva carga lectiva, impide a los estudiantes españoles alcanzar niveles altos de ejecución." (GUTIÉRREZ BARRENECHEA, María del Mar: La formación de intérpretes profesionales en los conservatorios en el marco de la reforma educativa: Madrid como paradigma., Madrid, MEC, 2007, p. 197.)

${ }^{359}$ Véase en este sentido una muestra del análisis sobre el tema que realiza Zaldívar, al que volveremos más adelante: "Alcanzaban en 1990 estas titulaciones artísticas no universitarias su condición verdaderamente superior pero, efectivamente, ni sus enseñanzas, ni sus centros y profesorado, se han ido adecuando de verdad a la socialmente asumida visión española de entender la educación superior como igual a la universitaria, al no encontrarse estas artes integradas ni adscritas a la universidad ni disponer de una normativa propia que las hiciera correspondientemente equivalentes." (ZALDÍVAR GRACIA, Álvaro: "El reto de la investigación creativa y «performativa»", en Eufonía: Didáctica de la música, no 38, Barcelona, Graó, 2006, pp. 88-90). 
"La LOPEG se promulgó en 1995. Poco tiempo hubo para poner en marcha esas medidas dirigidas a mejorar la calidad. La llegada al gobierno del Partido Popular, un año más tarde, trajo también como objetivo una política centrada en la calidad de la educación aunque con un planteamiento distinto al de los socialistas." 360

En efecto, las urnas otorgaron la victoria a los populares en las elecciones de 1996, una victoria que daba por primera vez a la derecha el gobierno de la nación durante la democracia, con su corespondiente cambio de signo ideológico propio de la alternancia democrática.

Ahora bien, es preciso recalcar que pese al cambio político de los acontecimientos, la LOPEG dejaba una herencia cualitativa de vital importancia para las Enseñanzas Artísticas Superiores (EEAASS), al dar el primer paso en un tema tan trascendental como es el de la regulación de la investigación artística en los campos propios de sus enseñanzas: ${ }^{361}$

"Disposición adicional cuarta. De los centros superiores de enseñanzas artísticas.

Los centros superiores de enseñanzas artísticas fomentarán los programas de investigación en el ámbito de las disciplinas que les sean propias." 362

Las elecciones generales de 2004 traerían la segunda alternancia en el poder del PSOE con José Luís Rodríguez Zapatero al frente

360 Puelles Benítez, Manuel, op. cit., p. 201.

${ }^{361}$ La regulación era realmente importante pero una vez más, el desafío sería poder llevarla a la práctica educativa en las aulas: "Un mandato importante, pues con él se equiparaban parcialmente estos centros con los universitarios (hasta entonces, los únicos a los que se les encomendaba la docencia unida a la investigación), pero terminó por ser una tarea que, por falta de adecuado desarrollo, no pudo ser eficazmente cumplida al no ser ni exigible ni evaluable (como si lo es en el ámbito universitario)." ZALDívAR GRACIA, Álvaro, op. cit., p. 90.

${ }^{362}$ Ley Orgánica 9/1995, de 20 de noviembre,...(B.O.E. de 21 de noviembre de 1995, Disposición Cuarta). 
como presidente. María Jesús San Segundo Gómez de Cadiñanos es nombrada ministra de Educación y Ciencia e inicia su tarea estrenando el proceso de debate público que concretaría el Anteproyecto de Ley Orgánica de la Educación de 30 de marzo de 2005, en Proyecto de Ley Orgánica de la Educación de 26 de agosto de 2005, para finalmente ser sancionado como Ley Orgánica 2/2006, de 3 de mayo, de Educación. Como muy bien sintetiza Marzal Raga:

"La Ley Orgánica 2/2006, de Educación (LOE) pone fin al rosario de modificaciones legislativas en materia educativa que tras la LOGSE se produjeron" [...] "derogando expresamente dicho texto - cuya trascendencia en la historia educativa de las enseñanzas musicales es innegable -, así como la LOPEG y la LOCE, por las que se introducen reformas parciales en aquella." 363

En efecto, la Ley de Educación de 2006 intentó actuar como receptáculo aglutinador de las normativas anteriores que buscaban dar respuesta, a través de sucesivos parches normativos, a los conflictos que la comunidad educativa iba descubriendo. Pero la ley, pese al valioso ejercicio de condensación que pretendía, estaba lejos de conseguir el consenso de las principales fuerzas políticas que la opinión pública demandaba, revelando que si bien es necesario una actualización de las políticas educativas acorde con los cambios sociales de su tiempo, el continuo cambio de posición ideológica sobre educación que impone el partido de turno ocupando el poder, estaba llevando a una proliferación de normas y planes sospechosamente innecesaria que empezaba a exigir una revisión de los planteamientos políticos:

"En realidad, lo que los poderes públicos del Estado hacían era constatar la existencia de un estado de opinión, cada vez mayor en la sociedad española, que abogaba por un sistema educativo dotado de la estabilidad necesaria para avanzar hacia metas mayores de calidad. Tanto la derecha como la izquierda, presionadas por la opinión pública y por la necesidad política, estaban llegando a la convicción de que las reformas

${ }^{363}$ Marzal Raga, Consuelo, op. cit., p. 143. 
y contrarreformas constantes no podían producir más que confusión." [...] "Prácticamente todo el mundo era consciente de que en los últimos veinticinco años habíamos tenido ocho leyes orgánicas de educación (a las que habría que añadir la LOE de 2006 y la ley de 2007, modificadora de la LOU). Es cierto que no todas habían tenido el mismo valor ni los mismos apoyos sociales y políticos, pero la continua promulgación de unas tras otras, además de provocar cansancio y escepticismo, hacía inevitable que la propia sociedad se preguntara por la virtualidad de las reformas en esos cinco lustros por la suerte de las leyes orgánicas que las habían respaldado. ¿No habían aprobado los grupos parlamentarios el artículo 27 de la Constitución como expresión concreta del consenso? ¿Es que el pacto escolar constituyente había sido un esfuerzo baldío?"364

En definitiva, lo que el artículo 27 de la Constitución y su intención en la búsqueda del pacto escolar constituyente, así como la LOGSE o la LOE demuestran, es que a pesar de ser notables preceptos, se muestran impotentes a la hora de alcanzar un acuerdo consensuado entre la amplia diversidad de posicionamientos e intereses que concurren en la sociedad española.

Sin embargo, desde otro punto de vista podemos tener la certeza que si la LOE fue desarrollada con cierta normalidad, fue gracias a la experiencia adquirida con la LOGSE y las normativas posteriores, lección cuyo aprendizaje permitiría concebir para el futuro el reto de la convergencia de la educación superior española con los sistemas educativos europeos, concurriendo en un espacio común.

\subsubsection{Leyes de Educación durante los gobiernos del Partido Popular: LOU, LOCE y LOMCE}

La primera alternancia al poder del Partido Popular después de la larga etapa de Felipe González, permitió gobernar a los populares durante dos legislaturas consecutivas que tuvieron un carácter muy

${ }^{364}$ Puelles Benítez, Manuel, op. cit., p. 233. 
distinto en la gestión de su política educativa. Ésta se caracterizó por una ausencia de actividad normativa durante el primer período de 1996 al 2000, y por la redacción de la LOU y la LOCE en su segunda etapa, de 2000 al 2004, aunque finalmente con la llegada nuevamente de los socialistas la LOCE nunca llegaría a desenvolverse. Más recientemente, la segunda llegada al gobierno de la derecha con Mariano Rajoy en 2011, ha permitido hasta ahora desplegar una nueva ley de Educación, la LOMCE.

Cuando José María Aznar llega al gobierno en 1996, lo hace con un estrecho margen sobre la oposición, lo que le obligó a pactar con partidos nacionalistas ante la falta de una mayoría suficiente que le permitiese hacerlo en solitario. Esperanza Aguirre y Gil de Biedma, ocupa la cartera del Ministerio de Educación y Cultura hasta 1999 siendo relevada por Mariano Rajoy Brey durante un año antes de la celebración de las nuevas elecciones. Cabe destacar, que durante este tiempo no hubo ninguna acción remarcable sobre el sistema educativo general.

En contraste con este silencio legislativo y la falta de un debate público sobre educación, Pilar del Castillo Vera, nueva ministra de Educación, Cultura y Deporte manteniendo su cargo hasta el final de la legislatura, desplegó durante su mandato la siguiente normativa: Ley Orgánica 6/2001, de 21 de diciembre, de Universidades; Ley Orgánica 5/2002, de 19 de junio, de las Cualificaciones y de la Formación Profesional; Ley Orgánica 10/2002, de 23 de diciembre, de Calidad de la Educación.

La Ley Orgánica de Calidad de Educación brotaba como consecuencia de los desarreglos que la LOGSE había mostrado tras dos décadas de vigencia ${ }^{365}$ - el descenso en el rendimiento de los

\footnotetext{
${ }^{365}$ Algunos especialistas comentan a este respecto: "Conforme fue avanzando la implantación de la LOGSE se hizo evidente la existencia de una serie de disfunciones y errores que necesitaban rectificación. La comunidad escolar, las fuerzas sociales y políticas, los medios de comunicación pusieron en evidencia que determinados aspectos de la LOGSE a pesar del acierto de su diseño general, no estaban funcionando adecuadamente, bien por defectos propios de la reforma escolar, bien como consecuencia de su desarrollo normativo y ejecución práctica." (Ídem, p. 215).
} 
escolares o la desobediencia hacia el profesorado entre otros factores - y que no había dado tiempo a ser enmendados con la LOPEG al cambiar el signo político en los últimos comicios. Así que como resultado, la LOCE intentaba ser el nuevo "parche" de la LOGSE pero con diferente signo político en el poder. Los problemas de la LOCE surgirían primeramente por la falta de financiación, aspecto que han heredado todas la Leyes Educativas hasta la LOE, y en segundo lugar por los procedimientos adoptados por el ejecutivo, ya que al desarrollarse bajo una mayoría absoluta no tuvo en cuenta otras agentes activos de la comunidad educativa, repitiéndose una situación similar más adelante con el proceso de preparación y aprobación de la LOMCE en 2013.

Sucesivas normas fueron retrasando el calendario de aplicación de la Ley y con la repentina llegada al gobierno de Zapatero, la LOCE quedaría finalmente derogada por la Ley de Educación en 2006. Como comprobaremos en el análisis de la ley en el capítulo siguiente, este hecho fue positivo para la regulación de las enseñanzas artísticas, ya que no hubiesen salido muy bien paradas en caso de haberse aplicado la disposición.

Tras ser líder de la oposición durante los dos mandatos socialistas de Rodríguez Zapatero, Mariano Rajoy jura su cargo como presidente en diciembre de 2011, dirigiendo el gobierno de la nación en su X legislatura. José Ignacio Wert Ortega es ahora designado nuevo ministro del Educación, Cultura y Deporte. Tras la presentación el 21 de septiembre de 2012 del anteproyecto de Ley Orgánica para la Mejora de la Calidad Educativa al Consejo de Ministros, y la posterior aprobación el 17 de mayo de 2013 del Proyecto de Ley Orgánica para la Mejora de la Calidad Educativa (LOMCE), el Congreso de los Diputados aprueba el 28 de noviembre la Ley Educativa que se publica en el Boletín Oficial del Estado del 10 de diciembre como, Ley Orgánica 8/2013, de 9 de diciembre, para la mejora de la calidad educativa.

Si la LOCE venía a revisar y modificar artículos de la LOGSE de 1990 y la LOPEG de 1995, la LOMCE viene a reformar, que no a derogar, artículos de sus predecesoras, LOE de 2006 y LODE de 1985. 
La LOMCE fue aprobada en su tramitación en las Cortes única y exclusivamente por el Partido Popular que gobierna en esta legislatura con mayoría absoluta, y que ha visto cómo la ley ha sido contestada contundentemente por la opinión pública y diversos representantes de todos los niveles educativos. Rajoy gobierna en medio de un panorama económico devastador y elabora un decreto con medidas urgentes para recortar el gasto público en educación $^{366}$, cumpliendo con el objetivo de déficit fijado por la Unión Europea. El martes 22 de mayo de 2012, convocada por los cinco sindicatos de la enseñanza CCOO, ANPE, CSIF, STES y UGT, tiene lugar una huelga general de todos los niveles de la enseñanza pública sin precedentes en la historia democrática, como protesta al Real Decreto-ley que afecta al sector educativo.

Junto a este contexto socioeconómico, a la polémica LOMCE hay que sumarle la fuerte oposición que ha recibido desde su primera elaboración como anteproyecto por los partidos de izquierda, partidos nacionalistas y sectores sociales representados por asociaciones de padres y alumnos que temen ver lesionada la integridad de la educación pública, utilizando como arma arrojadiza la coyuntura de crisis económica que obliga al gobierno a tomar políticas de austeridad. Por este motivo, se encabezan nuevas movilizaciones y protestas el 24 de octubre de 2013 con la convocatoria de una Huelga General de la Enseñanza Pública, en contra esta vez también de la LOMCE y de la política educativa del gobierno basada en los recortes de inversión pública en educación.

\subsubsection{La LOGSE: el modelo curricular y la programación didáctica de Piano}

Después de la reglamentación general de los Conservatorios de Música en 1966, y al expirar sin éxito el plazo previsto por la "Ley Villar" para incorporar los conservatorios al régimen universitario, le tocaría a la Ley Orgánica de Ordenación General del Sistema

${ }^{366}$ Real Decreto-ley 14/2012, de 20 de abril, de medidas urgentes de racionalización del gasto público en el ámbito educativo (B.O.E. de 21 de abril). 
Educativo el turno de emprender la adaptación de las enseñanzas artísticas a los nuevos aires democráticos.

La LOGSE cataloga en su artículo tercero los estudios musicales como enseñanzas de régimen especial, advirtiendo que dichas enseñanzas se regularán por las normas dispuestas en la presente ley, exceptuando de tal prescripción a la educación universitaria que se reglamentará por su propia normativa:

“Artículo 3

1. El sistema educativo comprenderá enseñanzas de régimen general y enseñanzas de régimen especial." [...]

“3. Son enseñanzas de Régimen especial las siguientes:

a) Las enseñanzas artísticas.

b) Las enseñanzas de idiomas." [...]

"7. Tanto las enseñanzas de régimen general como las de régimen especial se regularán por lo dispuesto en esta ley, salvo la educación universitaria que se regirá por sus normas específicas". 367

En el Título segundo, la Ley desarrolla los contenidos relativos a las enseñanzas de régimen especial, dedicándole los artículos 38, 39, 40, 41 y 42, a las enseñanzas artísticas de música y danza. Los aspectos más destacables los hallamos en el artículo 39, párrafos primero y cuarto:

“Artículo 39

1. Las enseñanzas de Música y Danza comprenderán tres grados:

a) Grado elemental, que tendrá cuatro años de duración.

${ }^{367}$ Ley Orgánica 1/1990, de 3 de octubre,...(B.O.E. de 4 de octubre de 1990, Título Preliminar, art. 3). 
b) Grado medio, que se estructurará en tres ciclos de dos cursos académicos de duración cada uno.

c) Grado superior, que comprenderá un solo ciclo cuya duración se determinará en función de las características de estas enseñanzas." $[\ldots]$

“4. Para el establecimiento del currículo de estas enseñanzas se estará a lo dispuesto en el artículo 4 de esta ley". ${ }^{368}$

Las enseñanzas de música quedan divididas consiguientemente en tres grados elemental, medio y superior, algo que no sorprende demasiado, ya que repite el patrón dibujado por la reglamentación de 1966. Pero lo que sin duda resulta especialmente novedoso es el concepto de currículo como nuevo principio estructural del presente modelo educativo. Veamos qué apunta la LOGSE al respecto:

\section{"Artículo 4}

1. A los efectos de lo dispuesto en esta ley, se entiende por currículo el conjunto de objetivos, contenidos, métodos pedagógicos y criterios de evaluación de cada uno de los niveles, etapas, ciclos, grados y modalidades del sistema educativo que regulan la práctica docente.

2. El Gobierno fijará, en relación con los objetivos, expresados en términos de capacidades, contenidos y criterios de evaluación del currículo, los aspectos básicos de éste que constituirán las enseñanzas mínimas, con el fin de garantizar una formación común de todos los alumnos y la validez de los títulos correspondientes. Los contenidos básicos de las enseñanzas mínimas, en ningún caso requerirán más del 55 por ciento de los horarios escolares para las Comunidades Autónomas que tengan lengua oficial distinta del castellano, y del 65 por ciento para aquellas que no la tengan.

3. Las Administraciones educativas competentes establecerán el currículo de los distintos niveles, etapas, ciclos, grados y

368 Ídem, Título II, Capítulo Primero, art. 39. 
modalidades del sistema educativo, del que formarán parte, en todo caso, las enseñanzas mínimas". ${ }^{36}$

Topamos aquí con dos de las características que ya habíamos anunciado anteriormente. Por un lado aparece el modelo curricular, como opción alternativa al modelo tecnocrático de la Ley General de $1970,{ }^{370}$ basado según la LOGSE, en la ordenación de los diferentes niveles, ciclos, cursos y demás elementos del sistema educativo, conforme a un conjunto de parámetros prefijados que responden a la combinación de objetivos, contenidos, métodos pedagógicos y criterios de evaluación. En segundo lugar, prorrumpe la responsabilidad de las Comunidades Autónomas de añadir a ese 55 o 65\%, según sea el caso, de enseñanzas mínimas comunes para todo el estado, el contenido restante hasta completar el currículo que conforma el sistema educativo. Establecidas las bases reguladoras de las enseñanzas musicales y a la luz del nuevo modelo curricular instituido por la Ley, se inicia el período de aplicación y desarrollo de la misma. ${ }^{371}$

El Real Decreto 389/1992, de 15 de abril, suscita la separación de los Conservatorios de Música en Centros Profesionales y Superiores, otorgando a cada uno de ellos diferentes espacios y atribuciones conforme a su nueva clasificación:

"Por otra parte, y a los mismos efectos, se efectúa una necesaria clarificación y definición de los distintos modelos de centros, tanto a través de la delimitación de su ámbito competencial y de las especialidades mínimas con que en cada caso deben contar, como por el distinto régimen jurídico aplicable en razón a la validez académica de las enseñanzas que impartan; en este contexto, el presente Real Decreto efectúa, en el caso de la música y la danza, una distinción entre el modelo de centros que imparte enseñanzas regladas

${ }^{369}$ Ídem, Título preliminar, art. 4.

${ }^{370}$ Pliego DE ANDRÉs, Víctor: Temas pedagógicos para la oposición de conservatorios, Madrid, Musicalis, 1998, p. 84.

${ }^{371}$ Real Decreto 986/1991, de 14 de junio, por el que se aprueba el calendario de aplicación de la nueva ordenación del sistema educativo (B.O.E. de 25 de junio de 1991). 
conducentes a una formación específica de profesionales, cuyos requisitos regula detalladamente, y el modelo de escuelas de música o de danza en las que prima el carácter cultural sobre el profesional, y cuya regulación se remite a cada Administración educativa.

Especial relevancia adquieren los centros que imparten enseñanzas artísticas de nivel superior, para los cuales el presente Real Decreto establece unos requisitos acordes con el nivel de los estudios y de los títulos a que conducen y coherentes con los exigidos en nuestro país a los centros docentes superiores". 372

Este hecho es especialmente significativo en la medida en que implica la planificación de diferentes currículos formativos para las enseñanzas musicales de uno y otro nivel, lo que a su vez acarrea la aparición de programaciones diferentes y el consiguiente riesgo de desconexión en la continuidad de los grados.

Para el Grado Elemental y Medio de las enseñanzas de música, el Real Decreto 756/1992, de 26 de junio, ${ }^{373}$ establece los aspectos básicos del currículo que constituyen las enseñanzas mínimas de estos grados comunes para todo el Estado. En el caso del Grado Superior, el Real Decreto 671/1995, de 21 de abril, ${ }^{374}$ establece los aspectos básicos de currículo de este nivel para todo el territorio español. Corresponde a las Administraciones educativas competentes completar el contenido final de los currículos, englobando siempre estas enseñanzas mínimas. ${ }^{375}$ Verifiquemos cuáles son las

${ }^{372}$ Real Decreto 389/1992, de 15 de abril, por el que se establecen los requisitos minimos de los Centros que impartan Enseñanzas Artisticas (B.O.E. de 28 de abril de 1992).

${ }^{373}$ Real Decreto 756/1992, de 26 de junio, por el que se establece los aspectos básicos del curriculo de los grados elemental y medio de las enseñanzas de música (B.O.E. de 27 de agosto de 1992).

${ }^{374}$ Real Decreto 617/1995, de 21 de abril, por el que se establece los aspectos básicos del curriculo del grado superior de las enseñanzas de música y se regula la prueba de acceso a estos estudios (B.O.E. de 6 de junio de 1995).

${ }^{375}$ En el caso de la Comunidad Valenciana se desarrollaron las siguiente disposiciones: Decreto 151/1993, de 17 de agosto, del Gobierno Valenciano, por el 
transformaciones acontecidas en el contorno de nuestra disertación, examinando con más detenimiento estas disposiciones.

Un primer rasgo anecdótico, pero que nos advierte de algún modo sobre la magnitud de la nueva ordenación educativa, lo integra la extensión de las nuevas disposiciones desarrolladas si las comparamos con sus homólogas predecesoras en el tiempo. Tal es el caso del Real Decreto 756/1992, aunque como es obvio, las verdaderas reformas las hallamos dentro de la propia resolución. El preámbulo del Real Decreto nos sitúa ante el nuevo programa que se nos presenta, proporcionándonos las claves de las principales novedades.

Así cabe destacar en la nueva estructuración de los grados elemental y medio, la ampliación del período de estudios, fijando 4 años en el grado elemental y tres ciclos de dos cursos cada uno para grado medio, ${ }^{376}$ comenzando simultáneamente los estudios instrumentales, junto con los de Lenguaje musical (antes Solfeo). Otra variación consiste en el nuevo enfoque de la especialidad instrumental, planteada como eje vertebrador sobre el que gravitan el resto de asignaturas teóricas establecidas para cada grado, con el objetivo de ofrecer una formación integral al alumno. De este modo, se procura garantizar no solamente una educación sólida en el aspecto puramente instrumental, sino que además se incluyen también los aspectos históricos, estéticos y psicológicos del hecho

que establece el curriculo de los grado elemental y medio de música y se regula el acceso a dichos grados (DOGV de 2 de septiembre de 1993); Decreto 132/2001, de 26 de julio 2001, del Gobierno Valenciano, por el que se establece el currículo del grado superior de música en la Comunidad V alenciana y el acceso a dichas enseñanzas (DOGV de 14 de agosto de 2001).

${ }^{376}$ Más que una ampliación, lo que la LOGSE efectúa es una normalización de los estudios instrumentales. En el caso específico de la especialidad de Piano, un alumno del "Plan 66", realizaba un curso de preparatorio como mínimo, antes de comenzar el primer curso de grado elemental. Durante el grado medio era usual realizar el último curso $\left(8^{\circ}\right)$ en dos años, lo que nos da un cómputo general de diez años de estudios para finalizar el grado medio en dicho plan. Por lo que respecta al grado superior, no era inusual realizar cada curso $\left(9^{\circ}\right.$ y $\left.10^{\circ}\right)$ en dos años, en ocasiones se realizaban los dos cursos en tres años, y eran casos contados, los que completaban el programa a lo largo de un curso académico. 
musical. Esta premisa es nuclear, ya que el nuevo modelo curricular propuesto por la ley educativa sobrepasa el antiguo concepto de "programa", envolviéndolo en una visión más global del aprendizaje, donde se reúnen junto a las destrezas propias de la práctica instrumental, los conocimientos conceptuales, procedimentales o los valores del educando. Además se ha de contemplar la utilización de los recursos metodológicos apropiados para cumplir los objetivos propuestos, estableciendo igualmente los instrumentos que permitan evaluar el proceso de enseñanza y aprendizaje:

"Por otra parte, en el presente Real Decreto se fijan los aspectos básicos del currículo que constituyen las enseñanzas mínimas de música de los grados elemental y medio, partiendo de una noción de currículo que no se circunscribe a un mero programa o plan de estudios, sino que engloba todas las posibilidades de aprendizaje que ofrecen los centros especializados de enseñanza musical reglada, referidos a conocimientos conceptuales, procedimientos, destrezas, actitudes y valores. Incluye, además, el establecimiento de los medios adecuados para lograr estos objetivos, los métodos de evaluación de los procesos de enseñanza y aprendizaje, así como la capacidad de desarrollar experiencias educativas en el ámbito docente".377

La ley pone de relieve la metodología educativa como un nuevo aspecto a tener en cuenta en la reforma de la enseñanza, gravemente descuidado en los anteriores sistemas. ${ }^{378}$ La LOGSE despliega en su artículo segundo, tercer apartado, el marco general en el que se engloban estos principios metodológicos. Entre ellos subrayaríamos los siguientes:

“a) La formación personalizada, que propicie una educación integral en conocimientos, destrezas y valores morales de los

\footnotetext{
${ }^{377}$ Real Decreto756/1992, de 26 de junio..(B.O.E. de 27 de agosto de 1992).

${ }^{378}$ Es opinión de Pliego de Andrés que antaño "predominaba un aprendizaje esencialmente mecánico, memorístico y poco lógico". Nosotros compartimos plenamente este juicio (PLIEgo DE ANDrÉs, Víctor, op. cit., p. 99).
} 
alumnos en todos los ámbitos de la vida, personal, familiar, social y profesional.

d) El desarrollo de las capacidades creativas y del espíritu crítico.

f) La autonomía pedagógica de los centros dentro de los límites establecidos por las leyes, así como la actividad investigadora de los profesores a partir de su práctica docente.

h) La metodología activa que asegure la participación del alumnado en los procesos de enseñanza y aprendizaje". ${ }^{379}$

Los preceptos metodológicos expuestos ponen de relieve la importancia de la calidad de los procesos educativos, es decir, el ¿cómo voy a enseñar?, factor particularmente importante en el caso de las enseñanzas musicales, al ser una educación cuyo desarrollo solicita ciertos requerimientos y una adecuada disposición por parte del alumnado. De ahí que, renovando el mismo proceder que ya esgrimieron otros reglamentos con anterioridad, ${ }^{380}$ el actual Real Decreto también nos recuerda esta peculiaridad de los estudios artísticos:

"De acuerdo con ello, los aspectos básicos de los grados elemental y medio deberán garantizar una formación musical que proporcione el nivel de expresión artística propio de unos estudios especializados, que tienen como meta el ejercicio profesional, y que por ello están destinados a aquellos alumnos que posean aptitudes específicas y voluntad para dedicarse a ellos". ${ }^{381}$

No obstante, la especialidad instrumental debe conjugar el doble objetivo contemplado en las enseñanzas profesionales, dirigidas

${ }^{379}$ Ley Orgánica 1/1990, de 3 de octubre,... (B.O.E. de 4 de octubre de 1990, Título preliminar, art. 2.3).

380 Véase SAlaverría, Pedro: "Reglamento Orgánico Provisional del Real Conservatorio de Música y Declamación" en Memoria acerca de la Escuela Nacional de Música y Declamación de Madrid..., pp. 58-67.

${ }^{381}$ Real Decreto756/1992, de 26 de junio,...(B.O.E. de 27 de agosto de 1992). 
por un lado, a crear la base fundamental para la posterior especialización en el grado superior, o bien como soporte básico que favorezca la orientación hacia otras materias en el futuro:

"De acuerdo con el objetivo profesional de las enseñanzas, el planteamiento educativo de los grados elemental y medio se fundamenta en el estudio de una especialidad instrumental que actúa de eje vertebrador del currículo con la doble finalidad preparatoria de servir de formación básica para acceder a estudios de especialización en el grado superior, dentro de la opción elegida, o servir de fundamento para la apertura hacia otros itinerarios". ${ }^{382}$

Toda esta reflexión nos catapulta hacia el elemento fundamental de nuestra disertación. Desde la actual perspectiva, ¿cuál es la programación que propone la nueva reforma educativa a la luz de estas modificaciones?

La respuesta se exhibe tan sencilla como inquietante: ninguna. $\mathrm{O}$ al menos, no bajo el aspecto al que habíamos estado acostumbrados hasta este momento. La "Programación de Piano" representativa de los años setenta y ochenta, conforme al estilo o modelo cimentado en la ejecución pianística de un repertorio que el alumno ha de interpretar al final del curso académico, dará paso en la década de los noventa a las "Programaciones Didácticas", documentos elaborados por cada uno de los diferentes departamentos que constituyen los conservatorios en el uso de sus atribuciones de autonomía pedagógica y organizativa:

"Artículo 3.

Al establecer el currículo de los grados elemental y medio, las Administraciones educativas fomentarán la autonomía pedagógica y organizativa de los centros, favorecerán el trabajo en equipo de los profesores y estimularán la actividad investigadora de los mismos a partir de su práctica docente". ${ }^{383}$

\footnotetext{
${ }^{382}$ Ibidem.

${ }^{383}$ Ibidem.
} 
En efecto, el modelo curricular encierra entre otras particularidades, la característica de ser un modelo abierto, es decir, un sistema en el que partiendo desde la ley elaborada por el Gobierno se atraviesa cada conservatorio hasta llegar al profesor como último eslabón de una cadena, donde todos forman parte de un proceso capaz de definir el currículo formativo que mejor se adapte al contexto sociocultural de cada centro. ${ }^{384}$ Por esta razón, no existe un modelo de programación preestablecida al estilo de fórmula magistral, sino que por el contrario se nos presentan los ingredientes de una receta en el que cada comunidad educativa tiene la capacidad y la responsabilidad de realizar su propia propuesta particular. El modo de combinar estos ingredientes es lo que originará, en última instancia, la programación didáctica de Piano:

"Con este planteamiento se persigue que, tanto al fijar las enseñanzas mínimas comunes para todo el Estado como al establecer los distintos currículos por cada Administración educativa, estos sean suficientemente amplios, abiertos y flexibles. De esta forma los profesores podrán elaborar proyectos y programaciones que desarrollen en la práctica las virtualidades del currículo establecido, adaptándolo a las características de los alumnos y a la realidad educativa de cada centro". 385

El mismo espíritu se desprende, a la hora de organizar los contenidos previstos por la disposición:

"Por otra parte, los contenidos que se establecen no han de ser interpretados como unidades temáticas, ni, por tanto, necesariamente organizados tal y como aparecen en este Real

\footnotetext{
${ }^{384}$ La flexibilidad del modelo curricular permite una mayor participación del profesorado: "Puesto que el currículo es una propuesta abierta, es necesario que cada centro, cada materia y cada profesor lo complete para adaptarlo a su ámbito de acción. Este proceso, que desciende de las propuestas generales a las particularidades de cada aula y de cada alumno, se denomina proceso de concreción o desarrollo curricular. Se desenvuelve en tres niveles que van de lo más general a lo más concreto. El tercer nivel corresponde a la programación." (Pliego DE ANDRÉS, Víctor, op. cit., p. 87).

${ }^{385}$ Real Decreto 756/1992, de 26 de junio,...(B.O.E. de 27 de agosto de 1992).
} 
Decreto. Recogen una relación que incluye diversas variedades del «saber hacer» teórico-práctico junto a contenidos de orden estético propios de las enseñanzas musicales, así como aquellos de carácter moral que deben estar presentes en todo el proceso educativo. La ordenación y sistematización de los mismos corresponde a los proyectos y programaciones que elaboren los profesores y los centros". ${ }^{386}$

¿Dónde hallamos los ingredientes de esta receta? Los artículo 4 y 8 del Real Decreto 756/1992, establecen los objetivos generales de los grados elemental y medio, mientras que los anexos I,a) y I,b) de la resolución, muestran respectivamente los contenidos, objetivos y criterios de evaluación que constituyen las enseñanzas mínimas. Por otro lado, en las instrucciones distribuidas a los centros docentes por sus respectivos gobiernos autonómicos encontramos las indicaciones precisas que han de contemplarse en la elaboración de las programaciones didácticas de cada asignatura:

"La programación didáctica incluirá, necesariamente, los siguientes aspectos para cada una de las asignaturas y especialidades asignadas a los órganos de coordinación didáctica del Conservatorio:

-Distribución por cursos de los objetivos, contenidos y criterios de evaluación.

-Las decisiones de carácter general sobre la metodología didáctica que se va a aplicar.

-Los procedimientos e instrumentos de evaluación del aprendizaje de los alumnos.

-La aplicación de las normas sobre criterios de promoción, haciendo especial referencia a los mínimos exigibles, y los criterios sobre periodicidad y comunicación de las calificaciones.

-Los criterios de recuperación para los alumnos que tienen asignaturas pendientes.

${ }^{386}$ Ibidem. 
-El repertorio, la bibliografía y los recursos didácticos que se vayan a utilizar.

-La programación de cuántas actividades de orden académico y complementario se pretenda realizar.

-Las medidas de atención a la diversidad y las adaptaciones curriculares para el alumnado que las precise.

Los profesores programarán su actividad docente de acuerdo con las programaciones didácticas. En caso de que algún profesor decida incluir en la programación de su actividad docente alguna variación con respecto a la programación didáctica conjunta, dicha variación, y la justificación correspondiente, deberá ser incluida en la programación didáctica del Departamento, teniendo en cuenta que para ser autorizada deberá respetar los mínimos curriculares establecidos". ${ }^{387}$

En conclusión, el departamento pertinente de cada conservatorio elaborará su oportuna programación didáctica de Piano, respetando los contenidos mínimos propuestos por el Estado. El desarrollo curricular se cierra con la programación didáctica de aula, elaborada por cada profesor de la asignatura, y sujeta a las observaciones dispuestas en la programación didáctica del departamento. No es objetivo de este trabajo realizar un examen exhaustivo sobre los defectos y virtudes del nuevo modelo de programación adoptado en los conservatorios a raíz de las nacientes propuestas metodológicas formuladas en la LOGSE. Se trata de una cuestión de gran calado, cuyo contenido daría por sí solo elementos para desarrollar un trabajo de investigación aparte. Sin embargo, nuestro estudio concentra entre sus cometidos, aportar todas aquellas evidencias contenidas en el ámbito de su ejercicio, capaces de esclarecer las características y trayectoria de la actual programación.

${ }^{387}$ Consellería de Cultura, Educació i Ciència, Direcció general d'ordenació i innovació educativa i política lingüística, Resolución de 27 de mayo de 1998 por la que se regula la organización y el funcionamiento de los Conservatorios de música pertenecientes a la Consellería de Cultura, Educación y Ciencia de la Comunidad Valenciana. No publicada, sino que fue distribuida en los centros. 
Los contenidos desplegados en la ley son profusos y los objetivos contemplan tanto el programa tradicional basado en el repertorio, como nuevos parámetros musicales encauzados hacia aspectos tan importantes como son la música de conjunto o la metodología, ingredientes prácticamente abandonados en el plan anterior y que ahora se ponen de relieve con el propósito de fomentar la autonomía de los alumnos ante los problemas interpretativos. ${ }^{388}$ Sin embargo, el último nivel de concreción del proceso curricular, la acción docente llevada a cabo por el profesor en el aula, sigue siendo un desafío que genera no pocas dudas e incertidumbres. Por ejemplo, la tipificación de las actividades de enseñanza y aprendizaje en unidades didácticas, que se perfila claramente como un modelo ajustado a las enseñanzas de régimen general, no acaba de encontrar una definición tan afinada en el caso de las enseñanzas artísticas. Ante la indecisión respecto a cuál es el lugar y en qué proporción han de combinarse los diferentes elementos del currículo que constituyen la programación, por ejemplo en el caso concreto del repertorio, tampoco encontramos una respuesta satisfactoria. Nos hallamos por tanto ante un asunto de máxima relevancia del que todavía queda terreno por explorar, y en el que especialmente el campo de la investigación tiene un compromiso decisivo en el desenlace satisfactorio de su evolución.

${ }^{388}$ La independencia de los alumnos se ve ahora reforzada mediante el desenvolvimiento de sus facultades: "La enseñanza de piano en el grado medio tendrá como objetivo contribuir a desarrollar en los alumnos las capacidades siguientes: a) Interpretar un repertorio que incluya obras representativas de diferentes épocas y estilos de dificultad adecuada a este nivel. b) Conocer las diversas convenciones interpretativas vigentes en distintos períodos de la música instrumental, especialmente las referidas a la escritura rítmica o a la ornamentación. c) Practicar la música de conjunto, integrándose en formaciones camerísticas de diversa configuración y desempeñando papeles de solista con orquesta en obras de dificultad media, desarrollando así el sentido de la interdependencia de los respectivos cometidos. d) Aplicar con autonomía progresivamente mayor los conocimientos musicales para solucionar por sí mismo los diversos problemas de ejecución que puedan presentarse relativos a digitación, pedalización, fraseo, dinámica." (Real Decreto 756/1992, de 26 de junio,..., Anexo I, b), Piano. Grado Medio. Objetivos). 
El Real Decreto 671/1995, de 21 de abril, ${ }^{389}$ es la disposición encargada de regular el currículo de enseñanzas mínimas del grado superior de Música en los conservatorios. El diseño planteado advierte en su exposición el riesgo que conlleva basar los estudios superiores en una formación polarizada exclusivamente en los estudios de la especialidad como perfeccionamiento del período iniciado en el grado medio. Para evitar este sistema, el presente currículo establece un conjunto de materias que acompañan a la especialidad con la finalidad de completar la práctica instrumental con una formación teórico-humanística adecuada:

"El presente Real Decreto por el que se determinan los aspectos básicos del currículo del grado superior establece y organiza, junto con las materias específicas de cada especialidad, otras basadas en la profundización en contenidos teórico-humanísticos que, lejos de suponer una mera complementariedad, imprimen a este tramo de los estudios un verdadero carácter de enseñanza superior, siguiendo con ello el ejemplo de las diferentes instituciones europeas en las que estos estudios están avalados por una experiencia tan larga como satisfactoria, al tiempo que se evita basar su planteamiento en una mera extensión del tradicional concepto de «virtuosismo», centrado casi exclusivamente en el perfeccionamiento de lo estrictamente relacionado con la propia especialidad". 390

El artículo cuarto, nos proporciona el objetito principal a cumplir con las enseñanzas de este ciclo superior:

"Artículo 4.

Las enseñanzas conducentes a la obtención del Título superior de Música deberán proporcionar una formación práctica, teórica y metodológica a través de la profundización en las materias que conforman la especialidad elegida, con el fin de

${ }^{389}$ Real Decreto 617/1995, de 21 de abril, por el que se establece los aspectos básicos del currículo del grado superior de las enseñanzas de Música y se regula la prueba de acceso a estos estudios (B.O.E de 6 de junio de 1995).

${ }^{390}$ Ibidem. 
garantizar la cualificación de los futuros profesionales de la música en los ámbitos relativos a la creación, la interpretación, la investigación y la docencia". ${ }^{391}$

Para ello se constituyen 35 especialidades que se abordan en cuatro grandes áreas, a saber: composición, interpretación, que incluye canto e instrumentos, dirección de coro y dirección de orquesta, musicología y pedagogía.

Esta última es sin duda alguna la gran novedad respecto a los planes anteriores, pudiéndose estudiar además en cualquiera de sus dos modalidades:

“3. La especialidad de Pedagogía constará de las dos opciones siguientes:

Opción a): Pedagogía del lenguaje y la educación musical.

Opción b): Pedagogía del canto y de las especialidades instrumentales que se detallan en los anexos I y II del presente Real Decreto". 392

De este modo se pretende dar respuesta a diferentes perfiles profesionales dentro de una misma especialidad, promocionando una cualificación más específica de los alumnos. La disposición prevé asimismo cuatro cursos para la obtención del Título superior, en el caso de la especialidad de Piano, y la posibilidad de completar el currículo con otras asignaturas no vinculadas a las materias propuestas en el Real Decreto. En relación con el campo de la investigación, el Real Decreto establece en su disposición adicional segunda, la concertación de los acuerdos necesarios con las universidades para facilitar la creación de programas de estudios de tercer ciclo dirigidos a licenciados de conservatorios. ${ }^{393}$

\footnotetext{
${ }^{391}$ Ibidem.

392 Ibidem.

393 Real Decreto 617/1995, de 21 de abril, (B.O.E de 6 de junio de 1995, Disposición adicional segunda).
} 
El elemento más menguado del Real Decreto lo constituye la descripción de los contenidos de las materias, sobre todo si lo comparamos con su homólogo de grado medio. Es cierto que el currículo de grado superior se articula en materias y no en asignaturas, como sucede en grado medio, de lo que se desprende que cada Administración educativa, debe completar posteriormente el currículo, estableciendo aquellas asignaturas que crea convenientes para el correcto desarrollo de las materias propuestas. ${ }^{394}$ No obstante, los resúmenes propuestos por el Real Decreto para cada una de las materias se nos descubren a todas luces insuficientes. Veamos si no, los contenidos establecidos para la materia de Piano, en cualquiera de sus dos modalidades, como especialidad o en la opción de Pedagogía del Instrumento:

"Piano. / Perfeccionamiento de las capacidades artística, musical y técnica, que permitan abordar la interpretación del repertorio más representativo del instrumento. Estudio de los criterios interpretativos aplicables a dicho repertorio, de acuerdo con su evolución estilística". ${ }^{395}$

Sin lugar a dudas se trata de todo un ejercicio de concisión y laconismo. Tal vez por esta razón se nos vuelva a recordar la importancia del trabajo conjunto de los departamentos didácticos, así como la promoción de las actividades artísticas e investigadoras de los profesores como elemento indispensable tanto en el remate final del desarrollo curricular, como en el correcto funcionamiento

394 “Artículo 6. 3. Las Administraciones educativas, al establecer el currículo, organizarán cada una de las materias en una o varias asignaturas, haciendo constar aquellas materias de las establecidas en el presente Real Decreto a las que corresponden, y determinarán el curso o cursos en que deberán realizarse, pudiendo incrementar los tiempos lectivos mínimos que se fijan en la presente norma para éstas. Asimismo, establecerán los criterios de promoción que consideren oportunos, así como las normas que regulen la permanencia de los alumnos en el centro." (Real Decreto 617/1995, de 21 de abril,..., B.O.E de 6 de junio de 1995, art. 6. 3).

395 Real Decreto 617/1995, de 21 de abril,...(B.O.E de 6 de junio de 1995, Anexo II, Piano). 
de los conservatorios. ${ }^{396}$ De hecho fuera de los generosos márgenes de estas últimas observaciones, no vamos a encontrar ninguna otra información en el currículo del grado superior capaz de suministrarnos instrucciones más precisas sobre la elaboración de la programación didáctica de Piano, ya que como se desprende de la lectura del anterior enunciado, esta responsabilidad recae básicamente sobre el departamento de cada conservatorio.

\subsubsection{El absentismo de la administración pública respecto a las enseñanzas artísticas de música}

Desde la sanción de la Ley Orgánica 5/1980, hasta la última norma de educación, Ley Orgánica 8/2013, han pasado 33 años, en cuyo período se han aprobado 9 leyes orgánicas de educación (LOECE/1980, LRU/1983, LODE/1985, LOGSE/1990, LOPEG/1995, LOU/2001, LOCE/2002, LOE/2006 y LOMCE/2013) lo que significa un cómputo medio de una ley cada 3 años y medio, es decir, aparece una ley nueva antes de que se agote el período de una legislatura política ordinaria de cuatro años. De donde se infiere que el pacto escolar acordado en el artículo 27 de la Constitución no ha conseguido una ordenación político-social acorde, capaz de asegurar una regulación de la política educativa española coherente y estable.

Por otro lado, hemos podido comprobar con varias evidencias a lo largo de nuestro viaje, el abandono político que ha sufrido la regulación de las Enseñanzas Artísticas de Música prácticamente desde su inicio con la institución del primer establecimiento de enseñanzas musicales, el Real Conservatorio de Madrid, al margen del plan general de educación, para tras un breve lapso de tiempo que no llegaría a una década de reconocimiento de las enseñanzas de mú-

\footnotetext{
396 “Artículo 6. 2. Al establecer el currículo del grado superior de las enseñanzas de Música, las Administraciones educativas fomentarán la autonomía pedagógica y organizativa de los centros, favorecerán el trabajo en equipo de los profesores, y estimularán la actividad artística e investigadora de los mismos a partir de su práctica docente." (Real Decreto 617/1995, de 21 de abril,..., B.O.E de 6 de junio de 1995, art. 6. 2).
} 
sica con la Ley Moyano de 1857, perpetuar su peregrinar hasta 1990 en el que vuelven a introducirse en el sistema educativo junto con las enseñanzas de régimen general, después de más de 120 años excluidas de los sistemas educativos.

Si las enseñanzas artísticas han mostrado problemas para su inserción normalizada en el conjunto del sistema educativo, la equiparación del ciclo superior de estas enseñanzas ha seguido como es de esperar igual suerte. La LGE, la LOGSE y la LOE han ido organizando este ciclo superior con distinta fortuna, y pese a conseguir importantes avances, no han llegando a obtener ni siquiera hoy en día el status superior correspondiente al de las enseñanzas universitarias, o al de centros equivalentes en otros países europeos, al faltar las enseñanzas de tercer ciclo conducentes al doctorado.

Existen obviamente momentos importantes de la normativización musical como son, la Ley Moyano de 1857, la Ley General de Educación de 1970 o la LOGSE, pero aún así, las enseñanzas artísticas de música han sufrido un retraso dañino fruto del abandono legislativo de los poderes públicos:

"Puede decirse, por tanto, que dentro de las deficiencias generales que acompañan al completo sistema educativo del país, la situación de las enseñanzas musicales es un punto más deficiente y con su consideración se puede comprender perfectamente que, aun surgiendo de cuando en cuando figuras singulares en el panorama de la Música española, haya sido imposible hasta el momento la consecución de estructuras organizativas estables como Orquestas, Compañías o Centros de representación de relevancia, porque falta la estructura formativa adecuada para ello. Sólo los últimos tiempos comienzan a ser una excepción a la tónica general narrada." 397

La historia de la organización de las Enseñanzas de Música, sólo ha empezado a despegar en las últimas décadas, buscando un desarrollo normalizado que evite los extremos protagonizados en el pasado, donde figuras aisladas de arrollador talento y reconocido

${ }^{397}$ EMBID IRUjO, A.: Un siglo de legislación musical..., p. 85. 
prestigio para la Música, se han visto obligadas a emigrar ante la imposibilidad de desarrollarse en un ambiente académico estable de calidad. En efecto, ante la falta de una banda media estructurada que proporcione solidez al sistema educativo en el ámbito musical, es lógico que la sociedad se resienta de una educación musical menguada. ${ }^{398}$

Como muy bien resume la doctora Martínez Díaz:

"el marco legal que ha definido el sistema educativo español a lo largo de la historia, ha otorgado un tratamiento diferenciado a las Enseñanzas Artísticas Superiores en relación con las universitarias, lo que ha condicionado la baja consideración economicosocial de estos estudios;" 399

Embarcados en un proyecto común desde 1999 como es la convergencia en el Espacio Europeo de Educación Superior (EEES), el menoscabo general por omisión característico del estado español hacia las enseñanzas musicales, se hace todavía más evidente cuando se contrasta con el de los países vecinos europeos. ${ }^{400}$

Así pues, en un primer plano descubrimos que las enseñanzas artísticas han sufrido un abandono en su regulación por parte de los poderes políticos, una situación que se ha visto envuelta a su vez, por un escenario general de "no pacto" del estado en materia educativa durante toda la democracia, es decir, una situación en la que

398 Este menoscabo se refleja en conductas irracionales que explican los resultados de esta baja consideración hacia estas enseñanzas: "debido a la escasa consideración economicosocial y a la diferenciación respecto de los estudios universitarios, un tercio de los alumnos/as que cursan estas enseñanzas realizan simultáneamente otros estudios universitarios." (MARTÍNEZ DíAz, Carmen María Luisa: El desarrollo de las Enseñanzas Superiores de Arte Dramático, Danza y Música en la Comunitat Valenciana. Antecedentes históricos, situación actual y perspectiva de futuro, Valencia, Universitat de València, 2012, p. 262).

399 Ídem, p. 31.

400 En este sentido estamos de acuerdo con Agüerría Cueva cuando menciona por ejemplo el prestigio social que tienen los profesores de las enseñanzas musicales en el resto de Europa en comparación con España. Véase: AgüErría Cueva, Fernando, op. cit., p. 260. 
cada partido entrante en el gobierno de la nación, implantaba su política nuevamente sin tener en cuenta la de su predecesor, lo que en el caso de las enseñanzas musicales nos ha conducido hacia un mal dentro de otro mal.

Por un lado, podemos convenir que las Comunidades Autónomas han proporcionado una solución parcial a la situación, mediante el despliegue de normas que han permitido la creación de Institutos Superiores de Enseñanzas Artísticas que dan respuesta momentáneamente al compromiso de la Declaración de Bolonia de crear conjuntamente un Espacio Europeo de Educación Superior. Por otra parte, será necesario un gran esfuerzo para operar los cambios necesarios para que las Enseñanzas Musicales se embarquen en una dinámica de cambios estructurales, que les permitan interactuar con otros campos, disciplinas e instituciones, de manera que la interacción entre interpretación, docencia e investigación comporte la actualización de los programas de Máster y Doctorados preparados para desarrollar investigaciones en el campo de la interpretación y creación musicales, aunando el avance en nuevos terrenos con la mejora de los ya transitados.

\subsection{La convergencia de las Enseñanzas Artísticas con el Espacio Europeo de Educación Superior}

Entre los múltiples y diversos aspectos que plantean el desarrollo de las normativas aquí estudiadas y su relación con en el ámbito musical, desearíamos a continuación recalar en uno de los que tal vez haya sufrido más transformaciones, aunque posiblemente como iremos comprobando, no todas las que hubiesen sido deseables. Nos estamos refiriendo a la evolución que han sufrido las Enseñanzas Artísticas Musicales en el ciclo Superior.

La configuración de España en una nación compuesta por Comunidades Autónomas que a su vez entran a formar parte del conjunto de países que componen la Unión Europea, ha resistido durante toda la democracia y en especial en las últimas décadas como tónica general, el desenvolvimiento de una cantidad significativa de reglamentaciones que intentan articular el desarrollo de la nación 
como país miembro de la alianza europea por un lado, mientras que por el otro ha de gestionar su estructura interna divida en 17 gobiernos autonómicos. ¿Cuáles son a nuestro juicio las consecuencias que ha tenido para la política educativa española su incorporación a la citada organización internacional? Intentaremos a continuación presentar algunas posibles respuestas a esta cuestión.

Es bastante probable que la principal causa, y posiblemente la más significativa, de los cambios acaecidos en el ciclo superior de la enseñanza musical consecuencia de su unión al grupo de naciones vecinas, sea debido a la Declaración de Bolonia.

Este proceso, que recibe su nombre de la declaración conjunta que suscribieron el 19 de junio 1999, veintinueve ministros de educación europeos para la creación de un Espacio Europeo de Educación Superior (EEES), se inició en una reunión anterior celebrada el 25 mayo de 1998 conocida como la Declaración de la Sorbona. Desde entonces, cada dos años se reúnen ${ }^{401}$ los países implicados, 47 hasta el momento, para valorar los progresos realizados en el EEES e ir estableciendo los siguientes pasos a tomar.

Lo que este proceso ha impulsado es la convergencia de los respectivos sistemas educativos de los países involucrados, mediante la aceptación de un compromiso que conlleve cumplir una serie de requisitos, a saber:

1. La aceptación del Sistema de Créditos ECTS (European Credits Transfer System) que permite el reconocimiento y la equivalencia entre los estudios realizados en diferentes países.

2. El sistema educativo superior se estandariza en todos los países participantes y se estructura en 2 niveles: Grado, Postgrado. La finalización del Postgrado lleva a la obten-

401 Las reuniones que se han llevado a cabo hasta ahora han sido: Bolonia (18-19 Junio-1999), Praga (18-19 Mayo-2001), Berlín (18-19 Septiembre2003), Bergen (19-20 Mayo-2005) y Londres (17-18 Mayo-2007), Lovaina (28-29 Abril-2009), Budapest/Viena (10-12 Marzo-2010) Bucarest (26-27 Abril 2012) y próximamente, Yerevan (2015). Se pueden consultar los datos y declaraciones adoptadas por los ministros en la siguiente web oficial del Espacio Europeo de Educación Superior: http://www.ehea.info/. 
ción del título de Máster. Se establece asimismo un tercer ciclo que conduce a la obtención del Doctorado.

3. La creación del Suplemento al Título para facilitar la comprensión y comparar mejor las titulaciones entre países.

4. Potenciar programas que aseguren la movilidad de estudiantes y profesores perteneciente a instituciones que impartan enseñanzas superiores.

En síntesis, lo que se busca es en un primer paso, fomentar una Europa del conocimiento cuyo espacio de educación superior sea atractivo y de calidad para profesores y alumnos de todo el mundo e incentive su acercamiento, y en segunda instancia ayudar a mejorar el empleo de los países miembros, favoreciendo la movilidad y la competitividad.

Entre los numerosos y difíciles retos que Europa tenía que afrontar, se encontraba el de conseguir el equilibrio en esa zona de convergencia de conocimiento entre los diferentes países miembros, logrando mantener simultáneamente el respeto a las diferentes singularidades e idiosincrasias de los países participantes del proceso. $^{402}$

Con esta nueva coyuntura educativa europea como telón de fondo, las enseñanzas superiores y por consiguiente las artísticas, adquieren en España una nueva perspectiva y poseen un nuevo horizonte hacia el que dirigirse. El Ministerio de Educación, Cultura y Deporte elabora en febrero de 2003, el texto "La Integración del sistema

\footnotetext{
402 Algunas voces se muestran escépticas sobre los resultados del proceso: "Las reformas educativas en Europa se plantean en términos de construcción de la identidad cultural europea, a la vez que, como en el Tratado de Maastricht, se afirma la diversidad y respeto de las peculiaridades culturales de las regiones y nacionalidades históricas. Esta diversidad cultural se ha traducido en una vacilante política de integración educativa, reducida, prácticamente, a la estrategia de homologación, intercambio y definición de criterios europeos en el ámbito curricular, delimitando las estrategias de modernización educativa a los Estados nacionales, mientras globalmente las políticas comunicativas son dirigidas por parámetros transnacionales de desarrollo." (GutiÉRREZ BARRENECHEA, María del Mar, op. cit., p. 124).
} 
universitario español en el Espacio Europeo de Enseñanzas Superior. Documento-Marco ${ }^{403}$, en respuesta a los objetivos fijados por Europa, para asumir las transformaciones necesarias que permitan adaptar las estructuras universitarias al EEES. Mientras tanto habrá que esperar a la Ley Orgánica de Educación de 2006, para lograr idéntica tarea en las enseñanzas artísticas.

En efecto, la LOE supone un avance significativo para las Enseñanzas Artísticas Superiores (EEAASS), ya que son separadas del ámbito escolar y reubicadas en el marco del Espacio Europeo de Educación Superior, adaptando consiguientemente los currículos de las distintas enseñanzas a dicho contexto. No obstante, queda pendiente la disyuntiva de incluir estas enseñanzas dentro de las universitarias o crear un nuevo espacio ex profeso para las mismas; la LOE aboga por la segunda solución, medida que no acaba de dejar satisfechos a gran parte del colectivo de profesionales docentes en particular y a la comunidad educativa en general.

A pesar de los esfuerzos de la Ley de 2006, existe la opinión fundamentada de que España se ha quedado lejos en comparación con sus países vecinos de encontrar una solución satisfactoria a la problemática de las EEAASS y su equiparación en el marco global de las enseñanzas superiores:

"Podemos concluir, por tanto, que es éste un problema ya resuelto en los países más avanzados de nuestro entorno y de los cuales podríamos tomar referencias para adecuar nuestra legislación educativa en materia de enseñanzas artísticas. La propia inercia de los cambios que impulsa la Declaración de Bolonia debería llevarnos a regularizar esta situación, por más que la LOE y su consiguiente desarrollo normativo, aunque supone un avance con respecto a la situación anterior, toda-

${ }^{403}$ Ministerio de Educación, Cultura y Deporte: La Integración del Sistema Universitario Español en el Espacio Europeo de Enseñanza Superior. DocumentoMarco, 2003, [documento en línea]

$<$ http://www.eees.es/pdf/Documento-Marco_10_Febrero.pdf $>$ [consultado el 14-07-2014]. 
vía está muy alejada de los planteamientos organizativos y académicos de estos paises" (sic). ${ }^{404}$

\subsubsection{El marco jurídico de los Centros Superiores de Enseñanzas Artísticas}

Una de las posibles causas de este retraso, está basada en la indefinición, todavía inexacta a falta de un marco jurídico acorde, sobre la autonomía de los Centros Superiores de Enseñanzas Artísticas. Al parecer, la LOE adolece de falta de concreción en este aspecto y no acaba de zanjar un asunto que se arrastra desde la LOGSE, al no exhibir claramente una regulación que reglamente de manera más precisa el aspecto de la autonomía académica y organizativa de estos centros. A pesar del significativo empujón que la LOE proporciona a la organización de las enseñanzas artísticas, se queda no obstante corta a la hora de reconocer hasta las últimas consecuencias la autonomía constitucional característica de las instituciones educativas superiores. En este sentido nos parece clarificador el análisis de la doctora Marzal Raga que reproducimos a continuación:

"Uno de los elementos centrales en la regulación de los centros docentes que imparten las enseñanzas musicales de la LOE es el reconocimiento de un ámbito de autonomía pedagógica, de organización y de gestión en los términos recogidos en la Ley. Esta autonomía se define así como un derecho de configuración legal que no adquiere la condición de derecho fundamental, y con un ámbito distinto a la autonomía constitucionalmente reconocida a las Universidades (art. 27. $10 \mathrm{CE}$ ) y un alcance mucho más limitado, pues no permite separarse de la tutela de la Administración competente. Precisamente la ausencia de heterotutela es una de las manifestaciones de la autonomía universitaria que no puede predicarse de los Conservatorios - ni aun los Superiores - que, al igual que los demás centros docentes que imparten enseñanzas no

${ }^{404}$ Agüerría Cueva, Fernando, op. cit., p. 236. 
universitarias, están sujetos, en mayor o menor medida según veremos, a su Administración de adscripción."

La autora pone de relieve el desgraciadamente ya tradicional debate que como decíamos se arrastra desde la LOGSE, sobre cuál debería ser el marco legal que diera carpetazo definitivo a la situación de los centros que imparten las enseñanzas artísticas en el Ciclo Superior. ${ }^{406}$ Fruto de aquella deliberación se plantearon dos soluciones que respondían a diferentes modelos organizativos, a saber: la plena integración de los centros que imparten las enseñanzas artísticas en la universidad; o la ubicación de tales enseñanzas en un ámbito propio y autónomo, independiente del universitario. ${ }^{407}$

Como muestran los dictámenes referidos, cualquiera de las dos opciones contiene pros y contras, pero en cualquier caso ambas implican siempre asegurar la calidad necesaria para proporcionar un

${ }^{405}$ MARZal RagA, Consuelo, op. cit., p. 285

406 Para profundizar sobre este debate consúltese: EMBID IRUJO, Antonio: Informe sobre la conveniencia de promulgar una Ley Orgánica reguladora de la Organización en régimen de Autonomía de las Enseñanzas superiores artísticas en España, Zaragoza, Asociación española de Centros Superiores de Enseñanzas Artísticas (eds.), Salamanca, Jet Prints S.L., 1997; EmBID IrUjO, Antonio: Un siglo de legislación...; CONFERENCIA SECTORIAL DE EDUCACIÓN, GRUPO DE TRABAJO: Las Enseñanzas Artísticas a examen. Evolución histórica, panorama actual y perspectiva (Dictamen), Julio, 1999.

${ }^{407}$ Existen voces autorizadas que se decantan hacia ambas posiciones: Sobre la postura en defensa de la creación de Universidades Artísticas creadas ad hoc para el ámbito musical: "En cualquier caso, la solución universitaria, con la particularidad que aquí se señala de la creación de Universidades "artísticas", es la más congruente con las características de estas enseñanzas tal y como han ido siendo progresivamente dibujadas a lo largo de una historia educativa plagada en acontecimientos y con las necesidades objetivas para desarrollar una actividad educativa de la más alta calidad posible que, como muestran diversos ejemplos extranjeros, precisa de un alto grado de autonomía para un desarrollo lo más libre y creativo posible de tales enseñanzas." (EMBID Irujo, A.: Un siglo de legislación..., p. 113). Argumentos a favor de la integración de los centros superiores artísticos en la universidad: "Con todo, en nuestra opinión, la incorporación de los Estudios Superiores de música a la Universidad se muestra inaplazable." (MARZAL RAGA, Consuelo, op. cit., p. 20). 
grado de autonomía completo a estos centros, planteando el mismo ordenamiento jurídico que poseen la universidades y añadiendo además ahora, que el proceso deberá ubicarse dentro de la Declaración de Bolonia y el marco del EEES. Por otro lado hay que mencionar, que los estudios demostraron notoriamente el retraso de nuestro sistema a finales del siglo pasado, en comparación con los modelos de los países de la Unión Europea; de modo que ahora es la normativa europea también quien nos exige que regularicemos la "esquizofrenia jurídica" $" 408$ en la que se encuentran enredadas las enseñanzas artísticas.

Confrontada ante ambas opciones, la creación de un nuevo espacio para estos centros superiores, o la plena integración en las facultades universitarias, la administración pública optó por la primera de ellas creando el Consejo Superior de Enseñanzas Artísticas en $1997 .^{409}$ La creación de este organismo que ya venía contemplado en el artículo 45 de la LOE, aspiraría a proporcionar el ámbito propio y diferenciado que le corresponde a las enseñanzas artísticas superiores, con el objetivo de desplegar la normativa correspondiente para delimitar la organización y contenido fundamentales de estas enseñanzas. Ante el peligro de que las enseñanzas artísticas quedaran disueltas en la regulación de la educación general con la estructura propia de las enseñanzas secundarias, se crea este organismo cuya naturaleza queda definida en el artículo 2 del Real Decreto 365/2007, de 16 de marzo:

“Artículo 2. Naturaleza.

El Consejo Superior de Enseñanzas Artísticas es el órgano consultivo del Estado y de participación en relación con las

${ }^{408}$ Citamos textualmente la expresión de Embid Irujo ya que consideramos que describe bastante fielmente la situación. (EMBID IRUJO, A.: Un siglo de legislación..., p. 106).

${ }^{409}$ Real Decreto 365/2007, de 16 de marzo, por el que se regula el Consejo Superior de Enseñanzas Artísticas (B.O.E. de 4 abril de 2007). Se puede consultar la normativa que regula este Consejo en su web:

<http://www.mecd.gob.es/cseartisticas> [consultado el: 9-1-2014]. 
enseñanzas artísticas establecidas en la Ley Orgánica 2/2006, de 3 de mayo, de Educación." 410

En definitiva, el Espacio Europeo de Educación Superior, la Ley Orgánica de Educación y el Consejo Superior de Enseñanzas Artísticas, adscrito al Ministerio de Educación y Ciencia a través de la Secretaría General de Educación, van ha constituir los pilares sobre los que descansará el progreso de las EEAASS.

El siguiente paso vendría por parte de las Comunidades Autónomas que se apoyarían en la LOE, para crear un ámbito jurídicoadministrativo particular que regule las EEAASS incorporadas al Espacio Europeo de Educación Superior. Diversas Administraciones Autonómicas de la geografía española irán elaborando las normativas que permitirán este desenvolvimiento y el marco jurídico imprescindible para favorecer la autonomía necesaria y específica de los Centros Artísticos Superiores.

Acorde con este propósito, los gobiernos autonómicos desarrollan distintos modelos que se pueden clasificar en cuatro tipos: la fundación de un Organismo Autónomo, modelo desarrollado por las Comunidades de Aragón y Valencia; el segundo modelo basado en la Agencia Administrativa adoptado por la Comunidad de Andalucía; ${ }^{411}$ y el tercer modelo basado en la Fundación, que aplicarán

${ }^{410}$ Real Decreto 365/2007, de 16 de marzo, (B.O.E. de 4 abril 2007, art. 2).

${ }^{411}$ Recomendamos el análisis jurídico sobre los modelos autonómicos de organización de los conservatorios superiores de música que realiza Marzal Raga y del que descubrimos un extracto a continuación: "La organización autonómica de los Conservatorios Superiores de música se articula en torno a dos modelos, uno, de gestión indiferenciada sin acudir a fórmulas personificadas por el cual los centros docentes dependen orgánica y funcionalmente de la Consejería competente en materia de educación. Y otro, de gestión directa a través de fórmulas personificadas públicas (Comunidad de Aragón o Comunidad valenciana) o privadas (Comunidad de Cataluña, País Vasco o Baleares). A ellos se añade más recientemente el modelo de Agencias que, para la Administración General del Estado define la Ley 28/06, de 18 de julio, de Agencias Estatales para la mejora de servicios públicos, y la Comunidad de Andalucía utiliza en la Ley 17/2007, de 10 de diciembre, de Educación de Andalucía mediante la creación del Instituto Andaluz de Enseñanzas 
País Vasco con el Centro Superior de Música del País Vasco (Musikene), Cataluña y la Escuela Superior de Música de Cataluña (ESMUC), así como la Comunidad Canaria y Balear con sendos Conservatorios Superiores.

En consonancia con lo expuesto, Aragón es la primera comunidad en crear un organismo autónomo, el Instituto Aragonés de Enseñanzas Artísticas Superiores (IAEAS) creado y regulado por la Ley 17/2003, de 24 de marzo, por la que se regula la organización de las Enseñanas Artísticas Superiores en su ámbito de gestión (B.O.A. de 11 de abril; B.O.E de 7 de mayo), ${ }^{412}$ al que le seguirá la Comunidad Valenciana con el Instituto Superior de Enseñanzas Artísticas (ISEACV), creado al amparo de la Ley 8/2007, de 2 de marzo, de la Generalitat, de Ordenación de Centros Superiores de Enseñanzas Artísticas y de la creación del Instituto Superior de Enseñanzas Artísticas de la Comunitat Valenciana. (D.O.C.V. de 8 de marzo de 2007; B.O.E. de 9 de abril de 2007). ${ }^{413}$ Por otro lado y siguiendo el modelo de Agencia Administrativa, la Comunidad Andaluza aprueba en el Parlamento autonómico la Ley 17/2007, de 10 de diciembre, de Educación de Andalucía, (B.O.J.A. de 26 de diciembre de 2007; B.O.E. de 23 de enero de 2008), en la que recoge en el Capítulo VI, Titulo II, Sección III, los principios organizativos de las enseñanzas artísticas superiores. $^{414}$

Por lo que respecta a estos Institutos y según el Informe anual sobre el estado y situación de las Enseñanzas Artísticas para el Curso 2009-2010,

Artísticas Superiores como Agencia administrativa de dicha Administración." (MARZAL RAGA, Consuelo, op. cit., p. 293).

${ }^{412}$ Se puede consultar la normativa pertinente en la web del Consejo Aragonés de Enseñanzas Artísticas:

$<$ http:/ / mwn.educaragon.org/arboles/ arbol.asp?strseccion $=$ PPI10 \&sepRuta $=$ Sistema $\% 20$ Educativo/> [consultado el 9-01-2014].

${ }^{413}$ Se puede consultar la normativa reguladora del ISEACV en su web: $<$ http://www.iseacv.es/web_cst/isea1_0.php > [consultado el 9-01-2014]

${ }^{414}$ Puede consultarse la normativa pertinente, en el Portal de las enseñanzas artísticas superiores de la Junta de Andalucía:

$<$ http://www.juntadeandalucia.es/educacion/webportal/web/ensenanzasartisticas-superiores/las-eeaass> [consultado el 9-01-2014] 
elaborado por el Ministerio de Educación y el Consejo Superior de Enseñanzas Artísticas:

"Las tres leyes autonómicas convergen en el establecimiento de un marco jurídico-administrativo propio (los Institutos de Enseñanzas Artísticas Superiores), como entidades administrativas." [...] "De igual modo, confluyen básicamente en el tratamiento normativo dado a los centros superiores de enseñanzas artísticas, como centros con autonomía de gestión, capacidad para establecer convenios y relaciones institucionales plurales y capacidad para investigar." 415

Este comentario del Informe, muestra dos aspectos representativos de los establecimientos de Enseñanzas Superiores: en primer lugar el tema sobre la naturaleza de la autonomía de estos Centros Superiores que venimos glosando hasta aquí, y que a juzgar por este informe parece dar por zanjado al crear las Comunidades Autónomas el marco jurídico-administrativo oportuno con los Institutos de Enseñanzas Superiores; y un segundo aspecto que introduce otra característica primordial de la Educación Superior como es la investigación.

Sobre la Autonomía de Gestión e Investigación, parece también hacer referencia la última Ley Educativa de la Democracia, la LOMCE. Habrá que sopesar en el futuro y analizar cuáles van a ser las consecuencias jurídico-administrativas de los nuevos apartados 7 y 8 que la LOMCE en su artículo único apartado cuarenta y seis, añade al artículo 58 de la LOE:

“«7. Las Administraciones educativas podrán adscribir centros de Enseñanzas Artísticas Superiores mediante convenio a las Universidades, según lo indicado en el artículo 11 de la Ley Orgánica 6/2001, de 21 de diciembre, de Universidades.

8. Las Administraciones educativas podrán establecer procedimientos para favorecer la autonomía y facilitar la organiza-

415 VV.AA.: Informe anual sobre el estado y situación de las Enseñanzas Artísticas. CURSO 2009-2010, Madrid, MECD, 2011, p. 21. 
ción y gestión de los Conservatorios y Escuelas Superiores de Enseñanzas Artísticas.»»"416

Falta como decimos ver el desarrollo posterior de estos apartados, pero al parecer la nueva ley parece optar por una solución intermedia, en el que estas enseñanzas podrán, tanto adscribirse a las universidades como seguir desplegando su ámbito de gestión organizativa.

En cualquier caso gestión y autonomía en el ámbito de la Educación Superior van unidas al desarrollo de la investigación en estas Instituciones Superiores.

\subsubsection{Investigación en los centros superiores de música}

Es por esto, que uno de los objetivos que se le plantearon a partir de la década de los 90 con la LOGSE, a los Centros Superiores que impartían entonces el Grado Superior de Música, fue el de proponer la docencia como una potencia que trabaja en sinergia con la investigación en el ámbito académico. Ciertamente la Investigación, como la LOE confirmó más tarde, se consolidaba como una de las actividades estratégicas, inherente a la naturaleza de los Centros Superiores que acercaban los Estudios Musicales Superiores a los universitarios y las diferenciaban de otras enseñanzas no universitarias. Por otra parte, existía como ya hemos visto, la obligación de garantizar convenientemente la integración al Proceso de Bolonia y al nuevo Espacio Europeo de Educación Superior, y esto implicaba obviamente en su nueva estructuración académica dividida en Grado, Postgrado y Doctorado, el inaplazable impulso de la actividad investigadora.

Los primeros antecedentes que encontramos en la legislación, abordando la construcción de un ámbito investigador propio de las enseñanzas artísticas musicales, los encontramos en el Real De-

${ }^{416}$ Ley Orgánica 8/2013, de 9 de diciembre,...(B.O.E. de 10 de diciembre de 2013, Artículo único. Cuarenta y seis). 
creto 617/1995 que regulaba el currículo del grado superior de la LOGSE:

"Artículo 6.

2. Al establecer el currículo del grado superior de las enseñanzas de Música, las Administraciones educativas fomentarán la autonomía pedagógica y organizativa de los centros, favorecerán el trabajo en equipo de los profesores, y estimularán la actividad artística e investigadora de los mismos a partir de su práctica docente.",417

Esta referencia del Real Decreto relaciona investigación y docencia como tareas a desarrollar conjuntamente, aunque no especifica qué tipo de investigación hay que llevar a cabo.

En este sentido, más precisa se pronunció la LOPEG en su disposición cuarta, en la que como ya hemos podido comprobar, ${ }^{418}$ la normativa regula muy positivamente la investigación en los centros musicales, e incide claramente en que esta actividad y sus programas han de desarrollarse en campos afines a las enseñanzas impartidas en estos centros educativos, dando así un nuevo paso importantísimo en la normalización de esta actividad y su convergencia con la especificidad de las enseñanzas musicales.

A partir de aquí, la LOE ratificaría esta orientación, repitiendo textualmente la redacción de la LOPEG:

“Artículo 58. Organización de las enseñanzas artísticas superiores.

5. Asimismo las Administraciones educativas fomentarán convenios con las universidades para la organización de estudios de doctorado propios de las enseñanzas artísticas.

${ }^{417}$ Real Decreto 617/1995, de 21 de abril,...(B.O.E. de 6 de junio de 1995, art. 6.2).

${ }^{418}$ Vid. supra, p. 167, cita 362. 
6. Los centros superiores de enseñanzas artísticas fomentarán programas de investigación en el ámbito de las disciplinas que les sean propias." 419

Los centros superiores pasan por tanto a impartir estudios conducentes al Titulo de Máster, aunque todavía no pueden impartir el tercer ciclo que otorga el Título de Doctor, razón por la que se crean convenios con la universidades para la organización de estos estudios pero eso sí, debiéndose respetar el carácter propio de estas enseñanzas artísticas.

Esto crearía inevitablemente en un principio no pocas fricciones, debido a las diferentes particularidades organizativas y académicas de las instituciones involucradas, dado que si bien los conservatorios de música, exceptuando momentáneamente la disciplina de Musicología, no tenían en su historia ningún antecedente ni experiencia académica en el campo de la investigación científica, las facultades universitarias demostraban entonces como mínimo, la misma falta de preparación académica en lo que respecta a la gran mayoría de las materias impartidas en los conservatorios de música, sobre todo en el campo de las especialidades instrumentales. Los estudiantes que hayan superado su segundo ciclo en los conservatorios de música superiores se basarán por tanto en la misma normativa para regular los estudios de doctorado que las universidades. $^{420}$

Conviene por tanto subrayar que la LOE permitió por un lado regular un nuevo ciclo de enseñanzas en los conservatorios que no existía hasta entonces, el postgrado y la consiguiente obtención del Titulo de Máster, mientras que por otra parte se reforzaron los vínculos creados con las universidades en la LOGSE, para cursar estudios de doctorado. Y esta actividad investigadora que comienza en 1995 con el Real Decreto 617, tiene entre sus objetivos principales desarrollar la investigación artística en áreas de conocimiento afín a las materias impartidas en las enseñanzas de los Conservato-

${ }^{419}$ Ley Orgánica 2/2006, de 3 de mayo,...(B.O.E. de 4 de mayo, art. 58).

${ }^{420}$ Real Decreto 99/2011, de 28 de enero, por el que se regulan las enseñanzas oficiales de doctorado (B.O.E. de 10 de febrero). 
rios de Música, o dicho de otro modo, ligada a los procesos de creación, interpretación y educación musical que específicamente se desarrollan en estos centros educativos superiores, emprendiendo un ámbito propio de investigación, que lo caracterice y diferencie de otras disciplinas más tradicionales ligadas a la Musicología o la Universidad.

En nuestra opinión, llevando el asunto al terreno que más nos interesa en nuestra disertación, esta fuerza sinérgica de docencia e investigación ha de unirse a una tercera en el caso de las enseñanzas musicales de las especialidades instrumentales, a saber, la de la interpretación o ejecución musical. El intérprete, instrumentista o ejecutante, adóptese el término que se prefiera, y docente, está además siendo reclamado a convertirse en investigador.

A lo largo de nuestro discurso iremos abordando esta cuestión, vaya por delante como adelanto que una línea posible de formación de los intérpretes se caracterizará por ser más abierta e interdisciplinar, al conjugar varias facetas simultáneamente, y en el que la investigación artística puede convertirse en una útil herramienta para el intérprete que ha de continuar su actividad con actuaciones musicales públicas, así como para su labor docente. Sin embargo, la falta de programas académicos adecuados para los músicos intérpretes, puede acabar descarrilando en una obsesiva caza y captura del instrumentista especialmente cualificado para su tarea, que ve mermadas sus facultades no tanto por la falta de capacidad para la investigación científica, sino por la ausencia de planificación en los planteamientos de los programas de doctorado, no ajustados a las necesidades de su perfil profesional.

Cabría la posibilidad de formar excelentes investigadores que acaben siendo pésimos instrumentistas, pero también cabe el peligro de que excelentes instrumentistas no encuentren programas adecuados en los que desarrollar su capacidad investigadora. Por esta razón consideramos que una posible vía de solución, entre las posibles opciones existentes, sea la de equipar convenientemente a los intérpretes cualificados, enseñándolos a investigar y dotándolos de las herramientas científicas que les permitan ahondar en campos y temas de investigación acordes con su labor docente y musical. 
Las implicaciones en este sentido que ha tenido la Declaración de Bolonia en el Arte Musical, unido a otros factores que iremos estudiando, han sido determinantes para ir construyendo un área propia de Investigación Artística Musical. Participamos del sentir de aquellos que:

"Para cuantos estén interesados u obligados a fomentar la investigación musical en sus territorios más "propios" - como dice el artículo 58 de la Ley Orgánica de Educación - la investigación desde la práctica artística ha de ser entendida como una vía no única - en universidades o conservatorios superiores - pero sí privilegiada, pues así se garantizará que los artistas prácticos - creadores e intérpretes - investiguen sobre lo que más les interesa y lo que mejor saben hacer, asegurando así la más profunda y crítica formación de los mismos con la correspondiente mejora en la propia práctica profesional y en la educación artística superior."

${ }^{421}$ ZALDÍvAR GraCiA, Álvaro: "Investigar desde la práctica artística", en $L i$ bro de Actas del I CONGRÉS INTERNACIONAL "INVESTIGACIÓ EN MÚSICA', Valencia, ISEACV, 2010, p. 126. Disponible en el URL: $<$ http://es.scribd.com/doc/114390243/Cim1-Actas-Isea-Congreso> [consultado el 15-07-2014]. 



\title{
LOMCE 2013, final de trayecto. Leyes de educación musical en democracia después de la LOGSE
}

\subsection{Los pilares de una nueva educación}

\begin{abstract}
ON EL FIN DE MOtivar UN DEBATE sobre las particularidades más sobresalientes a tener en cuenta, para el impulso de políticas educativas en el futuro que propicien el desarrollo de sociedades en colectividades más humanizadas, la UNESCO constituyó en 1993 la Comisión Internacional sobre la Educación para el siglo XXI, agrupación que al final de su tarea, elaboró un informe cuyos análisis, resultados y propuestas pudimos más tarde disfrutar el público en general. ${ }^{422}$
\end{abstract}

\footnotetext{
${ }^{422}$ DeLORS, Jacques: La Educación encierra un tesoro, Madrid, UNESCO-Santillana, 1996. Disponible en el URL:

<https://www.yumpu.com/es/document/view/14061924/delors-jacquesla-educacion-encierra-un-tesoropdf-instituto- > [consultado el 21-07-2014].
} 
La Comisión trabajó con un gran volumen de información, como se puede apreciar en el documento y además dispusieron de total libertad para articular sus opiniones. En la segunda parte del informe que comienza con el capítulo cuarto, topamos con una interesante sección en la que a través de un agudo análisis se establecen cuatro pilares claves de la educación para el futuro según sus autores. En él, se indica que la sociedad del siglo XXI planteará retos sin precedentes a la educación, debido entre otros factores al volumen de información al que se tendrá acceso para su tratamiento, circulación o almacenamiento.

El papel de la educación en una sociedad sacudida por estos torbellinos informativos, será, vaticinaba bastante acertadamente el informe en 1996, el de actuar como una sistema de navegación que permita al individuo no perderse y saber discernir, entre las fugaces tendencias de carácter eminentemente provisional, aquellos programas que posean realmente la cualidad de promocionar efectivamente a las personas. Ante este panorama, se plantea una salida que consiste en trascender el papel tradicional de la educación como sistema que provee cuantitativamente a los educandos, completándolo con sistemas educativos que proporcionen las capacidades necesarias para actualizar esos conocimientos a lo largo de toda la vida y así adaptarse a los cambios sociales:

"Para cumplir el conjunto de las misiones que le son propias, la educación debe estructurarse en torno a cuatro aprendizajes fundamentales, que en el transcurso de la vida serán para cada persona, en cierto sentido, los pilares del conocimiento: aprender a conocer, es decir, adquirir los instrumentos de la comprensión; aprender a hacer, para poder influir sobre el propio entorno; aprender a vivir juntos, para participar y cooperar con los demás en todas las actividades humanas; por último, aprender a ser, un proceso fundamental que recoge elementos de los tres anteriores. Por supuesto, estas cuatro vías del saber convergen en una sola, ya que hay entre ellas múltiples puntos de contacto, coincidencia e intercambio." 423

${ }^{423}$ Ídem, pp. 95-96. 
Así que en el futuro, la educación aconsejará potenciar el aprendizaje como una capacidad flexible que acompañará al individuo a lo largo de toda su vida, abarcando múltiples áreas de conocimiento que permitirán una constante exploración del mundo, de los demás y de un mismo a través de la compatibilización dinámica de los cuatro pilares anteriormente descritos:

"En el presente informe, la Comisión ha optado por designar este proceso continuo de educación, que abarca toda la existencia y se ajusta a las dimensiones de la sociedad, con el nombre de «educación a lo largo de la vida». A juicio de la Comisión, esta noción representa la clave para entrar en el siglo XXI, y el requisito fundamental para un dominio cada vez mayor de los ritmos y tiempos del ser humano, que supera con mucho la necesidad de adaptarse a los imperativos del mundo del trabajo." ${ }^{424}$

Evidentemente, el enfoque de la educación desde este punto de vista, comporta la búsqueda de nuevos conceptos que reflejen apropiadamente estos cambios de perspectiva, como es el caso por ejemplo, de la evolución sufrida en determinadas áreas laborales, del concepto de calificación profesional al de competencia personal, en términos utilizados por el informe, en el que el segundo concepto define una habilidad más global que abarca tanto la adquisición de conocimientos y destrezas mecánicas tradicionales, como la combinación de éstas con otras aptitudes del individuo como son las habilidades sociales, o la capacidad de resolver o afrontar situaciones imprevistas no programadas:

"Cada vez con más frecuencia, los empleadores ya no exigen una calificación determinada, que consideran demasiado unida todavía a la idea de pericia material, y piden, en cambio, un conjunto de competencias específicas a cada persona, que combina la calificación propiamente dicha, adquirida mediante la formación técnica y profesional, el comportamiento

${ }^{424}$ Ídem, p. 112. 
social, la aptitud para trabajar en equipo, la capacidad de iniciativa y la de asumir riesgos." 425

Para poder atender en el futuro estos requerimientos del mundo profesional, los sistemas educativos han de planificar los diseños de sus currículos de forma que contemplen todos estos tipos de aprendizaje, resumidos en los cuatro pilares anteriores; estas cuatro guías recopilan las competencias más idóneas para ser transmitidas a los escolares, y por su característica flexibilidad podrán ser renovadas a lo largo de toda la vida, permitiéndoles poder adaptarse posteriormente a un mundo profesional de manera más versátil.

Otro de los aspectos que resalta el informe como posible propósito a tener en cuenta para el futuro de la educación, es el que destaca el especialista jordano y miembro de la Comisión, ln'am Al Mufti.

En la original exposición que presenta el epílogo del informe bajo el título de, La excelencia en la educación: hay que invertir en el talento, Mufti aporta algunas conclusiones sobre las que consideramos merece la pena reflexionar.

El autor ahonda en la cuestión, sobre las repercusiones que conllevan las profundas transformaciones estructurales actuales en las sociedades, y de cómo éstas plantean un serio reto a los países y sus administraciones educativas, que han de afrontar estos cambios con la suficiente energía y racionalidad, para hacer frente a las demandas del período histórico que viven. Una posible solución propuesta a este asunto es la inversión en la calidad de la educación:

"Es menester que las políticas de reforma estén encaminadas a la excelencia en materia de educación." ${ }^{426}$

La equidad en la educación significaría para el autor, no sólo adaptarse obviamente a los alumnos con necesidades por retraso en su aprendizaje, sino que representa una característica a tener en cuenta

${ }^{425}$ Ídem, p. 100.

${ }^{426}$ Al MufTI, In’am: “La excelencia en la educación: hay que invertir en el talento", en DELORS, Jacques, op. cit., p. 229. 
también para los alumnos que demuestran una mayor, incluso excepcional, capacidad de aprendizaje:

"Como dijo una vez Jefferson, «No hay nada más alejado de la igualdad que tratar de igual modo a seres desiguales»»"

En definitiva, la tesis de Mufti consiste en que no podemos permitirnos el lujo de privar a las sociedades del talento de nadie, incluidos aquellos que poseen capacidades únicas fuera de lo común. Después de un primer avance basado en la estandarización de la educación en las sociedades desarrolladas, viene un segundo paso consistente en la búsqueda de la calidad del sistema, y éste pasa por la equidad, entendida como el respeto y atención particular a todos los desiguales talentos de las personas, para así lograr finalmente un avance más respetuoso y efectivo.

En esta importante e ingente tarea es preciso contar tanto con los profesores, que son reciclados en su profesión a través de programas de formación permanente, como con toda la comunidad educativa, escuelas, padres y familia, asociaciones y en última instancia la misma sociedad civil perteneciente a una comunidad.

Si hemos acometido esta introducción mostrando este interesante informe de la UNESCO, es por la sencilla razón de que creemos que los temas que acabamos de presentar, introducen magníficamente algunas de las líneas maestras utilizadas en la elaboración posterior de los sistemas educativos de algunos países, como por ejemplo fue el caso español.

\subsection{Las enseñanzas de música en la LOCE, LOE y LOMCE}

A lo largo de la historia española los diversos sistemas educativos y normativas desplegadas en materia de enseñanza, han procurado normalizar la situación educativa atendiendo a las necesidades prioritarias de la población en cada momento. Desde que en 1857 la Ley de Instrucción Pública decretara la obligatoriedad escolar, la generalización de la educación básica como derecho básico fundamen-

${ }^{427}$ Ídem, p. 230. 
tal de los ciudadanos, constituyó uno de los principales objetivos de los sucesivos planes y medidas reglamentarias con el afán de subsanar las necesidades más acuciantes. Bajo esta perspectiva aparecieron la Ley 14/1970, General de Educación y de Financiamiento de la Reforma Educativa, y la Ley Orgánica 8/1985, reguladora del Derecho a la Educación, presentando la educación como un servicio público prioritario que el estado debía proporcionar. La Ley Orgánica 1/1990, de 3 de octubre, de Ordenación General del Sistema Educativo, ampliaba hasta diez años el período de obligatoriedad escolar. Alcanzado por tanto el objetivo de universalizar la educación pública y obligatoria a todos los ciudadanos, parece lógico juzgar que el siguiente paso a establecer sea la mejora de la calidad de la educación pública. En consecuencia, a mediados de la década de los noventa, aparecen dos normativas orientadas hacia este propósito, la Ley Orgánica 9/1995 de la Participación, la Evaluación y el Gobierno de los Centros Docentes, y la Ley Orgánica 10/2002, de 23 de diciembre, de Calidad de la Educación. Unificando todos estos criterios señalados, aparece finalmente la Ley Orgánica 2/2006, de 3 de mayo, de Educación, disposición por la que se rige el actual sistema educativo mientras se aplica la Ley Orgánica 8/2013, de 9 de diciembre, para la mejora de la calidad educativa.

El Real Decreto 1577/2006, de 22 de diciembre, fijaría los aspectos básicos del currículo de las enseñanzas profesionales de música reguladas en la LOE, ${ }^{428}$ completando el currículo en el caso especifico de la Comunidad Valenciana, el Decreto 159/2007, de 21 de septiembre, del Consell, por el que se establece el curriculo de las enseñanzas elementales de música y se regula el acceso a estas enseñanzas ${ }^{429}$ y el Decreto 158/2007, de 21 de septiembre, del Consell, por el que se establece el cu-

\footnotetext{
${ }^{428}$ Real Decreto 1577/2006, de 22 de diciembre, por el que se fijan los aspectos básicos del currículo de las enseñanzas profesionales de música reguladas por la Ley Orgánica 2/2006, de 3 de mayo, de Educación (B.O.E de 20 de enero de 2007).

${ }^{429}$ Decreto 159/2007, de 21 de septiembre, del Consell, por el que se establece el curriculo de las enseñanzas elementales de música y se regula el acceso a estas enseñanzas (D.O.G.V. de 25 de septiembre de 2007).
} 
rrículo de las enseñanzas profesionales de música y se regula el acceso a estas enseñanzas. ${ }^{430}$

Por otro lado, las enseñanzas superiores vendrían organizadas a partir de la LOE por el Consejo Superior de Enseñanzas Artísticas, como nuevo órgano consultivo del gobierno en esta materia. El Real Decreto 365/2007, de 16 de marzo, por el que se regula el Consejo Superior de Enseñanzas Artísticas, ${ }^{431}$ y la Orden ECI/1687/2007, de 4 de junio, por la que se nombran los consejeros del Consejo Superior de Enseñanzas Artísticas, ${ }^{432}$ son parte de la normativa que regula este nuevo organismo. A raíz de esta fundación, en la Comunidad Valenciana se dispondría la Ley 8/2007, de 2 de marzo, por la que se crea el ISEACV. ${ }^{433}$

Este pequeño avance resumido de la normativa en la educación superior, es una muestra de cómo la ordenación académica de las enseñanzas artísticas superiores, que engloba entre sus enseñanzas, los estudios de música impartidos en los conservatorios superiores, caminaría a partir de ahora hacia un nuevo horizonte impelida por una oleada de prescripciones legislativas, encargadas de formalizar entre otros aspectos, el contorno reglamentario que nos conducirá hacia los futuros modelos de programaciones de la especialidad de Piano.

Como ya estuvimos viendo la LOPEG en el capítulo 5. 2. 2. sobre la leyes educativas durante el gobierno socialista, empezaremos ahora con La Ley Orgánica 10/2002, de 23 de diciembre, de Calidad de la Educación, conocida como LOCE, una ley desarrollada por el go-

${ }^{430}$ Decreto 158/2007, de 21 de septiembre, del Consell, por el que se establece el currículo de las enseñanzas profesionales de música y se regula el acceso a estas enseñanzas (D.O.G.V. de 25 de septiembre de 2007).

${ }^{431}$ Real Decreto 365/2007, de 16 de marzo,...(B.O.E. de 4 de abril de 2007).

432 Orden ECI/1687/2007, de 4 de junio, por la que se nombran los consejeros del Consejo Superior de Enseñanzas Artísticas (B.O.E de 13 de junio de 2007).

${ }^{433}$ Ley 8/2007, de 2 de marzo, de la Generalitat, de Ordenación de Centros Superiores de Enseñanzas Artísticas y de la creación del Instituto Superior de Enseñanzas Artisticas de la Comunitat Valenciana (D.O.G.V de 8 de marzo de 2007). 
bierno popular que buscó con viveza, tanto la mejora como la igualdad en la educación:

"Pero nunca como hoy ha sido más necesaria la convergencia entre esas dimensiones esenciales de la educación; nunca ha sido tan evidente que calidad y equidad, desarrollo económico y cohesión social, no son elementos contrapuestos, sino objetivos ineludibles, a la vez que complementarios, del avance de nuestras sociedades,"434

como denunciar el descrédito y la vulnerabilidad del que se habían resentido los profesores, devolviéndoles su autoridad a la vez que se potenciaba el reconocimiento al esfuerzo en el alumnado:

"Este nuevo impulso reformador que la Ley promueve se sustenta, también, en la convicción de que los valores del esfuerzo y de la exigencia personal constituyen condiciones básicas para la mejora de la calidad del sistema educativo, valores cuyos perfiles se han ido desdibujando a la vez que se debilitaban los conceptos del deber, de la disciplina y del respeto al profesor." 435

Sin embargo, la ordenanza tenía unas consecuencias nefastas para la regulación de las enseñanzas artísticas, ya que la música salía gravemente perjudicada. Si comparamos la LOCE con la LOGSE, vemos que esta última había regulado la música y la danza, como enseñanzas de régimen especial, junto al arte dramático, las artes plásticas y el diseño, diferenciadas de las enseñanzas de régimen general, lo que dejaba la puerta abierta al ciclo superior, para seguir su propio camino en otro espacio adecuado para este tipo de enseñanzas. Sin embargo, la LOCE mostraba su fatídica ordenación al tipificar la enseñanza musical, incluido el ciclo superior, dentro de las enseñanzas escolares de régimen especial.

De manera que, en lo que toca al ciclo superior de las enseñanzas de música, mientras la LOGSE había equiparado la titulación supe-

${ }^{434}$ Ley Orgánica 10/2002, de 23 de diciembre,...(B.O.E. de 24 de diciembre, preámbulo).

${ }^{435}$ Ibidem. 
rior a las universitarias, los diferentes informes y dictámenes recomendaban la adscripción de dichas enseñanzas a la universidad o la creación de un espacio administrativo superior en régimen pleno de autonomía, y la constitución del EEES se estaba llevando a cabo, la LOCE por su parte, generaba un conflicto en contra de toda esta dinámica de progreso para la música y su organización. Paradójicamente, la Ley de "Calidad" de 2002 significaba para la música un claro retroceso, ya que a través de su artículo 7.3 las enseñanzas artísticas, incluyendo su último ciclo de formación superior, volvían a incorporarse con las escolares, imposibilitando a este último ciclo su desarrollo ulterior en un espacio propio de enseñanzas superiores, equivalentes a las universitarias.

En palabras de Jordi Font, habíamos alcanzado la cima del quinquenio negro que representaba esta fase de las enseñanzas artísticas superiores:

"Ese mismo año (1999), se iniciaba el proceso de convergencia de la educación superior en Europa, a partir de la Declaración de Bolonia, que fijaba un plazo para su culminación: 2010. Desde este momento, las universidades emprenderían el proceso de transformación de sus enseñanzas. Las enseñanzas artísticas superiores, por el contrario, quedarían atascadas hasta 2004, en lo que podríamos denominar su "quinquenio negro" desde la transición democrática. La parálisis y hasta el retroceso de éstas tuvo su momento álgido en 2002, con la Ley Orgánica de Calidad de la Educación (LOCE), que vino a interrumpir bruscamente el proceso iniciado por la LOGSE, omitiendo cualquier referencia a la ordenación de las enseñanzas artística superiores y quedando sus centros relegados a los parámetros de la enseñanza secundaria." 436

${ }^{436}$ FONT, Jordi: "II. Crónica de un trayecto" en, Las enseñanzas artísticas superiores. Legislación, Murcia, ACESEA, 2010, pp. 12-13. Disponible en el URL:

<http://www.acesea.es/www/files/Libro-2010-DEF.pdf.> [consultado el 21-7-2014]. 
De donde se infiere que la derogación de la LOCE en 2006 al ser sancionada la LOE, fue sin duda una buena noticia por lo que respecta al ámbito de las enseñanzas superiores de música.

Como indica el preámbulo del texto, la Ley Orgánica 2/2006, de 3 de mayo, de Educación, no pretende sepultar los planes anteriores, sino que en un esfuerzo por aglutinar los progresos realizados hasta nuestros días en materia educativa, procura hacer frente a los desafíos de su tiempo incorporando nuevos recursos sobre aquellos con más tradición que ya han demostrado su validez y fiabilidad:

"la Ley parte de los avances que el sistema educativo ha realizado en las últimas décadas, incorporando todos aquellos aspectos estructurales y de ordenación que han demostrado su pertinencia y su eficacia y proponiendo cambios en aquellos otros que requieren revisión. Se ha huido de la tentación de pretender cambiar todo el sistema educativo, como si se partiese de cero, y se ha optado, en cambio, por tener en cuenta la experiencia adquirida y los avances registrados. En última instancia, la Ley se asienta en la convicción de que las reformas educativas deben ser continuas y paulatinas y que el papel de los legisladores y de los responsables de la educación no es otro que el de favorecer la mejora continua y progresiva de la educación que reciben los ciudadanos". ${ }^{437}$

Las enseñanzas artísticas se regulan en el capítulo sexto de la disposición, y en efecto el nuevo plan no plantea grandes diferencias con sus predecesores en relación a las enseñanzas de música de grado medio. Sin embargo, la ley planea novedades destacables para el resto de niveles, como son: la desaparición del grado elemental de la ordenación general del sistema educativo, ${ }^{438}$ y la creación del Consejo Superior de Enseñanzas Artísticas, como nuevo órgano consultivo del Estado y de participación en relación con las

${ }^{437}$ Ley Orgánica 2/2006, de 3 de mayo,...(B.O.E. de 4 de mayo de 2006, preámbulo).

438 “Artículo 48. Organización. 1. Las enseñanzas elementales de música y de danza tendrán las características y la organización que las Administraciones educativas determinen." (Ley Orgánica 2/2006, de 3 de mayo,..., B.O.E. de 4 de mayo de 2006, capítulo VI, art. 48. 1). 
enseñanzas superiores de música. ${ }^{439}$ De ahí el contraste entre las novedades curriculares previstas para el grado medio, en las que no apreciamos grandes cambios comparados con los principios establecidos en la LOGSE, y el nuevo horizonte de las enseñanzas superiores $^{440}$ determinado principalmente por el marco legislativo de educación superior en España y el EEES. ${ }^{441}$

La ley emprendió su reforma educativa teniendo en cuenta estos aspectos y por supuesto otros tantos, propios del amplio alcance de una Ley Orgánica. Así, la Norma, consciente de los cambios sociales y la necesidad de adaptarse a ellos expresa:

"Esa preocupación por ofrecer una educación capaz de responder a las cambiantes necesidades y a las demandas que plantean las personas y los grupos sociales no es nueva.” [...]

"A la vista de la evolución acelerada de la ciencia y la tecnología y el impacto que dicha evolución tiene en el desarrollo social, es más necesario que nunca que la educación prepare adecuadamente para vivir en la nueva sociedad del conocimiento y poder afrontar los retos que de ello se derivan." ${ }^{442}$

Además, la normativa se apoya en tres fundamentos básicos. El primero de ellos consiste en garantizar una educación de calidad a toda la ciudadanía, recordando que:

439 Ley Orgánica 2/2006, de 3 de mayo,...(B.O.E. de 4 de mayo de 2006, capítulo VI, art. 45. 3).

440 “Artículo 46. Ordenación de las enseñanzas. 2. La definición del contenido de las enseñanzas artísticas superiores, así como la evaluación de las mismas, se hará en el contexto de la ordenación de la educación superior española en el marco europeo y con la participación del Consejo Superior de Enseñanzas Artísticas y, en su caso, del Consejo de Coordinación Universitaria." (Ley Orgánica 2/2006, de 3 de mayo,...B.O.E. de 4 de mayo de 2006, capítulo VI, art. 46. 2).

${ }^{441}$ Recordemos que el Espacio Europeo de Educación Superior nació a raíz del acuerdo suscrito en la Declaración de Bolonia, el 19 de junio de 1999, por parte de los Ministros de Educación de 29 países europeos.

${ }^{442}$ Ley Orgánica 2/2006, de 3 de mayo,...(B.O.E. de 4 de mayo de 2006, preámbulo). 
"Ningún país puede desperdiciar la reserva de talento que poseen todos y cada uno de sus ciudadanos." 443

El segundo principio es una exhortación a la necesidad de que para llevar una reforma y mejora tan profundas, es necesario el compromiso de toda una sociedad. Para ello no sólo es importante equipar al profesorado con las herramientas pedagógicas actualizadas necesarias, sino que también hay que declarar abiertamente el reconocimiento social que merece la función docente, mediante el consiguiente apoyo institucional y reglamentario. Por eso la ley, dentro del Título III sobre el profesorado, dedica en concreto el capítulo IV al reconocimiento, apoyo y valoración de este colectivo. En cualquier caso, los logros finales conseguidos por los alumnos tienen directa incumbencia con toda la comunidad educativa.

El proceso de edificación de un espacio común europeo en educación, se presenta como el tercer desafío exhibido en la norma. Este principio tendrá repercusiones muy directas sobre todo en la educación superior.

Pero es que además de estos aspectos, la ordenanza contempla otros igualmente importantes como es el de la «educación a lo largo de la vida», definido anteriormente por la Comisión Internacional de la UNESCO. Por tanto, la LOE también entiende la formación como un desarrollo constante del individuo que se lleva a cabo a lo largo de su existencia, ${ }^{44}$ por eso se expresa también en términos de conocimientos y competencias al describir este tipo de educación básica para toda la vida:

"Fomentar el aprendizaje a lo largo de toda la vida implica, ante todo, proporcionar a los jóvenes una educación completa, que abarque los conocimientos y las competencias básicas que resultan necesarias en la sociedad actual, que les permita desarrollar los valores que sustentan la práctica de la

\footnotetext{
${ }^{443}$ Ibidem.
}

${ }^{444} \mathrm{El}$ artículo 5 de la LOE que lleva por título El aprendizaje a lo largo de la vida, está dedicado por completo a explicar el carácter principal de este concepto. 
ciudadanía democrática, la vida en común y la cohesión social, que estimule en ellos y ellas el deseo de seguir aprendiendo y la capacidad de aprender por sí mismos."445

En lo concerniente a las enseñanzas musicales, la Ley Orgánica de Educación, aparte de prever la competencia artística como una de las competencias básicas de la educación obligatoria, lo que siempre es un valor estimable al predisponer a una sociedad hacia la expresión sensible de ideas y sentimientos mediante la música, estructura por otro lado en el Capítulo VI las enseñanzas artísticas, organizando las de música en el artículo 45.2, en 3 niveles: las enseñanzas elementales reguladas por las administraciones educativas correspondientes; las enseñanzas profesionales de 6 años de duración; y las enseñanzas superiores, que presentarían como principal novedad con el anterior sistema educativo, que se imparten en los Conservatorios Superiores pero enmarcados éstos por el EEES.

Las enseñanzas elementales quedaban por consiguiente en manos de las Consejerías de Educación de las respectivas administraciones autonómicas, encargadas de configurar las características y la organización de las mismas. Esto significa que al establecer el currículo de este nivel elemental, cada Comunidad tendría en cuenta las circunstancias especiales concretas que concurriesen en este tramo de enseñanza, correspondiente a la realidad de su territorio.

El currículo de las enseñanzas profesionales a diferencia de las elementales, sí quedaba sujeto a lo regulado por el artículo 6 de la nueva Ley Orgánica de Educación.

Es preciso recalcar la diferencia de diseño que hubo en el desarrollo curricular entre las enseñanzas profesionales musicales y la educación básica. En efecto, las enseñanzas profesionales de música nunca contemplaron una de las más notorias novedades que traía consigo la definición del nuevo currículo, a saber: las competencias básicas:

“Artículo 6. Currículo.

${ }^{445}$ Ley Orgánica 2/2006, de 3 de mayo,...(B.O.E. de 4 de mayo de 2006, preámbulo). 
1. A los efectos de lo dispuesto en esta Ley, se entiende por currículo el conjunto de objetivos, competencias básicas, contenidos, métodos pedagógicos y criterios de evaluación de cada una de las enseñanzas reguladas en la presente Ley."446

El aprendizaje por competencias venía a protagonizar la misma revolución que la LOGSE había representado años atrás con la estructuración en objetivos, contenidos y criterios de evaluación del currículo. La efervescencia que tuvo aquella primicia pedagógica, tenía ahora su homólogo en la innovación que traía consigo el aprendizaje por competencias; ${ }^{447}$ si bien, esta novedad no llegó nunca a regularse en las enseñanzas profesionales de música, lo que no deja de resultar insólito en unas enseñanzas cuyos objetivos y contenidos son eminentemente procedimentales.

Dicho de otra manera lo que el aprendizaje por competencias aportaba al sistema educativo, expuesto de manera muy abreviada, era la aplicación en una situación concreta de los contenidos teóricos y prácticos que se aprendían, es decir, saber, saber hacer y saber aplicar. Por eso no deja de sorprendernos la eventualidad de que precisamente en los conservatorios de música profesionales, en los que la práctica junto al instrumento es el eje vertebrador de las

${ }^{446}$ Ídem, art. 6.1.

${ }^{447}$ Asociaciones como iCOBAE o Atlántida, son un ejemplo claro que ilustra esta necesidad de actualizar los diferentes currículos y materiales pedagógicos al aprendizaje de las competencias básicas. iCOBAE como organización que dirige su propósito hacia la formación de profesores en competencias básicas, tiene la función de cooperar con el profesorado para la incorporación de dichas competencias en el currículo y la práctica docente. Las medidas para llevar a cabo este plan, pasan por la reflexión y análisis de la propia práctica docente, hasta el diseño de nuevos materiales didácticos actualizados. El enlace web de la asociación iCOBAE es:

http://icobae.blogspot.com.es/

Por su parte el proyecto Atlántida, se constituye como una amplia red, que reúne un grupo ecléctico de profesionales de diferentes sectores, centros educativos integrados o colaboradores, departamentos universitarios, grupos de asesores y orientadores, y que intentan mediante experiencias de innovación, actualizar el currículo y ordenación de los centros escolares. En la web en: http://www.proyectoatlantida.net/ 
enseñanzas - es difícil imaginar a un instrumentista que finalice sus estudios de piano en este ciclo que sepa teóricamente mucho sobre su instrumento, pero no sepa tocarlo - nunca se introdujo el aprendizaje por competencias, sino que se continuó con el mismo plan anterior, por contenidos y objetivos, eso sí, actualizados.

Por otro lado, pocos de nosotros podíamos imaginar en 1985, las consecuencias que iba tener para las enseñanzas artísticas de música veinte años más tarde, la adhesión de España a la Comunidad Europea. Hay que mencionar que la LOE proporcionó el contexto legal para ajustar las enseñanzas artísticas superiores al proceso iniciado por la Declaración de Bolonia en 1999:

“Artículo 3. Las enseñanzas." [...]

“5. La enseñanza universitaria, las enseñanzas artísticas superiores, la formación profesional de grado superior, las enseñanzas profesionales de artes plásticas y diseño de grado superior y las enseñanzas deportivas de grado superior constituyen la educación superior." 448

El reconocimiento que otorga la LOE a este tramo superior de las enseñanzas artísticas supone un importante empujón para este espacio educativo en comparación con el sistema anterior, pero como veremos más adelante el tortuoso camino que ha recorrido este nivel de enseñanzas para encontrar su ubicación y reconocimiento jurídico dentro del espacio de la educación superior que despliega el artículo 3.5 de la LOE, es sintomático una vez más de la dificultad por la que han pasado estas enseñanzas en España, rayando prácticamente la indiferencia política, para alcanzar este reconocimiento:

"no podemos dejar de entender que todas las enseñanzas superiores (todas: universitarias o no) están directamente afectadas, siendo incluso, mejor dicho, sin exclusión alguna, las protagonistas esenciales de este magno proyecto de una Europa unida desde el conocimiento y no sólo en lo económico.

${ }^{448}$ Ley Orgánica 2/2006, de 3 de mayo,...(B.O.E. de 4 de mayo de 2006, art. 3. $5)$. 
Sin embargo, parece que en España, hasta hace sólo unos meses, la docencia artística superior no universitaria (y allí se incluyen, salvo excepciones - como la diplomatura de Magisterio en especialidad musical, o la licenciatura de segundo ciclo en Historia y Ciencias de la Música —, la mayoría de los estudios musicales superiores), había quedado del todo olvidada."

A pesar de las dificultades, las enseñanzas artísticas superiores, forman parte de la educación superior junto a la enseñanza universitaria, la formación profesional de grado superior, las enseñanzas profesionales de artes plásticas y diseño de grado superior y las enseñanzas deportivas de grado superior. De este modo, la educación superior no se limita con la LOE, única y exclusivamente al ámbito universitario sino que se hace extensivo a otras áreas de conocimiento como la que conforman las enseñanzas artísticas:

"Por otro lado, establece las denominadas enseñanzas artísticas superiores, que agrupan los estudios superiores de música y danza, las enseñanzas de arte dramático, las enseñanzas de conservación y restauración de bienes culturales y los estudios superiores de artes plásticas y diseño. Estas últimas enseñanzas tienen carácter de educación superior y su organización se adecua a las exigencias correspondientes, lo que implica algunas peculiaridades en lo que se refiere al establecimiento de su currículo y la organización de los centros que las imparten." 450

Estas peculiaridades en la organización y establecimiento de los centros y su currículo, implican la creación del Consejo Superior de

449 ZALDÍvAR GrACIA, Álvaro: "Las enseñanzas musicales y el nuevo Espacio Europeo de Educación Superior: el reto de un marco organizativo adecuado y la necesidad de la investigación creativa y performativa", en Revista interuniversitaria de formación del profesorado, no 52 (19,1), Zaragoza, Asociación Universitaria de Formación del Profesorado, 2005, p. 102, [documento en línea] <http:/ / www.aufop.com/aufop/revistas/indice/impresa/17> [consultado el 23-07-2014].

${ }^{450}$ Ley Orgánica 2/2006, de 3 de mayo,...(B.O.E. de 4 de mayo de 2006, preámbulo). 
Enseñanzas Artísticas, ${ }^{451}$ como nuevo órgano consultivo del Estado para la articulación de estas enseñanzas. Hay que mencionar además, que el desenvolvimiento del contenido de las enseñanzas artísticas superiores se hará bajo la gestión de este nuevo organismo, en colaboración, si procede, con el Consejo de Coordinación Universitaria, y bajo el contexto de la ordenación de la educación superior española en el marco europeo. ${ }^{452}$

Los artículos 54 a 58 de la Sección Tercera, Capítulo VI, Título I, de la Ley, regulan las enseñanzas artísticas superiores. El artículo 54 regula la distribución de los Estudios Superiores de Música y de danza que se desarrollarán en un único ciclo, mientras que el artículo 58 trata otros aspectos muy importantes sobre la organización de estas enseñanzas que sintetizamos a continuación:

- El Consejo Superior de Enseñanzas Artísticas y las Comunidades Autónomas mediante consulta del gobierno, definirán la estructura y el contenido básico de los diferentes estudios que componen las enseñanzas artísticas superiores.

- En los centros de enseñanzas artísticas superiores se podrán ofertar estudios de postgrado conducentes a títulos de Máster equivalente, a todos los efectos, a los títulos universitarios de postgrado.

- Las Comunidades Autónomas y las universidades podrán entablar fórmulas de colaboración para el desarrollo de doctorados, propios de las enseñanzas artísticas, lo que sin duda es un gran adelanto para la actividad investigadora de estas instituciones educativas, las cuales deberán promover proyectos de investigación propios del ámbito de sus disciplinas. Todo esto fomentará, como vimos anteriormente, la creación en diferentes comunidades autónomas de los Institutos Superiores de Enseñanzas Artísticas.

${ }^{451}$ Ídem, art. 45.3.
${ }^{452}$ Ídem, art. 46.2. 
En conclusión, la LOE contribuye muy positivamente a favor de la organización y progreso de los estudios superiores de música, buscando tanto un espacio propio de autonomía, como programas de investigación y doctorado acordes con las áreas de conocimiento a las que se dedican dichas enseñanzas, lo que significa un avance considerable en comparación con el artículo 42.4 de la LOGSE que sólo proponía fomentar estudios de tercer ciclo para los titulados superiores de música, en programas de doctorado propios de la universidad.

En lo que toca a la LOMCE, el preámbulo de la última ley educativa aprobada en 2013, que empezará a entrar en vigor en el curso 2014-2015, ${ }^{453}$ intenta hacer frente como sus predecesoras a los difíciles vaivenes que caracterizan a la sociedad actual, lo que exige una incesante actualización de los sistemas educativos en su afán por dar respuesta a los nuevos tipos de aprendizajes emergentes.

La reforma educativa nace en un contexto difícil protagonizado por el final de un ciclo económico, que no puede ser excusa sin embargo, para rezagarse y dejar descolgado el desarrollo social aconsejable en estas circunstancias, y que exige además afrontar los retos que permitan, a través de las reformas educativas pertinentes, seguir progresando en niveles óptimos de prosperidad.

Por esta razón, se siguen observando de cerca objetivos como la calidad del sistema educativo y la equidad del mismo. Como decíamos con anterioridad, una vez se ha cumplido el objetivo de la escolarización de una sociedad, hay que continuar trabajando en conseguir la calidad del sistema, para evitar la igualdad en la insuficiencia.

Las administraciones públicas son conscientes, al menos en sus normativas, que este avance en la marcha de una sociedad a través de la innovación de sus recursos educativos, no es posible sin la colaboración y la combinación sinérgica de las fuerzas de todas las partes implicadas en el proceso, desde la primera instancia educativa, el alumnado, pasando por todos los agentes intermedios comprometidos con la educación.

${ }^{453}$ Ley Orgánica 8/2013, de 9 de diciembre,...(B.O.E. de 10 de diciembre). 
Sin embargo, por profunda que sea una reforma, esta renovación no significa una eliminación de todo lo anterior. La LOMCE observa las sugerencias de la Organización para la Cooperación y el Desarrollo Económicos (OCDE), e intenta aplicar, como se estaba haciendo hasta ahora, las reformas educativas sobre aquellas cuestiones específicas que han demostrado ser un claro inconveniente para el correcto funcionamiento del sistema educativo, manteniendo por otro lado la durabilidad de las estructuras que sí han demostrado su conveniencia.

Con estas premisas en mente, la nueva ley acomete la reforma educativa persiguiendo los siguientes objetivos y principios:

"reducir la tasa de abandono temprano de la educación, mejorar los resultados educativos de acuerdo con criterios internacionales, tanto en la tasa comparativa de alumnos y alumnas excelentes, como en la de titulados en Educación Secundaria Obligatoria, mejorar la empleabilidad, y estimular el espíritu emprendedor de los estudiantes. Los principios sobre los cuales pivota la reforma son, fundamentalmente, el aumento de la autonomía de centros, el refuerzo de la capacidad de gestión de la dirección de los centros, las evaluaciones externas de fin de etapa, la racionalización de la oferta educativa y la flexibilización de las trayectorias." 454

Dicho lo anterior, examinaremos a continuación algunos puntos del articulado de la ley que afectan a las enseñanzas de música y que nos parecen más destacables.

En lo tocante a los elementos estructurales del currículo, nos referimos a la distribución de competencias del Gobierno en el que se añade el nuevo artículo 6 bis, éstos mantienen básicamente casi su misma estructura, es decir: objetivos, competencias, contenidos, metodologías didácticas, se añaden los estándares y resultados de aprendizaje evaluable, y continúan los tradicionales criterios de evaluación.

${ }^{454}$ Ídem, preámbulo, VI. 
Las Titulaciones obtenidas al final de cada ciclo formativo son las de Técnico en Música al superar las enseñanzas profesionales, ${ }^{455} \mathrm{y}$ la de Título Superior de Música de la especialidad cursada, para todo el alumnado que haya finalizado con éxito el ciclo superior. La ley clarifica que esta titulación esta comprendida en el nivel 2 del Marco Español de Cualificaciones para la Educación Superior y que será equivalente al título de Grado expedido por las Universidades. Además insiste en que:

"Siempre que la normativa aplicable exija estar en posesión del título universitario de Grado, se entenderá que cumple este requisito quien esté en posesión del título Superior de Música o Danza." ${ }^{456}$

Esta insistencia en la equivalencia de las titulaciones impartidas en los Conservatorios y Escuelas Superiores de Música, y las titulaciones de Grado, transmiten el malestar de fondo que existe como vimos desde la LOE, respecto a la completa regularización de estas enseñanzas en su ciclo superior. Efectivamente, el mundo musical educativo reviviría un nuevo y amargo capítulo en su historia normativa, con la resolución de la sentencia del Tribunal Supremo al estimar en parte el recurso contencioso administrativo interpuesto por la Universidad de Granada, y anular por no ser conformes a Derecho los artículos 7.1, 8, 11, 12, y la disposición adicional séptima del Real Decreto 1614/2009, de 26 de octubre por el que se establecen la ordenación de las enseñanzas artísticas superiores reguladas en la LOE. ${ }^{457}$

Uno de los resultados de este triste episodio de la regulación de las enseñanzas superiores, es la pérdida de la denominación de Grado

455 Regulado en el punto cuarenta del artículo único de la, Ley Orgánica 8/2013, de 9 de diciembre, (B.O.E. de 10 de diciembre).

${ }^{456}$ Regulado en el punto Cuarenta y dos, tercer apartado, del artículo único de la, Ley Orgánica 8/2013, de 9 de diciembre, (B.O.E. de 10 de diciembre).

457 Sentencia de 13 de enero de 2012, de la Sala Tercera del Tribunal Supremo, por la que se anulan los articulos 7.1, 8, 11, 12 y la Disposición Adicional Séptima del Real Decreto 1614/2009, de 26 de octubre, por el que se estableció la ordenación de las enseñanzas artísticas superiores reguladas por la Ley Orgánica 2/2006, de 3 de mayo, de Educación (B.O.E. de 23 de marzo). 
que confería el Real Decreto 1614/2009, al título expedido por las correspondientes instituciones educativas, al final de este ciclo. Más allá de la importancia y significación de la pérdida o cambio de nomenclatura de las titulaciones superiores de música, se esconde evidentemente, la falta de resolución político-administrativa sobre la regulación con pleno derecho de las enseñanzas artísticas en el ámbito superior, avalado además ahora por el marco europeo de la educación superior, que no acaba de encontrar una solución definitiva satisfactoria a este proceso.

En este sentido, sobre la sangrante cuestión del espacio administrativo ocupado por las enseñanzas artísticas superiores, la LOMCE en el punto cuarenta y seis, modifica el artículo 58 de la LOE añadiendo dos nuevos párrafos. ${ }^{458}$ Habrá que esperar y estudiar qué resultados puede tener el desglose de estos dos nuevos preceptos, ya que a través de ellos, la LOMCE permite con el apartado 7 - algo que ya introducía la LOE en el artículo 58.4 al proponer fórmulas de colaboración entre los estudios de enseñanzas artísticas superiores y las universidades de sus respectivos ámbitos - una nueva fórmula todavía no explotada que consiste en la adscripción de centros de educación superior a las universidades, regulado en la LOU; mientras que, en un primer análisis, el apartado 8 parece apoyarse en el camino iniciado por los Institutos Superiores de Enseñanzas Artísticas, y sostener su autonomía de gestión, aspecto que junto a la investigación constituyen los pilares básicos de los centros de enseñanza superior.

\subsection{El proceso de concreción del currículo de las Enseñanzas Artísticas Superiores, en la LOE}

En las próximas páginas vamos a realizar un recorrido por el Marco Legislativo, esto es, por las distintas reglamentaciones que a lo largo de los diferentes niveles administrativos han ido regulando las enseñanzas artísticas superiores, durante el período de vigencia de la LOE, a la espera de la aparición de la nueva normativa que se supone irá desplegando la aplicación de la LOMCE.

${ }^{458}$ Vid. supra, p. 194, cita 416. 
Desarrollar convenientemente un planteamiento educativo es uno de los deberes más comprometidos debido en parte, al gran número de estructuras educativas que se ven involucradas. Este recorrido, que en el caso concreto de la LOE tiene su inicio en la normativa europea, y que nos conducirá hasta las guías docentes de los departamentos de los conservatorios, posee una dirección vertical, o tomando prestado la terminología de la planificación educativa, podríamos decir que atraviesa diferentes niveles de concreción. ${ }^{459}$ El proceso que vamos a repasar comienza en Europa con la Declaración de Bolonia, prosigue en nuestro país a través de la gestión del Ministerio de Educación, y de los distintos gobiernos autonómicos, y se prolonga, atravesando los Institutos Superiores de Enseñanzas Artísticas, hasta los equipos docentes encargados de elaborar los materiales pertinentes para la programación de sus asignaturas.

\subsubsection{E1 proceso de Bolonia y su influencia en las EEAASS}

Las reuniones que mantuvieron los ministros de educación de algunos países europeos, dieron lugar a la elaboración de la Declara-

${ }^{459}$ Los niveles de concreción se utilizan para designar los distintos agentes implicados en la definición del currículo: "Los diseños curriculares, hemos ido diciendo en puntos anteriores, constituyen tomas de decisiones que se van produciendo a diversos niveles, se integran, por tanto, en una estructura jerárquica en la cual los niveles superiores condicionan y predeterminan, al menos en parte, las decisiones que se toman en los niveles inferiores. La literatura oficial ha solido denominarlos 'niveles de concreción', entendiendo, de forma no del todo correcta, que lo que cada sucesivo nivel hace en concretar las líneas maestras que se han dibujado en el superior. Pero en realidad, lo que se hace (lo que debería hacer) no es concretar u operativizar las decisiones anteriores, sino adaptarlas a la situación en la que van a ser desarrolladas." (ZABAlZA, Miguel, ZabalZA CerdeIriÑA, María Ainoa: Planificación de la docencia en la universidad. Elaboración de las Guías Docentes de la Materias., Madrid, Narcea, 2010, p. 99). Otra definición sería: "Este proceso, que desciende de las propuestas generales a las particularidades de cada aula y de cada alumno, se denomina proceso de concreción o desarrollo curricular." (Pliego De ANDRÉs, Víctor, op. cit., p. 87). También en: VV.AA.: Del proyecto educativo a la Programación de Aula, Barcelona, Graó, 2006, p. 53. 
ción de la Sorbona en 1998 y la de Bolonia un año después. Estos documentos constituyen el pistoletazo de salida, de la carrera por instituir una zona de convergencia entre los diferentes sistemas educativos superiores de los países europeos allí comprometidos, que quedaría bautizado y suscrito por los ministros reunidos como Espacio Europeo de Educación Superior:

"La Declaración de la Sorbona de 25 de mayo de 1998, inspirada en estas mismas consideraciones, subraya el papel fundamental de las universidades en el desarrollo de las dimensiones culturales europeas e insistía en la necesidad de crear un espacio europeo de enseñanza superior como medio privilegiado para fomentar la movilidad y la empleabilidad de los ciudadanos y el desarrollo global de nuestro continente." 460

En completa alineación con las propuestas presentadas en Europa, el Ministerio de Educación, Cultura y Deporte español, toma las riendas del proceso y articula las reformas pertinentes en las estructuras de los estudios superiores, para adecuar estas enseñanzas al espacio europeo de enseñanza superior. Con este escenario se elabora en febrero de 2003, el Documento-Marco La integración del Sistema Universitario Español en el Espacio Europeo de Enseñanza Superior.

La incorporación de la educación superior española al nuevo programa europeo, significa emprender la senda de una experiencia educativa de mayor calidad, donde la expresión competitividad, juega un papel fundamental para los países comprometidos en el proyecto. La oferta del conjunto de enseñanzas superiores que aporta Europa a través de este espacio, pretende convertirse en una ventana hacia el exterior que propicie la concurrencia de los estudiantes del resto del mundo, a cada una de las especialidades ofertadas por las instituciones educativas superiores europeas. El atrac-

${ }^{460}$ DeClaración DE BOLONIA: El Espacio Europeo de la enseñanza superior. Declaración conjunta de los ministros superiores de educación reunidos en Bolonia el 19 de junio de 1999, [documento en línea]

<http:/ / www.ond.vlaanderen.be/hogeronderwijs/bologna/links/language/ 1999_Bologna_Declaration_Spanish.pdf> [consultado el 14-3-2014]. 
tivo y mayor reto que afronta simultáneamente el viejo continente, es el de agrupar armónicamente las pretensiones unificadoras de una Europa con un espacio educativo común, al tiempo que se respetan las particularidades diferenciadoras de cada nación.

Las reuniones que se constituyen para seguir el correcto planteamiento y que fijan el curso 2010/2011 como fecha límite para finalizar la correcta implantación de los nuevos planes de estudio acordes con el EEES, generan al final de cada una de ellas un documento donde se explicitan los logros conseguidos y los próximos objetivos. Esta documentación, ${ }^{461}$ podemos considerarla como la primera legislación dinamizadora de todo el proceso que se extenderá a lo largo y través de todos los países y niveles educativos respectivamente.

Entre los objetivos fundamentales a alcanzar con este proceso se persigue especialmente:

- la implantación del concepto de la formación a lo largo de la vida;

- favorecer la movilidad de profesores y estudiantes y la posterior inserción profesional en cualquier país del EEES;

- la promoción de la Equidad y Calidad de los sistemas educativos, mediante la convergencia en este espacio común europeo, que proporciona mayor competitividad al modelo.

Para ello, se crean los instrumentos necesarios que permiten regular las distintas partes del proyecto entre los que destacamos:

- La creación del ECTS como unidad de medida de haber académico, que permite la homologación del trabajo realizado por alumnos al facilitar las equivalencias y el reconocimiento de los estudios realizados en dife-

${ }^{461}$ La Web oficial del Espacio Europeo de Educación Superior y el proceso de Bolonia, donde puede consultarse entre otros aspectos la documentación desplegada en dicho proceso es: http://www.ehea.info/ 
rentes países. El ECTS se regula en la normativa española por el Real Decreto 1125/2003, de 5 de septiembre, por el que se establece el sistema europeo de créditos y el sistema de calificaciones de las titulaciones universitarias de carácter oficial y validez en todo el territorio nacional, B.O.E. de 18 septiembre de $2003 .{ }^{462}$

- La expedición del Suplemento Europeo al Título. Este sistema permite a los centros de enseñanzas superiores, impulsar la movilidad de estudiantes y titulados españoles en el espacio europeo de enseñanza superior, y se regula por el Real Decreto 1044/2003, de 1 de agosto, por el que se establece el procedimiento para la expedición por las universidades del Suplemento Europeo al Título. B.O.E. de 11 septiembre 2003.

- Otro mecanismo organizativo importante es la creación del Marco Español de Cualificaciones para la Educación Superior (MECES), regulado por el Real Decreto 1027/2011 de 15 de julio, por el que se establece el Marco Español de Cualificaciones para la Educación Superior, B.O.E. de 3 de agosto de 2011, el cual especifica un total de 4 niveles en las titulaciones expedidas en Europa. El Real Decreto 900/2007, de 6 de julio, constituye el Comité encargado de definir el Marco Español de Cualificaciones para la Educación Superior. ${ }^{463}$

462 La idoneidad de la implantación del ECTS se ha indicado en las declaraciones de Bolonia (1999) y Praga (2001), y de su inserción se deriva un cambio metodológico que se define principalmente por estar centrado en el alumno y tener en cuenta no sólo las horas presenciales sino también, los tiempos de estudio que utiliza para lograr los fines educativos implícitos en las materias que conforman el plan de estudios.

${ }^{463}$ El Marco Español de Cualificaciones para la Educación Superior (MECES) tiene una función integradora importante, ya que permite hacer visible todas la titulaciones correspondientes a la educación superior, y no sólo aglutina a la enseñanza universitaria sino a las enseñanzas profesionales y de régimen especial, reconociendo que las enseñanzas artísticas comparten el mismo nivel en el espacio europeo de educación superior. Como se puede comprobar en el Anexo del Real Decreto, el Título Superior de Música 
- Por ultimo se crea la ANECA como respuesta a su homologa europea ENQA, que tiene entre sus principales funciones asegurar la calidad de los programas emprendidos. ${ }^{464}$

Después del marco europeo y la respuesta de compromiso española de participar en este importante reto que lanzó la Declaración de Bolonia, corresponde a los centros educativos tomar el relevo en la materialización del proyecto. Como es natural las actuaciones que requiere la cristalización del EEES implica una inversión de

comparte el mismo nivel 2 que el Grado universitario, aspecto que ya recoge la LOMCE, mientras que el Máster en Enseñanzas Artísticas, comparte el nivel 3 junto al Máster universitario. El nivel 4 corresponde al Título de Doctor.

${ }^{464}$ La Agencia Nacional de Evaluación de la Calidad y Acreditación (ANECA) nace con el objetivo de garantizar la calidad del sistema universitario y el de todo el sistema de educación superior, mediante el desarrollo de diferentes programas de evaluación, certificación y acreditación con el propósito de equiparar nuestro sistema superior educativo al marco europeo de Educación Superior.

Desarrolla diferentes programas de evaluación de Instituciones y Enseñanzas como son el programa Pep, Academia, Verifica, Monitor, Docentia, Audit, Acredita, Acredita Plus, o la Mención de Calidad a programas de Doctorado. La ANECA es una fundación estatal creada el 19 de julio de 2002, en un acuerdo del Consejo de Ministros, en cumplimiento de lo establecido en el artículo 32 de la Ley Orgánica de Universidades.

La ANECA es la agencia española equivalente a la European Network for Quality Assurance in Higher Education (ENQA), y la tarea de ambas es garantizar la calidad del espacio europeo de educación superior. La ENQA se transformó en 2004 en la European Association for Quality Assurance in Higher Education, aunque siguió conservando el mismo acrónimo y misión de promover la acción conjunta en Europa, para mantener los estándares y garantía de calidad de la educación superior en los países implicados en el proceso de Bolonia.

Conjuntamente, las distintas Comunidades Autónomas del territorio español, han creado su correspondiente agencia autonómica de evaluación y calidad. Sus enlaces web son los siguientes ANECA: http://www.aneca.es/ANECA/Presentacion; ENQA http://www.enqa.eu/. 
energía apreciable en todos los niveles de su consecución, y el de los centros de enseñanzas superiores no iba a ser menor.

De manera que, hemos comprobado cómo la LOE ha sido el marco legal responsable hasta la fecha de dar viabilidad a la concreción del EEES en las enseñanzas artísticas superiores. Por otro lado, las Comunidades Autónomas han creado los Institutos Superiores de Enseñanzas Artísticas para dar cabida al impulso de convergencia europeo, mientras que los conservatorios son las instituciones educativas encargadas de articular el proceso de los estudios superiores de música, con Europa como telón de fondo.

Conforme a esto, hemos repasado también cómo dos de las principales características de estos Institutos Superiores son conseguir erigirse como instituciones que gocen de plena autonomía pedagógica, administrativa y de gestión, así como la incorporación en sus planes de enseñanza de la actividad investigadora en aquellas áreas y ámbitos propios de las disciplinas que imparten sus centros, lo que implica un esfuerzo considerable para el profesorado, que ve como se expanden los límites del horizonte de su perfil profesional.

En efecto, el itinerario eminentemente práctico que tenían hasta ahora las enseñanzas impartidas en los conservatorios de música, se ve enriquecido por una lado, por una mayor expansión en nuevos temas del campo teórico, (que ya existían a través de sus especialidades de Musicología o Historia de la Música) y por la aparición de una nueva área que combina la práctica con la teoría y la profundización en temáticas relacionadas con la investigación artística:

"Con carácter general, los estudios de grado en los centros superiores de educación musical se pueden distribuir en tres categorías:

- Estudios orientados principalmente a potenciar el desarrollo de la personalidad y la competencia artística del estudiante.

- Estudios orientados principalmente a incrementar las competencias teóricas y de investigación. 
- Estudios orientados específicamente a la combinación de las competencias artísticas con las teóricas.” ${ }^{665}$

Puesto que ya hemos expuesto algunos de los aspectos que más nos interesaban de la LOE y su implicación con la organización de la educación musical, veamos a continuación el estatuto encargado de aplicar, en el siguiente escalafón de la escala legislativa, los preceptos regulados por la Ley Orgánica.

\subsubsection{E1 Real Decreto 1614/ 2009}

El artículo 46.2 de la Ley Orgánica de Educación, dispone que la exposición del contenido y evaluación de las EEAASS se debe llevar a cabo en el contexto de la organización de la educación superior española en el marco europeo, contando primordialmente para ello con la participación del Consejo Superior de Enseñanzas Artísticas, y en su caso con la del Consejo de Universidades.

Por otro lado, la LOE regulaba las EEAASS en sus artículos 54 a 58 , especificando entre el conjunto de estas enseñanzas los estudios superiores de música.

A la luz de lo expresado en el artículo 58, y en consonancia con los parámetros que se desprenden del EEES, se desarrolla el Real Decreto 1614/2009, de 26 de octubre, por el que se establece la ordenación de las enseñanzas artísticas superiores reguladas por la Ley Orgánica 2/2006, de 3 de mayo, publicado en el B.O.E., de 27 de octubre de 2009.

El Real decreto 1614 tiene la doble misión de componer la estructuración de las enseñanzas artísticas incorporadas al sistema educativo, a la vez que las dota del espacio adecuado y flexible que le corresponde, dentro del marco del EEES.

${ }^{465}$ VeinTIMILLA BONET, Alberto: "Las enseñanzas musicales en el EEES", en Las enseñanzas artísticas superiores en el espacio europeo de educación superior, MECD, Madrid, 2010, pp. 146-147. Disponible en el URL: $<$ http://www.acesea.es/www/files/EASenEEES.pdf> [consultado el 21-72014]. 
Podríamos resumir en los siguientes puntos, las principales particularidades extraídas del preámbulo de la Disposición:

1. Renovación del proceso de enseñanza-aprendizaje que pasa del profesor al alumno.

2. Aprendizaje basado en competencias.

3. Adecuación de los procedimientos de evaluación.

4. Aprendizaje a lo largo de la vida.

5. Incorporación de los créditos ECTS.

6. Aplicación del Suplemento Europeo al Título para favorecer la movilidad de alumnos y profesores de este ciclo.

7. Estructuración de las enseñanzas en Grado, Máster y Doctorado.

8. Desarrollo de la Investigación, en el ámbito propio de las disciplinas impartidas en estas enseñanzas.

Según el preámbulo del Real decreto, para alcanzar estos propósitos, los centros de enseñanzas artísticas superiores:

“deberán disponer de autonomía en los ámbitos organizativo, pedagógico y económico y corresponde a las Administraciones educativas impulsar y dotar a dichos centros de los recursos necesarios para garantizar el cumplimiento de los principios que sustentan el nuevo espacio común europeo."466

A lo largo de los artículos 4 al 10, se van desglosando los distintos contenidos a regular como son: el sistema europeo de transferencia de créditos (ECTS); el sistema de calificaciones; el reconocimiento y transferencia de créditos para promover la movilidad, o la definición de la Estructura general en Grado, Máster y Doctorado.

466 Real Decreto 1614/2009, de 26 de octubre, por el que se establece la ordenación de las enseñanzas artísticas superiores reguladas por la Ley Orgánica 2/2006, de 3 de mayo (B.O.E. de 27 de octubre, preámbulo). 
El artículo 9 que organiza las enseñanzas artísticas de Máster es sin lugar a dudas uno de los avances más positivos de estas enseñanzas, ya que permite tras la consecución de los estudios del Título Superior, obtener el Título de Máster en Enseñanzas Artísticas, cuya titulación está orientada, hacia una mayor especialización académica o profesional, o bien para iniciarse en la actividad investigadora. ${ }^{467}$

También merece mención especial el último punto referente a los estudios de Doctorado en Música, ya que el real decreto reconoce de manera bastante clara, la posibilidad de poder realizar doctorados en los ámbitos de la interpretación y la creación, lo que significa un firme apoyo normativo de la investigación artística, explicándose con una terminología muy explícita que incide sobre la interpretación y la creación:

“Artículo 10. Estudios de Doctorado.

Las Administraciones educativas, de acuerdo con el artículo 58.5 de la Ley Orgánica 2/2006, de 3 de mayo, de Educación,

${ }^{467}$ El Conservatorio Superior de Música de Valencia imparte desde el curso escolar 2013/2014, el Máster en Enseñanzas Artísticas de Interpretación Musical e Investigación Performativa, verificado por la Agencia Nacional de Evaluación de la Calidad y Acreditación (ANECA), y delineado conforme al modelo de estudios de postgrado en música impartido por las Instituciones superiores de música del Espacio Europeo de Educación Superior.

El programa es interesante desde la perspectiva que permite optar por dos itinerarios: el de la excelencia interpretativa a través de la especialización del repertorio; o el módulo investigador, que permite posteriormente el acceso al Doctorado. Se puede consultar la información en el siguiente enlace:

<http://www.csmvalencia.es/es/postgrados2013.php> [consultado el 9-12014].

Otros Másteres son ofertados en la Escuela Superior de Música de Catalunya que se pueden consultar en el siguiente enlace:

<http://www.esmuc.cat/Estudia-a-1-ESMUC/Masters> [consultado el 9-12014]; o también existe la opción de los Cursos de postgrado ofrecidos por el Conservatorio Superior de Zaragoza:

$<$ https:/ / www.csma.es/edicionContenidos.do? metodo $=$ mostrarPantalla\&m enuIzqLargo $=1$ \&enlaceMenuIzquierda $=$ menuPostgrado\&enlaceMenuDerecha $=$ informacion\&idPaginaContenidos $=9>$ [consultado el 9-1-2014]. 
fomentarán convenios con las universidades para la organización de estudios de doctorado propios de las enseñanzas artísticas. Estos convenios deberán incluir los criterios de admisión y las condiciones para la realización y elaboración de la tesis doctoral y su adecuación a las particularidades de las enseñanzas artísticas superiores entre las que se podrá considerar la interpretación y la creación, de conformidad con lo establecido en este real decreto." ${ }^{468}$

Desarrollar el impulso de los programas de investigación en el ámbito de las disciplinas que sean propias de las enseñanzas artísticas, así como garantizar la autonomía en los ámbitos organizativo, pedagógico y de gestión, de los centros de EEAASS, regulados en las disposiciones quinta y sexta respectivamente de este Real decreto, se erigen como dos de los retos más importantes a tener en cuenta para lograr una plena ordenación de los estudios musicales superiores.

La LOE sentó las bases para llevar a buen término estos propósitos, y el Real Decreto 1614 daba una primera solución a la trayectoria trazada por su antecesora. A pesar de ciertos tropiezos, como la sentencia de 2012 de la Sala Tercera del Tribunal Supremo comentada, ni siquiera su aplicación niega el desarrollo corriente del resto de conquistas que las EEAASS han conseguido hasta el momento al estar adscritas al marco superior español dentro del proceso de convergencia europea, aunque tal vez sí refleje un síntoma de que estas enseñanzas no acaban de encontrar una solución jurídico-administrativa adecuada. Como hemos visto, los expertos barajaban dos soluciones, integrarse en la Universidad o crear un nuevo ámbito mediante la creación de una Ley orgánica que regulase la situación de estas enseñanzas modificando su estructura jurídica desde la constitución de 1978; finalmente surge una solución regional, en el que algunas comunidades autónomas amparadas en la Ley Orgánica de 2/2006 crearon los Institutos Superiores de Enseñanzas Artísticas, para poder dar viabilidad a los principios educativos emanados de la Declaración de Bolonia. La LOMCE abre una nueva vía de negociación, con la aparición de la regula-

${ }^{468}$ Real Decreto 1614/2009, de 26 de octubre,..., art. 10. 
ción de los centros adscritos a las universidades. Todo esto nos lleva a prolongar la espera de nuevas acciones político-administrativas, que tal vez resuelvan finalmente con soluciones más satisfactorias, la realidad de las enseñanzas artísticas superiores.

\subsubsection{E1 Real Decreto 631/2010}

El Real Decreto 631/2010, de 14 de mayo, por el que se regula el contenido básico de las enseñanzas artísticas superiores de Grado en Música establecidas en la Ley Orgánica 2/2006, de 3 de mayo, de Educación, publicado en el B.O.E., de 5 de junio de 2010, es la siguiente disposición general del Ministerio de Educación, encargada de continuar desplegando la aplicación de las enseñanzas artísticas en el nuevo contexto europeo de educación superior.

Este precepto, viene a completar la descripción del contenido básico de los planes de estudio conducentes al Título Superior de Música (en la norma aparece originalmente Grado y Graduado, ambas terminologías anteriores a la aplicación de la sentencia del Tribunal Supremo), previsto en el artículo 11 del Real Decreto $1614 / 2009$, de 26 de octubre, encargado como hemos visto de ordenar las EEAASS reguladas por la Ley Orgánica 2/2006.

Su principal tarea, descrita y regulada en el Artículo 1 de la disposición, es la de elaborar los contenidos del plan de estudios correspondiente a cada título, que posteriormente habrán de aprobar las diferentes administraciones educativas en sus respectivos territorios. Con este propósito se establecen las competencias transversales, generales y específicas de las especialidades, así como los perfiles profesionales de cada una de ellas, y se determinan las materias de cada especialidad, su descripción y el número de créditos asignado.

En su preámbulo, este Real Decreto explica las nuevas particularidades de los planes de estudios superiores de Música, que delimitados por la normativa europea recurren a una novedosa metodología de aprendizaje centrado en los alumnos, y que gravita en torno a la adquisición y desarrollo de las competencias del educando. 
Como ya vimos en la introducción de la LOE, con el informe de la Comisión de la UNESCO, la armonización entre los tradicionales contenidos teóricos, las habilidades técnicas prácticas, unido a las competencias, clasificadas en tres tipos, transversales, generales y específicas, serán las responsables de propiciar un proceso de aprendizaje satisfactorio que permita posteriormente una mejor adaptación del alumno a la actividad profesional.

\subsubsection{E1 Real Decreto 631/2010 y su relación con los Descriptores de Dublín y los Learning Outcomes de la Asociación Europea de Conservatorios}

El diseño final del Real Decreto 631, fue inicialmente preparado por el Consejo Superior de Enseñanzas Artísticas (CSEA), y se basó primeramente en un borrador sobre los contenidos y aspectos básicos de los estudios superiores de música, que se inspiró a su vez en otro diseño elaborado por la Asociación Española de Centros Superiores de Enseñanzas Artísticas (ACESEA), para su confección final.

En el Artículo 6 de la disposición, encontramos expuestos los diseños de los planes de estudio conducentes al Título Superior de las 7 especialidades: Composición, Dirección, Interpretación, $\mathrm{Mu}-$ sicología, Pedagogía, Producción y Gestión, y Sonología.

En el anexo II descubrimos las Competencias transversales (comunes a todas las especialidades), Competencias Generales (también comunes a todas las especialidades) Competencias Específicas de cada Especialidad, así como la descripción de los Perfiles Profesionales de las mismas. Por su lado los Anexos II y III presentan las Materias, las Descripción de los Contenidos y los ECTS mínimos para el ciclo.

El Artículo 7 anuncia cómo las Administraciones educativas completarán el plan de estudios hasta el total de 240 créditos, los mínimos fijados en el real decreto. 
Quisiéramos llamar la atención, sobre la descripción que hace la disposición del perfil profesional del Título Superior de Música en la especialidad de Interpretación:

"El Graduado o Graduada en interpretación deberá ser un profesional cualificado con un dominio completo de las técnicas de interpretación del instrumento y su repertorio, y en su caso, de instrumentos complementarios. Deberá estar preparado para ejercer una labor interpretativa de alto nivel de acuerdo con las características de su modalidad y especialización, tanto en el papel de solista como formando parte de un conjunto, así como, en su caso, en su condición de intérprete acompañante de música y de danza. Deberá conocer las características técnicas y acústicas de su instrumento, profundizando en su desarrollo histórico. Deberá tener formación para el ejercicio del análisis y del pensamiento musical, y disponer de una sólida formación metodológica y humanística que le ayude en la tarea de investigación afín al ejercicio de su profesión." ${ }^{469}$

Como se puede apreciar, la definición revela una enunciación amplia de la interpretación que recoge propiedades similares a las que exponemos como resultado de nuestro análisis de la acción programadora de la asignatura de piano hasta la presente Ley Orgánica de Educación 2/2006. Nosotros planteábamos los fundamentos de la técnica pianística, el repertorio, los contenidos históricos, estéticos y psicológicos del hecho musical, el modelo curricular y la actividad investigadora, ${ }^{470}$ como los futuros ingredientes de una receta a tener en cuenta para posteriores planificaciones de la asignatura;

${ }^{469}$ Real Decreto 631/2010, de 14 de mayo, por el que se regula el contenido básico de las enseñanzas artísticas superiores de Grado en Música establecidas en la Ley Orgánica 2/2006, de 3 de mayo, de Educación (B.O.E. de 5 de junio, Anexo I, Perfil profesional del Título de Graduado o Graduada en Música en la especialidad de Interpretación).

${ }^{470}$ MOLTÓ DONCEL, Jorge L.: "La acción programadora en la especialidad de piano, a la luz de las contribuciones aportadas por la reglamentación musical", en ArtsEduca, no 7, Valencia, Ana M. Vernia Carrasco, 2014, pp. 18-43, [documento en línea] <http://es.slideshare.net/artseduca/artseduca7smallpdfcom $>$ [consultado el 21-7-2014]. 
este Real Decreto, en su descripción del Perfil de Intérprete, entra en perfecta consonancia con nuestra argumentación, coincidiendo ambas en la exposición de sus planteamientos.

Por otro lado, es importante también señalar, la coherencia del Real Decreto con el marco europeo de educación superior que garantiza la relación entre este primer ámbito de la ordenación de las EEAASS, con los futuros planes de estudio que acaben de finalizar las distintas comunidades autónomas y en ultima instancia, los equipos docentes.

Es posible comprobar como, para convenir las distintas competencias que han de componer los planes de estudio, el Real Decreto especifica las competencias profesionales que corresponden a un titulado superior en música, inspirándose para ello en los Descriptores de Dublín.

Esta metodología permite establecer una unión entre los objetivos, contenidos y competencias del primer y segundo ciclo, así como del doctorado, de todos los estudios superiores de música impartidos en aquellos centros que se encuentren en el EEES. Esto significa que los planes de estudio de todos estos países asociados, parten de unos principios comunes que son los Descriptores de Dublín, adaptados a la enseñanza musical por la Asociación Europea de Conservatorios (AEC) y bautizados con el calificativo de descriptores de Dublín/Polifonía:

"The polifonia dublin descriptors are an adaptation by AEC of the now well-known and widely used Dublin Descriptors that propose a general description of the three study cycles Bachelor-Master-Doctorate in Higher Education across all types of study and disciplines. The Polifonia Dublin Descriptors emphasize the notion of artistic knowledge, skills and understanding, and are intended to explain, among other things, how the three study cycles in music relate to each 
other, and how one cycle can be seen to build upon the other two cycles." 471

Efectivamente, puede comprobarse que si escogemos dos de las múltiples competencias transversales del Título Superior de Música que recoge el Real Decreto, verbigracia, "Recoger información significativa, analizarla, sintetizarla y gestionarla adecuadamente", y "Desarrollar razonada y críticamente ideas y argumentos", ambas coinciden con la competencias genéricas de la AEC, "La recopilación, el análisis y la interpretación de la información" y "El desarrollo de las ideas y argumentos de manera crítica." 472

La concordancia entre los documentos es evidente lo que ejemplifica la coherencia entre las distintas instancias educativas.

Otro ejemplo que ilustra la relación entre las competencias genéricas con las específicas del RD, y cómo éstas se relaciones con los descriptores de Dublín/Polifonía de la AEC, lo podemos comprobar en el apéndice 7 .

471 “Los Descriptores de Dublín/polifonía son una adaptación de la AEC de los descriptores de Dublín ya bien conocidos y ampliamente utilizados que proponen una descripción general de los tres ciclos de estudio Grado-Master-Doctorado en Educación Superior en todos los tipos de estudios y disciplinas. Los Descriptores de Dublín/Polifonía enfatizan la noción de conocimiento artístico, las habilidades y la comprensión, y pretenden explicar, entre otras cosas, cómo los tres ciclos de estudio en la música se relacionan entre sí, y cómo se puede ver un ciclo para construir los otros dos" (POLIFONIA ThIRD CYClE WORKING GROUP: Guide to third cycle studies in higher music education, Utrech, AEC, 2007, p. 20). Los descriptores de Dublín/Polifonia se puede consultar en:

<http://www.jointquality.nl/content/ierland/Complete_set_Dublin_Descriptors_2004_1.31.doc $>$ [consultado el 22-7-2014].

472 Estas competencias pertenecen a los "Generic outcomes, 1st cycle, Independence," de la AEC: "Gathering, analysing and interpreting information. Developing ideas and arguments critically", en The AEC Learning Outcomes for the 1st, 2nd and 3rd cycle, [documento en línea] <http://www.aec-music.eu/userfiles/File/aec-polifonia-learning-outcomes-en.pdf $>$ [consultado el 8-1-2014]. 


\subsubsection{El diseño del Currículo de los planes de estudio de enseñanzas superiores de Música en las Comunidades Autónomas}

El Artículo 7 sobre la Organización de las materias, del Real Decreto 631, dispone que las correspondientes administraciones educativas, acabarán de concretar el plan de estudios hasta llegar al total de los 240 créditos fijados por el real decreto.

Esto significa que si contamos los créditos que regula el real decreto, a saber: materias que componen la formación básica, que son 24; más los correspondientes a las materias de la formación especializada, que constituyen 102 más; y a todo esto le sumamos finalmente el trabajo final de ciclo que tendrá un mínimo de 6 créditos, contabilizamos un total de 132 créditos, lo que significa que los 108 restantes hasta alcanzar el total, son los que las administraciones educativas junto con los centros deberán acabar de organizar.

Como se puede apreciar en el anexo II del real decreto, el carácter general en la descripción de las materias así como en la definición de los contenidos de las mismas, responde al objetivo de ser lo suficientemente flexible como para permitir posteriormente la concreción en diferentes asignaturas de estas materias, según dispongan los centros y la administraciones, acorde a las necesidades o perfiles educativos de su comunidad escolar.

Estos niveles de concreción curricular, imprimen un carácter altamente participativo de todas las instancias educativas implicadas en el proceso. Desde los primeros ministros de educación europeos que firmaron la Declaración de Bolonia en 1999, hasta los profesores que rematan el plan de estudios al confeccionar sus asignaturas y plasmar sus planificaciones en las Guías docentes, pasando por los organismos mediadores, todos forman parte de una cadena que desarrolla el EEES.

Este último nivel de concreción, permite que cada Institución Superior de Enseñanza, pueda moldear sus idearios y planes estratégicos, combinando equidad y calidad, cualificación y eficiencia, en grados particulares y diferenciadores, lo que genera una oferta he- 
terogénea para los educandos que elegirán en función de sus expectativas, la oferta educativa que más se ajuste a su proyecto profesional futuro.

No es nuestra misión, entrar en un análisis comparativo sobre cada una de las normativas autonómicas que desarrollan el plan de estudios en sus respectivos territorios. Cada administración regional desplegará sus correspondientes regulaciones para acabar de planificar las enseñanzas. Por ejemplo, en el ámbito autonómico de la Comunidad Valenciana, que es el que nos atañe más directamente, son el Decreto 48/2011, de 6 de mayo, del Consell, por el que se establece la ordenación de las enseñanzas artísticas superiores y se determina el marco normativo para la implantación de los planes de estudio correspondientes a los títulos oficiales de graduado o graduada en las diferentes enseñanzas artísticas superiores, en el ámbito de la Comunitat Valenciana, y la Orden 24/2011, de 2 de noviembre, de la Conselleria de Educación, Formación y Empleo, por la que se establecen y autorizan los planes de estudio de los centros de enseñanzas artísticas superiores de música dependientes del ISEACV, conducentes a la obtención del título de Graduado o Graduada en Música, las normas encargadas de completar los planes de estudio de las enseñanzas superiores de música en los conservatorios de esta Comunidad Autónoma. ${ }^{473} \mathrm{Y}$ así, cada región irá desplegando respectivamente su normativa particular, atendiendo a las señas de identidad que la definen como sociedad.

No obstante, y a pesar de estos elementos positivos diferenciadores, es importante que el diseño de las asignaturas de los planes de estudio en la enseñanza superior musical, sustente a su vez una estructura que sea equiparable en los diferentes centros de la Comunidad Europea, manteniéndose para ello hasta el último nivel de concreción las directrices de Bolonia. Además como veremos más adelante, el cambio de metodología que supone el ECTS, focalizando el centro de gravedad del proceso de aprendizaje en el alumno, propiciará la aparición de nuevas estrategias de enseñanza, sistemas de evaluación y racionalización de los tiempos de estudio

\footnotetext{
${ }^{473}$ Si se desea examinar la normativa que regula las enseñanzas superiores en la Comunidad Valenciana, consúltese el enlace del ISECV:

<http://www.iseacv.es/web_cst/isea1_4.php.> [consultado el 31-8-2014].
} 
de los alumnos, para alcanzar los objetivos, junto a otras especificaciones que deberán contemplarse en la descripción de las asignaturas del plan de estudios.

Para ayudar a las Instituciones y sus equipos directivos, asociaciones como la AEC o el Grupo polifonía, han desarrollado valiosísimas herramientas para llevar a cabo este trabajo. Trasladar las directrices de Bolonia a la Música y alcanzar finalmente al profesorado de los conservatorios encargados de impartir la docencia dentro de este marco, es otro de los desafíos a abordar. Sensibilizar a todas las capas de la comunidad educativa con unos planteamientos que se germinaron en sitios tan alejados unos de otros, puede acarrear fallos e interrupciones en la consecución del plan a través de los diferentes niveles, lo que puede provocar una desconexión de los actores implicados en el proceso:

"In many ways, the challenge to curriculum designers in conservatoires as they work to create courses and documentation in line with the Bologna Process is one of translation - how to convert the European Higher Education jargon into terms that musicians can feel reasonably comfortable with, and how to give the formal coherence and clarity beloved of educationalists to the rich, but often somewhat chaotic, pattern of learning and teaching activities that take place within the walls of a conservatoire. In the end, like any translation, this process won't entirely satisfy the native speakers of either language!"474

\footnotetext{
474 "En muchos sentidos, el reto para los diseñadores del currículo en los conservatorios que trabajan para crear cursos y documentos en línea con el proceso de Bolonia, es el de la traducción - cómo convertir la jerga del Espacio Europeo de Educación Superior en términos con los que los músicos puedan sentirse razonablemente cómodos y cómo dar la coherencia formal y la claridad deseada de los educadores a los ricos, pero a menudo tan caóticos, patrones de actividades de enseñanza-aprendizaje que tienen lugar dentro de las paredes de un conservatorio. Al final, como en cualquier traducción, jeste proceso no satisfará plenamente a los hablantes nativos de ningún idioma!" (COX, Jeremy: Curriculum design and development in higher music education, Utrech, AEC, 2007, p. 7).
} 


\subsection{E1 EEES y su adaptación al último nivel de concreción. El trabajo de los equipos docentes}

El proceso de concreción curricular en su último nivel, está a cargo de los equipos docentes de las instituciones que imparten las asignaturas de las enseñanzas artísticas superiores, que en el caso de la Música se llevan a cabo en los conservatorios mayoritariamente, así que a continuación intentaremos exponer algunas de las claves de este proceso.

La Guía docente va a convertirse en el nuevo modelo de documento que mediatice la acción programadora, durante esta última etapa que están protagonizando los conservatorios superiores. Cabe esperar que la Guía docente que realicen el equipo de profesores que imparte la asignatura de Instrumento Principal del itinerario de Piano del conservatorio de la provincia $\mathrm{x}$, difiera de su documento análogo realizado en el país vecino, inclusive de la realizada en la comunidad autónoma limítrofe, ya que en parte como decíamos, en esta variedad reside uno de los atractivos de la flexibilidad de un diseño curricular abierto. Sin embargo, es posible que el proceso de Bolonia en Música, haya movilizado más políticas educativas, recursos humanos y energías a nivel comunitario que en ningún otro tiempo, en busca de esa convergencia por un espacio de enseñanza superior común.

Posiblemente, una de las características que hace única esta reforma sea la expansión de sus ejes horizontal y vertical. Horizontal en el sentido de los países comprometidos, recordemos que hasta la fecha son más de 40 países involucrados en un proyecto que podríamos definir como el de una Europa del conocimiento unida por la educación musical y vertical porque la reforma está lejos de ser una simple y caritativa intención política de los países firmantes comprometidos de muy buena fe, pero sin mayores consecuencias para la población que la de una simple declaración de intenciones; lejos de este planteamiento surge un movimiento como hemos ido comprobando a lo largo de este capítulo, que atraviesa todas las esferas e instituciones de la educación, hasta llegar a dos de sus más principales actores, profesores y alumnos. 
Hasta ahora hemos podido comprobar cómo el Marco legislativo emanado del compromiso de Bolonia se ha extendido desde Europa, ha atravesado la normativa nacional, hasta llegar a la regulación autonómica, para involucrar en su destino final a docentes y estudiantes.

La tarea a la que se enfrentan equipos directivos y docentes para aplicar las directrices del EEES a los respectivos centros educativos, no es baladí, y cualquier ayuda es poca para llevar a cabo el encaje de bolillos en el que se convierte a menudo este quehacer. ${ }^{475}$

Por consiguiente, una de las claves de la elaboración de la Guía docente reside en primer lugar, en la toma de conciencia de que formamos parte de un engranaje, de un proyecto en el que han colaborado múltiples asociaciones y grupos de trabajo coordinados hasta conseguir levantar la estructura a la que queramos o no pertenecemos. Es por esto que la Guía Docente, como elemento que concreta el diseño curricular a través de la planificación pormenorizada de nuestra asignatura o módulo asignado, forma parte del dinamismo que activa la convergencia hacia la construcción del Espacio Europeo de Educación Superior.

Esta idea de constituir un aparato educativo más amplio que trabaja conjuntamente, se hace patente a la hora de elaborar la Guía docente, ya que el documento se construye conjuntamente entre los profesores que imparten la asignatura, lo que implica una signi-

475 Algunos trabajos de gran utilidad son: De Miguel DíAz, Mario (dir.): Adaptación de los Planes de Estudio al proceso de convergencia europea, Dirección Gral. De Universidades. Programa de Estudios y Análisis, Madrid, 2004, [documento en línea]

$<$ http://www.ulpgc.es/hege/almacen/download/42/42375/adaptacion_de _la_homologacion_de_los_planes_de_estudio_a_la_convergencia_europea. pdf.> [consultado el 22-7-2014]. Especialmente interesante para las enseñanzas de música es la obra de: Cox, Jeremy, op. cit. Para ayudar a los profesores en la planificación de la Guías docentes nosotros hemos consultado entre la bibliografía existente, el volumen de: ZABALZA, Miguel, ZABALZA CERDEIRIÑA, María Ainoa, op. cit. Además de estas obras de referencia, los Institutos Superiores suelen elaborar documentos internos para el profesorado como por ejemplo: ISEACV: Criterios para la elaboración de la guia Docente (Documento sin editar). 
ficativa novedad, puesto que invita a trabajar en equipo, a profesionales que normalmente están acostumbrados a gestionar individualmente "su" asignatura con "sus" alumnos; pensemos por ejemplo en el profesor de la asignatura de Instrumento principal de su itinerario correspondiente con ratio $1 / 1$ en el aula, impartiendo sus enseñanzas. ${ }^{476}$ Por consiguiente, son los profesores los que elaboran la Guía de la asignatura, que forma parte junto con otras asignaturas de una materia y que a su vez conforma el Plan de Estudios.

Durante el transcurso de esta colaboración, será importante evitar polarizaciones que nos lleven a callejones sin salida. Por un lado, un equipo congestionado de normativas y excesivamente burocratizado puede acabar en un equipo estéril; de otra parte, un departamento sin grupos de trabajo, en el que cada cual se encierra en su torre de marfil, pierde una fuente de riqueza y creatividad considerables. Una posible solución pase tal vez por la dinamización de grupos que sepan unir la diferencia en el conjunto, respetando la individualidad de cada componente dentro del grupo. Es posible que la aplicación de estas fórmulas, logre poco a poco actualizar este tipo de conductas enquistadas del pasado. ${ }^{477}$

${ }^{476}$ El trabajo en equipo de los profesores es garantía de calidad en la práctica docente, sin embargo algo nos une a los profesores de las enseñanzas superiores universitarias y artísticas, y es la dificultad para trabajar conjuntamente: "Los profesores vivimos tan intensamente nuestra autonomía ideológica, científica y didáctica que se nos hace pesado cualquier proceso que tienda a romper ese statu quo. Nuestra actuación como sujetos singulares en un contexto de alto prestigio como es la universidad, genera una cultura profesional muy especial con una fuerte orientación centrípeta, en la que se hace difícil la coordinación y la conexión interna del trabajo de cada cual." [...] "Es muy difícil desde esta perspectiva, conseguir proyectos formativos con un cierto sentido global y con una coherencia y continuidad interna aceptables. Las sinergias, cuando se producen, surgen más de la yuxtaposición de esfuerzos que de la integración de los mismos por lo que, al final, su efectividad se reduce notablemente." (ZABAlZA, Miguel, ZABALZA CERdeiriÑA, María Ainoa, op. cit., p. 216)

${ }^{477}$ La constante innovación, unida a estructuras laborales complejas que exigen el conocimiento de múltiples habilidades aplicadas en situaciones que demandan cada vez más diligencia, son sólo algunos de los factores que re- 


\subsubsection{Ingredientes del cambio de paradigma en la Enseñanza Superior Musical}

Otra novedad que viene dada por el proceso de convergencia europea, es el cambio de paradigma que representa el giro del foco de atención en el binomio profesor-alumno. El aprendizaje a lo largo de la vida, la enseñanza por competencias, o la incorporación del ECTS, traen consigo cambios sustanciales como el cambio de rol del profesor que ha de pasar de ser un mero transmisor de informaciones y contenidos, a un dinamizador del proceso de enseñanza-aprendizaje, algo que ya ocurrió de modo semejante décadas antes, en las enseñanzas profesionales de música, con la implantación de la LOGSE. El polo de atracción bascula por tanto hacia el estudiante, a quién hay que gestionar, entre otros parámetros, cuál será la carga de trabajo que empleará en sus estudios. Enseñar en este contexto es por tanto una tarea diferente de la realizada hasta ahora:

"Las competencias tradicionales del profesorado (conocer bien su disciplina y saber explicarla a los alumnos) resultan insuficientes para llevar a cabo esa tarea, se requiere un cierto conocimiento de los procesos de aprendizaje (saber cómo aprenden nuestros estudiantes y, en función de eso, pensar en cómo podríamos planificar nuestra materia y elaborar materiales didácticos adecuados para conseguir optimizar su dominio.) $" 478$

A estas alturas de nuestro discurso, podemos ir ya advirtiendo cómo se perfila el retrato de este plan educativo. Sus principales rasgos se articulan en un todo, difíciles de separar, ya que un ele-

quieren el trabajo en equipo. Para un análisis, sobre el desarrollo de la Competencia de trabajo en equipo, en el panorama sociolaboral, véase el interesante artículo de: VV. AA.: "Competencia de trabajo en equipo: definición y categorización", en Profesorado. Revista de curriculum y formación del profesorado, vol. 15, no 3, Granada, Universidad de Granada, 2011, pp. 329-344, [documento en línea]

<http://digibug.ugr.es/bitstream/10481/23174/1/rev153COL8.pdf> [consultado el 11-1-2014].

${ }^{478}$ ZabalZA, Miguel, ZabalZa Cerdeiriña, María Ainoa, op. cit., pp. 69-70. 
mento se relaciona íntimamente con el otro y éste a su vez con un tercero. El aprendizaje para toda la vida conlleva un aprendizaje por competencias, y ambos, con la ayuda de mecanismos como el ECTS, inclinan la balanza del proceso de enseñanza-aprendizaje, profesor-alumno, hacia los segundos términos, aprendizajealumno; todo ello para favorecer a lo largo de los ciclos educativos, una mayor autonomía del estudiante.

\subsubsection{E1 ECTS}

Consideremos ahora, por su trascendencia significativa, derivada de la unificación del marco de educación superior español al EEES, el empleo de herramientas ya mencionadas como el ECTS, y su papel en la homogenización de los sistemas educativos.

El ECTS comienza a aplicarse en 1989 en el marco del programa de movilidad de estudiantes Erasmus, con el fin de facilitar el reconocimiento de los períodos que los estudiantes cursaban en el extranjero y permitir la movilidad de los alumnos adscritos al programa por Europa. A partir de aquí el ECTS evoluciona hasta utilizarse en la actualidad como sistema de acumulación tanto a nivel institucional, como regional y nacional.

Entre los objetivos que se presentan de especial interés para la creación del EEES en la Declaración de Bolonia, figura la recomendación de adoptar un sistema de créditos común:

"Puesta a punto de un sistema de créditos como puede ser el ECTS como medio apropiado para promover una mayor movilidad entre los estudiantes. Estos créditos también podrían obtenerse fuera del sistema de enseñanza superior, por ejemplo en el marco de aprendizaje permanente, siempre que cuenten con el reconocimiento de las universidades." 479

\footnotetext{
479 DeClaración DE BOLONIA: El Espacio Europeo de la enseñanza superior. Declaración conjunta de los ministros superiores de educación reunidos en Bolonia el 19 de junio de 1999, [documento en línea]
} 
Posteriormente en la reunión de Praga de 2001 se ratifica la postura:

"Los Ministros hicieron hincapié en que, para una mayor flexibilidad en los procesos de aprendizaje y calificación, es necesaria la adopción de piedras angulares comunes de calificaciones, sostenidas por un sistema de créditos tal como el ECTS o uno que sea compatible con el ECTS, proporcionando tanto funciones de transferibilidad como de acumulación. Conjuntamente con los sistemas que garantizan la calidad reconocida mutuamente tales arreglos facilitarán el acceso de estudiantes al mercado laboral europeo y mejorarán la compatibilidad, el atractivo y la competitividad de la educación superior europea. El uso generalizado de tal sistema de créditos y del Suplemento del Diploma fomentará el progreso en esta dirección." 480

Consolidada la opción, es necesario definir el sistema. La Dirección General de Educación y Cultura de la Comisión Europea, elaboró un documento, en el que podemos encontrar una primera descripción:

"El Sistema europeo de transferencia y acumulación de créditos (ECTS) es un sistema centrado en el estudiante, que se basa en la carga de trabajo del estudiante necesaria para la consecución de los objetivos de un programa. Estos objetivos se especifican preferiblemente en términos de los resultados del aprendizaje y de las competencias que se han de adquirir." 481

<http://www.ond.vlaanderen.be/hogeronderwijs/bologna/links/language/ 1999_Bologna_Declaration_Spanish.pdf> [consultado el 14-3-2014].

${ }^{480}$ Comunicado de Praga: Declaración de Praga, 2001. Hacia el Área de la Educación Superior Europea Declaración del encuentro de los Ministros Europeos en funciones de la Educación Superior en Praga, 19 de mayo de 2001, [documento en línea] < http://www.eees.es/pdf/Praga_ES.pdf > [consultado el 22-7-2014]. 481 Dirección General de EduCACión y Cultura de la CoMisión EUROPEA: Sistema europeo de transferencia y acumulación de créditos (ECTS) Caracte- 
Esta primera definición nos muestra un primer rasgo particular del crédito europeo, consistente en un sistema que se centra en el estudiante. Sin embargo, la definición no nos acaba de clarificar cómo se consigue este objetivo, necesitamos más datos que nos lo aclaren.

La siguiente definición de la profesora Pagani parece explicarnos un poco mejor el concepto:

"Los créditos ECTS representan, mediante un valor numérico asignado a cada unidad de curso, el volumen de trabajo que el estudiante debe realizar para superar cada una de las asignaturas. Traducen el volumen de trabajo que cada unidad de curso requiere en relación con el volumen total de trabajo necesario para completar un año de estudios en el centro, es decir, lecciones magistrales, trabajos prácticos, seminarios, periodos de prácticas, trabajo de campo, Trabajo personal en bibliotecas o en el domicilio - así como los exámenes u otros posibles métodos de evaluación. Los créditos ECTS se basan, por tanto, en el volumen total de trabajo del estudiante (workload) y no se limitan exclusivamente a las horas de asistencia presencial." 482

Es decir, el ECTS recoge tanto el trabajo que realiza el alumno dentro como fuera de clase para llevar a cabo sus tareas, y esta peculiaridad va ser una novedad altamente positiva para las enseñanzas artísticas en comparación con el sistema de créditos anterior, ${ }^{483}$

rísticas esenciales, Luxemburgo, Oficina de Publicaciones Oficiales de las Comunidades Europeas, 2004, p. 3.

482 Pagani, Raffaella: "Concepto de crédito europeo", [documento en línea] <http://www.unican.es/NR/rdonlyres/04594170-0315-4C5B-B3DF-

FEC24D0CCBEA/0/doc4.pdf> [consultado el 22-7-2014].

${ }^{483}$ En el sistema educativo anterior, para equiparar las enseñanzas de música al sistema universitario, se adoptó el sistema de créditos sin efectuar una adecuada correspondencia de esa metodología a los estudios musicales. La sistemática de las enseñanzas musicales, que implica una carga de trabajo del alumno muy considerable no presencial, se daba de bruces con el sistema de cómputo de horas lectivas empleado durante la LOGSE en las universidades, por lo que el traslado del modelo de una institución a otra sin las consi- 
puesto que la metodología de las enseñanzas, pongamos por caso, de la especialidad de interpretación, se basan sobre todo en el trabajo que lleva a cabo el estudiante fuera del centro educativo, trabajando con su instrumento.

$\mathrm{Al}$ tener que calcular no sólo el tiempo que el alumno empleará en clase, sino también aquel que requerirá para la consecución del conjunto de tareas necesarias para lograr los objetivos del curso, percibimos cómo el proceso de enseñanza-aprendizaje se centra principalmente en el proceso de aprendizaje, provocando el cambio del foco de atención que comentábamos, dirigido ahora hacia el alumno.

Esto no significa que la dedicación del profesor sea menor, pero sí que cambia el concepto de enseñanza, que evoluciona en el sentido de entender al profesor como un dinamizador del desarrollo educativo del estudiante:

"Es un concepto de enseñanza más amplio. Al profesor/a se le pide que guíe/acompañe al alumno/a a través de un conjunto de actividades educativas donde la clase presencial es un elemento para la consecución de una serie de competencias en las que los conocimientos (su comprensión y su manejo) son una parte." 484

Desde la perspectiva de este cambio paradigmático de la enseñanza, significa como ya hemos comentado que la planificación y las metodologías que lleve a cabo el profesor, juegan un papel esencial en este nuevo planteamiento. Cuando determinemos las actividades que van a realizar nuestros alumnos, hemos de contar también con otras variables como son: cómo llevarlas a cabo; qué tiempo van a utilizar para llevarlas acabo; y cómo evaluarlas.

guientes precauciones y adaptaciones, demostró síntomas de incompatibilidad.

484 ANECA: Programa de convergencia europea. El crédito europeo, Madrid, ANECA, 2003, p. 15, [documento en línea] <http://www.aneca.es/Documentos-ypublicaciones/Otros-documentos-de-interes/Convergencia-Europea $>$ [consultado el 12-1-2014]. 
De modo que el tiempo del estudiante es el recurso de base que hemos de gestionar y el que posee verdadero valor, por eso los currículos o las asignaturas, no son mejores por tener más o menos créditos, sino por estar bien concertados todos los tiempos de las actividades educativas que conducirán a la obtención de las competencias adjudicadas: clases, trabajo personal, trabajo de campo, investigación,...

La estructura del ECTS tiene unas características que conviene saber para nuestra planificación docente. La ANECA la describe de la siguiente manera:

"El ECTS se basa en la convención de que 60 créditos miden la carga de trabajo de un estudiante a tiempo completo durante un curso académico. La carga de trabajo para un estudiante en un programa de estudios a tiempo completo en Europa equivale, en la mayoría de los casos, a 36/40 semanas por año, y en tales casos un crédito representa de 25 a 30 horas de trabajo. La carga de trabajo se refiere al tiempo teórico en que se puede esperar que un estudiante medio obtenga los resultados del aprendizaje requeridos." 485

Como se afirma arriba, el sistema de transferencia de créditos europeo permite cuantificar también los resultados de aprendizaje que el alumno cumplirá tras completar un proceso de enseñanza. La carga de trabajo completo que se necesita para obtener una titulación de primer ciclo de una duración de tres a cuatro años, equivale a 180 o 240 créditos.

Dicho esto, entendemos ahora por qué la elaboración de materiales didácticos adecuados y el empleo de nuevas metodologías, se perfilan como estrategias óptimas y necesarias para fomentar este cambio de paradigma del proceso de enseñanza-aprendizaje, dirigido a la consecución de un aprendizaje cada vez más autónomo del estudiante.

Con el EEES como telón de fondo y toda su dinámica desplegada, la programación de nuestra asignatura no puede reducirse a la des-

${ }^{485}$ Ídem, p. 8. 
cripción de unas tareas contenidas en unidades didácticas y secuenciadas a lo largo de un período sobre el que después se realizará un examen evaluativo. No es tan simple. En verdad, al tener el profesor que acompañar a sus alumnos en la adquisición y desarrollo de un conglomerado de competencias, contenidos teóricos y prácticas, con la finalidad última de buscar su autonomía, el modo de obrar o proceder, va a jugar un papel esencial en todo este proceso. Como muy bien resume el profesor De Miguel Díaz:

"una vez delimitadas las competencias a alcanzar, la siguiente cuestión a decidir a la hora de establecer la metodología de trabajo" [será] "establecer las distintas modalidades de enseñanza que se van a tener en cuenta a la hora de impartir una materia, para que los estudiantes adquieran los aprendizajes establecidos." 486

Precisar y establecer las modalidades y metodologías de enseñanza para cumplir los objetivos de cada curso y ciclo, se perfila por tanto como una importante pauta a tener en cuenta.

Con respecto a esta cuestión, es importante señalar las diferentes naturalezas que definen las enseñanzas de las distintas titulaciones impartidas en centros universitarios o artísticos. En el caso de las enseñanzas de música, tanto profesionales como superiores, la enseñanza de Piano, pongamos por caso, se diferencia por su perfil eminentemente práctico, aunque no exclusivamente, es decir, el estudiante que cursa sus estudios de interpretación en el itinerario de Piano en el ciclo superior, combina en su práctica instrumental, una suerte de contenidos teóricos y prácticos que hay que demostrar en situaciones siempre nuevas - por ejemplo conciertos o recitales - lo que implica necesariamente un cierto dominio y capacitación - competencia - en su práctica artística.

Esta descripción muy esquemática y resumida que acabamos de presentar sobre lo que representa cursar los estudios instrumentales de la especialidad de Piano, a saber, la asignatura de Piano como eje vertebrador sobre el que gravitan el resto de asignaturas, se ha

${ }^{486}$ De Miguel DíAz, Mario (coord.): Metodologías de enseñanza y aprendizaje para el desarrollo de competencias, Madrid, Alianza, 2006, p. 19. 
dado, en mayor o menor medida con sus correspondientes evoluciones y transformaciones históricas, a lo largo de todo el período que hemos estudiado. Expresado de manera más llana, desde que existen los sistemas educativos, aprender a tocar el piano significaba principalmente, sentarse a tocar el instrumento.

Con esto, no quisiéramos transmitir la simpleza que el proceso de Bolonia y sus novedades educativas no tienen nada que aportar a las enseñanzas artísticas, tienen y mucho como hemos estado viendo y seguiremos demostrando. Pero parece apreciarse que esta actualización en las enseñanzas artísticas, se ha llevado a cabo de manera más notoria en otros ámbitos, como por ejemplo la inclusión de la investigación y la inserción de estas tareas en los estudios superiores, que en el de la competencia profesional relacionada con la práctica del instrumento; aunque ésta última, como es natural, siempre haya de verse afectada por las reformas de los distintos planes.

Si hemos traído a colación este argumento, es para plantear que el aprendizaje por competencias, como lo hemos estado viendo hasta aquí, tal vez ha resultado metodológicamente más desafiante y novedoso, para aquellas titulaciones universitarias que presentan un gran volumen de contenidos teóricos en sus planes de estudio. Pero principalmente, lo que nos interesaba exponer, era la problemática sobre la búsqueda de metodologías en el contexto educativo actual que permitan la amalgama a medio camino, de aquellos objetivos que conciernen a la práctica instrumental, con los contenidos teóricos que acompañan a esta práctica.

Y en nuestro sondeo nos topamos con una solución, que por sus características parece encajar a la perfección con este requerimiento: los Estudios de Caso.

Basándonos en la siguiente exposición, podemos ilustrar muy bien cómo los Estudios de Caso pueden llegar a ser altamente operativos para las enseñanzas artísticas:

"El análisis profundo de ejemplos tomados de la realidad engarza dialécticamente la teoría y la práctica en un proceso reflexivo que se convierte, a su vez, en aprendizaje significativo, 
al tener que mostrar y analizar cómo los expertos han resuelto o pueden resolver sus problemas, las decisiones que han tomado o podrían tomar y los valores, técnicas y recursos implicados en cada una de las posibles alternativas. El hecho de buscar una comprensión e interpretación completa del caso, así como de las decisiones y posibles puntos de vista de su actor provoca un aprendizaje activo, que trasciende los límites del propio espacio de enseñanza-aprendizaje, y sirve para generar soluciones, contrastarlas e, incluso, ejercitarse en procedimientos de solución." 487

Como vemos los estudios de caso conectan en su metodología, teoría y práctica. A su vez, provocan un aprendizaje activo en aquellos que se ven inmersos en este proceder y han de buscar una solución al problema mediante su comprensión global, a través del análisis, tomando decisiones y finalmente proponiendo soluciones. ¿Acaso no nos es posible reconocer evidentes resonancias en el proceso que lleva a cabo un intérprete cuando se enfrenta al reto de emprender el estudio de una pieza nueva en su repertorio, con la descripción que acabamos de plantear sobre los estudios de caso?

La utilización que se puede hacer de esta metodología aplicada a la enseñanza de las especialidades instrumentales en los conservatorios, puede resultar altamente adecuada si extrapolamos la enunciación anterior al campo artístico de la interpretación cuando se señala que, los expertos (en nuestro caso los intérpretes) tomando problemas reales (las obras a interpretar), quieren buscar una comprensión e interpretación completa del caso (el intenso proceso cognitivo que lleva el estudio de la pieza a interpretar), a través del análisis profundo de ejemplos tomados de la realidad (el análisis para la interpretación que realiza el ejecutante), que engarza dialécticamente la teoría y la práctica (todos los datos que puede recoger el intérprete en la investigación de la obra, unidos a su ejecución) para poder resolver sus problemas, las decisiones que han tomado o podrían tomar y los valores, técnicas y recursos implicados en cada una de las posibles alternativas (las decisiones

${ }^{487}$ Ídem, p. 77 
que el ejecutante toma para la elaboración de la interpretación o múltiples interpretaciones que realizará basándose en el resultado de sus análisis).

Así que en conclusión, la metodología del estudio de caso en su variante para los procesos creativos artísticos asociados a la interpretación, puede resultar de gran utilidad porque como hemos podido comprobar, permite entre otros aspectos: desarrollar la facultad de penetrar a fondo mediante el análisis, la realidad que se estudia, ayudando a descifrarla; potencia el trabajo de síntesis al poder abordar elementos teóricos y prácticos del problema abordado; e implica profundamente al sujeto en el proceso, al tener que tomar decisiones sobre su escrutinio, y plantear soluciones.

\subsubsection{El aprendizaje por competencias: definición y debate}

La noción de competencia es sin lugar a dudas, otra de las innovaciones educativas con más repercusiones en el mundo académico. La amplia bibliografía que trata sobre este concepto demuestra la relevancia del debate entre aquellos que la defienden y sus detractores, dependiendo de las posiciones pedagógicas que ocupen. ${ }^{488}$

Como explican los expertos, tal vez uno de sus aspectos a favor, sea que el concepto de competencia:

“de algún modo puede ser un «recipiente» apropiado para contener de forma rigurosa una enseñanza más acorde con

488 Sobre el debate en torno a la cuestión del aprendizaje por competencias véase por ejemplo: BARNETT, Ronald: Los límites de la competencia. El conocimiento, la educación superior y la sociedad, Barcelona, Gedisa, 2001; BLANCO, Ascensión (coord.): Desarrollo y evaluación de competencias en Educación Superior, Madrid, Narcea, 2010; GIMENO SACRISTÁN, José (comp.): Educar por competencias. ¿Qué hay de nuevo? Madrid, Morata, 2008; LASNIER, Françoise: Réussir la formation par compétences, Montreal, Guérin, 2000; Perrenoud, Philippe: Diez nuevas competencias para enseñar, Barcelona, Graó, 2004; POZO, Juan I., PÉREZ ECHEVArRIA, María del P.: Psicología del aprendizaje universitario: formación en competencias, Madrid, Morata, 2009; SANZ DE ACEDO, Mª Luisa: Competencias cognitivas en educación Superior, Madrid, Narcea, 2010; VV.AA.: Aprendizaje, competencias y rendimiento en educación superior, Madrid, La Muralla, 2007. 
una perspectiva de formación integral, en equidad y para toda la vida." 489

Existe, empero la dificultad de diferenciar los campos de actuación que permitan distinguir los objetivos de las competencias:

"Lo que deben tener claro es que ambos términos pretenden clarificar qué es lo que pretendemos trabajar con nuestro estudiantes. Los objetivos nos lo plantean en términos de propósitos o metas que pueden incluir actividades prácticas o no. Las competencias incluyen siempre esa actividad práctica, es decir, requieren que los estudiantes utilicen lo que han aprendido para realizar alguna operación práctica (resolver un caso, producir un producto, realizar una actividad)."490

Para comprender mejor estos matices, tal vez nos ayude la siguiente idea condensada que establece tres tipos o niveles de aprendizaje. En primer lugar, el aprendizaje por objetivos, permite la adquisición de contenidos teóricos de una materia; a continuación tendríamos otro nivel de enseñanza representado por las capacidades, es decir el alumno ha de hacer, lo que ha aprendido; en tercer y último lugar llegan las competencias, cuya novedad primordial respecto a sus antecesoras es que esos conocimientos y capacidades han de desarrollarse junto a otras características del individuo, habilidades sociales, resolución de conflictos..., que le permitirán aplicar en distintas situaciones de la vida nunca experimentadas antes, los contenidos y capacidades adquiridos en los ciclos formativos correspondientes. Resumiendo podemos decir que el primer nivel es saber, el segundo saber hacer, tercero saber aplicar lo aprendido en una situación nueva concreta. Por eso decíamos que las enseñanzas artísticas de música siempre han utilizado aunque fuera de manera intuitiva y rudimentaria estos tres niveles de enseñanza-aprendizaje por objetivos, capacidades y competencias.

En la década de los 90, con la aplicación de la LOGSE en los conservatorios, comenzaba un nuevo diseño curricular en el que entre

489 Zabala, Antoni, Arnau, Laia: 11 ideas clave. Cómo aprender y enseñar competencias., Barcelona, Graó, 2007 (reimpr. 2010), p. 11.

490 ZabalZA, Miguel, ZabalZa CERdeiriña, María Ainoa, op. cit., p. 142. 
otros novedosos conceptos se hablaban de los objetivos, criterios de evaluación y contenidos de la asignatura, y cómo estos últimos se podían clasificar en conceptos, procedimientos y actitudes. ${ }^{491}$

Las competencias representan un nuevo giro de tuerca en el que aquellos tres elementos han de interrelacionarse conjuntamente de forma efectiva para afrontar diferentes situaciones en la vida. La competencia por tanto se sitúa en un nivel superior que abraza los anteriores, para combinarlos y trascender los principios educativos tradicionales del saber, y saber hacer. En efecto, con este sistema se intentan evitar errores educativos del pasado que han trascendido a la sabiduría popular con expresiones como un "burro cargado de libros" o incluso ya se ha hablado en cierto sentido de la "inteligencia fracasada", ${ }^{492}$ locuciones que sirven en cualquier caso para ilustrar los vicios de un tipo de aprendizaje polarizado en la acumulación irracional de saberes, sean del tipo que sean, sin interrelación alguna entre ellos.

Esclarecer en una definición lo más clara y precisa posible el concepto de competencia, es un reto que se debe en parte a la diversidad de acepciones que recibe desde diversos ámbitos como son el educativo pero también el laboral y profesional.

Una definición que compartimos y que describe a las competencias de forma lúcida sería la siguiente:

"La competencia ha de identificar aquello que necesita cualquier persona para dar respuesta a los problemas a los que se enfrentará a lo largo de su vida. Por tanto, competencia consistirá en la intervención eficaz en los diferentes ámbitos de la vida mediante acciones en las que se movilizan, al mismo

${ }^{491}$ ColL, César: Psicología y currículo: una aproximación psicopedagógica a la elaboración del currículum escolar, Buenos Aires, Paidós, 2008, p. 139.

492 Adoptamos literalmente la elocuente expresión de la obra homónima de Marina: MARINA, José Antonio: La inteligencia fracasada, Barcelona, Anagrama, 2008. 
tiempo y de manera interrelacionada, componentes actitudinales, procedimentales y conceptuales."

Estos expertos nos recuerdan que el aprendizaje de las competencias es un aprendizaje para la acción, ${ }^{494}$ puesto que no se trata tanto de poseer conocimientos como de saber emplear soluciones concretas a problemas concretos en situaciones concretas, de ahí la importancia del elemento contextual, ${ }^{495}$ ya que no se acaba de demostrar la adquisición completa de una competencia, hasta que no es aplicada en un escenario cuyas circunstancias no han sido previstas completamente.

Otra matización que consideramos importante relacionada con la definición de competencias es la que nos viene de la traducción del término "Learning outcomes", utilizado en la cultura anglosajona, y que podemos traducir como "resultados de aprendizaje". La acepción del término "resultados" para dirigirnos al proceso de enseñanza y las competencias, nos parece interesante desde la perspectiva que implica el compromiso por parte del profesor para que su labor docente sea "rentable" para los alumnos; la asistencia a nuestras clases debería significar para nuestros alumnos, una variación en su balanza de resultados de aprendizaje. ${ }^{496}$

${ }^{493}$ En estos autores es interesante comprobar cómo llegan a su enunciación después del análisis a través de diversas acepciones: ZABALA, Antoni, ARNAU, Laia, op. cit., p. 45.

${ }^{494}$ Los autores hablan de: "un aprendizaje para actuar." Ídem, p. 213.

${ }^{495}$ Es decir: "referido al momento de aplicar estos saberes a las tareas que la persona debe desempeñar." Ídem, p. 49.

496 Reproducimos a continuación algunas de las cuestiones que sobre este asunto nos podemos plantear los profesores como ejercicio para practicar una sana autocrítica: "Dicho en palabras más simples, los objetivos y competencias deben concretar y explicitar de una forma clara (y parsimoniosa) las mejoras y/o ganancias que los alumnos obtendrán como consecuencia de cursar nuestra materia. ¿Qué responderían ustedes si alguien, ustedes mismos, se plantearan la pregunta de 'qué ganan mis estudiantes del periodo que pasan conmigo? ¿Qué es lo que ellos sacan en limpio de haber pasado un semestre o varios en nuestras clases?" [...] "Y sin embargo ésa es la función que debieran cumplir: concretar de forma clara y explícita lo que se pretende 
En los planes de estudio regulados por las administraciones podemos comprobar como las competencias genéricas, transversales y específicas se relacionan para definir cuáles forman parte de cada materia. Esta relación se mantiene en la planificación de las Guías docentes de las materias, lo que significa que los objetivos que logra un determinado alumno en nuestra materia son fruto de la combinación de los tres tipos de competencias. En otras palabras, la resolución competente de un aprendizaje por parte del educando es el fruto de la combinación de las competencias generales de su titulación y específicas de su especialidad, pero también fruto del empleo de otras competencias transversales como pueden ser, la capacidad de solucionar problemas y tomar decisiones, o la habilidad social de saber liderar grupos de trabajo. Bajo esta perspectiva, el desarrollo de una competencia implica un tipo de progreso tendente a favorecer la eficiencia del educando, a lo largo de su vida.

De modo que, a partir de lo que acabamos de decir, derivamos que la enseñanza por competencias requerirá el uso de metodologías que impliquen ese acercamiento a las situaciones de la vida real, además de llevar a cabo las evaluaciones del grado de adquisición de las mismas.

En este sentido consideramos, a la luz de nuestra exposición y experiencia, que la utilización de metodologías como los estudios de caso, unido a ejercicios propios de las enseñanzas artísticas de música como son los recitales públicos, resultarían una combinación de procedimientos metodológicos excelentes, ya que en primer lugar permitirían la combinación de competencias actitudinales y conceptuales resultado principalmente de las aportaciones del estudio de caso, mientras que el marco abierto del recital público posibilitaría la entrada en juego de competencias generales y transversales, creando y dando forma a conceptos artísticos originales gracias al empleo de técnicas propias que permitirán al alumno trabajar en el futuro de forma autónoma, animándole, a tomar parte en

alcanzar en un curso.” (ZABALZA, Miguel, ZABALZA CERdEIRIÑA, María Ainoa, op. cit., p. 143). 
actividades con iniciativa propia y espíritu emprendedor, necesarias para su posterior desarrollo profesional.

\subsubsection{El nuevo rol del profesor}

La LOE, expone con bastante claridad en el Título II. Capítulo I, las funciones del profesorado. Del artículo 91, destacamos los parágrafos a) y l) del punto 1 así como el punto 2 en su totalidad que por su interés reproducimos a continuación:

“Artículo 91. Funciones del profesorado.

1. Las funciones del profesorado son, entre otras, las siguientes:

a) La programación y la enseñanza de las áreas, materias y módulos que tengan encomendados.

1) La investigación, la experimentación y la mejora continua de los procesos de enseñanza correspondiente." [...]

“2. Los profesores realizarán las funciones expresadas en el apartado anterior bajo el principio de colaboración y trabajo en equipo." 497

Aunque todos los párrafos son importantes hemos querido detenernos en éstos, porque resumen con bastante precisión algunas de las nociones que deseamos expresar.

Nos gustaría presentar que en primer lugar, la función del profesorado al programar su asignatura, o módulo que le corresponda, se encuentra vinculada a las tareas de investigación y experimentación, y en segunda instancia, que estas labores se realizarán en equipo.

Ya hemos tratado arriba lo que significa para los equipos docentes de los centros superiores el trabajo en equipo, así que abordaremos

${ }^{497}$ Ley Orgánica 2/2006, de 3 de mayo,... (B.O.E. de 4 de mayo de 2006, art. 91). 
directamente la primera de las funciones del profesorado. La programación de la asignatura nos conduce a la teoría de que la docencia es como cualquier otra profesión, una función que requiere responsabilidad, y este aspecto ha de ser revisado y actualizado para estar al día de las nuevas corrientes y descubrimientos que las ciencias y sus investigaciones nos van aportando.

El modelo de aprendizaje por competencias implica una formación, o al menos sería recomendable una sensibilización metodológica, que capacite al profesorado para el desempeño de su función docente. Pensamos además que esta formación por competencias puede ser altamente productiva, en concreto en aquellos casos en los que los profesores se encuentren de algún modo en contacto o en activo con aquellas funciones que enseñan, ya que como hemos visto hasta ahora la experiencia en la vida real, forma parte de la naturaleza primigenia de las competencias.

La actualización de los documentos organizativos de nuestros departamentos, tal vez después de gestionar la primera reacción adversa a empezar esta tarea, puede significar una oportunidad para actualizar nuestras conocimientos y reflexionar sobre la influencia que ejercemos en nuestros alumnos, debido a nuestro decisivo rol en el proceso de enseñanza-aprendizaje.

La investigación, experimentación y mejora de los procesos de enseñanza implica, junto al marco de convergencia europea, la optimización de los estándares de calidad e innovación.

Se puede argumentar, no sin razón, que la influencia desde distintas áreas de conocimiento puede abocar a la más completa desorientación del profesorado, que no sabe a qué atenerse. En la enseñanza, los responsables de ámbitos relacionados con la psicología, pedagogía o didáctica, presentan sus teorías, las cuales han de convivir con las de los expertos de aquellas áreas sobre las que cada profesor imparte su asignatura. Este diálogo, no siempre fácil, debe enfocarse desde el respeto y el enriquecimiento mutuo, creando nuevos espacios de intersección.

Un primer ejemplo de esta hipótesis consiste en la apuesta por el perfil mixto de los docentes, o podríamos decir de los especialistas- 
docentes. El tema es complejo y la solución no es fácil ya que se corre el riesgo de instaurar un modelo de cuyo vicio ya alerta el viejo refrán cuando advierte sobre el peligro de ser aprendiz de mucho y maestro de nada. En todo caso, defendemos la hipótesis $^{498}$ acerca de que los profesores encargados de estas enseñanzas demuestren su competencia en el ámbito de la especialidad que imparten así como en la docencia, cada cual en el grado y proporción que se sienta más identificado, dentro de una regular actualización de estos ámbitos.

Este aspecto unido al desarrollo de la actividad investigadora en las enseñanzas artísticas, abre un nuevo y prometedor horizonte de innovación profesional y educativa.

Toda esta reflexión nos conduce hacia la siguiente cuestión que nos interpele directamente: ¿cómo podemos optimizar la enseñanza de Piano en la actualidad en los términos aquí expuestos, es decir, que nuestros alumnos se interesen de forma creciente en el aprendizaje de su instrumento, favoreciendo su autonomía como artistas e intérpretes?

Esta pregunta no tiene una respuesta única, así que retomando nuestro tema, la contestación a este dilema en el momento actual

${ }^{498} \mathrm{Y}$ no somos los únicos: "estamos llamados a ser especialistas en nuestro campo científico, y también, especialistas en el desarrollo de procesos de enseñaza y aprendizaje de nuestra disciplina." (ZABALZA, Miguel, ZABALZA Cerdeiriña, María Ainoa, op. cit., p. 64). A este respecto hemos de introducir un aspecto importante sobre el que volveremos en repetidas ocasiones, y que consiste, como han evidenciado algunos autores en sus escritos, en la posible desafección de los profesores de música sobre temas educativos: "El profesor de música en España ha sido, tradicionalmente, individualista y poco participativo y se ha despreocupado, de forma generalizada, de materias relacionadas con la enseñanzas de la música: pedagogía, didáctica, psicología, historia, mostrándose reacio a la investigación y a la incorporación de novedades y nuevos planteamientos pedagógicos." [...] "La metodología adoptada se caracterizó por una enseñanza repetitiva basada en la imitación del alumno hacia el maestro, portador de las técnicas y los conocimientos, y en la que no abundó el espíritu crítico en torno a la labor docente encaminada principalmente a la consecución de solistas." (AgüERRíA CuEva, Fernando, op. cit., p. 259). 
de la disertación, pasaría por la propuesta de una Guía docente que sea coherente con los conceptos de equidad, calidad e innovación educativa. ¿Y cómo podemos armonizar con estos conceptos? Aquí van algunas orientaciones: ${ }^{499}$

- Confiriéndole a la docencia musical el sentido formativo práctico que le es propio, evitando la excesiva esclerotización burocrática y generando un contexto favorable para la organización del aprendizaje.

- Para ello será necesario una actualización en la selección de los contenidos ${ }^{500}$ más relevantes, disfrutar de buenos materiales didácticos (no prescindir de las TIC) y emplear metodologías que posibiliten el aprendizaje autónomo de los educandos. ${ }^{501}$

- Las clases de instrumento principal en las especialidades de interpretación de las enseñanzas superiores de música, tiene una ratio $1 / 1$, que posibilita mantener una excelente atención personal, que se conjugan excelentemente con las tutorías.

No obstante, para equilibrar, el punto anterior, en itinerarios como Piano, resultaría conveniente el desarrollo de actividades y pro-

499 Estas orientaciones, son una reelaboración enfocada para las enseñanzas artísticas de música, de las expuestas por Zabalza para la docencia universitaria en: ZABAlZA, Miguel, ZABALZA CERDEIRIÑA, María Ainoa, op. cit., p. 77.

${ }^{500}$ Por ejemplo se puede emplear el repertorio de obras a estudiar en los programas actualizando y ampliando el catálogo, con la recuperación, interpretación y grabación de repertorios musicales poco transitados. Sobre esta valoración se puede consultar la siguiente referencia: GUTIÉRREZ BARRENECHEA, María del Mar, op. cit., p. 210.

501 Como indicamos en el segundo punto es importante la adquisición de herramientas por parte de los alumnos que favorezca su autonomía y rendimiento del tiempo empleado en los estudios de sus instrumentos, y en este aspecto la aportación del profesor es determinante. Véase por ejemplo el estudio de: BARry, Nancy H., MCARTHUR, Victoria: "Teaching Practice Strategies in the Music Studio: A Survey of Applied Music Teachers", en Psychology of Music, vol. 22, London, Society for Research in Psychology of Music (SRPMME), 1994, pp. 44-55. 
yectos que permitan el trabajo en equipo y la cooperación entre profesores, aplicar sistemas de evaluación que se adapten a los nuevos aprendizajes, así como revisar la propia labor docente con mecanismos que propicien la autocrítica constructiva.

No desearíamos finalizar este apartado sin realizar un último apunte relacionado con la idiosincrasia de las enseñanzas de música. Pues aunque nos encontramos situados en la enseñanza superior, y las enseñanzas de música se encuentran reguladas en tres ciclos diferentes, la cohesión interna que existe a lo largo del total de la duración que implica llegar a dominar un instrumento, ${ }^{502}$ nos empuja hacia una última reflexión sobre el papel que tiene en el conjunto del desarrollo educativo del futuro intérprete, la coherencia entre los distintos niveles y la participación de la sociedad en el proceso, sobre todo de las familias.

La implantación del modelo de enseñanzas por competencias en el sistema educativo, implica la participación de todos los agentes de la comunidad educativa y esto es así aún más si cabe en el caso de las enseñanzas artísticas.

Si el objetivo de la educación musical es lograr músicos profesionales, entendido como lo hace la Sociedad Internacional para la Educación Musical (ISME), la cooperación de toda la comunidad y en especial la de las familias, es esencial:

“el músico profesional es el que acepta la responsabilidad para desarrollar y diseminar la música como parte integral de la vida, y cuya creación e interpretación de la música refleja percepción, entendimiento, apreciación y maestría de forma que tenga significado para la gente." 503

502 Las investigaciones sobre el asunto no dejan de progresar: "No se ha conseguido detectar condiciones genéticas diferenciales, pero sí una relación decisiva entre la edad en que se empieza y el tiempo dedicado al estudio riguroso, llegando incluso a establecer como duración media aproximada un periodo de preparación a tiempo completo de diez años." (GuTIÉRREZ BARRENECHEA, María del Mar, op. cit., p. 197.

${ }^{503}$ Citado en GutiérRez BArReneChEA, María del Mar, op. cit., p. 146. 
Un músico competente tiene más probabilidades de serlo, si en sus comienzos se incentivan los primeros contactos con el instrumento, más como un juego que como una obligación, ${ }^{504}$ intentando asociar experiencias agradables y positivas a estos primeros acercamientos con la música.

Posteriormente, el sostén de los padres, a través de actividades como el acompañamiento en la creación de un clima adecuado de estudio para ayudar a sostener la práctica diaria del instrumento, unido a las experiencias vitales del contacto con los primeros profesores, encargados de transmitir al alumno el amor a la música asociado a los primeros rudimentos de la técnica instrumental, serán otras de las experiencias claves en la formación y desarrollo del talento $^{505}$ del estudiante de música.

Y con estas recomendaciones en su aprendizaje inicial, comienzan los estudios de ciclo superior encargado de finalizar el proceso, o de reforzarlo para proseguir en los posteriores ciclos de Máster y Doctorado.

${ }^{504}$ Consúltese la interesante obra de: BLOOM, B. S.: "Generalizations about talent development", y SOSNIAK, Lauren "Learning to be a concert pianist", ambos en BLOOM, Benjamin S. (ed.): Developing talent in young people, New York, Ballantine Books, 1985. También de Sosniak: SoSNIAK, Lauren: 'From Tyro to Virtuoso: A Long-term Commitment to Learning", en Wilson, Frank R. y Roehmann, Franz L. (eds.), Music and Child Development, St. Louis, MMB Music, 1990, pp. 274-290.

${ }^{505} \mathrm{La}$ influencia del talento innato, es un interesante campo de estudio que sigue generando interés actualmente entre la comunidad científica: GALTON, Francis: Hereditary genius: An inquiry into its laws and consequences, Memphis, General Books, 1869/2012; GARDNER, Howard: The arts and buman development, New York, Wiley, 1973; Ericsson, K. Anders, Krampe, R. Th., HeIzman, S.: "Can We Create Gifted People?”, en Ciba Foundation Symposium 178 - The Origins and Development of High Ability, Chichester, Wiley, 1993, pp 222-249; ERICSSON, K. Anders: "Deliberate practice and the acquisition of expert performance: An overview”, en: JøRGENSEN, Harald, LEHMANN, Andreas C. (eds.): Does Practice Make Perfect? Current Theory and Research on Instrumental Music Performance, Oslo, Norwegian State Academy of Music, 1997, pp 9-51; y Williamon, Aaron (ed.): Musical Excellence: Strategies and Techniques to Enhance Performance. Oxford, Oxford University Press, 2004. 
Este vertiginoso repaso en la trayectoria formativa de un estudiante de música que decide emprender sus estudios elementales (4 años de duración), que proseguirá en los conservatorios profesionales (6 años), que continuará sus estudios interpretativos en el itinerario de Interpretación de Piano para obtener su Título Superior (4 años), y que podrá perfeccionar en diversos itinerarios con un Máster Artístico (2 años), y un Doctorado (3-4 años), nos ayuda a ver la conexión entre los distintos ciclos formativos, y a situarnos en el lugar que tenemos asignado como docentes dentro de ese proceso. Somos conscientes que la planificación de nuestra asignatura en cualquiera de sus ciclos y cursos, es un compromiso que forma parte de un apasionante y magno proyecto (nada menos que 20 años de formación académica), como lo es en efecto la formación de un Intérprete de Piano. 



\section{Las enseñanzas superiores de música en Europa}

\subsection{Del nacimiento de Europa a la creación de las redes académicas, o de la Comisión Europea al Grupo Polifonía}

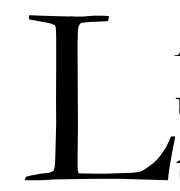

A UNIÓN EUROPEA NACE CON el anhelo de contrapesar una primera mitad del siglo XX protagonizada por los continuos conflictos entre países, que llegan al paroxismo en las dos cruentas guerras mundiales que estremecieron a Europa entre 1914 a 1918 y de 1940 a 1945.

El deseo de ver una Europa unida en paz y prosperidad, infundieron el sentimiento necesario a algunos líderes políticos para protagonizar el impulso de un proyecto, la creación de la Unión Europea, una realidad que se ha mantenido viva hasta nuestros días. Entre los padres fundadores se encontraban: Konrad Adenauer, Winston Churchill, Robert Schuman o Altiero Spinelli. ${ }^{506}$

506 Para ver estos aspectos sobre la Unión Europea y sus orígenes, puede consultarse el siguiente enlace: 
Un paso inicial en dirección hacia esta unión, fue el tratado que Francia, Alemania, Italia y los Países Bajos, firman en la década de los 50, constituyendo la Comunidad Europea del Carbón y del Acero (CECA), primer acercamiento que conduciría en 1957 a la firma de los «Tratados de Roma»; por el segundo se constituía una Comunidad Europea de la Energía Atómica, y con el primero se compone la Comunidad Económica Europea (CEE).

Entre los principales organismos e instituciones que constituyen actualmente la Unión Europea ${ }^{507}$ se encuentran: el Parlamento Europeo, que representa a los ciudadanos; El Consejo Europeo, que congrega a los jefes de Gobierno de cada país, mientras que El Consejo de la Unión Europea reúne a los diferentes representantes de los gobiernos de los Estados miembros, es decir, a aquellos ministros responsables de su ámbito de gestión; y la Comisión Europea que promueve los intereses de la UE de forma global, planteando reglamentaciones al Parlamento Europeo y al Consejo de la UE.

Estas instituciones trabajan conjuntamente; en síntesis, la Comisión presenta normativas que el Parlamento y el Consejo adoptan mediante el procedimiento legislativo ordinario. Los países miembros aplicarán las leyes aceptadas y la Comisión velará por el cumplimiento de las mismas.

La Comisión Europea se divide en numerosas Direcciones Generales y servicios. Estos últimos pueden tener tareas concretas, como la confección de estudios estadísticos, mientras que las Direcciones Generales, se distribuyen según sus respectivos terrenos de actuación. La Dirección General de Educación y Cultura gestiona a través del Área de Educación y Formación, las políticas de cooperación en materia educativa de los estados miembros, entre

<http://europa.eu/about-eu/eu-history/index_es.htm> [consultado el 227-2014].

507 Puede accederse a los enlaces que conducen a las diferentes Instituciones de la UE desde el URL:

$<$ http://europa.eu/about-eu/institutions-bodies/index_es.htm> [consultada el 22-7-2014]. 
las que se encuentra el refuerzo y promoción del Programa de Aprendizaje a lo largo de la vida.

En efecto, a través de la Decisión $N^{0}$ 1720/2006/Ce del Parlamento Europeo y del Consejo de 15 de noviembre de 2006 por la que se establece un programa de acción en el ámbito del aprendizaje permanente, ${ }^{508}$ el parlamento europeo y el consejo de la unión europea, aprobaron la normativa encargada de desarrollar el Programa de Aprendizaje Permanente (PAP, o LLP en inglés) ${ }^{509}$ diseñado para permitir a las personas tomar parte en experiencias de aprendizaje, en cualquier etapa de su vida,

Este propósito viene estimulado por el impulso de unas estrategias de marco general, como resultado de los análisis socioeconómicos que confirmaban la universalización de la economía y el aumento de la competitividad, con un cada vez mayor protagonismo de las tecnologías de la información y la comunicación, de ahí que la Unión Europea pretenda dinamizar su economía poniendo en marcha un plan de desarrollo. Con esta finalidad nace, la Estrategia o Agenda de Lisboa, proyecto aprobado por el Consejo Europeo en marzo de 2000, cuyo principal objetivo estratégico era transformar la economía de la Unión:

"La Unión se ha fijado hoy un nuevo objetivo estratégico para la próxima década: convertirse en la economía basada en el conocimiento más competitiva y dinámica del mundo, capaz de crecer económicamente de manera sostenible con más y mejores empleos y con mayor cohesión social." 510

508 Decisión $n^{\circ}$ 1720/2006/CE del Parlamento Europeo y del Consejo, de 15 de noviembre de 2006, por la que se establece un programa de acción en el ámbito del aprendizaje permanente, OJ L 327, 24/11/2006, pp. 45-68.

${ }^{509} \mathrm{El}$ programa se puede consultar en el enlace web:

$<$ http://ec.europa.eu/education/tools/llp_en.htm $>$ [consultado el 22-72014].

${ }^{510}$ Las conclusiones de la presidencia extraídas de la sesión especial que el Consejo Europeo celebró los días 23 y 24 de marzo de 2000, se pueden consultar en el siguiente enlace:

<http://www.consilium.europa.eu/ueDocs/cms_Data/docs/pressData/es/ ec/00100-r1.es0.htm> [consultado el 22-7-2014]. 
Entre las diferentes medidas a adoptar para llevar a buen término este propósito, se contempla la modernización del modelo social de Europa a través de la inversión en capital humano y el desarrollo de políticas encaminadas a combatir la exclusión social. En el contexto de la Estrategia de Lisboa, el Consejo Europeo refrendó en 2002, el programa "Educación y Formación 2010" y más tarde su continuador "Educación y Formación 2020", 511 como nuevo marco estratégico para la colaboración europea en el área de la Educación y la Formación.

Entre sus objetivos, se encuentra el adecuar los sistemas de educación y formación europeos a los nuevos requerimientos de la sociedad del conocimiento, para que redunde en una mejora de la calidad del mercado laboral. Un proyecto como la formación permanente de la ciudadanía, tendrá como principal misión, procurar oportunidades de aprendizaje y formación a diversos grupos de ciudadanos, cuyos programas de estudio estén adecuadamente orientados a las diferentes etapas vitales de sus destinatarios. La mejor integración en el mercado laboral, como resultado de una formación de calidad y en igualdad de condiciones en las etapas formativas, es una de las pautas que define a la Unión Europea, y que germina en Bolonia.

También se hace especial hincapié en la movilidad y para ello se necesitan modos abiertos de coordinación, en los que se respeten las competencias en educación y formación de cada uno de los Países de la Unión.

Dicho brevemente, el Aprendizaje a lo largo de la vida es un programa central de la política educativa europea que quiere facilitar el acceso al aprendizaje de los ciudadanos, en cualquier etapa vital de sus vidas. Para llevar a cabo este plan se articulan cuatro subprogramas sectoriales: Comenius, orientado a las escuelas; Leonardo da Vinci que tutela la educación y formación profesional; el programa Grundtvig enfocado para la educación de adultos; y el programa

511 Para el programa Educación y Formación 2020 (ET 2020) consúltese el siguiente enlace:

$<$ http://europa.eu/legislation_summaries/education_training_youth/general_framework/ef0016_es.htm> [consultado el 22-7-2014]. 
Erasmus que es el programa que más nos interesa en estos momentos, puesto que se encarga de la educación superior.

El programa Erasmus arranca su andadura en 1987, y se ha convertido posiblemente, en uno de los programas comunitarios más populares y con más éxito de todos los emprendidos en estos últimos 25 años.

Su área de acción son los procesos de enseñanza y aprendizaje de la educación superior y el impulso de sus propuestas contribuye al desarrollo del Espacio Europeo de Educación Superior, mediante programas trasnacionales de cooperación entre las instituciones de enseñanzas superiores.

Para comprender mejor estos programas de cooperación, vamos a centrarnos en las redes temáticas Erasmus, unos sistemas que han permitido a las instituciones en educación superior cooperar en proyectos de innovación con objetivos sobre campos específicos, como por ejemplo la creación de la red constituida por el Grupo Polifonía.

El Grupo Polifonía ha estado encargado de generar y coordinar la coyuntura necesaria para la aplicación del EEES en el área específica de la Educación Musical Superior en Europa, labor que posteriormente se irradiaría a las distintas instituciones superiores artísticas europeas.

Como podemos comprobar, ${ }^{512}$ la red cuenta con la participación de 55 instituciones de educación y formación musical, repartidas por 26 países europeos y 4 fuera de las fronteras de nuestro continente, cifras que la convierten en una de las redes más grandes de Europa, y está co-cordinada por el Koninklijk Conservatorium de La Haya y la Asociación Europea de Conservatorios (AEC).

El Grupo Polifonía desarrolla su actividad en ciclos de tres años: el primero de ellos (2004-2007) fue designado por la Comisión Europea como proyecto catalogado dentro de las «Historias con éxito»

${ }^{512}$ Para conocer el Grupo Polifonía y todos los detalles de su ámbito de gestión, puede visitarse su web: http://www.polifonia-tn.org/. 
(Erasmus success story 2007) de las redes Erasmus; el segundo ciclo se desarrolló durante los años 2007-2010; y el tercer ciclo finaliza en septiembre de 2014.

\section{2. «Bologna in Music»: el papel de las Asociaciones educativas artísticas europeas}

El punto anterior nos ha permitido extraer una visión panorámica de todos los organismos y estructuras más significativos, así como de los principales proyectos desarrollados desde la Construcción de la Unión Europa, hasta el último grupo humano responsable de dar viabilidad al EEES en Música.

Como ya hemos descrito en capítulos anteriores, y repasamos ahora a modo de síntesis introductoria, el Espacio Europeo de Educación Superior, fue un proyecto que nació a raíz de la reunión de los ministros de Francia, Alemania, Italia y Reino Unido, celebrada en París el 25 de mayo de 1998, y que se ratificaría en 1999 con la Declaración de Bolonia, esta vez suscrita ya por 30 estados europeos.

La Declaración de Bolonia prevé la construcción de un espacio de convergencia de la educación superior en Europa, como respuesta a dos objetivos principales: favorecer el incremento de las tasas de empleo, y crear un sistema de educación superior atractivo para los estudiantes y profesores de todo el mundo, conforme a criterios de calidad, movilidad, diversidad y competitividad.

Para la consecución de estos objetivos se establecen seis prioridades: la adopción de un sistema que facilite la comparación de la titulaciones, como por ejemplo el Suplemento al Diploma; se estructura la educación superior en dos ciclos; se decide aplicar un sistema de créditos, como es el sistema europeo de transferencia de créditos ECTS; se favorece la cooperación Europea para asegurar el desarrollo de criterios y procedimientos que garanticen la calidad. La European Network for Quality Assurance in Higher Education (ENQA) y la ANECA emiten sendas normativas para este cometido; se promueve la creación de un espacio efectivo de con- 
vergencia de educación superior mediante la unificación de los sistemas, planes de estudio y diseños curriculares europeos; y por último, se busca, eliminando los posibles escollos, promocionar la movilidad de los estudiantes, profesores y personal administrativo de las universidades y otras instituciones de enseñanza superior europea.

Se fija como plazo límite para alcanzar estos propósitos hasta el año 2010, y así en sucesivas reuniones bianuales se revisa el progreso de las propuestas a la vez que se recogen las nuevas intenciones para futuras citas, recopilándose todo ello en las Declaraciones que se extraen de la Conferencias Ministeriales. La búsqueda de esta consolidación en Europa de un espacio común de la enseñanza superior, no significa la «uniformalización» de los sistemas educativos de las naciones comprometidas con el proyecto, sino que se persigue el respeto a la variedad y riqueza cultural que define a los países de la Unión, así como la autonomía de las instituciones educativas correspondientes.

Como ya hemos visto, el marco de convergencia es un acicate para todas las instituciones de enseñanza superiores, no sólo para las universitarias, $y$ hemos podido comprobar a través de la normativa correspondiente, cómo este proceso se ha llevado a cabo en España, pero, ¿qué ha sucedido antes?, ¿cómo han regulado los diferentes organismos responsables, la aplicación del EEES en el ámbito musical?

Como venimos describiendo, en España, de entre los tres ciclos formativos existentes en música actualmente, elemental, profesional y superior, probablemente sea este último el que más transformaciones haya sufrido en las últimas dos décadas, debido principalmente al proceso de convergencia europea de educación superior.

Aquellas instituciones europeas que imparten enseñanzas musicales superiores y están integradas en las universidades, sólo han tenido que seguir el cauce reglamentario ordinario, sin embargo para auxiliar a aquellos otros numerosos países cuyos centros superiores tenían que aplicar las consiguientes novedades que comportaba el proceso de Bolonia, entidades como la AEC, o la Liga Europea de 
Institutos Artísticos (ELIA) ${ }^{513}$ pusieron en marcha varias actuaciones para coordinar el proceso.

Fundada en 1990, ELIA es una de las principales redes dedicadas a la educación superior en Artes y sus actividades cuentan con el apoyo de la Dirección General de Educación y Cultura de la Comisión Europea. La principal diferencia con la AEC, es que aunque incluye también la Música, aglutina y focaliza no obstante su labor principalmente en las otras disciplinas artísticas como son la Danza, Teatro, Diseño, Bellas Artes, Arte y medios de comunicación o Arquitectura.

Actualmente, cuenta con 300 miembros de 47 países que representan a una comunidad de alrededor de 300.000 estudiantes, para quienes la asociación, intenta promover nuevas opciones y oportunidades para la mejora de las prácticas artísticas a nivel europeo. Por eso ELIA realiza conferencias, desarrolla proyectos de investigación y elabora publicaciones, dirigidas tanto a la comunidad educativa de las artes en la enseñanza superior, así como al público en general.

En su asamblea general celebrada en Barcelona en el 2000, los miembros asociados aprobaron un manifiesto en el que describiendo la compleja realidad social de nuestra época, abogaban por la defensa del Valor de las Artes y la importancia del aprendizaje a través de las artes en la educación, al tiempo que destacaban el desarrollo que esta sufriendo el ciclo superior de educación artística y las implicaciones que conlleva el proceso de Bolonia para este ámbito educativo.

Por su parte, la AEC apareció en 1953 con el propósito de establecer contactos a través del intercambio de experiencias, entre los centros de educación musical de Europa.

${ }^{513}$ La AEC y ELIA, ponen a disposición entre otros mecanismos sus páginas web http://www.aec-music.eu/home, y http://www.elia-artschools.orgL, en las que aparece toda la información de interés, relacionada con el efecto del proceso de Bolonia en música, y los distintas políticas desarrolladas por estas organizaciones. 
A través de la Declaración adoptada en la asamblea general de la AEC, celebrada en noviembre de 1999 en Bucarest, la organización de conservatorios europea empezó a jugar su trascendental papel en la aplicación de los principios de la Declaración de Bolonia a la educación musical superior.

Además, en la misma declaración, la AEC recomendaba para el deseable nivel de compatibilidad del proceso, la adecuación de los sistemas educativos de ciertos países, entre ellos España, a los parámetros del EEES, como es el de la estructuración de las enseñanzas en dos ciclos:

"3. The Association believes it to be essential to the optimum functioning of musical higher education in Europe that all its member institutions, among whom there is broad recognition of mutual compatibility, should be able to participate fully in exchange, transfer and progression of students within both of these cycles. In this context, the Association particularly urges the rapid recognition by countries such as Spain, Portugal, Italy and Greece that practically-based musical study is applicable in principle to both cycles." 514

La advertencia en el caso español no es ociosa, ya que hemos de recordar el peligro del que escapamos, al aplicar finalmente las directrices de convergencia superior europea, después del quinquenio negro normativo sufrido por las enseñanzas artísticas superiores en España que amenazó seriamente con dejarlas completamente al margen del EEES.

514 “3. La Asociación cree que es esencial para el funcionamiento óptimo de la educación superior musical en Europa que todas sus instituciones miembros, entre los cuales existe un amplio reconocimiento de compatibilidad mutua, deben ser capaces de participar plenamente en el intercambio, la transferencia y la progresión de los estudiantes dentro de estos dos ciclos. En este contexto, la Asociación insta en particular al rápido reconocimiento por parte de países como España, Portugal, Italia y Grecia, que el estudio musical basado en la práctica sea aplicable, en principio, a los dos ciclos." (AEC: The AEC Declaration (1999), [documento en línea] <http://www.aecmusic.eu/userfiles/File/aec-declaration-1999(1).pdf> [consultado el 22-72014]). 
Por otra parte, dentro del marco de proyectos de redes temáticas del programa Sócrates de la Comisión Europea, la AEC y la ELIA, elaboraron para la conferencia ministerial de Berlín en 2003, el documento Towards a European Space for Higher Arts Education (Hacia un espacio europeo para la Educación Superior en las Artes), texto en el que ambas asociaciones expresaban su apoyo al proceso de Bolonia, a la vez que insistían en la necesidad de tomar en especial consideración, la especificidad de estas enseñanzas a la hora de aplicar las políticas pertinentes del ciclo superior artístico. Así por ejemplo, en el ámbito de la investigación artística las asociaciones lanzaban la siguiente consideración:

\section{“5. Artistic development and research}

5.1 The teaching and learning environment in higher arts education is based on artistic development and research. In some countries, artistic development in this context is recognised as a form of research. Artistic development and research taking place in higher arts education have to be recognised on a level equivalent to all other disciplines of higher education. Dedicated funding and incentives are needed in order to develop further the research/artistic development dimension in higher arts education." 515

Ambas asociaciones defienden la transparencia a la hora de establecer el total reconocimiento y equivalencia del ciclo superior de

515 “5. Desarrollo artístico e investigación. 5.1 La enseñanza y el ambiente de aprendizaje en la educación superior artística se basa en el desarrollo artístico y la investigación. En algunos países, el desarrollo artístico en este contexto se reconoce como una forma de investigación. El Desarrollo artístico y de investigación que tiene lugar en la educación superior artística tiene que ser reconocido en un nivel equivalente al de todas las demás disciplinas de la educación superior. Serán necesarias la financiación y dedicación de incentivos con el fin de desarrollar aún más el progreso de la investigación artística en la educación artística superior." (AEC, ELIA: Towards a European Space for Higher Arts Education. AEC-ELIA Position Paper, 2003, [documento en línea] $<$ http://www.aec-mu-

sic.eu/userfiles/File/aeceliapositionpaperenglish(1).pdf > [consultado el 16$1-2014])$. 
estas enseñanzas con las universitarias, e inciden en el establecimiento de un ámbito propio de investigación artística.

\subsection{Estructuras auxiliares para la implantación del EEES: los marcos de cualificaciones, la Iniciativa Conjunta de Calidad (JQI), y el proyecto Tuning}

Recordemos que una de las directrices de la Declaración de Bolonia era la convergencia de un espacio efectivo de enseñanza superior, a través de la confección de programas de estudio equiparables entre ellos, gracias a la cooperación entre las instituciones implicadas.

Para cumplir con el acuerdo de Bolonia y plasmar los objetivos estratégicos de Lisboa, alrededor de 100 establecimientos de educación pertenecientes a la Unión Europea, se pusieron a trabajar en el año 2000 sobre un programa conjunto, coordinado por las Universidades de Deusto (España ) y Groningen (Países Bajos), bautizado con el nombre de proyecto Tuning. ${ }^{516}$ El programa se desenvuelve a partir de la experiencia acumulada en ensayos anteriores, sobre el marco institucional de las redes temáticas Sócrates-Erasmus y proyectos piloto ECTS, y sus resultados serían aplicables a todas las instituciones superiores que buscasen ese espacio común de convergencia.

Como su propio nombre indica en inglés, Tuning nace con el objetivo de sintonizar o armonizar los diferentes sistemas educativos de los países de la Unión Europea, y para ello contempla los objetivos prefijados en la Declaración de Bolonia, sobre la transparencia de los Títulos, la división en dos ciclos, o la incorporación del ECTS. Tuning brinda una vía a todas las disciplinas y áreas de conocimiento que impartidas en las instituciones superiores, quieran imbuirse en el Espacio Europeo de Enseñanza Superior.

516 Toda la documentación desarrollada por esta estructura educativa se puede visitar en su página web: http://www.unideusto.org/tuningeu/. 
Tuning formula unos puntos de referencia expresados en términos de competencias genéricas y específicas, al final del primer y segundo ciclo de las diferentes disciplinas. Matizamos que este modo de «afinar» la educación de los países miembros, no pretende fabricar planes de estudio idénticos, antes bien todo lo contrario, si se fijan estos puntos al final de cada ciclo es para preservar la riqueza de la multiplicidad cultural y educativa de los países de la Unión, sin pretender invadir los espacios propios de autonomía que poseen las diferentes administraciones e instituciones involucradas.

Para alcanzar esta convergencia al tiempo que se respeta la autonomía de las instituciones, Tuning desarrolla su metodología sobre 5 líneas de actuación: las competencias genéricas; las competencias específicas; el empleo del ECTS como sistema de acumulación; los procesos de aprendizaje, enseñanza y evaluación; y la búsqueda de la calidad en el proceso educativo.

Con estas directrices los centros de enseñanzas superiores sintonizan sus respectivos planes de estudio, a la vez que se incentiva la innovación de los sistemas educativos, materializándose así el lema de Tuning:

"Armonización de las estructuras y programas educativos respetando su diversidad y autonomía."

Como ya hemos estado viendo en el apartado 6. 4. 1., otra característica de la metodología Tuning es el cambio de paradigma que supone pasar de concentrar los procesos educativos de los profesores a los estudiantes. El planteamiento de una educación basada en competencias y resultados de aprendizaje conlleva este cambio de visión, reorientándose de los «inputs» del profesor a los «outputs» del alumno para, a través de este cambio, intentar proporcionar una incorporación al mercado laboral más competitiva.

${ }^{517}$ GONZÁLEZ, Julia, WAGENAAR, Robert (coords.): Una introducción a Tuning Educational Structures in Europe. La contribución de las universidades al proceso de Bolonia, Bilbao, Publicaciones de la Universidad de Deusto, 2009, p. 13, [documento en línea]

<http://www.unideusto.org/tuningeu/images/stories/Publications/Tuning _brochure_en_espanol_listo.pdf $>$ [consultado el 22-7-2014]. 
Además, se hace necesaria la utilización de metodologías y criterios evaluativos nuevos por parte del profesor, que tendrá que prever en la planificación de la Guía docente, el cómputo de horas totales que comportará al alumno realizar las actividades programadas para el curso, animando así a los profesores a la autorreflexión sobre su tarea docente y el diseño de sus actividades.

La metodología a aplicar será por tanto revisada para adecuarse al nuevo plan, y dependerá del tipo de disciplina impartida, siendo recomendables junto a la tradicional clase magistral, actualizar el abanico de posibilidades con otros métodos como: los seminarios y talleres; las tutorías; o los estudios de caso.

A todo lo dicho hasta aquí, es conveniente también recalcar la compatibilidad del método Tuning, con los marcos de cualificaciones europeos.

¿En qué consisten estos marcos? La Conferencia de Ministros europeos de Educación Superior celebrada en Bergen el 19 y 20 de mayo de 2005, tomó la decisión de adoptar un marco comprensivo de cualificaciones para el espacio europeo de educación superior (MC-EEES), construido sobre los denominados «Descriptores de Dublín». Este marco contempla la existencia de tres ciclos, permitiendo, en cada contexto nacional, la posibilidad de ciclos intermedios, cada uno de ellos caracterizado mediante descriptores genéricos basados en resultados de aprendizaje e incluyendo una cuantificación orientativa de los créditos que se deben asignar por ciclos. Pero, ¿de dónde proceden estos descriptores?

Desde el inicio del proceso de Bolonia, una asociación de expertos reunidos en un grupo denominado, Iniciativa Conjunta de Calidad (JQI), elaboró una serie de definidores generales que expresaban las metas de aprendizaje a lograr por los alumnos para el final de cada uno de los ciclos educativos que contenía el plan, y que se han conocido comúnmente como los «Descriptores de Dublín». ${ }^{518}$ Se

${ }^{518}$ JoInT Quality InITIATIVE: Shared 'Dublin' descriptors for Short Cycle, First Cycle, Second Cycle and Third Cycle Awards, 2004, [documento en línea] $<$ http://www.jointquality.nl/content/ierland/Complete_set_Dublin_Descriptors_2004_1.31.doc> [consultado el 24-8-2014]. 
realizó una primera propuesta de los descriptores en Marzo de 2002 para las Licenciaturas y postgraduados, pero posteriormente se efectuó una segunda versión en Marzo de 2004, basándose en las directrices de la reunión ministerial de Berlín de 2003. Sobre esos descriptores se siguió trabajando hasta llegar a la Conferencia Ministerial de 2005 en Bergen, en la que se adoptó la medida de crear, inspirándose en los Descriptores de Dublín, el Marco de Cualificaciones para el EEES, MC-EEES, ${ }^{19}$ que a su vez entra en sintonía con el Marco Europeo de Cualificaciones para el Aprendizaje a lo Largo de la Vida (EQF son sus siglas en inglés), lanzado por la Comisión Europea en 2006. El EQF y el MC-EEES son compatibles, pero diferentes en la presentación de sus descriptores, ya que el segundo tiene por objeto ordenar los sistemas de educación superior europeos utilizando para ellos titulaciones comunes, mientras que el EQF lo que persigue es compatibilizar los diferentes sistemas.

La razón por la que la Comisión Europea emprendió la creación del Marco Europeo de Cualificaciones, fue en respuesta al requerimiento tanto por parte de los Estados miembros como por diversas partes involucradas en el proceso, de encontrar un sistema más transparente de cualifaciones entre los países, que permitiera su comparación y así favorecer la movilidad y el aprendizaje permanente.

Muy resumidamente, el EQF ${ }^{520}$ es un sistema estructurado en 8 niveles cuyos descriptores de nivel son expresados en términos de Contenidos, Destrezas y Competencias. Los niveles 6, 7 y 8 equi-

${ }^{519}$ El Marco general de cualificaciones del Espacio Europeo de Educación Superior, aprobado en 2005, con los créditos correspondientes a los ciclos de licenciatura, maestría y doctorado, puede consultarse en: $<$ http://www.mecd.gob.es/dctm/mecu/marco-europeoes.pdf?documentId=0901e72b8090922b > [consultado el 22-7-2014].

${ }^{520}$ Para una mayor información sobre el EQF véase el siguiente documento descargable: DiRECCIÓN GENERAL DE EDUCACIÓN Y CULTURA DE LA COMISIÓN EUROPEA.: El Marco Europeo de Cualificaciones para el aprendizaje permanente, [documento en línea] $<$ http://www.mecd.gob.es/dctm/mecu/files/eqfniveleses.pdf?documentId $=0901 \mathrm{e} 72 \mathrm{~b} 80 \mathrm{~d} 5 \mathrm{c} 46 \mathrm{e}>$ [consultado el 22-7-2014]. 
valen al primero, segundo y tercer ciclo, conducentes a las titulaciones de Grado, Máster y Doctorado, del MC-EEES.

Tanto el EQF como el MC-EEES son metamarcos que buscan la transparencia y compatibilización de los sistemas utilizados, pero ambos tienen objetivos y descriptores diferentes. El EQF está orientado al ámbito laboral y profesional, mientras que el MCEEES es el encargado de la formación del Espacio Europeo de Educación Superior según el contexto de Bolonia. A raíz del MCEEES y el EQF evolucionan en España el MECES ${ }^{521}$ y el MECU. ${ }^{522}$

A pesar de la posible fragosidad de todo lo expuesto, es importante abordar momentáneamente estas cuestiones, para comprobar el modo y manera en el que las enseñanzas superiores de Música se encuentran por completo inmersas en todo este proceso.

\subsection{Los Descriptores de Dublín y la metodología Tuning en el Espacio de Educación Superior de Música}

La AEC recalca que el Espacio de Educación Superior de Música puede mantener sus características distintivas a la vez que se ajusta al MC-EEES, y concordar sus enseñanzas con los tres niveles propuestos en dicho marco. Una prueba bien patente de ello es la amplia definición que los Descriptores de Dublín realizan sobre la investigación, incluyendo a las disciplinas artísticas:

"The word 'research' is used to cover a wide variety of activities, with the context often related to a field of study; the term is used here to represent a careful study or investigation based on a systematic understanding and critical awareness of knowledge. The word is used in an inclusive way to accom-

${ }^{521}$ El MECES se desarrolla a través del Real Decreto 1027/2011, de 15 de julio,...(B.O.E. de 3 de agosto).

${ }^{522}$ Para más información sobre el Marco Europeo de Cualificaciones para el Aprendizaje a lo largo de la vida (MECU), consúltese el siguiente enlace del MECD: <http://www.mecd.gob.es/mecu.html> [consultado el 22-7-2014]. 
modate the range of activities that support original and innovative work in the whole range of academic, professional and technological fields, including the humanities, and traditional, performing, and other creative arts. It is not used in any limited or restricted sense, or relating solely to a traditional 'scientific method'.,"523

A esto hay que añadir que los Descriptores de Dublín son enunciados generales sobre los logros y pericias asociados a los finales de cada ciclo según Bolonia. Puesto que no son descripciones exactas y rigurosas de ninguna materia concreta, necesitan ser adaptados a cada disciplina mediante referencias cruzadas entre ambos, de ahí la reformulación de los Descriptores al área musical realizado por la $\mathrm{AEC}^{524}$

Pues bien, el proyecto Tuning consciente de la necesidad de transparencia en la correspondencia de las titulaciones, se desarrolló paralelo a estos marcos de cualificaciones, pero con la diferencia respecto a los descriptores de Dublín, que mientras éstos eran definidores de final de ciclo, Tuning desarrolló las competencias y resultados de aprendizaje de niveles intermedios así como por áreas disciplinares, entre ellas la educación musical.

523 “La palabra 'investigación' se utiliza para cubrir una amplia variedad de actividades, cuyo contexto suele relacionarse con un campo de estudio; el término se utiliza aquí para representar un estudio o investigación meticuloso basado en una comprensión sistemática y la conciencia crítica del conocimiento. La palabra se utiliza en un sentido inclusivo que integra la gama de actividades que fomentan el trabajo original e innovador en todo el espectro de campos académicos, profesionales y tecnológicos, incluyendo las Humanidades y las tradicionales Artes Escénicas y otras de índole creativa. No se utiliza en ningún sentido limitado o restringido, o referido sólo a un 'método científico’ tradicional." (JOINT QUALITY INITIATIVE, op. cit.)

${ }^{524}$ Sobre la aplicación de los Descriptores de Dublín al espacio de educación superior de música y la compatibilidad con los diferentes marcos, consúltense los apéndices A, B y C de: AeC-POLIFOniA, Tuning Project: Reference Points for the Design and Delivery of Degree Programmes in Music, Bilbao, Publicaciones de la Universidad de Deusto, 2009, [documento en línea]<http://www.unideusto.org/tuningeu/images/stories/Publications/tuningMusic2011.pdf $>$ [consultado el 22-7-2014]. 
El proyecto Innovación en la Educación Superior Artística incluido en la red temática Sócrates de la Comisión Europea, fue el responsable de respaldar y desarrollar en 2001 un programa de tres años, para investigar y difundir el proceso de Bolonia, mediante el uso de buenas prácticas en colaboración internacional entre las instituciones de los países asociados.

En la disciplina de Música, la Hogeschool Gent de Bélgica alojó este proyecto desarrollado conjuntamente por la ELIA y la AEC, en el que colaboraron un gran número de institutos de todas las disciplinas artísticas de la EU y países asociados. Una vez constituido el Grupo de Trabajo Bolonia de la AEC, se procedió a estudiar las implicaciones de la Declaración de 1999, en los conservatorios de música.

Entre los objetivos alcanzados, el Grupo de Trabajo de la AEC, consiguió redactar un conjunto de «Resultados de Aprendizaje» para el primer nivel (nuestra antigua licenciatura, y actual Grado y Título Superior de conservatorios) y el segundo nivel (postgraduado que conduce a la titulación de Máster y Máster artístico), de las enseñanzas de música.

Posteriormente un segundo Grupo de Trabajo fue constituido para el trienio 2004-2007, esta vez en el marco de la red temática Erasmus para la Música, denominado Grupo Tuning de Polifonía, cuyo objetivo principal era seguir con el trabajo desarrollado por el grupo anterior de la AEC, y conducir hacia un nuevo nivel de perfeccionamiento los puntos de referencia de cada nivel de las enseñanzas artísticas superiores de música. A los resultados de aprendizaje elaborados para el primer y segundo ciclo, se le añadieron los correspondientes al tercer ciclo de estudios, conducentes al doctorado. Hay que mencionar además, que esta optimización se basó en la relación que se estableció entre los resultados de aprendizaje que existían hasta entonces, con otros aspectos como el proceso de enseñanza-aprendizaje basado en competencias, el ECTS, la metodología Tuning, o el MC-EEES o el marco EQF. ${ }^{525}$

${ }^{525}$ Los resultados de aprendizaje de la AEC para el Primer, Segundo y Tercer ciclo se pueden descargar del siguiente enlace: 
Por otro lado, la adaptación que se hicieron de los Descriptores de Dublín para los tres ciclos, fueron bautizados con el nombre de «Descriptores de Dublín/Polifonía». ${ }^{526}$

Con todas estas contribuciones se intentaba facilitar a las instituciones su inserción en la perspectiva de Bolonia, estableciendo la base estructural necesaria para ir transformando por ejemplo, el diseño de sus currículos, basados a partir de entonces en el aprendizaje de los alumnos por competencias o el sistema ECTS, entre otras novedades.

El Grupo Tuning de Polifonía, definió la Educación Musical Superior como:

"estudios musicales realizados en el contexto de la educación superior que cuentan con un enfoque principal centrado en el desarrollo práctico y creativo del estudiante."527

Esta definición confirma lo unido que está el arte musical y su educación a la enseñanza por competencias. La AEC entiende que este tipo de enseñanzas se imparten en los conservatorios, aunque asume este término de forma muy amplia ya que su definición abarca cualquier institución superior ya sean conservatorios, academias, escuelas o facultades universitarias.

La metodología Tuning actúa como base sobre la que se desarrollan los puntos de referencia de cada disciplina y sirve para elaborar programas de estudio transparentes y comparables. Esos puntos de referencia son expresados a través de los resultados de aprendizaje, que en el caso de las enseñanzas de música vendrían formulados

$<$ http://www.aec-music.eu/userfiles/File/aec-polifonia-learning-outcomesen.pdf $>$ _ [consultado el 22-7-2014].

${ }^{526}$ Se puede descargar el archivo en el siguiente enlace de la AEC: $<$ http://www.aec-music.eu/userfiles/File/polifonia-dublindescriptors150107external.pdf > [consultado el 17-1-2014].

${ }^{527} \mathrm{El}$ texto en inglés es el siguiente: "musical studies undertaken in the context of Higher Education that have a primary focus upon the practical and creative development of the student." (AEc-Polifonia, Tuning Project, op. cit., p. 15). 
por los Descriptores de Dublín/Polifonía y los Descriptores de ciclo de la AEC, que son a su vez una adaptación de los utilizados para el resto de las enseñanzas superiores.

Las competencias encarnan una compleja combinación de capacidades cognitivas, prácticas y valores que se funden en el individuo y que detallan el grado de habilidad con que son puestas en práctica.

Los resultados de aprendizaje son la forma de expresar una competencia como meta de aprendizaje por parte de los estudiantes, a la finalización de un proceso corto o largo de enseñanza-aprendizaje. Según la metodología Tuning:

"Los resultados del aprendizaje son manifestaciones de lo que se espera que un estudiante sepa, entienda y sea capaz de demostrar una vez concluido el aprendizaje." 528

En cierto modo, podríamos decir que Resultado de Aprendizaje y Competencias son los puntos de vista de un mismo objeto desde ángulos opuestos. Los resultados de aprendizaje propios de un proceso de enseñanza-aprendizaje son expresados por el profesor como meta de ese proceso, mientras que las competencias son las capacidades que el alumno adquiere o desarrolla en el mismo proceso:

“- Los resultados del aprendizaje son formulaciones de lo que el estudiante debe conocer, comprender o ser capaz de demostrar tras la finalización del proceso de aprendizaje. Pueden estar referidos a una sola unidad o módulo del curso o a un período de estudios, por ejemplo un programa de primer, segundo o tercer ciclo. Los resultados del aprendizaje especifican los requisitos mínimos para la concesión de un crédito.

- Las competencias representan una combinación dinámica de conocimientos, comprensión, habilidades y capacidades. La promoción de estas competencias es el objeto de los pro-

${ }^{528}$ GONZÁLEZ, Julia, WAGENAAR, Robert (coords.), op. cit., p. 9. 
gramas educativos. Las competencias cobran forma en varias unidades de curso y son evaluadas en diferentes etapas., ${ }^{, 529}$

Según Tuning, las competencias se clasifican en genéricas, comunes a todas las áreas de conocimiento, y específicas, las afines a cada disciplina. Esta tipificación responde a la proposición que preparar a los estudiantes para su futuro, implica tanto la formación en los contenidos específicos de la materia que se cursa, como en aquellas otras competencias más globales y transferibles que el alumno podrá aplicar a lo largo de su vida en el ámbito social y profesional.

A su vez las competencias genéricas se dividen en tres categorías:

“- Competencias instrumentales: capacidades cognitivas, metodológicas, tecnológicas y lingüísticas;

- Competencias interpersonales: capacidades individuales tales como habilidades sociales (interacción y cooperación sociales);

- Competencias sistémicas: capacidades y habilidades relacionadas con sistemas globales (combinación de comprensión, sensibilidad y conocimientos; para ello es preciso adquirir previamente competencias instrumentales e interpersonales). ${ }^{.530}$

Otro aspecto importante a recalcar de las competencias es que son evaluables y cuantificables:

"En este contexto, una competencia o un conjunto de competencias significa que una persona pone en práctica determinada capacidad o habilidad para desempeñar una labor y que puede hacerlo de un modo que permita evaluar el nivel de consecución. Las competencias se pueden valorar y desarrollar. Significa que, normalmente, las personas no poseen o carecen de una competencia en términos absolutos, sino que la dominan en diferentes grados, de ahí que se puedan colo-

\footnotetext{
${ }^{529}$ Ídem, pp. 16-17.

${ }^{530}$ Ídem, p. 17.
} 
car las competencias en un continuo y desarrollar mediante el ejercicio y la educación." 531

De manera que gracias a sus propiedades intrínsecas, las competencias sirven de puntos de referencia flexibles - no pretenden convertirse en rígidos códigos normativos - que permiten la intervención de múltiples agentes a través de un lenguaje común, al tiempo que otorgan autonomía en la confección de los currículos de las instituciones educativas.

Tuning trabajó en principio sobre las competencias específicas de nueve disciplinas como Administración de Empresas, Química, Ciencias de la Educación, Estudios Europeos, Historia, Geología, Matemáticas, Enfermería y Física. Pero posteriormente, como ya hemos visto, aprovechando el soporte de las redes temáticas, se crearon los resultados de aprendizaje/competencias de diversas áreas concretas como el de la Música. El trabajo elaborado quedó reflejado en la publicación de la AEC Reference Points for the Design and Delivery of Degree Programmes in Music, que se puede descargar la página oficial de Tuning, http://www.unideusto.org/tuning/.

En el capítulo 4 del documento, se tratan los aspectos relacionados con los Resultados de Aprendizaje y Competencias en los descriptores de nivel. Allí podemos comprobar como la AEC, realiza una división de los Resultados de Aprendizaje en tres tipos: 1. Resultados prácticos (basados en habilidades); 2. Resultados teóricos (basados en el conocimiento) y 3 . Resultados genéricos.

Los descriptores de ciclo sirven para todo tipo de estudios de interpretación, composición, dirección y pedagogía, y son plenamente compatibles con los marcos de cualificaciones del Marco Europeo de Cualificaciones para el aprendizaje a lo largo de la vida, y el Marco de Cualificaciones del Espacio Europeo de Educación Superior, basado en los Descriptores de Dublín. Para ayudar a los centros educativos a realizar su currículo, la AEC publicó el documento Curriculum Design and Development in Higher Music Education, ${ }^{532}$

${ }^{531}$ Ídem, p. 28.
${ }^{532}$ Cox, Jeremy, op. cit. 
y la Guide for Third Cycles Studies in Music ${ }^{533}$ que persigue el mismo objetivo pero centrado en los estudios de tercer ciclo conducentes al Doctorado.

La utilización de los resultados de aprendizaje en los planes de estudio y currículos de las enseñanzas de música superiores, es uno de los nuevos fenómenos que trajo consigo Bolonia, al igual que el empleo del sistema de transferencia de créditos europeo.

Por lo que respecta al ECTS, Tuning destaca que junto a la utilidad de este sistema para la mejora de la movilidad del alumnado, el crédito europeo mejora también el avance en el diseño de los programas de estudio definidos por niveles a través de los resultados de aprendizaje, ya que se tratan de conceptos complementarios:

"Se trata de dos caras de una misma moneda. Mientras que los créditos expresan el volumen de aprendizaje, los resultados del aprendizaje expresan su contenido." 534

Los créditos se obtienen con la consecución de los resultados de aprendizaje, aunque la correspondencia no es matemática, sino que se trata de promedios e índices que reflejan el tiempo que empleará un estudiante medio para alcanzar los resultados de aprendizaje. Esto puede depender de los conocimientos y habilidades que tengan que ser aprendidos, así como del contexto.

Otro rasgo del ECTS es que mide el volumen de trabajo pero no la calidad, es decir, el grado o nivel de excelencia que se ha demostrado en la adquisición del aprendizaje.

Así, según la descripción que realiza Tuning del ECTS, éste consiste en una medida de haber académico que calcula el trabajo de un estudiante medio, valorando el tiempo que utilizará para llevar a cabo su tarea. Según esta definición que parte del tiempo que emplea el estudiante, se barajan los siguientes parámetros para calcular el trabajo medio del estudiante; casi todos los países están de acuerdo en reconocer que un curso escolar de entre 34 y 40 sema-

\footnotetext{
${ }^{533}$ POLIFONIA THIRD CYCLE WORKING GROUP, op. cit.

${ }^{534}$ GONZÁleZ, Julia, WAGENAAR, Robert (coords.), op. cit., p. 59.
} 
nas que contiene a su vez de 40 a 42 horas de trabajo por semana, computan un total de 1360 a 1680 horas anuales. Como cada curso de ciclo superior tiene asignados 60 créditos, significa que un crédito comprenderá entre 22 y 28 horas de trabajo. Partiendo de acuerdos sobre cifras medias ponderadas, se establece un total anual de 1520 horas que dan como resultado 25 horas por ECTS.

Pero no sólo es importante este cómputo medio de estimación de trabajo del alumno, sino que hay que tener en cuenta otro importantes aspecto, y es que esa unidad de crédito equivalente a 25 horas de trabajo, contiene además de las clases presenciales, la preparación previa de las mismas o el trabajo independiente que hace el alumno para llevar a cabo su tarea, lo que nos lleva irremediablemente a un nuevo enfoque en la planificación de la asignatura por parte del profesor, que ha de tener muy en cuenta estos parámetros en la programación de su asignatura:

"Una de las principales aportaciones del proceso de asignación de créditos es que obliga a los profesores a reflexionar sobre el diseño del programa de estudios y los métodos de enseñanza." 535

Como hemos de tener en consideración tanto la asistencia a clase, como la relación de otras actividades necesarias, hemos de intentar no pasarnos de los créditos asignados a nuestra asignatura para no invadir los tiempos de otros profesores.

Se debe agregar que este aspecto del sistema de créditos y su problemática sobre la distribución de la unidad de crédito en tiempo presencial y digámosle, tiempo de trabajo autónomo del estudiante, se recrudece en el caso de la música, que ya sufrió con la LOGSE la falta de coherencia y aplicabilidad del sistema de créditos anterior al ECTS. Como muy bien indica la AEC:

"At its greatest, the amount of time spent in daily practice by Higher Music Education students can reach 7 or 8 hours. Especially when sustained over weekends and vacation periods, this represents a contribution to overall workload larger

${ }^{535}$ Ídem, p. 80. 
than the total workload across all elements of the curriculum of typical students in many other disciplines. As a result of this, the calculation of student workload in relation to credit values necessarily adopts a nominal, rather than literal, view of student practice time. Student overload is a constant danger in Higher Music Education programmes and needs to be monitored carefully. In practice, it is generally balanced by the fact that students in this discipline have exceptionally high levels of commitment and identify themselves with their subject of study in ways that dissolve the usual boundaries between study time and personal time."

Hemos reproducido textualmente el mensaje de la AEC, puesto que a pesar de su longitud consideramos que no se puede expresar con más elocuencia una de las principales características de las enseñanzas artísticas; el ECTS no es más que un sistema referencial para dejar explícitamente la medida de trabajo del estudiante, que en el caso de los itinerarios de interpretación son nominales, y se aproximan tan poco a la realidad que casi rozan lo anecdótico. ${ }^{537}$

536 "La cantidad de tiempo empleado en la práctica diaria por los estudiantes de Educación Superior de Música puede alcanzar en su mayor grado, las $7 \mathrm{u}$ 8 horas de dedicación. Especialmente cuando se mantiene este ritmo, durante los fines de semana y períodos vacacionales, representa una contribución a la carga de trabajo global más grande que el volumen de trabajo total entre todos los elementos del plan de estudios o estudiantes típicos en muchas otras disciplinas. Como resultado de esto, el cálculo de la carga de trabajo de los estudiantes en relación con los valores de crédito adopta necesariamente un valor nominal, más que literal, desde el punto de vista de la práctica del estudiante. La sobrecarga del estudiante es un peligro constante en los programas de educación musical superior y debe ser monitorizado cuidadosamente. En la práctica, se equilibra generalmente con el hecho que los estudiantes en esta disciplina tienen niveles excepcionalmente altos de compromiso y autoidentificación con su objeto de estudio, de manera que se disuelven las fronteras habituales entre el tiempo de estudio y el tiempo personal." (AEC-POLIFOniA, Tuning ProjeCt, op. cit., p. 37).

${ }^{537}$ Para ahondar en la relación del ECTS con la Educación Superior Musical existe la siguiente guía: BOELE, Evert B.: Implementation and Use of Credit Points in Higher Music Education, Utrech, AEC, 2007. Disponible en el URL: <http://www.aec-music.eu/userfiles/File/aec-handbook-implementation- 
and-use-of-credit-points-in-higher-music-education-enrev-2009.pdf> [consultado el 23-7-2014]. 



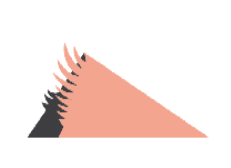

\section{Conclusiones}

L INICIO DE ESTA OBRA argumentábamos los motivos que
nos habían alentado a tomar la determinación de empren-
der nuestra labor. En síntesis, el objetivo que nos planteábamos consistía en mostrar una visión panorámica de la acción programadora de la especialidad de Piano, estableciendo cabalmente las líneas maestras de su trayectoria mediante el análisis y examen crítico de su evolución histórica dentro de la práctica educativa. Una vez analizados y examinados los hechos presentados y gracias a la perspectiva alcanzada sobre la programación de Piano y su evolución histórica desde la Constitución española de 1812 hasta la actualidad, podemos distinguir ocho momentos principales a través de los cuales se produjeron algunas de las transformaciones más substanciales sobre la acción programadora de la especialidad. Éstos son:

1. 1812-1857: Período inaugural que abarca desde el nacimiento de la primera organización administrativa de la Instrucción Pública en España en 1812, hasta la Ley Moyano. 
2. 1857-1865: Floreciente etapa que discurre durante la vigencia de la Ley de Instrucción pública de 1857, hasta la crisis de 1865.

3. 1865-1868: Este breve lapso de tiempo, concuerda con la crisis sociopolítica vivida en España durante los años anteriores a la Revolución de 1868.

4. 1868-1874: Coincidiendo con el sexenio democrático, comienza este cuarto momento de lenta recuperación para las enseñanzas artísticas.

5. 1875-1936: El inicio del siglo XX, cierra un ciclo en la educación musical e inaugura una nueva época.

6. 1939-1975: Transcurso que abarca las reglamentaciones de los conservatorios durante el régimen franquista.

7. 1976- 2006: La penúltima etapa comprende los progresos efectuados desde la constitución de España como estado democrático hasta la LOGSE y su período de vigencia.

8. 2006-2013: El último período se desarrolla desde la implantación de la LOE hasta la última Ley orgánica que regula el sistema educativo español en la actualidad, la LOMCE.

Ocho etapas en la reglamentación musical

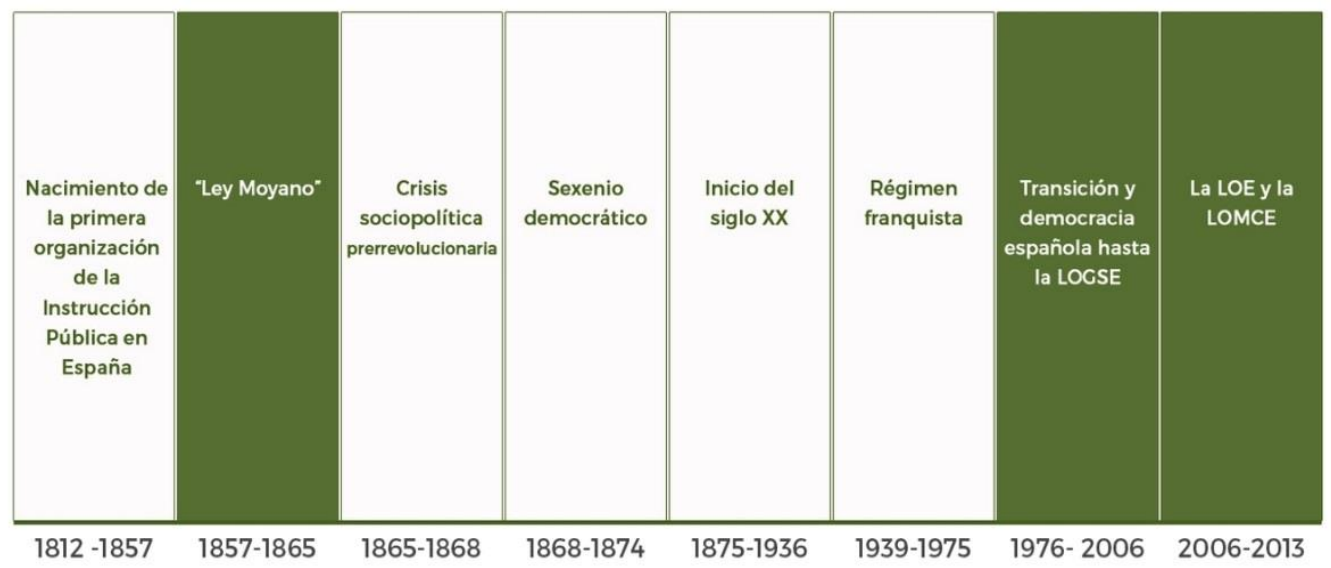

Fig. 1 
Asimismo cabe señalar que, de acuerdo con nuestro análisis, evidenciamos cinco modelos programáticos en la asignatura, que han evolucionado a lo largo de dos grandes ciclos.

Establecemos un primer ciclo que se prolonga desde la constitución del primer conservatorio de música en 1830 hasta la LOGSE de 1990. En este período, descubrimos que los estudios técnicos y ejercicios de mecanismo han sido los fieles representantes de los fundamentos de la técnica pianística en la organización de la asignatura, y que junto a ellos encontramos el repertorio de obras representativas de la especialidad instrumental, como el otro polo de atracción de la materia durante este tiempo.

En esta primera época, podemos establecer la presencia de tres tendencias metodológicas claramente diferenciadas, tomando como factor discriminatorio el predominio de uno de estos dos polos de atracción. En un primer período, los ejercicios técnicos inundaban las páginas de los Métodos decimonónicos. Más tarde, a mitad de la primera década del siglo XX aproximadamente, los estudios de piano se centraron en los "estudios" para piano, dedicando así especial atención a la técnica instrumental, mientras que el juego pianístico se completaba con la ejecución de algunas obras en los cursos finales. Ulteriormente, en una tercera etapa, la programación de la asignatura evolucionó hacia el "programa" de piano, basado en un número concreto de piezas representativas del repertorio pianístico ajustadas al nivel y dificultad de cada curso. A partir de la década de los 70, las obras monopolizaron la práctica totalidad de la programación de Piano, desbancando por completo a los ejercicios técnicos, del mismo modo que éstos lo habían hecho hasta entonces con las piezas del repertorio.

La consigna de esta última tendencia es clara, aprehender y desarrollar la técnica pianística a través de las obras seleccionadas para el curso. La metodología adoptada en la práctica pianística gravita consiguientemente alrededor del repertorio constituido por un número determinado de obras, clasificadas en apartados, de modo que al final del curso académico se han de interpretar una selección de obras de la lista presentada por el aspirante, para lograr el correspondiente certificado académico. Este suceso resulta especial- 
mente significativo puesto que, considerando el nivel de progreso alcanzado por las diferentes teorías sobre la técnica pianística en ese mismo tiempo, resulta desproporcionado el asentimiento de una metodología focalizada en un único aspecto concreto de la práctica instrumental, aunque sea un elemento tan valioso como de hecho lo constituye, el repertorio.

En un segundo ciclo, que refleja las contribuciones desde la década de los 90 hasta 2013 final de nuestra observación, también advertimos dos elementos importantes. El primero de ellos consiste en el modelo curricular presentado por la LOGSE, que junto a los fundamentos de la técnica pianística y el repertorio, plantearía la especialidad de Piano como una materia abierta que ha de contar con el subsidio y la complementación de otras disciplinas, entre las que destacaríamos el conjunto de contenidos históricos, estéticos y psicológicos del hecho musical.

El segundo componente de este período viene de mano de la LOE y la adscripción de España al proceso de convergencia de educación superior. Estos sucesos van a comportar una importante reforma de las enseñanzas artísticas superiores de música. La principal aportación al diseño de la regulación de la asignatura ha consistido desde nuestro punto de vista, en agregar la investigación artística al ámbito de las especialidades instrumentales, concentrándose así esta nueva actividad de los conservatorios superiores, en la práctica musical.

En consecuencia, los cinco modelos de la acción programadora de la enseñanza de la especialidad de piano que proponemos, se han distinguido por su identificación con los siguientes tres lineamientos: los ejercicios técnicos y el repertorio; el currículo abierto que conlleva una mayor participación de otras disciplinas en la especialidad; y finalmente la investigación artística como última aportación al diseño de la asignatura en los conservatorios superiores. 
Cinco Modelos de acción programadora

\begin{tabular}{|l|ll|}
\hline 2006 & Investigación artística & La LOE y el EEES \\
\hline 1990 & El modelo curricular & $\begin{array}{l}\text { Con la LOCSE se complementa la } \\
\text { especialidad de Piano con otros } \\
\text { contenidos }\end{array}$ \\
\hline 1970 & “Programa de Piano" & $\begin{array}{l}\text { Las obras monopolizan la } \\
\text { práctica totalidad de la } \\
\text { programación de Piano }\end{array}$ \\
\hline 1915 & Estudios para piano & $\begin{array}{l}\text { Solamente algunas obras en los } \\
\text { últimos cursos }\end{array}$ \\
\hline 1830 & Ejercicios técnicos & Métodos decimonónicos \\
\hline
\end{tabular}

Fig. 2

Respecto a las conclusiones extraídas tocante a la evolución de las enseñanzas de Piano, señalaríamos principalmente el interesante desarrollo que ha conducido a estas enseñanzas al pasar, de una instrucción en la que no existía ningún tipo de distribución definida y cuya duración exacta se basaba en el compromiso de responsabilidad adquirido por el Maestro ante el Rey y ante el público para conducir al alumno por el camino "más llano, corto y seguro desde el primero hasta el último paso de la carrera", a alcanzar el diseño contemporáneo.

Desde este principio en la década de los 30 del siglo XIX, el vertiginoso repaso a más de dos siglos de reglamentación nos ha permitido ver la evolución desde entonces hasta llegar a la actual trayectoria formativa de un estudiante de Piano, que decide emprender sus estudios elementales (4 años de duración), que proseguirá en los conservatorios profesionales ( 6 años), que continuará sus estudios interpretativos en el itinerario de Interpretación de Piano para obtener su Título Superior (4 años), y que podrá perfeccionar, prolongando su formación en diversos itinerarios con un Máster Artístico (2 años) y un Doctorado (3-4 años), si así lo decide. 
Al conocer ahora con más detalle, el progreso que nos ha conducido de un extremo a otro de estas planificaciones, y situarnos cada cual en el lugar que tenemos asignado como docentes dentro de ese proceso en la actualidad, somos conscientes que la planificación de nuestra asignatura en cualquiera de sus ciclos y cursos encarna la herencia de un compromiso de más de dos siglos de reglamentación musical que ha desembocado en un apasionante y magno proyecto (nada menos que 20 años de formación académica), como lo es en efecto la formación de un Intérprete de Piano.

Evolución del desarrollo de las enseñanzas de Piano

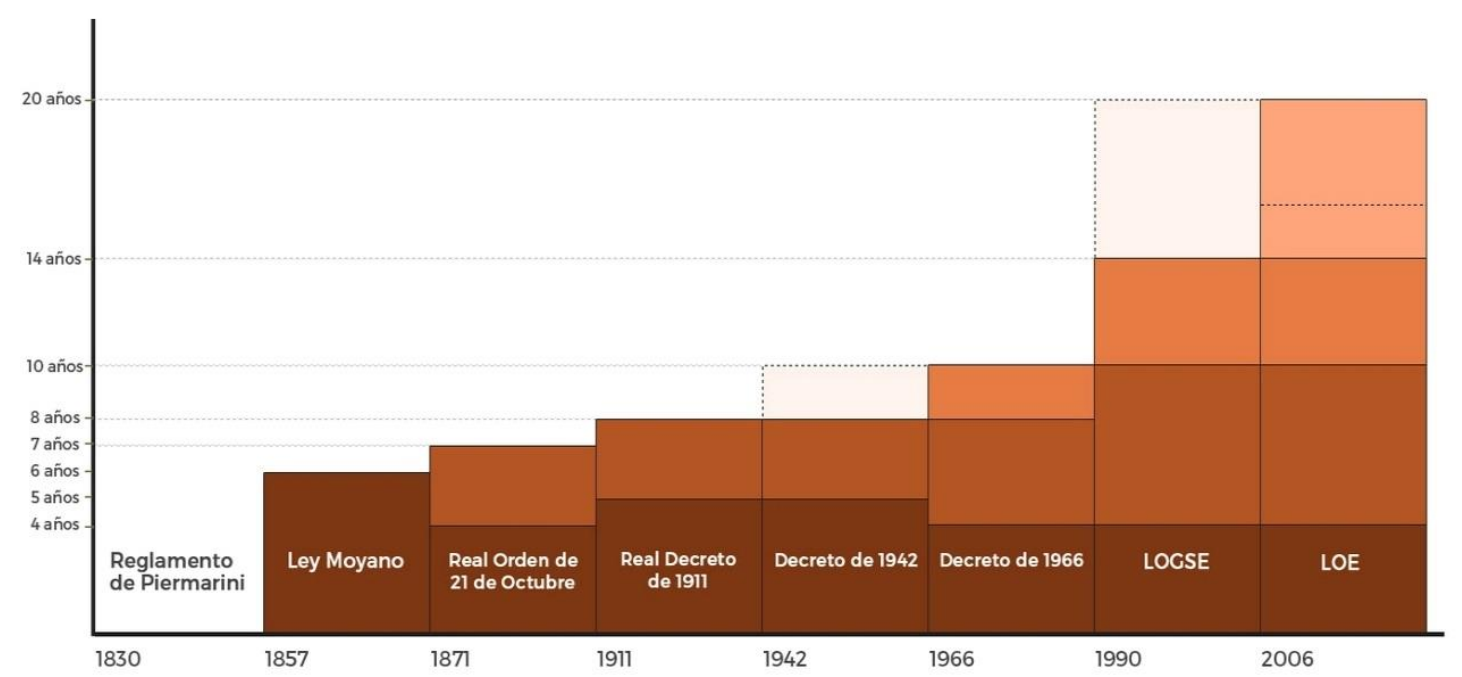

Fig. 3

También hemos descubierto entre las 8 etapas descritas y según los datos aportados sobre los modelos programáticos y la evolución de la asignatura de Piano, que parecen existir dos hitos de la reglamentación musical que destacan por la profundidad de su influencia en la regulación de las enseñanzas. Estos dos momentos son los correspondientes a la $2^{\text {a }}$ etapa, que se ocupa de la normativa durante la vigencia de la Ley Moyano, y a la $7^{\mathrm{a}}$ y $8^{\mathrm{a}}$ etapas correspondientes a nuestra época actual desde 1990 (Se pueden reconocer en las zonas sombreadas de verde oscuro de la Fig. 1).

Concluida la etapa fundacional del Conservatorio, comienza un próspero período para la reglamentación musical encuadrado en el 
marco legislativo de la Ley de Instrucción Pública de 9 de septiembre de 1857. La "Enseñanza de piano" propiamente dicha sorprende por la novedosa estructuración pedagógica que presenta, al mostrar una división en tres áreas, Mecanismo, Inteligencia y Expresión, acompañada de una descripción detallada de cada una de ellas. Se inaugura así la primera redacción en forma de estatuto reglamentario, de los elementos de la técnica pianística desde una perspectiva pedagógica, estableciéndose simultáneamente el principio generador de la programación didáctica de la asignatura. Una prueba irrefutable de la trascendencia de este planteamiento reside en que no volveremos a contemplar un desarrollo similar hasta la Ley de Ordenación General del Sistema Educativo de 1990, en el que la fórmula de currículo articulado en objetivos, contenidos y criterios de evaluación, resuena sutilmente con el diseño propuesto en estas instrucciones.

Estas evidencias demuestran las prerrogativas que ofrece un acertado reglamento de las enseñanzas cuando se encuentra secundado por el marco legislativo oportuno. La Ley de Instrucción Pública de 9 de septiembre, el Reglamento Orgánico Provisional de Pedro Salaverría y las Instrucciones de Ventura de la Vega, constituyen una combinación armonizada que irrumpiría con fuerza hasta el último nivel de la ordenación educativa, estimulando el manejo de un nuevo documento pedagógico: la programación en el aula. Estos hechos representan la primera tentativa de una acción programadora sistemática, aplicada a la asignatura de Piano.

El segundo hito corresponde a la reglamentación de las enseñanzas artísticas de música durante los prácticamente últimos 25 años. La influencia que han tenido en el desarrollo educativo de nuestra sociedad las legislaturas en el gobierno del partido socialista, aflora de manera evidente al comprobar que durante las dos rondas de su administración, se aprobaron dos de las leyes de educación, la LOGSE y la LOE, que han tenido mayor proyección en el sector educación durante el período democrático. Habrá que esperar cuál es el derrotero que seguirá la LOMCE actualmente vigente, propuesta por el gobierno popular. 
Dicho lo anterior, nos parece también oportuno subrayar que España ha protagonizado en las últimas cuatro décadas dos cambios sociopolíticos y económicos de evidente trascendencia, que parecen hallarse conectados entre sí. En primer lugar, nos topamos con el proceso que condujo a España de un régimen dictatorial a otro democrático, bautizado como La Transición. Consideramos que el segundo momento correspondiente a nuestro tiempo actual, parece indicar cierto tipo de conexión con su predecesor, al marcar el final de un ciclo que comenzó con la transición y mostrar en el tiempo presente signos de profunda remodelación estructural.

Enmarcados en este contexto, encontramos factores que dan signos de esta regeneración en la educación a diferentes niveles: internacional, nacional, regional e institucional. De un lado, Europa coincidiendo con el cambio de milenio expresó el valiente desafío de concebir no solamente una unión económica y monetaria internacional, sino que se propuso asimismo el reto de crear una comunidad europea del conocimiento y con esta inspiración nacería el Espacio Europeo de Educación Superior. Dieciséis años después, con la finalización del curso escolar 2013/2014, se expedían en España las primeras titulaciones superiores en los conservatorios a aquellos alumnos que se han formado en este nuevo marco educativo, singularizado por la internacionalización de su desarrollo. Además, la LOE fue la ley educativa responsable de dar viabilidad a la concreción del EEES en las Enseñanzas Artísticas Superiores. Para ello, las Comunidades Autónomas han creado los Institutos Superiores de Enseñanzas Artísticas para dar cabida al impulso de convergencia europeo, mientras que los conservatorios serían las estructuras educativas a nivel institucional, encargadas de articular el proceso de los estudios superiores de música, siempre con el EEES como telón de fondo.

El segundo hito, nos ha permitido igualmente apreciar cuatro evidencias de la reglamentación musical vinculadas a este tiempo correspondiente a los últimos años de regulación desde 1990, nos referimos a: la proliferación legislativa en la ordenación de los intereses educativos; la ordenación de las enseñanzas artísticas de música al margen de los sistemas educativos hasta este segundo hito; la positiva aportación europea a la última reforma del sistema educa- 
tivo; y la cada vez mayor presencia de la Investigación Artística en las enseñanzas de los Conservatorios Superiores de Música, un tema de vital importancia que por su trascendencia esperamos tratar detenidamente en futuras publicaciones.

¿Qué nos dicen estas cuatro evidencias? En primer lugar, desde la sanción de la Ley Orgánica 5/1980, hasta la última norma de educación, la Ley Orgánica 8/2013, han pasado 33 años, un período a lo largo del cual, se han aprobado 9 leyes orgánicas de educación (LOECE/1980, LRU/1983 LODE/1985, LOGSE/1990, LOPEG/1995, LOU/2001, LOCE/2002, LOE/2006 y LOMCE/2013) lo que significa un cómputo medio de una ley cada 3 años y medio, es decir, aparece una ley nueva antes de que se agote el período de una legislatura política ordinaria de cuatro años.

La LOGSE y la LOE, han demostrado ser más estables y fructíferas para las enseñanzas artísticas que la LOCE, y habrá que esperar para cotejarlas con la actual LOMCE. También es cierto que las normas socialistas han logrado un mayor consenso sociopolítico que las promulgadas por los populares; sin embargo desde nuestro punto de vista, ninguna de ellas ha logrado el deseado pacto escolar constituyente del artículo 27 de la Constitución y por consiguiente, no han obtenido el éxito esperado en su búsqueda de una solución más coherente y duradera a las necesidades del sector educativo español. La continua mudanza de posición ideológica sobre educación que ha implantado el partido de turno en el gobierno, ha conducido a una proliferación de normas y planes que se sumaban al agrandamiento administrativo que sufría España tanto a nivel internacional con su entrada a Europa, como a nivel regional por su organización territorial en autonomías. En resumidas cuentas, la abundancia de regulación normativa no parece haber cuajado en una correspondiente solución de la ordenación de los intereses educativos de nuestro país.

La segunda evidencia que podemos extraer de nuestro viaje a lo largo de la reglamentación musical, reside en el abandono político que han sufrido estas enseñanzas prácticamente desde su inicio. Con la institución del primer establecimiento de enseñanzas musicales, el Real Conservatorio de Madrid, al margen del plan general 
de educación, y tras un breve intermedio de reconocida estabilidad de 9 años desde la Ley Moyano de 1857 a los reales decretos de Manuel de Orovio en 1866, las enseñanzas de música han protagonizado un largo peregrinar fuera de los posteriores sistemas educativos, hasta su nueva inclusión en la LOGSE de 1990, en la que las enseñanzas de música volverían a reunirse junto al resto de las enseñanzas de régimen general, después de más de un siglo y dos décadas de exclusión.

Si el conjunto de las enseñanzas artísticas ha mostrado problemas para su inserción normalizada en el conjunto del sistema educativo, la equiparación del ciclo superior de estas enseñanzas ha seguido como es de esperar igual o peor suerte. Posiblemente el avance más significativo sea haber conseguido que el Título Superior de las EEAASS comparta junto al Título de Graduado expedido en las universidades, el mismo nivel 2 en el Marco Español de Cualificaciones para la Educación Superior, y que el Título de Máster en Enseñanzas Artísticas, comparta el mismo nivel 3 del citado MECES, junto a los Títulos de Másteres universitarios.

La historia de la organización de las Enseñanzas de Música sólo ha empezado a despegar en las últimas décadas, buscando un desarrollo normalizado y estructurado que proporcione solidez al sistema educativo en el ámbito musical. Es lógico, por tanto, que la sociedad actual se resienta de una educación musical menguada, retroalimentando un círculo vicioso en el que junto a la regulación de las enseñanzas artísticas aparece asociado el estigma de una baja consideración económico-social.

En tercer lugar, embarcados en un proyecto común desde 1999 como es el de la convergencia del Espacio Europeo de Educación Superior, el menoscabo general por omisión del estado español hacia las enseñanzas musicales, se hace todavía más evidente cuando se contrasta con el desarrollo alcanzado en los países vecinos europeos. 


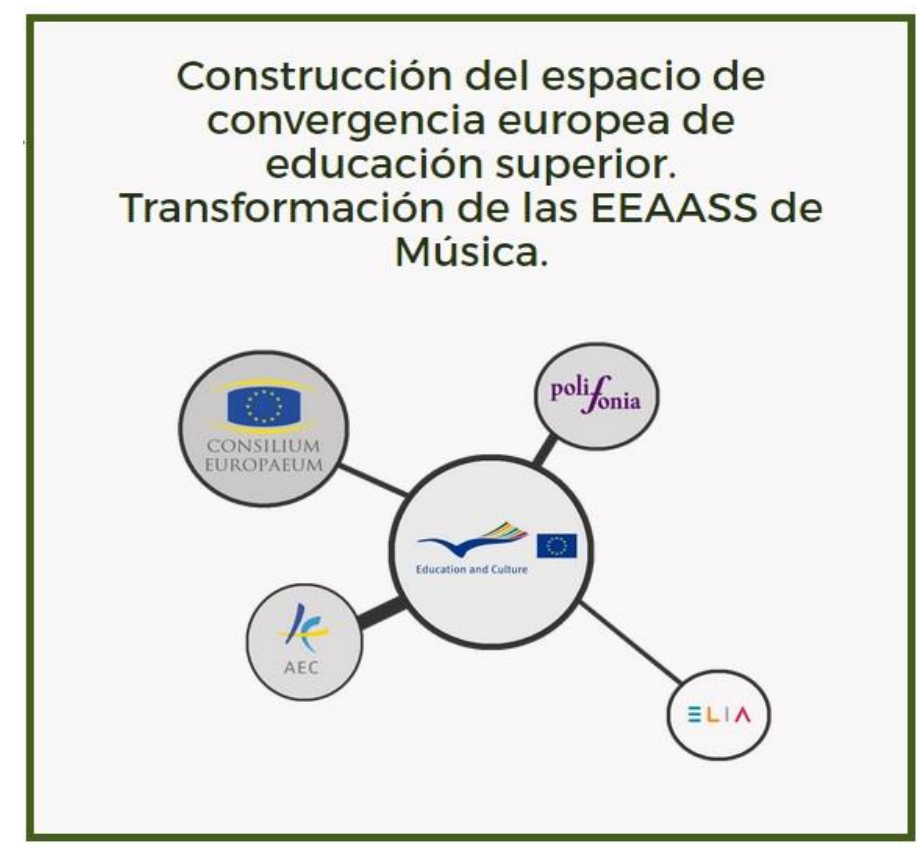

Fig. 4

Por otra parte, es cierto que las múltiples estructuras involucradas para la construcción del espacio de convergencia europea de educación superior, desarrolladas en España durante la vigencia de la LOE (véase la fig. 4), confirman una transformación de un alcance sin precedentes en la historia educativa española en general, y de las enseñanzas superiores de música en concreto. En efecto, de entre los cinco ciclos formativos existentes en música actualmente en España, elemental, profesional, y superior dividido en tres ciclos, Título Superior, Máster y Doctorado, probablemente sean las enseñanzas superiores las que más innovaciones hayan sufrido en las últimas dos décadas, debido principalmente al proceso de convergencia europea de educación superior.

Entre los principales factores implicados en esta última reforma de las Enseñanzas Superiores de Música hallamos los siguientes:

1. La aparición de programas como el Aprendizaje a lo largo de la vida.

2. Una renovación de los roles del profesor y el alumno en el proceso de enseñanza-aprendizaje.

3. La aplicación del sistema de aprendizaje basado en competencias. 
4. La estructuración de las enseñanzas en tres ciclos, Grado, Máster y Doctorado.

5. La incorporación de los créditos ECTS.

6. Desarrollo de la Investigación, en el ámbito propio de las disciplinas impartidas en estas enseñanzas.

7. La mayor relevancia de los procedimientos metodológicos en el proceso de enseñanza-aprendizaje.

Como resultado, toda esta panorámica nos sitúa frente a una perspectiva que enlaza con la cuarta y última de las evidencias que habíamos presentado. Las 8 etapas descritas nos han hecho conscientes que en la actualidad estamos viviendo un momento estelar de las enseñanzas artísticas. Si bien es cierto que la organización académica de la educación musical, ha sufrido una importante marginación durante más de un siglo al regular sus enseñanzas al margen de los sistemas educativos, la última reforma impulsada desde Europa nos demuestra que las enseñanzas superiores de música que se imparten en los conservatorios han sufrido en las últimas décadas cambios sin precedentes al organizar sus enseñanzas en tres ciclos, lo que implica entre otros aspectos la incorporación en el currículo formativo de estos centros educativos, los Másteres Artísticos y la capacidad de continuar con los estudios conducentes al doctorado, pero eso sí, en programas acordados en convenio con las universidades. Debido a estos últimos acontecimientos la Investigación Artística característica de los conservatorios, está empezando a desarrollar un ámbito de exploración propio acorde con estas enseñanzas que favorece la indagación dentro de las especialidades instrumentales, como es la especialidad de Piano, al poder abordar trabajos de investigación a través de la práctica artística.

Al comienzo de nuestro viaje por la regulación de la enseñanza de Piano, acompañar al alumno "desde el primero al último paso de su carrera", era posible con un Método Oficial de Piano bajo el brazo. En cambio, si en la actualidad los conservatorios de música desean seguir guiando al discente hasta el último nivel de enseñanza, tendremos que ser capaces de responder al reto que supone 
impartir en estos centros estudios de tercer ciclo conducentes al título de doctor, y este reto pasa ineludiblemente por zambullirse en la actividad investigadora. Una actividad investigadora que crezca, aumente y se propague en el ámbito académico propio de las disciplinas impartidas en los conservatorios, en nuestro caso concreto en el de la enseñanza de la especialidad de Piano. En definitiva, una investigación en el terreno específico e inconfundible del intérprete. 



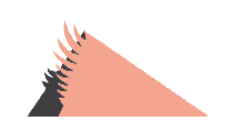

\section{Bibliografía}

\section{Legislación}

Constitución española de 19 de marzo 1812, [documento en línea] $<$ http://www.cervantesvirtual.com/portal/1812/> [consultado el 17-4-2008].

Constitución Española de 27 de diciembre de 1978 (B.O.E. de 29 de diciembre).

Ley de Instrucción pública de 9 de septiembre de 1857, Gaceta de Madrid, 10 de septiembre de $1857, \mathrm{n}^{\circ} 1710$.

Ley Orgánica 5/1980, de 19 de junio, por la que se regula el Estatuto de Centros Escolares (B.O.E. de 27 de junio).

Ley Orgánica 11/1983, de 25 de agosto, de Reforma Universitaria (B.O.E. de 1 de septiembre).

Ley Orgánica 8/1985, de 3 de julio, reguladora del Derecho a la Educación (B.O.E. de 4 julio). 
Ley Orgánica 1/1990, de 3 de octubre, de Ordenación General del Sistema Educativo (B.O.E. de 4 de octubre).

Ley Orgánica 9/1995, de 20 de noviembre, de la Participación, la Evaluación y el Gobierno de los Centros Docentes (B.O.E. de 21 de noviembre).

Ley Orgánica 6/2001, de 21 de diciembre, de Universidades (B.O.E. de 24 diciembre).

Ley Orgánica 5/2002, de 19 de junio, de las Cualificaciones y de la Formación Profesional (B.O.E. de 20 junio).

Ley Orgánica 10/2002, de 23 de diciembre, de Calidad de la Educación (B.O.E de 24 de diciembre).

Ley Orgánica 2/2006, de 3 de mayo, de Educación (B.O.E. de 4 de mayo).

Ley Orgánica 4/2007, de 12 de abril, por la que se modifica la Ley Orgánica 6/2001, de 21 de diciembre, de Universidades (B.O.E. de 13 de abril).

Ley Orgánica 8/2013, de 9 de diciembre, para la mejora de la calidad educativa (B.O.E. de 10 de diciembre).

Ley Orgánica 3/2014, de 18 de junio, por la que se hace efectiva la abdicación de Su Majestad el Rey Don Juan Carlos I de Borbón (B.O.E. de 19 de junio).

Ley Reguladora de los estudios del Bachillerato (B.O.E. de 23 de septiembre de 1938).

Ley de 29 de junio de 1943, sobre ordenación de la Universidad española (B.O.E. de 31 de julio).

Ley de 17 de julio de 1945, sobre Educación Primaria (B.O.E. de 18 de julio).

Ley de 16 de julio de 1949 de Bases de Enseñanza Media y Profesional (B.O.E. de 17 de julio).

Ley de 26 de febrero de 1953 sobre Ordenación de la Enseñanza Media (B.O.E. de 27 de febrero). 
Ley de 20 de julio de 1955 sobre «Formación Profesional Industrial» (B.O.E. de 21 de junio).

Ley de 20 de julio de 1957 sobre ordenación de las enseñanzas técnicas (B.O.E. de 22 de julio)

Ley 194/1963, de 28 de diciembre, por la que se aprueba el Plan de Desarrollo Económico y Social para el período 1964/1967 y se dictan normas relativas a su ejecución (B.O.E. de 31 de diciembre).

Ley 14/1970, de 4 de agosto, General de Educación y Financiamiento de la Reforma Educativa (B.O.E. de 6 de agosto).

Ley 1/1977, de 4 de enero, para la Reforma Política (B.O.E. de 5 de enero).

Ley 17/2003, de 24 de marzo, por la que se regula la organización de las enseñanzas artísticas superiores en Aragón (B.O.E. de 7 de mayo; B.O.A. de 11 de abril).

Ley 8/2007, de 2 de marzo, de la Generalitat, de Ordenación de Centros Superiores de Enseñanzas Artísticas y de la creación del Instituto Superior de Enseñanzas Artísticas de la Comunitat V alenciana (B.O.E. de 9 de abril de 2007; D.O.G.V de 8 de marzo).

Ley 17/2007, de 10 de diciembre, de Educación de Andalucía, (B.O.E. de 23 de enero de 2008; B.O.J.A. de 26 de diciembre de 2007).

Real decreto-ley 14/2012, de 20 de abril, de medidas urgentes de racionalización del gasto público en el ámbito educativo (B.O.E. de 21 de abril).

Real decreto sobre el establecimiento de un plan uniforme y general de enseñanza en todo el reino con arreglo á lo que prescribe la Constitución, Gaceta de Madrid, de 17 de Junio de 1820, no 95.

Real decreto por el que se aprueba el Plan General de Instrucción Pública, Gaceta de Madrid, suplemento de 9 de agosto de 1836, nº 600.

Real decreto aprobando el plan general de estudios para la instrucción pública del reino en la parte relativa á las enseñanzas secundaria y superior, Gaceta de Madrid, 25 de septiembre de 1845, nº 4029. 
Real decreto reformando las Escuelas del Notariado, Diplomática, Ingenieros industriales, Profesores mercantiles, Real Conservatorio de Música y Declamación, Bellas Artes, Náutica y Veterinaria, Gaceta de Madrid, 13 de octubre de 1866, nº 286.

Real decreto reorganizando el Real Conservatorio de Música y Declamación, Gaceta de Madrid, 20 de junio de 1868, nº 172.

Real decreto dictando reglas relativas á la reforma de la organización de la Escuela Nacional de Música y Declamación, Gaceta de Madrid, 12 de diciembre de 1896, no 347.

Real decreto reformando la Escuela Nacional de Música y Declamación y aprobando el adjunto reglamento orgánico del Conservatorio de Música y Declamación, Gaceta de Madrid, 15 de septiembre de 1901, nº 258.

Real decreto disponiendo que las Corporaciones provinciales que sostengan Conservatorios y Escuelas de Música y deseen que los estudios en ellos cursados tengan validez académica, soliciten su incorporación al Conservatorio de Madrid, Gaceta de Madrid, 17 de junio de 1905, nº 168.

Real decreto nombrando Director del Conservatorio de Música y Declamación á D. Cecilio de Roda y López, Gaceta de Madrid, 25 de enero de 1911, $\mathrm{n}^{\mathrm{o}} 25$.

Real decreto aprobando el Reglamento para el funcionamiento del

Conservatorio de Música y Declamación, Gaceta de Madrid, 14 de septiembre de 1911, no 257.

Real decreto aprobando el Reglamento para el gobierno y régimen del Real

Conservatorio de Música y Declamación, Gaceta de Madrid, 30 de agosto de $1917, \mathrm{n}^{\circ} 242$.

Real Decreto 986/1991, de 14 de junio, por el que se aprueba el calendario de aplicación de la nueva ordenación del sistema educativo (B.O.E. de 25 de junio).

Real Decreto 389/1992, de 15 de abril, por el que se establecen los requisitos minimos de los Centros que impartan Enseñanzas Artísticas (B.O.E. de 28 de abril). 
Real Decreto 756/1992, de 26 de junio, por el que se establece los aspectos básicos del currículo de los grados elemental y medio de las enseñanzas de música (B.O.E. de 27 de agosto).

Real Decreto 617/1995, de 21 de abril, por el que se establece los aspectos básicos del currículo del grado superior de las enseñanzas de música y se regula la prueba de acceso a estos estudios (B.O.E. de 6 de junio).

Real Decreto 1044/2003, de 1 de agosto, por el que se establece el procedimiento para la expedición por las universidades del Suplemento Europeo al Título (B.O.E. núm. 218, de 11 de septiembre).

Real Decreto 1125/2003, de 5 de septiembre, por el que se establece el sistema europeo de créditos y el sistema de calificaciones de las titulaciones universitarias de carácter oficialy validez en todo el territorio nacional (B.O.E. núm. 224, de 18 septiembre).

Real Decreto 1577/2006, de 22 de diciembre, por el que se fijan los aspectos básicos del currículo de las enseñanzas profesionales de música reguladas por la Ley Orgánica 2/2006, de 3 de mayo, de Educación (B.O.E. de 20 de enero).

Real Decreto 365/2007, de 16 de marzo, por el que se regula el Consejo Superior de Enseñanzas Artísticas (B.O.E. de 4 de abril).

Real Decreto 900/2007, de 6 de julio, por el que se crea el Comité para la definición del Marco Español de Cualificaciones para la Educación Superior (B.O.E. núm. 172, de 19 de julio).

Real Decreto 1614/2009, de 26 de octubre, por el que se establece la ordenación de las enseñanzas artísticas superiores reguladas por la Ley Orgánica 2/2006, de 3 de mayo, de Educación (B.O.E. de 27 de octubre de 2009).

Real Decreto 631/2010, de 14 de mayo, por el que se regula el contenido básico de las enseñanzas artísticas superiores de Grado en Música establecidas en la Ley Orgánica 2/2006, de 3 de mayo, de Educación (B.O.E. de 5 de junio de 2010).

Real Decreto 99/2011, de 28 de enero, por el que se regulan las enseñanzas oficiales de doctorado (B.O.E. de 10 de febrero). 
Real Decreto 1027/2011 de 15 de julio, por el que se establece el Marco Español de Cualificaciones para la Educación Superior (B.O.E. de 3 de agosto).

Decreto declarando disuelto el Conservatorio de Música y Declamación, y creando en Madrid una Escuela nacional de Música, Gaceta de Madrid, 20 de diciembre de 1868, $\mathrm{n}^{\circ} 355$.

Decreto aprobando el reglamento para la Escuela nacional de Música, Gaceta de Madrid, 27 de diciembre de 1868, nº 362.

Decreto aprobando el Reglamento de la Escuela Nacional de Música, Gaceta de Madrid, 5 de julio de 1871, nº 186.

Decreto creando la Junta Nacional de la Música y Teatros líricos, Gaceta de Madrid, 22 de julio de 1931, nº 203.

Decreto disponiendo que la Junta Nacional de Música y Teatros líricos formule un Plan general de enseñanza, con el fin de transformar los Conservatorios y Escuelas actuales que se juzguen convenientes en Escuelas Nacionales de Música, vinculando su función a la del Conservatorio Nacional de Madrid, que se transformará asimismo en Escuela Superior de Música, Gaceta de Madrid, 4 de febrero de 1932, $\mathrm{n}^{\circ} 35$.

Decreto de 15 de junio de 1942 sobre organización de los Conservatorios de Música y Declamación (B.O.E. de 4 de junio).

Decreto 2618/1966, de 10 de septiembre, sobre Reglamentación general de los Conservatorios de Música (B.O.E. de 24 de octubre).

Decreto de 14 de marzo de 1952 por el que se separan las enseñanzas de Música y Declamación de los actuales Conservatorios (B.O.E. de 1 de abril).

Decreto 151/1993, de 17 de agosto, del Gobierno Valenciano, por el que establece el currículo de los grados elemental y medio de música y se regula el acceso a dichos grados (D.O.G.V. de 2 de septiembre).

Decreto 132/2001, de 26 de julio 2001, del Gobierno V alenciano, por el que se establece el currículo del grado superior de música en la Comunidad $\checkmark$ alenciana y el acceso a dichas enseñanzas (D.O.G.V. de 14 de agosto). 
Decreto 158/2007, de 21 de septiembre, del Consell, por el que se establece el curriculo de las enseñanzas profesionales de música y se regula el acceso a estas enseñanzas (D.O.G.V. de 25 de septiembre).

Decreto 159/2007, de 21 de septiembre, del Consell, por el que se establece el curriculo de las enseñanzas elementales de música y se regula el acceso a estas enseñanzas (D.O.G.V. de 25 de septiembre).

Decreto 48/2011, de 6 de mayo, del Consell, por el que se establece la ordenación de las enseñanzas artísticas superiores y se determina el marco normativo para la implantación de los planes de estudios correspondientes a los titulos oficiales de graduado o graduada en las diferentes enseñanzas artísticas superiores, en el ámbito de la Comunitat Valenciana. (D.O.C.V. de 10 de abril de 2011).

Real Orden por la cual S. M. se ha dignado disponer se establezca en la Corte un Conservatorio de Música titulado de $M^{a}$ Cristina, marcando el Director, Profesores y Empleados de que se ha de componer, y sus correspondientes dotaciones anuales (Archivo Histórico del Real Conservatorio Superior de Música de Madrid, 15 de julio de 1830, Leg 1/1º.

Real Orden, mandando remesar los Reglamentos que rigen en los Conservatorios de Música de Nápoles, París y Milán, Madrid, 4 de agosto de 1830 (Archivo Histórico del Real Conservatorio Superior de Música de Madrid, Leg 1/2).

Real Orden, acompañando adjuntos $1^{\circ}$ : el Reglamento del establecimiento de instrucción de la Academia Real de Música de Suecia y $2^{\circ}$. El Reglamento de la-Sociedad Harmónica de Stockolmo, Madrid, 6 de octubre de 1830 (Archivo Histórico del Real Conservatorio Superior de Música de Madrid, Leg 1/11).

Rl. Orden, acompañando adjunto un proyecto de un Conservatorio de Música escrito por el maestro Morlachi 1er.Mstro.de la Capilla de S. M. el Rey de Sajonia, Madrid, 4 de noviembre de 1830 (Archivo Histórico del Real Conservatorio Superior de Música de Madrid, Leg 1/16).

Rl. Orn. acompañando adjunto un ejemplar del Reglamento interior de la Academia de Música de la Capital de la Gran Bretaña, Madrid, 4 de noviembre de 1830 (Archivo Histórico del Real Conservatorio Superior de Música de Madrid, Leg 1/17). 
Real orden nombrando una comisión para que en el plazo de tres meses proponga á la Dirección general las reformas que deban introducirse en la organización de la Escuela Nacional de Música y Declamación, Gaceta de Madrid, 17 de junio de 1894, no 168.

Orden disponiendo que los claustros de las Facultades y el Profesorado de las Escuelas é Institutos propongan las modificaciones que consideren procedentes en la legislación que actualmente rige para exámenes de asignaturas y para ejercicio de pruebas de títulos académicos, Gaceta de Madrid, 19 de octubre de 1871, no 292.

Orden resolviendo el expediente incoado sobre modificación del Reglamento del Conservatorio Nacional de Música y Declamación, Gaceta de Madrid, 29 de noviembre de 1932, no 334.

Orden de 2 de julio de 1943 por la que se dispone que don Antonio José Cubiles Ramos, Profesor numerario del Real Conservatorio de Músicay Declamación de Madrid pase a explicar las enseñanzas de «Virtuosismo del Piano», en dicho Centro (B.O.E. de 21 de julio).

Orden de 21 de junio de 1968 por la que se dispone la publicación del Reglamento para los exámenes de Grado en los Conservatorios de Música oficiales y se aprueban los programas de cada especialidad (B.O.E. de 27 de septiembre).

Orden de 21 de junio de 1968 por la que se dispone la publicación del Reglamento para los exámenes de Grado en los Conservatorios de Música oficiales y se aprueban los programas de cada especialidad/ Anexo II/ Programas correspondientes a los exámenes de fin de grado de los conservatorios de Música (B.O.M.E.C. de 29 de julio de 1968).

Orden de 26 de septiembre de 1979 por la que se aprueba el plan de estudios del primer ciclo de la facultad de bellas artes de la universidad politécnica de valencia (B.O.E. de 23 de octubre de 1979).

Orden ECI/1687/2007, de 4 de junio, por la que se nombran los consejeros del Consejo Superior de Enseñanzas Artísticas (B.O.E de 13 de junio).

Orden 24/2011, de 2 de noviembre, de la Conselleria de Educación, Formación y Empleo, por la que se establecen y autorizan los planes de estudio de los centros de enseñanzas artísticas superiores de música dependientes del 
ISEACV, conducentes a la obtención del titulo de Graduado o Graduada en Música (D.O.C.V. de 10 de noviembre de 2011).

Resolución de 27 de mayo de 1998 por la que se regula la organización y el funcionamiento de los Conservatorios de música pertenecientes a la Consellería de Cultura, Educación y Ciencia de la Comunidad V alenciana, Consellería de Cultura, Educació i Ciència, Direcció general d'ordenació i innovació educativa i política lingüística. (Distribuidas en los centros).

Sentencia 13 de febrero de 1981, del pleno del tribunal constitucional por el que se modifican determinados artículos del estatuto de centros escolares, aprobado por ley orgánica 5/1980, de 19 de junio (B.O.E. de 24 de febrero).

Sentencia de 13 de enero de 2012, de la Sala Tercera del Tribunal Supremo, por la que se anulan los artículos 7.1, 8, 11, 12 y la Disposición Adicional Séptima del Real Decreto 1614/2009, de 26 de octubre, por el que se estableció la ordenación de las enseñanzas artísticas superiores reguladas por la Ley Orgánica 2/2006, de 3 de mayo, de Educación. (B.O.E. de 23 de marzo).

Avisos. Con Real aprobación, dada á propuesta del director del Real conservatorio de música María Cristina, se ha hecho en el establecimiento el arreglo siguiente, Gaceta de Madrid, 16 de Abril de 1831, nº 48, p.198.

Artículo de Oficio, Gaceta de Madrid, 26 de Agosto de 1830, n 103, p. 421.

Artículo de Oficio, Gaceta de Madrid, 25 de Noviembre de 1830, $\mathrm{n}^{\circ}$ 144, pp. 581-582.

Colección de los decretos y ordenes generales expedidos por las cortes ordinarias de los años 1820 y 1821, en el segundo periodo de su diputación, que comprende desde 25 de febrero hasta 30 de junio del ultimo año impresa de orden de las mismas. Tomo VII, Madrid, Imprenta Nacional, 1821.

Colección legislativa de España, T. LXXXI, Madrid, Imprenta del Ministerio de Gracia y Justicia, 1859. 
Decretos y Resoluciones de la Junta Provisional, Regencia del Reino y los expedidos por su Majestad desde que fue libre del tiránico poder revolucionario, comprensivo al año de 1823.Por D. Fermín Martín de Balsameda, Intendente del Ejército Honorario, Tomo Séptimo, Madrid, Imprenta Real, 1824.

Decretos del Rey nuestro señor Don Fernando VII, y Reales Ordenes, Resoluciones y Reglamentos Generales expedidos por las secretarias del despacho universal y consejos de $S$. M. En los seis meses contados desde $1^{\circ}$. de enero hasta fin de junio de 1824. Por Don Josef Maria de Nieva. Tomo VIII, Madrid, Imprenta Real, 1824.

Decretos del Rey nuestro señor Don Fernando VII, y Reales Ordenes, Resoluciones y Reglamentos Generales expedidos por las secretarias del despacho universal y consejos de $S$. M. en los seis meses contados desde $1^{\circ}$. de julio hasta fin de diciembre de 1824. Con un Apendice. Por Don Josef Maria de Nieva. Tomo Nono, Madrid, Imprenta Real, 1825.

Decretos del Rey nuestro señor Don Fernando VII, y Reales Ordenes, Resoluciones y Reglamentos Generales expedidos por las secretarias del despacho universal y consejos de S. M. en los seis meses contados desde $1^{\circ}$. de enero hasta fin de diciembre de 1825. Por Don Josef Maria de Nieva. Tomo Decimo, Madrid, Imprenta Real, 1826.

Decretos del Rey nuestro señor Don Fernando VII, y Reales Ordenes, Resoluciones y Reglamentos Generales expedidos por las secretarias del despacho universaly consejos de $S$. M. en los seis meses contados desde $1^{\circ}$. de enero hasta fin de diciembre de 1826. Por Don Josef Maria de Nieva. Tomo Undecimo, Madrid, Imprenta Real, 1827.

Decretos del Rey nuestro señor Don Fernando VII, y reales ordenes, Resoluciones y reglamentos generales expedidos por las secretarias del despacho universaly consejos de S. M. desde $10^{\circ}$ de enero hasta fin de diciembre de 1830. Por Don Josef Maria de Nieva. Tomo Decimoquinto, Madrid, Imprenta Real, 1831.

Dictamen y proyecto de decreto sobre el arreglo general de la enseñanza pública; presentado a las Cortes por su Comisión de Instrucción Pública y mandados imprimir de orden de las mismas, Madrid, Cortes, 1814, [documento en línea] 
$<$ http://mdc.cbuc.cat/cdm4/document.php?CISOROOT=/guerr aInd $\&$ CISOPTR $=3862 \&$ CISOSHOW $=3826>$ [consultado 30-082014].

Noticias Extranjeras. España. Madrid 11 de Diciembre, Gaceta de Madrid, 12 de Diciembre de 1829, n 172, p. 645.

Noticias Nacionales. Madrid 30 de setiembre, Gaceta de Madrid, 30 de Septiembre de 1838, n 1414 , p. 2.

Parte no Oficial. España. Real Conservatorio de Música de Maria Cristina, Gaceta de Madrid, 24 de Julio de 1830, nº 89, pp. 363-364.

Decisión n 1720/2006/CE del Parlamento Europeo y del Consejo, de 15 de noviembre de 2006, por la que se establece un programa de acción en el ámbito del aprendizaje permanente, OJ L 327, 24/11/2006, pp. 45-68.

Conclusiones del Consejo, de 12 de mayo de 2009, sobre un marco estratégico para la cooperación europea en el ámbito de la educación y la formación (ET 2020), Diario Oficial de la Unión Europea, $n^{\circ} \mathrm{C} 119$ de 28/05/2009.

\section{Bibliografía}

AEC: The AEC Declaration (1999), [documento en línea] $<$ http://www.aec-music.eu/userfiles/File/aec-declaration1999(1).pdf > [consultado el 16-1-2014].

AEC, ELIA: Towards a European Space for Higher Arts Education. AEC-ELIA Position Paper, 2003, [documento en línea] $<$ http://www.aecmusic.eu/userfiles/File/aeceliapositionpaperenglish(1).pdf > [consultado el 16-1-2014].

AEC: The AEC Learning Outcomes for the 1st, 2nd and 3rd cycle, 2009, [documento en línea] <http://www.aec-

music.eu/userfiles/File/aec-polifonia-learning-outcomes-en.pdf $>$ [consultado el 8-1-2014]. 
AEC-POLIFONIA, TUNING PROJECT: Reference Points for the Design and Delivery of Degree Programmes in Musi, Bilbao, Publicaciones de la Universidad de Deusto, 2009, [documento en línea] $<$ http://www.unideusto.org/tuningeu/images/stories/Publication s/tuningMusic2011.pdf > [consultado el 17-1-2014].

AGUERRÍA CUEVA, Fernando: Historia de la educación musical en la España contemporánea. Un estudio de politica legislativa, Oviedo, FA, 2011.

ALBÉNIZ, Pedro: Método completo de Piano del Conservatorio de Música, 3 vols., Madrid, Almacén de Carrafa/ Librería de Hermosos/ Almacén de Lodre, 1840.

ÁLVAREZ DE MORALES, Antonio: Génesis de las Universidad Española Contemporánea, Madrid, Instituto de Estudios Administrativos, 1972.

ANECA: Programa de convergencia europea. El crédito europeo, Madrid, ANECA, 2003. Disponible en el URL:

$<$ http://www.aneca.es/Documentos-y-publicaciones/Otrosdocumentos-de-interes/Convergencia-Europea $>$ [consultado el 21-8-2014].

ANGLÉS, Higinio: La música española desde la Edad Media hasta nuestros días: catálogo de la exposición histórica, celebrada en conmemoración del primer centenario del nacimiento del maestro Felipe Pedrell/ por Higinio Anglés, Barcelona, Diputación Provincial de Barcelona, Biblioteca Central, 1941.

ARANGUREN, José: Método completo de Piano, Bilbao, Casa Dotesio, [ca. 1890].

BARNETT, Ronald: Los límites de la competencia. El conocimiento, la educación superior y la sociedad, Barcelona, Gedisa, 2001.

BARRY, Nancy H., MCARTHUR, Victoria: "Teaching Practice Strategies in the Music Studio: A Survey of Applied Music Teachers", en Psychology of Music, vol. 22, London, Society for Research in Psychology of Music (SRPMME), 1994, pp. 44-55. 
BAUMAN, Zygmunt: Modernidad líquida, Buenos Aires, Fondo de Cultura Económica, 2003.

BAUTISTA PUJOL, Juan: Nuevo mecanismo de piano, Barcelona, Tip. de J. B. Pujol, 1895.

BIBLIOTECA NACIONAL DE MADRID: Reglamento Orgánico del Real Conservatorio de Música y Declamación, s.l., s.d., MSS/12971/6.

BLANCO, Ascensión (coord.): Desarrollo y evaluación de competencias en Educación Superior, Madrid, Narcea, 2010.

BLANES ARQUÉS, Luís: Discurso de investidura Doctor Honoris Causa por la Universidad Politécnica de Valencia, 19 de enero de 2005, [documento en línea] < https://www.upv.es/organizacion/lainstitucion/honoris-causa/luis-blanes/discurso-es.html > [consultado el 29-7-2014].

BLEIBERG, Germán (dir.): Diccionario de Historia de España, Madrid, Revista de Occidente, 1968-1969, 3 vols.

BLOOM, Benjamin S. (ed.): Taxonomía de los objetivos de la educación, Alcoy, Marfil, 1971.

BLOOM, Benjamin S. (ed.): Developing talent in young people, New York, Ballantine, 1985.

BOELE, Evert B.: Implementation and Use of Credit Points in Higher Music Education, Utrech, AEC, 2007. Disponbile en el URL: $<$ http://www.aec-music.eu/userfiles/File/aec-handbookimplementation-and-use-of-credit-points-in-higher-musiceducation-enrev-2009.pdf $>$ [consultado el 23-7-2014].

BREITHAUPT, Rudolf María: Die natürliche Klaviertechnik, [I] Die freie, rhytmisch-natürliche (Automatik) des gesamten Spielorganismus (Schulter, Arme, Hánde, Finger) als Grundlage der "klavieristischeb" Technik, Leipzig, C. F. Kahnt Nachfolger, 1905 (2a edición revisada: íd., 1905).

BURREL I FLORIA, Guillem, (dir.): Crónica de España, Barcelona, Plaza y Janés, 1994, [documento en línea] 
<http:/ / www.xtec.es/ jrovira6/governs1/govern3.htm> [consultado el 18-07-2014].

CAPITÁN DÍAZ, Alfonso: Historia de la educación de España. I De los orígenes al Reglamento General de Instrucción Pública, Madrid, Dykinson, vol. I, 1991.

CAPITÁN DÍAZ, Alfonso: Historia de la Educación en España. II Pedagogía Contemporánea, Madrid, Dykinson, vol. II, 1994.

CARRILLO, Bienvenido, Abad, Carmen: "La programación didáctica como elemento fundamental de la acción docente en el área de música", en Música y Educación, nº . 26, Madrid, Musicalis, 1996, pp. 91-106.

CASO, José Indalecio: Guía legislativa: indice general de las leyes, decretos, órdenes y circulares contenidas en los noventa tomos de la Colección legislativa oficial de España, que comprende desde 24 de septiembre de 1810 hasta el dia, y particular por articulos de los códigos, leyes orgánicas, y otras muchas disposiciones; ordenado con arreglo a una clasificación especial por José Indalecio Caso, Madrid, Imp. de Alejandro Gómez Fuentenebro, 1859.

CHIANTORE, Luca: Historia de la técnica pianística, Madrid, Alianza, 2001.

COLL, César: Psicología y currículum, Barcelona, Laia, 1987.

COMISIÓN EUROPEA. Dirección general de Educación y Cultura: ¿Qué es el marco europeo de cualificaciones para el aprendizaje permanente?, Luxemburgo, Oficina de Publicaciones Oficiales de la Comunidad Europea, 2008.

COMPTA Y TORRES, Eduardo: Método Completo de piano, Madrid, Imp. de Enrique Abad, 1873.

COMUNICADO DE PRAGA: Declaración de Praga, 2001 Hacia el Área de la Educación Superior Europea. Declaración del encuentro de los Ministros Europeos en funciones de la Educación Superior en Praga, 19 de mayo de 2001, [documento en línea] < 
http://www.eees.es/pdf/Praga_ES.pdf > [consultado el 22-72014].

CONFERENCIA SECTORIAL DE EDUCACIÓN, Grupo de Trabajo: Las Enseñanzas Artísticas a examen. Evolución histórica, panorama actual y perspectiva (Dictamen), Julio, 1999.

CONSEJO EUROPEO: Conclusiones de la presidencia. Consejo europeo de Lisboa 23 y 24 de marzo de 2000, [documento en línea] <http://www.consilium.europa.eu/ueDocs/cms_Data/docs/pres sData/es/ec/00100-r1.es0.htm > [consultado el 22-7-2014].

CORBALÁN ABELLÁN, Maravillas: "La programación interdisciplinar en la enseñanza musical no superior", en Música y Educación, no . 38, Madrid, Musicalis, 1999.

COX, Jeremy: Curriculo design and development in higer education, Utrech, AEC, 2007.

Declaración de La Sorbona: Declaración conjunta para la armonización del diseño del Sistema de Educación Superior Europeo (a cargo de los cuatros ministros representantes de Francia, Alemania, Italia y el Reino Unido), [documento en línea]<http://www.ond.vlaanderen.be/hogeronderwijs/bologna/li nks/language/1998_Sorbonne_Declaration_Spanish.pdf> [consultado el 21-7-2014].

DECLARACIÓN DE BOLONIA: El Espacio Europeo de la enseñanza superior. Declaración conjunta de los ministros superiores de educación reunidos en Bolonia el 19 de junio de 1999, [documento en línea]

<http://www.ond.vlaanderen.be/hogeronderwijs/bologna/links/1 anguage/1999_Bologna_Declaration_Spanish.pdf $>$ [consultado el 14-3-2014].

DE LA MATA, Manuel: Método completo de Piano, Madrid, Pablo Martín editor, 1871.

DELGADO GARCÍA, Fernando: Los Gobiernos de España y la Formación del Músico (1812-1956), Sevilla, Servicio de Publicaciones de la Universitat de Sevilla, 2003, (microficha). 
DELORS, Jacques: La Educación encierra un tesoro; informe a la UNESCO de la Comisión Internacional sobre la Educación para el Siglo XXI, Madrid, UNESCO-Santillana, 1996. Disponible en el URL: <https://www.yumpu.com/es/document/view/14061924/delorsjacques-la-educacion-encierra-un-tesoropdf-instituto- $>$ [consultado el 21-07-2014].

DE MIGUEL DÍAZ, Mario (dir.): Adaptación de los Planes de Estudio al proceso de convergencia europea, Dirección Gral. De Universidades. Programa de Estudios y Análisis, Madrid, 2004, [documento en línea] $<$

http:/ / www.ulpgc.es/hege/almacen/download/42/42375/adapta cion_de_la_homologacion_de_los_planes_de_estudio_a_la_conve rgencia_europea.pdf.> [consultado el 22-7-2014].

DE MIGUEL DÍAZ, Mario (coord.): Metodologías de enseñanzay aprendizaje para el desarrollo de competencias, Madrid, Alianza, 2006.

DE PLACE, A.: "Johann Baptist Cramer", en François-René de Tranchefort, (dir.): Guía de la música de piano y de clavecín, Madrid, Taurus, 1990, p. 285.

DÍAZ, Joaquín: La administración educativa en España (1812-1931), [documento en línea]

$<$ http://www.mec.es/cide/jsp/plantilla.jsp?id=arch03a $>$ [consultado el 20-5-2007].

DIRECCIÓN GENERAL DE EDUCACIÓN Y CULTURA DE LA COMISIÓN EUROPEA: Sistema europeo de transferencia y acumulación de créditos (ECTS) Características esenciales, Luxemburgo, Oficina de Publicaciones Oficiales de las Comunidades Europeas, 2004.

DIRECCIÓN GENERAL DE EDUCACIÓN Y CULTURA DE LA COMISIÓN EUROPEA: El Marco Europeo de Cualificaciones para el aprendizaje permanente, [documento en línea]<http://www.mecd.gob.es/dctm/mecu/files/eqfniveleses.pd f.documentId=0901e72b80d5c46e $>$ [consultado el 22-7-2014].

ECO, Umberto: Cómo se hace una tesis. Técnicas y procedimientos de investigación, estudio y escritura, Barcelona, Gedisa, 1997. 
EMBID IRUJO, Antonio: Informe sobre la conveniencia de promulgar una Ley Orgánica reguladora de la Organización en régimen de Autonomía de las Enseñanzas superiores artísticas en España, Zaragoza, Asociación española de Centros Superiores de Enseñanzas Artísticas (eds.), Salamanca, Jet Prints S.L., 1997.

EMBID IRUJO, Antonio: Un siglo de legislación musical en España. Y una alternativa par la organización de las enseñanzas en su grado superior, Zaragoza, IFC Edición especial para ACESEA, 2000, pp. 77-116. Disponible en el URL:

<http://www.acesea.es/www/files/unsiglodelegislacionmusical.pd f> [consultado el 21-8-2014].

EMBID IRUJO, Antonio, Gurrea Casamayor, Fernando: Legislación sobre enseñanza. Enseñanzas de Régimen Especial (Artísticas y de Idiomas), vol. 2, Madrid, Tecnos, 2000.

ERICSSON, K. Anders, KRAMPE, R. Th., HEIZMAN, S.: "Can We Create Gifted People?”, en Ciba Foundation Symposium 178 - The Origins and Development of High Ability, Chichester, Wiley, 1993, pp. 222-249.

ERICSSON, K. Anders: "Deliberate practice and the acquisition of expert performance: An overview", en: Jørgensen, Harald, Lehmann, Andreas C. (eds.): Does Practice Make Perfect? Current Theory and Research on Instrumental Music Performance, Oslo, Norwegian State Academy of Music, 1997, pp 9-51.

ESCAMILLA, Amparo, LAGARES, Ana Rosa, GARCÍA FRAILE, Juan Antonio: La Loe: Perspectiva Pedagogica e Historica, Barcelona, Graó, 2006.

ESCUELA NACIONAL DE MÚSICA Y DECLAMACIÓN: Programa de las enseñanzas. 1 de agosto de 1875, Archivo Histórico del Real Conservatorio Superior de Música de Madrid, Doch. Bco. $1 / 3$.

ESCUELA NACIONAL DE MÚSICA Y DECLAMACIÓN:

Programa oficial de la enseñanza de piano 3, Madrid, Imp. de J. M. Ducazcal, 1891. 
ESTEBAN MUÑOZ, Elena: La versión pianística. Defensa de la huella estético-estilística del pianista en su interpretación en función de sus habilidades, conocimiento y creatividad, Tesis Doctoral (inédita), Universidad Autónoma de Madrid, 2004.

ESTÉVEZ VILA, Jaime: “Del Plan 66 al Plan LOGSE: aspectos positivos y problemáticos", en Música y Educación, no 49, Madrid, Musicalis, 2002, pp. 45-60.

FONT, Jordi: "Crónica de un trayecto", en VV.AA.: Las enseñanzas artísticas superiores. Legislación, Murcia, ACESEA, 2010, pp. 11-16.

FUSI AIZPURUA, Juan Pablo: Historia minima de España, Madrid/Méxio D.F., Turner, 2012.

GALTON, Francis: Hereditary genius: An inquiry into its laws and consequences, Memphis, General Books, 1869/2012.

GARCÍA DE CORTÁZAR, Fernando, González Vesga José Manuel: Breve historia de España, Madrid, Alianza, 2012.

GARCÍA TROBAT, Pilar: "Libertad de cátedra y manuales en la facultad de derecho (1845-1868)", en Cuadernos del Instituto Antonio de Nebrija de estudios sobre la universidad, $\mathrm{n}^{\circ} 2$, Madrid, Universidad Carlos III, 1999, pp. 37-58.

GARDNER, Howard: The arts and buman development, Nueva York, Wiley, 1973.

GIL DE ZÁRATE, Antonio: De la Instrucción Pública en España, 3 vols., Oviedo, Pentalfa, 1995.

GIMENO SACRISTÁN, José (comp.): Educar por competencias. ¿Qué hay de nuevo?, Madrid, Morata, 2008.

GÓMEZ AMAT, Carlos: Historia de la música española, Madrid, Alianza, 2007.

GONZÁLEZ, Julia, WAGENAAR, Robert (coords.): Una introducción a Tuning Educational Structures in Europe. La contribución de las universidades al proceso de Bolonia, Bilbao, Publicaciones de la Universidad de Deusto, 2009, [documento en 
línea]<http://www.unideusto.org/tuningeu/images/stories/Public ations/Tuning_brochure_en_espanol_listo.pdf > [consultado el 227-2014].

GUTIÉRREZ BARRENECHEA, María del Mar: La formación de intérpretes profesionales en los conservatorios en el marco de la reforma educativa: Madrid como paradigma, Madrid, MEC, 2007.

HERZ, Henri: Méthode complète de Piano op. 100, Maguncia y Amberes/Les fils de B. Schott, París/J. Meissonnier, Londres/Dalmaine et Cie., 1838.

HIGUERAS MUÑOZ, Francisco: Interpretación musical y creatividad. Construcción del discurso social a través del pensamiento social y la investigación contemporánea, Tesis doctoral (inédita), Universidad Rey Juan Carlos, 2008. Disponible en el URL:

<http://hdl.handle.net/10115/6012> [consultado el 15-07-2014].

IGLESIAS MARTÍNEZ, Nieves (dir.): La música en el Boletín de la Propiedad Intelectual, 1847-1915, Madrid, Ministerio de Educación y Cultura. Biblioteca Nacional, 1997.

JOINT QUALITY INITIATIVE: Shared 'Dublin' descriptors for Short Cycle, First Cycle, Second Cycle and Third Cycle Awards, 2004, [documento en línea] <

http://www.jointquality.nl/content/ierland/Complete_set_Dublin _Descriptors_2004_1.31.doc > [consultado el 22-7-2014].

JØRGENSEN, Harald, LEHMANN, Andreas C. (eds.): Does Practice Make Perfect? Current Theory and Research on Instrumental Music Performance, Oslo, Norwegian State Academy of Music, 1997.

JURADO LUQUE, Javier, RIFÓN LASTRA, Ana: “La Programación y la Unidad Didáctica en el nuevo sistema de oposiciones (con ejemplos de ambas)", en Música y Educación, $\mathrm{n}^{\circ}$ 58, Madrid, Musicalis, 2004, pp. 17-50.

KOMITEE, Shana: A Student Guide to Performance Studies, Cambridge/MA, Harvard University Faculty of Arts \& Sciences, 2011. Disponible en el URL: 
$<$ http://writingproject.fas.harvard.edu/files/hwp/ files/peformanc e_studies.pdf> [consultado el 15-07-2014].

KUGEL, Peter: "How professors develop as teachers", en Studies in Higher Education, vol. 18, $\mathrm{n}^{\circ} 3$ Abingdon, Routledge-Taylor \& Francis Group, 1993, pp. 315-328.

LACAL, Luisa: "Conservatorio", en Diccionario de la música técnico, histórico, bio-bibliográfico, Madrid, establecimiento tipográfico de San Francisco de Sales, 1899, pp. 133-134.

LASNIER, Françoise: Réussir la formation par compétences, Montreal, Guérin, 2000.

LAVIGNAC, Alberto: La educación musical, Barcelona, Gustavo Gili, 1904.

LONGUEIRA MATOS, Silvana: Educación musical: un problema emergente de intervención educativa. Indicadores pedagógicos para el desarrollo de competencias en educación musical, Tesis doctoral, Santiago de Compostela, Universidad de Santiago de Compostela, 2011. Disponible en el URL: <http://hdl.handle.net/10347/3697> [consultado el 14-07-2014].

LÓPEZ DE ARENOSA, Encarnación: "Educación musical profesional", en Música y Educación, $\mathrm{n}^{\circ}$ 37, Madrid, Musicalis, 1999, p. 15.

LÓPEZ MARTÍNEZ, Juan: "La LOE, un salto cualitativo para las enseñanzas artísticas", en Las enseñanzas artísticas superiores en el espacio europeo de educación superior, Madrid, MECD, 2010.

LORENZO MARTÍN, Rocío: Los contenidos de la educación pianistica en los conservatorios de música: una propuesta integrada, Tésis doctoral, Granada, Universidad de Granada, 2009. Disponible en el URL: $<$ http://hera.ugr.es/tesisugr/18510450.pdf> [consultado el 14-072014].

MARINA, José Antonio: La inteligencia fracasada, Barcelona, Anagrama, 2008. 
MARTÍNEZ DÍAZ, Carmen María Luisa: El desarrollo de las Enseñanz̧as Superiores de Arte Dramático, Danza y Música en la Comunitat V alenciana. Antecedentes históricos, situación actual y perspectiva de futuro, Tesis Doctoral, Valencia, Universitat de Valéncia, 2012.

MARZAL RAGA, Consuelo de los Reyes: El régimen jurídico de las enseñanzas musicales, Valencia, Institució Alfons el Magnànim, 2010.

MASARNAU, Santiago: Llave de la ejecución: seis modelos de pasos para el piano-forte, que, ejecutados sucesivamente por los doce tonos mayores desarrollan en breve tiempo la ejecución de la mano asegurando de paso su buena posición y contribuyendo también a la formación del oido, Madrid, A. Romero, [1862].

MASARNAU, Santiago: Tesoro del pianista, Madrid, Romero y Marzo, [1862].

MATTHAY, Tobias: The Act of Touch in all its Diversity. An Analysis and Synthesis of Piano-forte Tone-Production, London, Bosworth \& Co., 1903.

MEC: Libro Blanco para la Reforma del Sistema Educativo, Madrid, Sevicio de publicaciones, 1989.

Memoria acerca de la Escuela Nacional de Música y Declamación de Madrid escrita para ser presentada en la Exposición Universal de la Música y del Teatro que ha de verificarse en Viena en el año de 1892, Madrid, Imp. de José M. Ducazcal, 1892.

Memoria presentada por la Escuela de Música y Declamación en la Exposición Internacional de Filadelfia, Madrid, Imp. y Fundición de J. Antonio García, 1876.

MILLS, Janet: "Working in music: The conservatoire professor", en British Journal of Music Education, vol. 21, $\mathrm{n}^{\circ}$ 2, Cambridge, Cambridge University Press- Cambridge Journals, pp. 179-198.

MINISTERIO DE EDUCACIÓN, CULTURA Y DEPORTE: La Integración del Sistema Universitario Español en el Espacio Europeo de Enseñana Superior. Documento-Marco, 2003, [documento en línea] 
$<$ http://www.eees.es/pdf/Documento-Marco_10_Febrero.pdf > [consultado el 14-07-2014].

MINISTERIO DE EDUCACIÓN Y CIENCIA: Cuadernos de Actualidad Artistica 8/ Problemas actuales de la educación musical en España/ La Educación Musical Profesional/ II Decena de Música en Sevilla 1970/, Madrid, Dirección General de Bellas Artes, 1970.

MIRÓ, José: Método completo de Piano, Madrid, Zozaya, 1856.

MOLTÓ DONCEL, Jorge L.: "La acción programadora en la especialidad de piano, a la luz de las contribuciones aportadas por la reglamentación musical", en ArtsEduca, n ${ }^{\circ}$, Valencia, Ana M. Vernia Carrasco, 2014, pp. 18-43, [documento en línea] $<$ http://es.slideshare.net/artseduca/artseduca-7smallpdfcom> [consultado el 21-7-2014].

MONTES, Beatriz: "La influencia de Francia e Italia en el Real Conservatorio de Madrid", en Revista de Musicologia, vol. XX, $\mathrm{n}^{\circ}$ 1, Madrid, Sociedad Española de Musicología, 1997, pp. 467-478.

MONTGEROULT, Hélène: Cours complet pour l'enseignement du forté piano, conduisant progrefsivement des premiers éléments aux plus grandes difficultés, 3 vols., Paris, Chez Launer/Gravé et imprimé chez Marquerie frères, [ca. 1825].

NIETO, Albert: "Las grafías alternativas pianísticas: defensa para su inclusión en el conservatorio", en Música y educación, $\mathrm{n}^{\circ}$ 44, Madrid, Musicalis, 2000, pp. 97-108.

ORGANIZACIÓN DE LOS ESTADOS IBEROAMERICANOS PARA LA EDUCACIÓN LA CIENCIA Y LA CULTURA: Sistemas Educativos Nacionales. España, [documento en línea] < http://www.oei.es/quipu/espana/index.html > [consultado el 308-2014].

ORTIZ BALLESTEROS, Consuelo: "Un paseo por palacio a través del Real Conservatorio Superior de Música de Madrid", en Música. Revista del Real Conservatorio Superior de Música de Madrid, $\mathrm{n}^{\circ}$ 10-11, Madrid, Real Conservatorio Superior de Música de Madrid, 2005-2006, pp. 13-44. 
OVILO Y OTERO, Manuel: Manual de biografía y de bibliografía de los escritores españoles del siglo XIX/ por Manuel Ovilo y Otero, Tomo II, Paris, librería de Rosa y Bouret, 1859, [documento en línea] < http://es.wikisource.org/wiki/Manual_de_Biograf\%C3\%ADa:_V entura_de_la_Vega> [consultado el 30-8-2014].

PAGANI, Raffaella: "Concepto de crédito europeo", [documento en línea] <http:/ / www.unican.es/NR/rdonlyres/04594170-03154C5B-B3DF-FEC24D0CCBEA/0/doc4.pdf > [consultado el 22-72014].

PAYNE, Stanley G.: España. Una historia únicak, Madrid, Temas de Hoy, 2008.

PERELLÓ DOMÉNECH, Vicente: La enseñanza musical en la Comunidad Valenciana, Valencia, Generalitat Valenciana. Consellería de Cultura i Educació, 2003.

PÉREZ GUTIÉRREZ, Mariano: “Los Conservatorios Españoles. Historia, reglamentaciones, planes de estudio, centros, profesorado y alumnado", en Música y Educación, no 15, Madrid, Musicalis, 1993, pp. 17-48.

PÉREZ GUTIÉRREZ, Mariano: Diccionario de la música y los Músicos, 3 vols., Madrid, Istmo, 2000.

PERRENOUD, Philippe: Diez nuevas competencias para enseñar, Barcelona, Graó, 2004.

PLIEGO DE ANDRÉS, Víctor: Temas pedagógicos para la oposición de conservatorios, Madrid, Musicalis, 1998.

POLIFONIA THIRD CYCLE WORKING GROUP: Guide to third cycle studies in higher music education, Utrech, AEC, 2007.

Disponible en el URL: <http://www.aec-

music.eu/userfiles/File/aec-handbook-guide-to-third-cyclestudies-in-higher-music-education-en.pdf $>$ [consultado el 23-72014]. 
POZO MUNICIO, Juan Ignacio, Pérez Echevarria, María del Puy: Psicología del aprendizaje universitario: formación en competencias, Madrid, Morata, 2009.

Programa oficial de la Enseñanza de Piano adoptado en el Conservatorio de Música y Declamación. Ofrecido por la casa Antonio Matamala editory almacenista de Música, s.d., Archivo Histórico del Real Conservatorio Superior de Música de Madrid, Doc. Bca. C 2 (6, b).

Programa oficial de la Enseñanza de Piano del Conservatorio Nacional de Música y Declamación, s.d., Archivo Histórico del Real Conservatorio Superior de Música de Madrid.

PUELLES BENÍTEZ, Manuel de: Política, legislación y educación, Madrid, UNED, 2012.

QUINTANA, Manuel José: “Informe de la Junta creada por la Rejencia para proponer los medios de proceder al arreglo de los diversos ramos de Instrucción Pública", en Obras Completas, T. XIX, Madrid, B.A.E. Atlas, 1946.

REAL CONSERVATORIO DE MÚSICA: Enseñanza Oficial. Programa de la enseñanza del Piano para los exámenes privados trimestrales que tendrán lugar del 15 al 20 de diciembre, del 15 al 20 de Marzo, y del 25 al 30 de Mayo, s.d., Archivo Histórico del Real Conservatorio Superior de Música de Madrid.

REAL CONSERVATORIO SUPERIOR DE MÚSICA: Programa de la Enseñanza de Piano vigente desde 1. ${ }^{\circ}$ de octubre de 1973, Archivo Histórico del Real Conservatorio Superior de Música de Madrid.

ROBLEDO ESTAIRE, Luís: "La creación del Conservatorio de Madrid”, en Revista de Musicología, vol. XXIV, no 1-2, Madrid, Sociedad Española de Musicología, 1997, p. 189-223.

ROBLEDO ESTAIRE, Luís: "El Conservatorio que nunca existió: El proyecto de Melchor Ronzi para Madrid (1810)", en Música. Revista del Real Conservatorio Superior de Música de Madrid, no 7-8-9, Madrid, Real Conservatorio Superior de Música de Madrid, 20002002, pp. 13-25. 
ROSEN, Charles: Formas de sonata, Barcelona, Labor, 1994.

RUIZ-DOMÈNEC, José Enrique: La Trama del Pasado. Diecisiete momentos que cambiaron la historia del mundo, Barcelona, librosdevanguardia, 2014.

SALAS VILLAR, Gemma: "Pedro Pérez de Albéniz: en el segundo centenario de su nacimiento", en Cuadernos de música iberoamericana, vol. 1, Madrid, Instituto Complutense de Estudios Musicales, 1996, pp. $97-126$.

SALAS VILLAR, Gemma: El piano romántico español 1830-1855, Tesis Doctoral (inédita), Universidad de Geografía e Historia de Oviedo, 1997.

SALAS VILLAR, Gemma: "Santiago de Masarnau y la implantación del piano romántico en España", en Cuadernos de música iberoamericana, vol. 4, Madrid, Instituto Complutense de Estudios Musicales, 1997, pp. 197-222.

SALAS VILLAR, Gemma: “Aproximación a la enseñanza para piano a través de la cátedra de Pedro Albéniz en el Real Conservatorio de Madrid", en Revista de musicología, vol. XXII, n 1 , Madrid, Sociedad española de Musicología, 1999, pp. 209-246.

SALAS VILLAR, Gemma: "La enseñanza para piano durante la primera mitad del siglo XIX: los métodos para piano", en Nassarre: Revista aragonesa de musicología, vol. 15, n 1-2, Zaragoza, Institución «Fernando el Católico», 1999, pp. 9-56.

SANTAYANA, George: The Life of Reason: or The Phases of Human Progress, vol. I, Reason in Common Sense, New York, Charles Scribner's Sons, 1920.

SANZ DE ACEDO, $\mathrm{M}^{\mathrm{a}}$ Luisa: Competencias cognitivas en educación superior, Madrid, Narcea, 2010.

SARGET ROS, Ma Angeles: Evolución de los conservatorios de música a través de las disposiciones legales: la Comunidad Autónoma de Castilla-La Mancha, Tesis doctoral, UNED, 2000. 
SAWYER, Keith: Group Genius: The Creative Power of Collaboration, New York, Basic Books, 2007.

SEGURA, Roberto: Método elemental de piano por Roberto Segura. Primera parte, Valencia, Casa de los Sres. Prosper y Laviña, 1879.

SMALL, Christopher: Música. Sociedad. Educación, Madrid, Alianza, 1989.

SOBEJANO AYALA, José: El Adam español o lecciones metódicoprogresivas de forte piano. Por el profesor armonista D.n J. Sobejano Ayala, Madrid, Calcografía de D. Bartolomé Wimbs, 1826.

SOCIEDAD DIDÁCTICO-MUSICAL: Escuela elemental de piano. Dividida en cinco volumenes, correspondientes a los cinco años de dicha enseñanza, Madrid, J. M. Sardá, Pascual González y Eusebio Fernández, 1903.

SOPEÑA IBÁÑEZ, Federico: Historia del Real Conservatorio de Música de Madrid, Madrid, Ministerio de Educación y Ciencia. Dirección General de Bellas Artes, 1967.

SOSNIAK, Lauren A.: "Learning to be a concert pianist", en Bloom, Benjamin S. (ed.): Developing talent in young people, Nueva York, Ballantine Books, 1985, pp. 19-67.

SOSNIAK, Lauren A.: "Phases of Learning", en Bloom, Benjamín S. (ed.): Developing talent in young people, New York, Ballantine, 1985, pp. 409-438.

SOSNIAK, Lauren: 'From Tyro to Virtuoso: A Long-term Commitment to Learning”, en Wilson, Frank R. y Roehmann, Franz L. (eds.): Music and Child Development, St. Louis, MMB Music, 1990, pp. 274-290.

TINTORER, Pere: Curso completo de piano, Barcelona, [S.i., ca. 1878].

TOMÁS VILLARROYA, Joaquín: “El proceso constitucional. Capítulo VIII. La descomposición del régimen. El fin de la Constitución", en La era isabelina y el Sexenio Democrático, Historia de España fundada por don Ramón Menéndez Pidal, T. XXXIV, Madrid, Espasa-Calpe, 1981, pp. 345 y ss. 
TRAGÓ, José: Escuela de piano.-Estudios, Madrid, Almagro y C $\mathrm{C}^{\mathrm{a}}$, 1899.

TRAGÓ, José: Escuela de piano.-Seis sonatinas, Madrid, Almagro y C $\mathrm{C}^{\mathrm{a}}$, 1899.

VÁZQUEZ TUR, Mariano José D.: El piano y su música en el siglo XIX en España, Tesis Doctoral (inédita), Universidad de Santiago de Compostela, 1988.

VEINTIMILLA BONET, Alberto: "Las enseñanzas musicales en el EEES", en Las enseñanzas artísticas superiores en el espacio europeo de educación superior, Madrid, MECD, 2010. Disponible en el URL:

<http://www.acesea.es/www/files/EASenEEES.pdf> [consultado el 21-7-2014].

VIGUERIE, Bernard: Método completo de piano, Gonzalo, José (ed.), Madrid, Manuel Jiménez, 1873.

VILAR I TORRENS, Josep María: "Manejando el currículo en el conservatorio y en la escuela de música: ¿dónde debe estar el repertorio?”, en Música y Educación, n 43, Madrid, Musicalis, 2000, pp. 29-45.

VILLA, Aurelio, POBLETE, Manuel: Aprendizaje basado en competenciaa. Una propuesta para la evaluación de las competencias genéricas, Bilbao, Universidad de Deusto, 2008.

VV.AA.: Aprendizaje, competencias y rendimiento en educación superior, Madrid, La Muralla, 2007.

VV.AA.: "Competencia de trabajo en equipo: definición y categorización", en Profesorado. Revista de curriculum y formación del profesorado, vol. 15, no 3, Granada, Universidad de Granada, 2011, pp. 329-344, [documento en línea] <http:// digibug.ugr.es/bitstream/10481/23174/1/rev153COL8.p df $>$ [consultado el 11-1-2014].

VV.AA.: Del Proyecto Educativo a la Programación de Aula, Barcelona, Graó, 2006. 
VV.AA.: Enciclopedia de Historia de España. Diccionario biográfico, vol. IV, Madrid, Alianza Editorial, 1991.

VV.AA.: Informe anual sobre el estado y situación de las Enseñanzas Artísticas. CURSO 2009-2010, Madrid, MECD, 2011.

VV.AA.: La Hacienda desde sus ministros. Del 98 a la guerra civil, Zaragoza, Prensas Universitarias de Zaragoza, 2000.

WILLIAMON, Aaron (ed.): Musical Excellence: Strategies and Techniques to Enhance Performance, Oxford, Oxford University Press, 2004.

ZABALA, Antoni, Arnau, Laia: 11 ideas clave. Cómo aprender y enseñar competencias, Barcelona, Graó, 2007 (reimpr. 2010).

ZABALZA, Miguel, Zabalza Cerdeiriña, María Ainoa: Planificación de la docencia en la universidad. Elaboración de las Guías Docentes de la Materias, Madrid, Narcea, 2010.

ZALDÍVAR GRACIA, Álvaro: “Las enseñanzas musicales y el nuevo Espacio Europeo de Educación Superior: el reto de un marco organizativo adecuado y la necesidad de la investigación creativa y performativa", en Revista interuniversitaria de formación del profesorado, no 52 (19,1), Zaragoza, Asociación Universitaria de Formación del Profesorado, 2005, pp. 95-122, [documento en línea]

<http://www.aufop.com/aufop/revistas/indice/impresa/17> [consultado el 23-07-2014].

ZALDÍVAR GRACIA, Álvaro: "El reto de la investigación creativa y «performativa»", en Eufonía: Didáctica de la música, $\mathrm{n}^{\circ}$ 38, Barcelona, Graó, 2006, pp. 87-94.

ZALDÍVAR GRACIA, Álvaro: "Investigar desde el arte", en Anales, año 1, no 1, Santa Cruz de Tenerife, Real Academia Canaria de Bellas Artes de San Miguel Arcángel, 2008, pp. 57-64.

ZALDÍVAR GRACIA, Álvaro: "Investigar desde la práctica artística", en De la Calle, Román, Martínez, María L. (eds.): Investigar en los dominios de la música, Valencia, Real Academia de 
Bellas Artes de San Carlos, 2011, pp. 245-257. También en: Libro de Actas del I CONGRÉS INTERNACIONAL 'INVESTIGACIÓ EN MÚSICA', Valencia, ISEACV, 2010, pp. 124-129. Disponible en el URL: <http://es.scribd.com/doc/114390243/Cim1-ActasIsea-Congreso $>$ [consultado el 15-07-2014].

ZWEIG, Stefan: Momentos estelares de la humanidad. Catorce miniaturas bistóricas, Barcelona, Acantilado, 2002.

\section{Páginas web}

Aquí se puede encontrar toda la información necesaria sobre la Asociación Europea de Conservatorios (AEC), sus actividades, miembros, los proyectos en los que la organización está involucrada, y descargar numerosas publicaciones en varios idiomas.

http://www.aec-music.eu/home

Enlace a la página con los Cursos de postgrado ofrecidos por el Conservatorio Superior de Zaragoza CSMA.

https://www.csma.es/edicionContenidos.do?metodo $=$ mostrarPan talla\&menuIzqLargo $=1 \&$ enlaceMenuIzquierda $=$ menuPostgrado\& enlaceMenuDerecha=informacion\&idPaginaContenidos $=9$

Enlace al Máster del Conservatorio Superior de Música de Valencica CSMV, Curso 2013/2014. http:/ /www.csmvalencia.es/es/postgrados2013.php

Web oficial del proceso de Bolonia en el Espacio Europeo de Educación Superior. http://www.ehea.info/

La Liga Europea de Institutos de las Artes (ELIA) es una organización independiente de la red de educación superior artística que cuenta con más de 300 miembros en 47 países, que representan a unos 300.000 estudiantes. http://www.elia-artschools.org/ 
Enlace a la página con los Másteres ofertados en la Escola Superior de Música de Catalunya ESMUC.

http://www.esmuc.cat/Masters-i-postgraus,

EUR-Lex ofrece acceso gratuito a la legislación de la Unión Europea.

http:/ / eur-lex.europa.eu/es/index.htm

Sitio web oficial de la Unión Europea. Contiene información sobre la historia, organismos y funcionamiento de la UE.

http://europa.eu/index_es.htm

Página web de la Dirección General de Educación y Formación de la Comisión Europea, donde se puede consultar por ejemplo el programa de Aprendizaje a lo largo de la vida.

http://ec.europa.eu/education/

Esta página surge con el objetivo de ayudar a comprender el Espacio Europeo de Educación Superior. Contiene información relevante en materia de educación y el proceso de convergencia europea.

http://www.eees.es/es/documentacion

Asociación iCOBAE, su tarea se dirige hacia la cooperación con el profesorado para la incorporación de las competencias básicas en el currículo y la práctica docente. http://icobae.blogspot.com.es/

El Consejo Superior de Enseñanzas Artísticas es el órgano consultivo del Estado y de participación en relación con las enseñanzas artísticas.

http://www.mecd.gob.es/cseartisticas

Este es el portal del Marco Español de Cualificaciones para el aprendizaje a lo largo de la vida, (MECU) que pone a disposición el MECD. El objetivo de este portal es dar a conocer el MECU y el MECES.

http://www.mecd.gob.es/mecu.html 
Website de la red Erasmus para la Música Polifonia.

http://www.polifonia-tn.org/

El proyecto Atlántida, se constituye como una amplia red, que reúne un grupo ecléctico de profesionales de diferentes sectores, centros educativos integrados o colaboradores, departamentos universitarios, grupos de asesores y orientadores, que intentan mediante experiencias de innovación, actualizar el currículo y ordenación de los centros escolares. http:/ / www.proyectoatlantida.net/

Página web del Proyecto Tuning, en la que se encuentra toda la información relacionada con el proceso que se inició en Europa en el 2000 con el objetivo de enlazar los objetivos políticos del proceso de Bolonia con el sector de la educación superior. http://www.unideusto.org/tuningeu 



\section{Apéndices}

1. Extracto del Reglamento Orgánico del Real Conservatorio de Música y Declamación, MSS/12971/6, custodiado en la Biblioteca Nacional de España 


\section{Q Peiplaninento Giganico

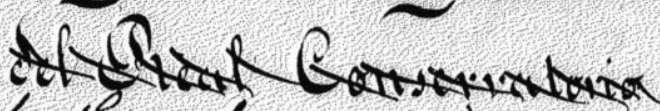

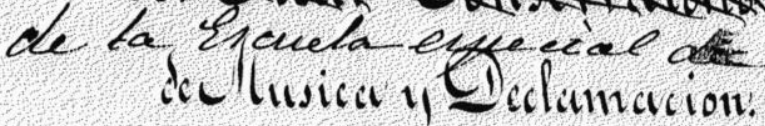

$$
\text { (i)cisitula of? }
$$

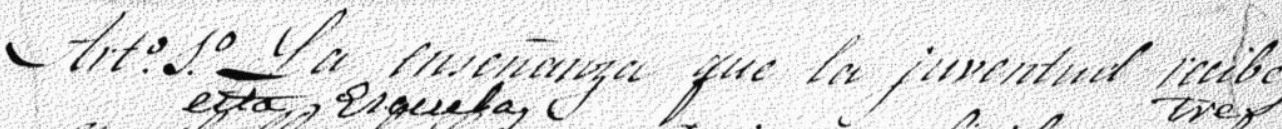

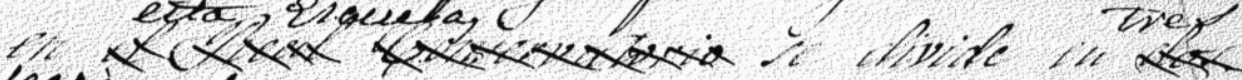

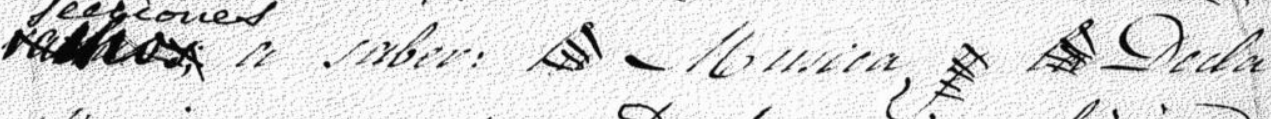
(nifridi general y Declamacion Lirica)

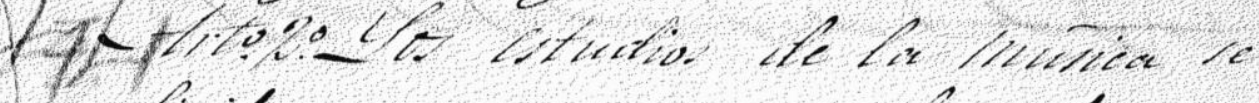

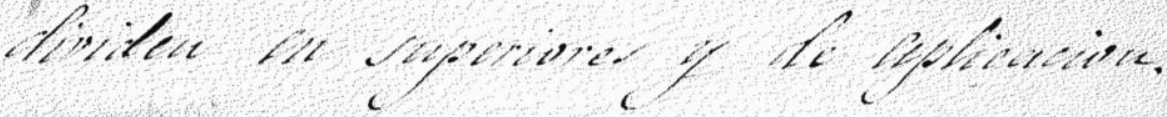
llitidios superiorcs.

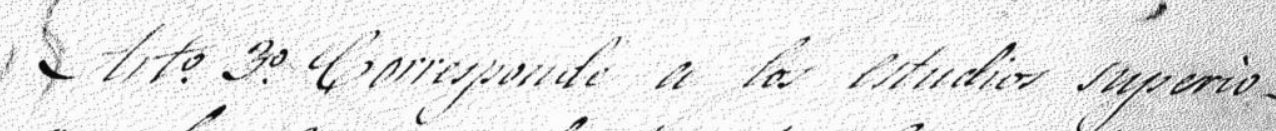

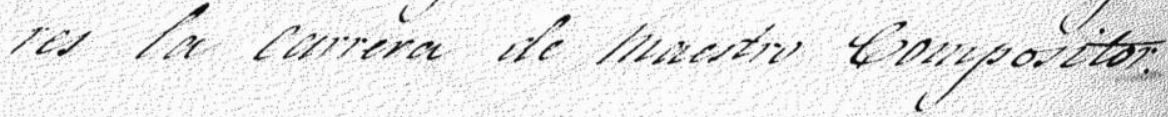
Hotridios de elplieacion.

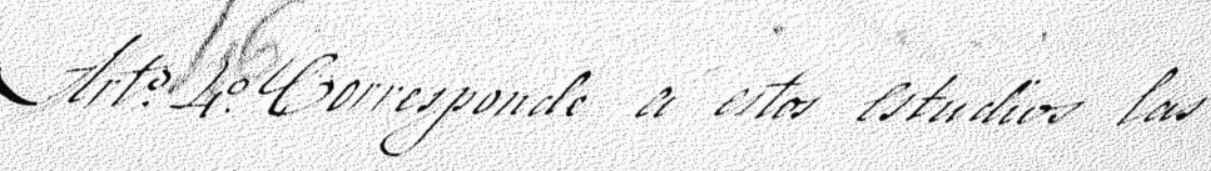




\section{Cronología de los principales reglamentos y disposiciones, a través de los cuales se han organizado las enseñanzas de música en los conservatorios}

- 15 de julio de 1830. Real Orden por la cual S. M. se ha dignado disponer se establezca en la Corte un Conservatorio de Música titulado de M. ${ }^{a}$ Cristina, marcando el Director, Profesores y Empleados de que se ha de componer, y sus correspondientes dotaciones anuales.

- 14 de noviembre de 1830. Real Orden concerniente al arreglo y mejor enseñanza del Conservatorio de Música.

- 16 de septiembre de 1830. Reglamento Interior aprobado por el Rey N.S. (Q.D.G.) para el gobierno económico y facultativo del Real Conservatorio de Música de Maria Cristina. Redactado por el director del centro, Francisco Piermarini.

- 29 de agosto de 1838. Real Orden por la que se da una nueva organización al Conservatorio de Música, procurando conciliar su existencia con la rigurosa economía que exigen las circunstancias, reduciendo el establecimiento a una escuela de alumnos externos. Firmado por el Viceprotector Sr. Conde de Vigo

- 5 de marzo de 1857. Reglamento orgánico del Real Conservatorio de Música y Declamación aprobado por S.M. Firmado por el D. Cándido Nocedal, Viceprotector del Real Conservatorio.

- 14 de diciembre de 1857. Reglamento orgánico provisional del Real Conservatorio de Música y Declamación. Firmado por D. Pedro Salaverría.

- 30 de enero de 1861. Instrucciones para el buen desempeño de las enseñanzas y para el régimen y disciplina del Real Conservatorio de Música y Declamación. Firmado por el director Sr. Ventura de la Vega. 
- 9 de octubre de 1866. Real Decreto por el que el Real Conservatorio de Música y Declamación deja la denominación de Escuela superior, para tomar la de Escuela especial que tenía antes de la Ley de 9 de Septiembre de 1857.

- 15 y 17 de junio de 1868. Proyecto de decreto y Real Decreto por el que se lleva a cabo la nueva organización del Conservatorio, establecido ahora como Escuela especial.

- 15 de diciembre de 1868. Decreto por el que se disuelve el Conservatorio de Música y Declamación y se crea una Escuela nacional de Música.

- 22 de diciembre de 1868. Decreto mediante el cual se aprueba el nuevo Reglamento para la Escuela Nacional de Música.

- 2 de julio de 1871. Decreto por el que se aprueba un nuevo reglamento para la Escuela Nacional de Música.

- 18 de octubre de 1871. Real Orden disponiendo, que los claustros de las Facultades y el Profesorado de las Escuelas e Institutos, propongan las modificaciones que consideren procedentes en la legislación que actualmente rige para los exámenes de asignaturas y para ejercicio de pruebas de títulos académicos.

- 12 de diciembre de 1896. Real Decreto por el que se modifican algunos artículos del anterior reglamento de 2 de julio de 1871, quedando derogadas todas las disposiciones que se opongan al actual Decreto.

- 13 de septiembre de 1901. Real Decreto, por el que se reforma la Escuela Nacional de Música y Declamación, y se aprueba el nuevo reglamento orgánico del Conservatorio de Música y Declamación.

- 16 de junio de 1905. Real Decreto, disponiendo que las Corporaciones provinciales que sostengan Conservato- 
rios y Escuelas de Música y deseen que los estudios en ellos cursados tengan validez académica, soliciten su incorporación al conservatorio de Madrid.

- 11 de septiembre de 1911. Real Decreto, por el que se organiza y aprueba un nuevo reglamento para el Conservatorio de Música y Declamación de Madrid.

- 7 de febrero de 1913. Real Decreto por el que se modifican determinados artículos del anterior reglamento de 11 de septiembre de 1911, creándose con esta reforma el cargo de Subdirector y constituyéndose una Junta económica.

- 25 de agosto de 1917. Real Decreto aprobando el reglamento para el gobierno y régimen del Real Conservatorio de Música y Declamación.

- 16 de abril de 1920. Real Decreto por el que se modifican algunos artículos del Reglamento de 25 de agosto de 1917.

- 22 de julio de 1931. Decreto creando la Junta Nacional de la Música y Teatros líricos.

- 4 de febrero de 1932. Decreto disponiendo que la Junta Nacional de Música y Teatros líricos formule un Plan general de enseñanza, con el fin de transformar los Conservatorios y Escuelas actuales que se juzguen convenientes en Escuelas Nacionales de Música, vinculando su función a la del Conservatorio Nacional de Madrid, que se transformará asimismo en Escuela Superior de Música.

- 29 de noviembre de 1932. Resolución del expediente sobre modificación del Reglamento del Conservatorio Nacional.

- 15 de junio de 1942. Decreto sobre la organización de los Conservatorios de Música y Declamación. 
- 2 de julio de 1943. Orden por la que se dispone que don Antonio José Cubiles Ramos, Profesor numerario del Real Conservatorio de Música y Declamación de Madrid, pase a explicar las enseñanzas de «Virtuosismo del Piano» en dicho centro.

- 14 de marzo de 1952. Decreto por el que se separan las enseñanzas de Música y Declamación de los actuales Conservatorios.

- 10 de septiembre de 1966. Decreto 2618/1966, sobre Reglamentación general de los Conservatorios de Música.

- 27 de septiembre de 1968. Orden de 21 de junio de 1968 por la que se dispone la publicación del Reglamento para los exámenes de Grado en los Conservatorios de Música oficiales y se aprueban los programas de cada especialidad.

- 28 de agosto de 1987. Real Decreto 1073/1987, por el que se modifica el Decreto 2718/1966, de 10 de septiembre, sobre Reglamentación General de los Conservatorios de Música.

- 15 de abril de 1992. Real Decreto 389/1992, por el que se establecen los requisitos mínimos de los Centros que impartan enseñanzas artísticas.

- 26 de junio de 1992. Real Decreto 756/1992, por el que se establece los aspectos básicos del currículo de los grados elemental y medio de las enseñanzas de música.

- 21 de abril de 1995. Real Decreto 617/1995, por el que se establece los aspectos básicos del currículo del grado superior de las enseñanzas de Música y se regula la prueba de acceso a estos estudios.

- 22 de diciembre de 2006. Real Decreto 1577/2006, por el que se fijan los aspectos básicos del currículo de las 
enseñanzas profesionales de música reguladas por la Ley Orgánica 2/2006, de 3 de mayo, de Educación.

- Real Decreto 1614/2009, de 26 de octubre, por el que se establece la ordenación de las enseñanzas artísticas superiores reguladas por la Ley Orgánica 2/2006, de 3 de mayo, de Educación.

- Real Decreto 631/2010, de 14 de mayo, por el que se regula el contenido básico de las enseñanzas artísticas superiores de Grado en Música establecidas en la Ley Orgánica 2/2006, de 3 de mayo, de Educación.

\section{Cronología de las principales programaciones que han or- ganizado la especialidad de piano}

- 1 de diciembre de 1871. Escuela de Música y Declamación. Programas de las enseñanzas de la misma. Contiene el Programa de la enseñanza de Piano, con las materias y estudios que comprenden cada año de los siete de que consta.

- 1891. Escuela Nacional de Música y Declamación. Programa oficial de la enseñanza de Piano.

- Restauración (Anterior a 1911). Programa oficial de la enseñanza de Piano adoptado en el Conservatorio de Música y Declamación. Ofrecido por la casa Antonio Matamala editor y almacenista de Música.

- Restauración (Posterior a 1911). Real Conservatorio de Música. Enseñanza Oficial. Programas de la enseñanza del Piano para los exámenes privados trimestrales que tendrán lugar: del 15 al 20 de diciembre, del 15 al 20 de marzo, y del 25 al 30 de mayo.

- Segunda República. Programa Oficial de la Enseñanza de Piano del Conservatorio Nacional de Música y Declamación. 
- 1966-1973. Real Conservatorio Superior de Música. Madrid. Programa oficial de la enseñanza de Piano. Disposiciones Generales.

- 1973. Real Conservatorio Superior de Música. Programa oficial de la enseñanza de Piano.

- 1990. Desde su aparición en la LOGSE, el modelo curricular abierto debe ser concretado por cada centro educativo, cada departamento didáctico y cada profesor, hasta adaptarlo a su particular contexto educativo. El documento encargado de organizar la asignatura es la programación didáctica.

- 2006. Con la LOE y la creación del Espacio Europeo de Educación Superior, la Guía docente es el documento encomendado para la planificación detallada de la asignatura.

\section{La enseñanza de piano en 1861}

\begin{tabular}{|c|c|c|c|c|c|c|c|c|}
\hline ASIGNATURAS & \multicolumn{7}{|c|}{ CURSOS } \\
\hline Piano & $*$ & $*$ & 1 & 2 & 3 & 4 & 5 & 6 \\
\hline Solfeo & 1 & 2 & 3 & $*$ & $*$ & $*$ & $*$ & $*$ \\
\hline Armonía elemental & $*$ & $*$ & $*$ & 1 & & & & \\
\hline
\end{tabular}


5. La enseñanza de piano en el Reglamento de 1911

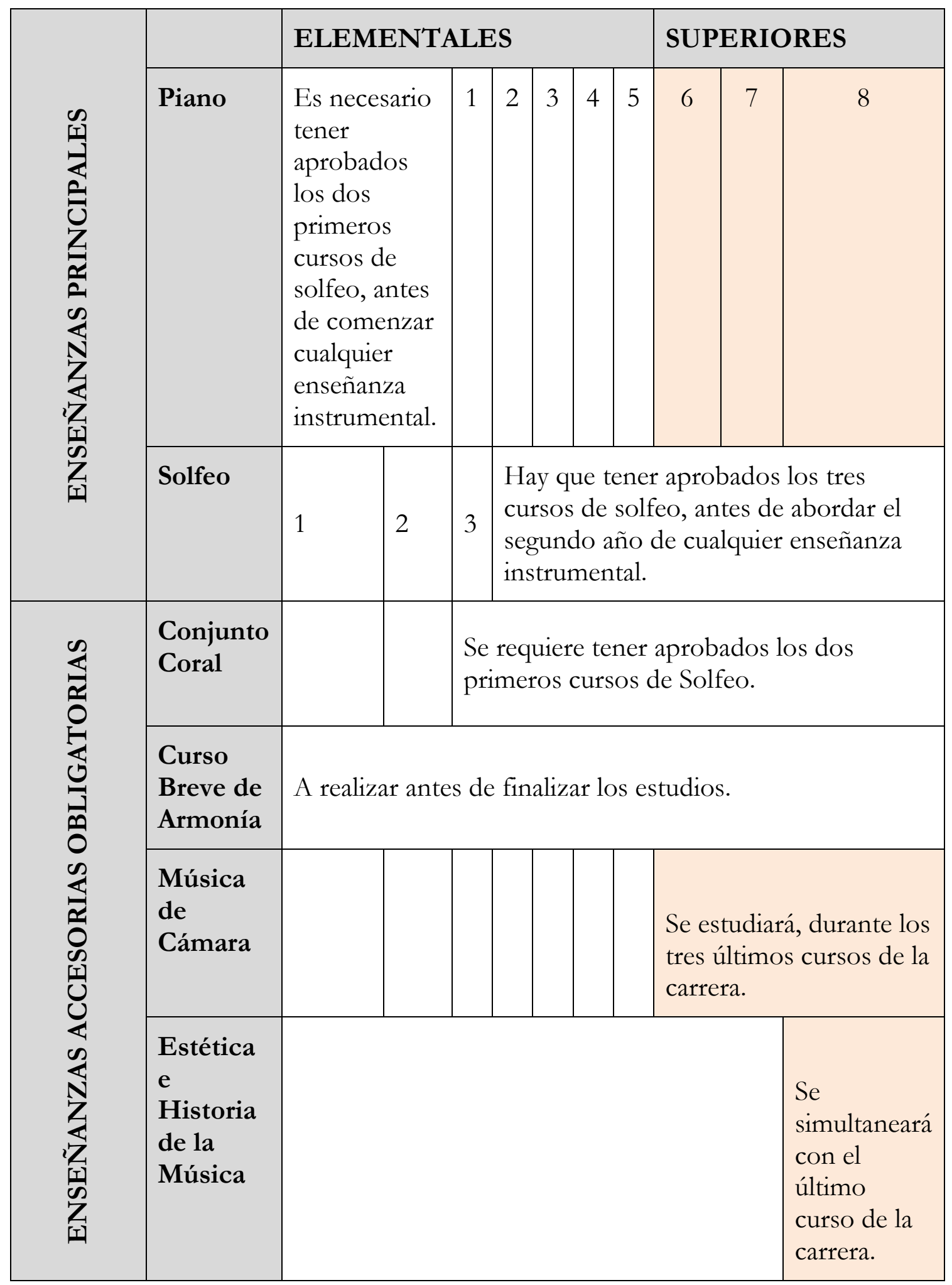


6. La enseñanza de piano en el Plan de Estudios de 1966

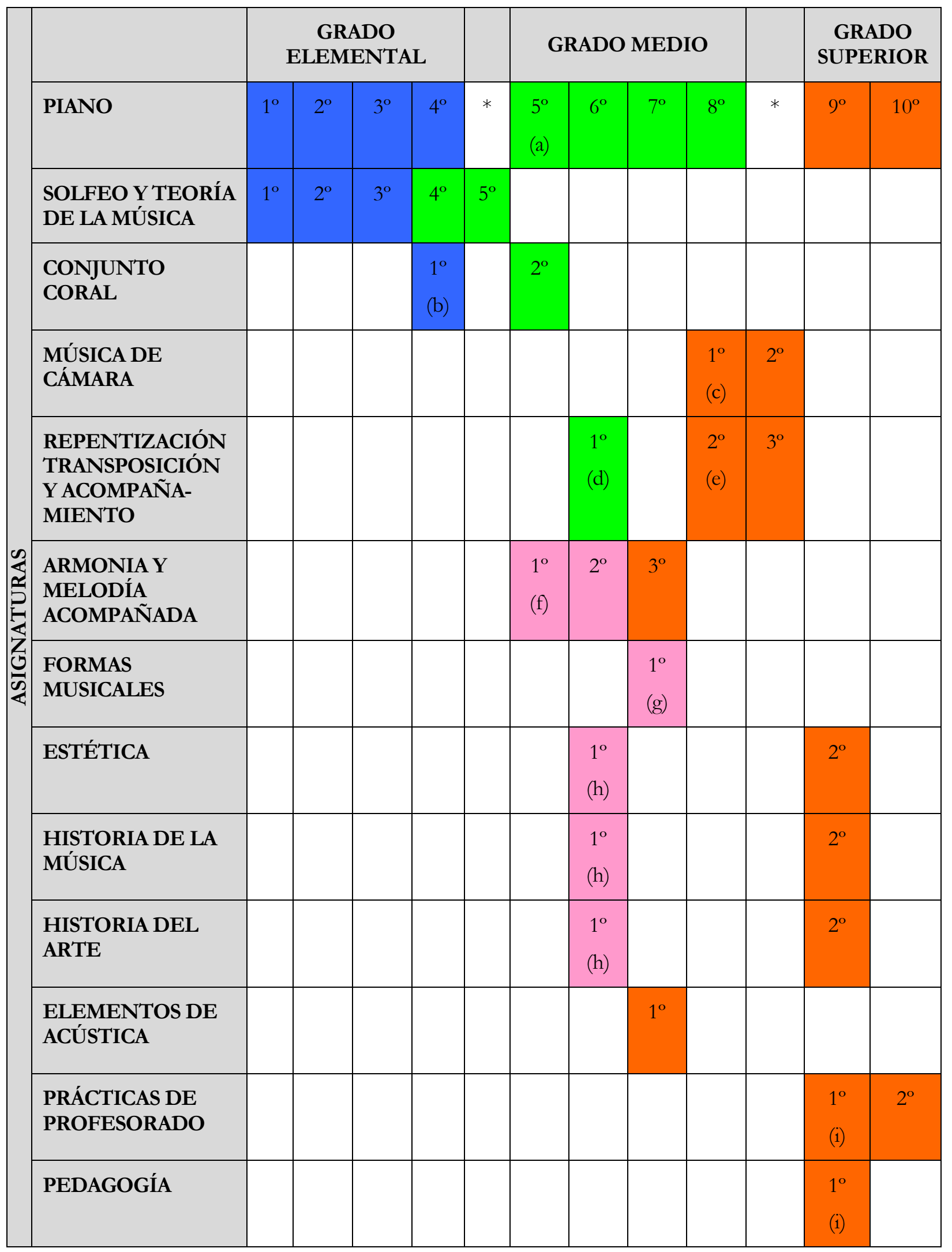




\section{Leyenda}

(a) Para los cinco primeros cursos se exigirá tener aprobado el curso de igual orden numérico de solfeo y teoría de la música. Este requisito obligaba a interrumpir durante un curso los estudios de instrumento, a aquellos alumnos que querían acceder al grado medio. El Real Decreto 1073/1987, de 28 de agosto, (B.O.E. de 5 de septiembre), subsanaba la situación permitiendo simultanear el quinto curso de Solfeo y Teoría de la Música, con el último de grado elemental.

(b) Conjunto coral e instrumental: será preciso tener aprobados tres cursos de solfeo y teoría de la música para iniciar conjunto coral.

(c) Música de cámara: Será preciso tener aprobado el penúltimo de los cursos de grado medio de un instrumento propio para el género. Al igual que el caso anterior, este requisito, obligaba a interrumpir durante un año los estudios de instrumento, a aquellos alumnos que deseaban acceder al grado superior. El Real Decreto 1073/1987, de 28 de agosto, (B.O.E. del 5 de septiembre), subsanaba la situación, solicitando únicamente tener aprobado el antepenúltimo curso.

(d) Repentización instrumental, transposición instrumental y acompañamiento: Se exigirá para el curso primero (repentización y transposición instrumental) tener aprobado el quinto curso de un instrumento propio para la transposición.

(e) Repentización instrumental, transposición instrumental y acompañamiento: Para los cursos segundo y tercero (acompañamiento) se precisará tener aprobado el curso de igual orden numérico de armonía y melodía acompañada y el quinto de piano.

(f) Armonía y melodía acompañada: se precisará tener aprobado el último curso de solfeo y teoría de la música.

(g) Formas musicales (curso teórico analítico): será obligatorio tener aprobados dos cursos de armonía y melodía acompañada.

(h) Estética e historia de la música, de la cultura y del arte: se precisará tener aprobado un curso de armonía y melodía acompañada.

(i) Prácticas de profesorado y pedagogía musical: se exigirá tener aprobado el último de los cursos de grado medio de la especialidad correspondiente.

TÍTULOS. Los distintos colores muestran las asignaturas necesarias para obtener el título correspondiente.

\begin{tabular}{|l|l|}
\hline $\begin{array}{l}\text { Diploma elemental: Asignaturas } \\
\text { sombreadas en AZUL }\end{array}$ & $\begin{array}{l}\text { Título de Profesor: Diploma de } \\
\text { Instrumentista más las asignaturas } \\
\text { sombreadas en ROSA }\end{array}$ \\
\hline $\begin{array}{l}\text { Diploma de Instrumentista: Diploma } \\
\text { elemental más las asignaturas sombreadas } \\
\text { en VERDE }\end{array}$ & $\begin{array}{l}\text { Título de Profesor Superior: Título de } \\
\text { profesor más las asignaturas sombreadas } \\
\text { en NARANJA }\end{array}$ \\
\hline
\end{tabular}


7. Ejemplo de la relación entre las competencias genéricas y las específicas del $\mathrm{RD}$ 631/2010, y cómo estas se relacionan a su vez con los descriptores de Dublín/ polifonía de la AEC

\subsection{Tabla donde se muestra esta relación con una competencia que trata sobre la creación de ideas interpretativas coherentes:}

\begin{tabular}{|c|c|c|c|}
\hline $\begin{array}{l}\text { Código de los } \\
\text { Descriptores } \\
\text { de Dublín }\end{array}$ & 1er ciclo. AEC. & Real Decreto 631 & $\begin{array}{c}\text { Real Decreto } \\
631\end{array}$ \\
\hline $\begin{array}{c}\text { B }(+\mathrm{C}) \\
\text { (Aplicación de } \\
\text { los } \\
\text { conocimientos } \\
\text { y la } \\
\text { comprensión. } \\
\text { Elaborar } \\
\text { Juicios.) }\end{array}$ & $\begin{array}{l}\text { Ser capaz de creary } \\
\text { realizar sus propios } \\
\text { conceptos artísticos. } \\
\text { Debe baber } \\
\text { desarrollado las } \\
\text { competencias } \\
\text { necesarias para } \\
\text { expresarlos. }\end{array}$ & $\begin{array}{l}\text { Crear y dar forma a sus } \\
\text { propios conceptos } \\
\text { artísticos habiendo } \\
\text { desarrollado la } \\
\text { capacidad de expresarse } \\
\text { a través de ellos a partir } \\
\text { de técnicas y recursos } \\
\text { asimilados. }\end{array}$ & $\begin{array}{c}\frac{\text { Competencia }}{\text { específica de }} \\
\frac{\underline{\text { la especialidad }}}{\underline{\text { de }}} \\
\frac{\text { Interpretación }}{\underline{\text { CE-2 }}} \\
\text { Construir una } \\
\text { idea } \\
\text { interpretativa } \\
\text { coherente y } \\
\text { propia. }\end{array}$ \\
\hline
\end{tabular}

${ }^{538}$ La relación entre los descriptores de Dublín y los resultados de aprendizaje para el primer ciclo según la AEC, se pueden consultar en: The AEC Learning Outcomes for the 1st, 2nd and 3rd cycle (version Junio de 2007) $<$ http://aecsite.cramgo.nl/DownloadView.aspx?ses $=8911>$ [consultado el $8-1-2014]$

539 "Skills in artistic expresión. At the completion of their studies, students should be able to create and realise their own artistic concepts and should have developed the necessary skills for their expression." En: The AEC Learning Outcomes... 


\subsection{Tabla en la que se distingue la correlación sobre una competencia que hace referencia al repertorio:}

\begin{tabular}{|c|c|c|c|}
\hline $\begin{array}{c}\text { Código de los } \\
\text { Descriptores de } \\
\text { Dublín }\end{array}$ & 1er ciclo. AEC. & Real Decreto 631 & $\begin{array}{c}\text { Real Decreto } \\
631\end{array}$ \\
\hline $\begin{array}{l}\text { B (Aplicación de } \\
\text { los conocimientos } \\
\text { y la comprensión.) }\end{array}$ & $\begin{array}{c}\text { Repertorio. } \\
\text { Haber aprendido, y si } \\
\text { es posible interpretando } \\
\text { en público obras } \\
\text { representativas del } \\
\text { repertorio de su } \\
\text { asignatura principal. }\end{array}$ & $\begin{array}{l}\text { Competencia } \\
\text { genérica-11 } \\
\text { Estar familiarizado } \\
\text { con un repertorio } \\
\text { amplio y actualizado, } \\
\text { centrado en su } \\
\text { especialidad pero } \\
\text { abierto a otras } \\
\text { tradiciones. Reconocer } \\
\text { los rasgos estilisticos } \\
\text { que caracterizan a } \\
\text { dicho repertorio y } \\
\text { poder describirlos de } \\
\text { forma claray } \\
\text { completa. }\end{array}$ & $\begin{array}{c}\frac{\text { Competencia }}{\text { específica de la }} \\
\frac{\text { especialidad de }}{\text { Interpretación }} \\
\frac{1}{\text { Interpretar el }} \\
\text { repertorio } \\
\text { significativo de su } \\
\text { especialidad } \\
\text { tratando de } \\
\text { manera adecuada } \\
\text { los aspectos que lo } \\
\text { identifican en su } \\
\text { diversidad } \\
\text { estilistica. }\end{array}$ \\
\hline
\end{tabular}

\section{0 "Repertoire skills}

- At the completion of their studies, students should have studied and, where appropriate, performed representative repertoire of the Principal Study area.

- In the process, they should have had experience of a variety of appropriate styles." En : The AEC Learning Outcomes... 


\section{JORGE LUÍS MOLTÓ DONCEL}

\section{Pianista. Profesor del CSMV}

Discípulo de los pianistas Emmanuel Ferrer-Laloe, Perfecto García Chornet y Aquiles Delle-Vigne, ha realizado diversos conciertos en festivales internacionales y salas de España, Francia y Austria, tanto en calidad de solista como con orquesta.

En 2009 obtiene el Diploma de Estudios Avanzados por la Universidad Politécnica de Valencia, doctorándose en el presente año en la Universidad Católica de Valencia "San Vicente Mártir" con la Tesis: El análisis del intérprete: un modelo para la investigación artística en la enseñanza superior de piano.

Su compromiso con la investigación le ha permitido crear con la pianista y doctora Trinidad Lull en 2005 el TYG PIANO DUO, http://tygpianoduo.com/, un innovador proyecto que presenta conjuntamente investigación artística e interpretación musical y suministra resultados en distintos formatos como conciertos, publicaciones o conferencias-concierto.

Ha impartido cursos organizados por la Dirección General de Educación y Cualidad Educativa de la Consellería de Educación, Formación y Empleo de Valencia, dentro del Plan de Formación Permanente del Profesorado.

Recientemente ha publicado el artículo "La acción programadora en la especialidad de piano, a la luz de las contribuciones aportadas por la reglamentación musical", en la revista Arsteduca, y su participación asidua en Jornadas y Congresos le ha permitido publicar recientemente la comunicación: La contribución de la Unión Europea al espacio de las enseñanzas superiores de música.

Actualmente es profesor de Repertorio con piano en el Conservatorio Superior de Música "Joaquín Rodrigo" de Valencia, compaginando dicha actividad con la investigación artística sobre el diseño de posibles modelos para proyectar las relaciones existentes entre el pensamiento reflexivo-analítico y la actividad creativa, características del intérprete. 


\section{Cuadernos de Bellas Artes}

\section{Otros títulos de la colección}

43- El paradigmo arteaguiano de lo maravilloso - Antonio García Montalbán

http://issuu.com/revistalatinadecomunicacion/docs/cba43

42- La influencia de la cultura funeraria egipcia en el arte y la literatura de la antigua Grecia - Adrián José Presentación Ortega http://issuu.com/revistalatinadecomunicacion/docs/cba42

41- Bernardo Adam Ferrero. La creatividad al servicio de las bandas de música - Raquel Mínguez Bargues

http://issuu.com/revistalatinadecomunicacion/docs/cba41

40- José Serrano y la plenitud de la zarzuela - José Salvador Blasco Magraner http://issuu.com/revistalatinadecomunicacion/docs/cba40

39- Látigos de escorpiones. Sobre el arte de la interpretación - Javier Alcoriza http://issuu.com/revistalatinadecomunicacion/docs/cba39

38- La figura de la mujer en la historia de la musicoterapia. Desde la Antigüedad hasta el Barroco - Ignacio Calle Albert http://issuu.com/revistalatinadecomunicacion/docs/cba38

37- La poesía en la Renaixença valenciana La obra poética de Vicente Peydró Diez- José Salvador Blasco Magraner y Francisco Carlos Bueno Camejo http://issuu.com/revistalatinadecomunicacion/docs/cba37

36- Iconografías del arte antiguo: Grecia y Roma- Jorge Tomás García http://issuu.com/revistalatinadecomunicacion/docs/cba36

35- País V asco - Portugal: $836 \mathrm{~km}$ de meditaciones en torno al arte Amaia Lekerikabeaskoa, Isusko Vivas y Antonio Delgado http://issuu.com/revistalatinadecomunicacion/docs/cba35

34- Los inicios del erotismo en la escena teatral lírica madrileña. Vicente Lleó y el género sicalíptico - José Salvador Blasco Magraner http://issuu.com/revistalatinadecomunicacion/docs/cba34 
